\title{
Joining of $\mathrm{Al}-\mathrm{B}_{\mathbf{4}} \mathrm{C}$ Metal Matrix Composites by Laser Welding and Friction Stir Welding
}

\author{
Dissertation \\ Presented in Partial Fulfillment of the Requirement for \\ the Degree of Doctor of Philosophy
}

By Junfeng Guo

UNIVERSITÉ DU QUÉBEC À CHICOUTIMI

2012

Director: X. Grant Chen (UQAC)

Co-director: Patrick Gougeon (NRC-ATC) 


\section{Abstract}

$\mathrm{Al}-\mathrm{B}_{4} \mathrm{C} \mathrm{MMCs}$ are important materials as neutron absorber in spent nuclear fuel storage and transportation due to their high boron $\left({ }^{10} \mathrm{~B}\right)$ concentration and thus high neutron absorption capability. However, wide application of these materials is still limited due to the lack of suitable joining techniques to fully take advantage of the materials. Problems such as porosity and chemical reaction between $\mathrm{Al}$ matrix and $\mathrm{B}_{4} \mathrm{C}$ particles can arise during fusion welding of the material. Therefore, the present study is intended to find effective and reliable welding techniques for Al-B ${ }_{4} \mathrm{C}$ MMCs. The weldability of AA1100$16 \% \mathrm{~B}_{4} \mathrm{C}$ (particle size: $11 \mu \mathrm{m}$ ) and $\mathrm{AA} 1100-30 \% \mathrm{~B}_{4} \mathrm{C}$ MMCs (median particle size: $15 \mu \mathrm{m}$ ) was evaluated using laser welding and friction stir welding. In comparison with conventional arc welding techniques, the deep and narrow fusion zones associated with laser welding can result in smaller heat affected zones, and thus less thermal distortion and mechanical property degradation. On the other hand, friction stir welding, as a solid state process, seems promising as it can avoid various problems that may otherwise be encountered during fusion welding of MMCs.

For laser welding without filler, it was found that most $\mathrm{B}_{4} \mathrm{C}$ particles were decomposed during welding leading to formation of needle-like $\mathrm{AlB}_{2}$ and $\mathrm{Al}_{3} \mathrm{BC}$ phases in the weld. In this case, a joint efficiency of $63 \%$ (UTS) after tensile test was obtained. The variation of laser power from 2 to $4 \mathrm{~kW}$ and welding speed from 1 to $2.5 \mathrm{~m} / \mathrm{min}$ did not affect the needle-like morphology. Based on thermodynamic calculation, $\mathrm{Ti}$ filler was used as the filler material aiming to improve the properties of laser joints. It was found that the addition of $\mathrm{Ti}$ with $150 \mu \mathrm{m}$ thick foil increased the joint efficiency to $75 \%$ due to the decrease of size and quantities of needle-like phases. The addition of Ti with filler wire instead of Ti foil did not show significant mechanical property improvement due to the $\mathrm{Ti}$ segregation and microstructure inhomogeneity in the weld zone.

On the other hand, the feasibility of friction stir welding for joining AA1100 based metal matrix composites reinforced with $\mathrm{B}_{4} \mathrm{C}$ particulate was studied for 16 and $30 \% \mathrm{~B}_{4} \mathrm{C}$ volume concentrations. For both composites, friction stir welding has a significant influence on the particle size distribution and the matrix grain size. For the AA1100$16 \% \mathrm{~B}_{4} \mathrm{C}$ composite, the average particle size decreases after welding by $\sim 20 \%$ and the grain size from 15 to $5 \mu \mathrm{m}$ as measured in the weld nugget. Tensile testing of welded joints showed up to $100 \%$ joint efficiency for both annealed $\mathrm{AA} 1100-16 \% \mathrm{~B}_{4} \mathrm{C}$ and $\mathrm{AA} 1100$ $30 \% \mathrm{~B}_{4} \mathrm{C}$ composite materials. However, if the ultimate tensile strength values of all the studied composites are similar at $\sim 130 \mathrm{MPa}$, the weld ductility is higher for the annealed materials. In addition, it was observed that varying the welding speed between 100 and 275 $\mathrm{mm} / \mathrm{min}$ does not influence the joint tensile properties and the particle size distribution in the nugget. Furthermore, a welding tool made of WC-Co showed much better durability 
than the steel tool for which tool wear occurred mainly on the shoulder edges. The FSW joint surfaces using both tools exhibited lower corrosion resistance compared with the base material. The joints made by WC- $15 \mathrm{wt} . \% \mathrm{Co}$ tool showed a better corrosion resistance than those made of steel tool.

Dissimilar joints between AA1100-16 vol.\% $\mathrm{B}_{4} \mathrm{C}$ MMC and AA6063 aluminium alloy were also successfully produced using FSW process. All dissimilar joints produced under the investigated welding conditions were stronger than the base materials of $\mathrm{Al}-\mathrm{B}_{4} \mathrm{C}$ composite and demonstrated high UTS at $\sim 126 \mathrm{MPa}$ and good elongation at $\sim 8 \%$. Analysis of the $\mathrm{Mg}$ concentration and $\mathrm{B}_{4} \mathrm{C}$ particle distribution indicates that a good material mixing and seamless bonding was achieved around the interface between the $\mathrm{Al}-\mathrm{B}_{4} \mathrm{C}$ composite and AA6063 alloy during FSW. The electron backscatter diffraction analysis showed that during dissimilar FSW, there was a gradual microstructure evolution on both material sides, resulting in a variety of grain structures in the different weld zones. In the weld zones of FSW joints, the materials underwent dynamic recovery and recrystallization to different extents depending on their thermal mechanical history. The grain refinement of both materials in the nugget zone was observed (MMC side: 15 vs. $8 \mu \mathrm{m}$; AA6063 side 76 vs. $20 \mu \mathrm{m}$ ). It is recommended that the 6063 aluminum alloy should be fixed on the advancing side and the use of an appropriate offset to the 6063 aluminum side is preferred.

Comparison of all tensile data revealed that laser welding may be a good alternative for joining $\mathrm{Al}-\mathrm{B}_{4} \mathrm{C}$ MMCs as the maximum joint efficiency can reach up to $75 \%$ (UTS). Further enhancement of mechanical properties may be achieved if an optimum Ti amount was added and the Ti was uniformly distributed in the weld. On the other hand, FSW was considered to be a superior choice for joining $\mathrm{Al}-\mathrm{B}_{4} \mathrm{C} \mathrm{MMCs}$ as it avoided chemical reactions and led to excellent mechanical properties. It is recommended that the FSW be used for materials in annealed conditions as the joint efficiency and ductility are higher than that of as rolled materials. It is worthwhile to highlight the fact that most of the tensile samples made of $\mathrm{MMCs}$ with $16 \mathrm{vol.}-\% \mathrm{~B}_{4} \mathrm{C}$ in annealed conditions failed in the base materials. This indicates that the FSW joints of these MMCs were stronger than the base materials, which is very promising for joining aluminium MMCs. 


\section{Résumé}

Les composites $\mathrm{Al}-\mathrm{B}_{4} \mathrm{C}$ à matrice métallique sont des matériaux importants comme absorbeurs de neutrons dans le stockage et le transport du combustible nucléaire en raison de leur concentration élevée en bore et donc de leur haute capacité d'absorption des neutrons. Toutefois, l'application de ces matériaux est encore limitée en raison, entre autres, de l'absence de techniques d'assemblage appropriées pour bénéficier pleinement des avantages des matériaux. Des problèmes tels que la porosité, la réaction chimique entre la matrice $\mathrm{Al}$ et des particules $\mathrm{B}_{4} \mathrm{C}$ peuvent se produire pendant le soudage par fusion. Par conséquent, la présente étude vise à trouver des techniques de soudage efficaces et fiables pour des composites $\mathrm{Al}-\mathrm{B}_{4} \mathrm{C}$ à matrice métallique. La soudabilité des composites à matrice métallique $\mathrm{AA} 1100-16 \% \mathrm{~B}_{4} \mathrm{C}$ (taille moyenne des particules: $11 \mu \mathrm{m}$ ) et $\mathrm{AA} 1100-30 \% \mathrm{~B}_{4} \mathrm{C}$ (taille moyenne des particules: $15 \mu \mathrm{m}$ ) a été évaluée à l'aide du soudage au laser et du soudage par friction malaxage. En comparaison avec les techniques classiques de soudage à l'arc, les zones de fusion pénétrantes et étroites associées au soudage au laser peuvent entraîner des zones affectées par chaleur plus petites, et donc moins de distorsion thermique et de dégradation des propriétés mécaniques. D'autre part, le soudage par friction malaxage, étant un procédé de soudage à l'état solide, est prometteur car il permet d'éviter divers problèmes qui pourraient autrement être rencontrés au cours de soudage par fusion.

Pour le soudage au laser sans matériau d'apport, il a été constaté que le plupart de particules $\mathrm{B}_{4} \mathrm{C}$ ont été décomposées lors du soudage conduisant à la formation de phases $\mathrm{AlB}_{2}$ et $\mathrm{Al}_{3} \mathrm{BC}$ en forme d'aiguille dans la soudure. Dans ce cas, une efficacité de joint à $63 \%$ (UTS) a été obtenue après essai de traction. La variation de puissance de laser de 2 à $4 \mathrm{~kW}$ et de la vitesse de soudage de 1 à $2.5 \mathrm{~m} / \mathrm{min}$ n'a pas d'incidence sur la morphologie en forme d'aiguille. Sur la base de calculs thermodynamiques, le titane a été utilisé comme matériau d'ajout visant à améliorer les propriétés des assemblages. Il a été constaté que l'ajout de Ti avec une feuille de $150 \mu \mathrm{m}$ d'épaisseur a augmenté l'efficacité de joint à $75 \%$ en raison de la diminution de la taille et la quantité des phases en forme d'aiguille. L'ajout de $\mathrm{Ti}$ sous forme de fil d'apport n'a pas montré une amélioration significative des propriétés mécaniques en raison de la ségrégation du titane et l'inhomogénéité microstructurale dans la zone soudée.

D'autre part, la faisabilité du soudage par friction malaxage pour assmebler les composites à matrice métallique $\mathrm{AA} 1100$ renforcées par des particules $\mathrm{B}_{4} \mathrm{C}$ est étudiée pour des concentrations en volume de 16 et de $30 \% \mathrm{~B}_{4} \mathrm{C}$. Pour les deux composites, le soudage par friction malaxage a une influence significative sur la distribution de la taille des particules et celle des grains de la matrice. Pour le composite AA1 100-16\% $\mathrm{B}_{4} \mathrm{C}$, la taille moyenne des particules diminue après le soudage de $\sim 20 \%$ et la taille de grain de 15 à 5 $\mu \mathrm{m}$ telle que mesurée dans la zone soudée. Les essais de traction des joints soudés a montré une efficacité allant jusqu'à $100 \%$ pour les matériaux composites à l'état recuit AA1100$16 \% \mathrm{~B}_{4} \mathrm{C}$ et $\mathrm{AA} 1100-30 \% \mathrm{~B}_{4} \mathrm{C}$. Toutefois, si les résistances ultimes en traction de tous les 
composites étudiés sont similaires à $\sim 130 \mathrm{MPa}$, la ductilité des joints soudés est plus élevée pour les matériaux recuits. En outre, il a été observé que la variation de la vitesse de soudage entre 100 et $275 \mathrm{~mm} / \mathrm{min}$ n'influence pas les propriétés de traction et la distribution de tailles des particules. En outre, l'outil de soudage en WC-Co a montré une durabilité bien meilleure que l'outil en acier pour lequel l'usure a eu lieu principalement sur les bords de l'épaulement. Les surfaces du joint FSW produits en utilisant les deux outils ont présenté une résistance à la corrosion inférieure par rapport au matériau de base. Par contre, les assemblages réalisés par l'outil de WC-Co $15 \mathrm{wt} \%$ ont montré une meilleure résistance à la corrosion que celles faites par l'outil en acier.

Des assemblages dissimilaires formés des composites $\mathrm{AA} 1100-16$ vol. $\% \mathrm{~B}_{4} \mathrm{C}$ avec un alliage d'aluminium AA6063 ont été produits avec succès par FSW. Tous les assemblages produits dans les conditions de soudage étudiées étaient plus forts que les matériaux de base d'Al- $\mathrm{B}_{4} \mathrm{C}$ et ont donné une résistance ultime élevée de $\sim 126 \mathrm{MPa}$ et un allongement de $\sim 8 \%$. L'analyse de la concentration de $\mathrm{Mg}$ et la distribution des particules $\mathrm{B}_{4} \mathrm{C}$ indique qu'un bon mélange du matériau a été réalisé pendant le soudage par friction malaxage, autour de l'interface entre le composite $\mathrm{Al}-\mathrm{B}_{4} \mathrm{C}$ et l'alliage AA6063. L'analyse EBSD a montré que pendant le soudage, il y avait une évolution progressive de la microstructure sur les deux côtés des matériaux, résultant en une variété de structures de grain dans les zones de soudure différentes. Dans les zones de soudure, les matériaux ont été dynamiquement recristallisés à des degrés différents en fonction de leur histoire thermo-mécanique. Le raffinement des grains des deux matériaux dans la zone du noyau a été observé (côté MMC : 15 vs $8 \mu \mathrm{m}$, côté AA6063: 76 vs $20 \mu \mathrm{m}$ ). Il est recommandé que l'alliage AA6063 soit positionné sur le côté avançant et l'utilisation d'un 'offset' approprié sur le côté AA6063 est préféré.

Une comparaison de toutes les données des tests de traction ont révélé que le soudage au laser peut être une bonne alternative pour l'assemblage des composites $\mathrm{Al}-\mathrm{B}_{4} \mathrm{C}$ et que l'efficacité du joint peut atteindre jusqu'à 75\% (UTS). Une plus grande amélioration des propriétés mécaniques peut être atteint si une quantité optimale de titane est apportée lors du soudage et que le titane est uniformément réparti dans la soudure. D'autre part, le soudage par friction malaxage a été considéré comme un choix judicieux pour assembler des composites $\mathrm{Al}-\mathrm{B}_{4} \mathrm{C}$ car il permet d'éviter les réactions chimiques et conduit à d'excellentes propriétés mécaniques. Il est recommandé que le soudage par friction malaxage soit utilisé pour des matériaux à l'état recuit parce que l'efficacité du joint et la ductilité sont plus élevés que celles des matériaux dans l'état laminé. Il est intéressant de souligner le fait que dans des conditions à l'état recuit la plupart des échantillons soudés entre composites $\mathrm{AA} 1100-16 \mathrm{vol} . \% \mathrm{~B}_{4} \mathrm{C}$ ont fracturé dans le matériau de base. Cela indique que des composites soudés par friction malaxage étaient plus forts que les matériaux de base, ce qui est très prometteur pour l'assemblage des composites à matrice d'aluminium. 


\section{Acknowledgement}

The author wishes to express his sincere appreciation to his co-directors Professor X. Grant Chen and Dr. Patrick Gougeon for their encouragement, understanding, support and guidance throughout this dissertation work.

The author would like to express his great gratitude to Dr. N.C. Parson and Dr. Lyne StGeorges as the jury members for their inspirational advices.

The author would also like to acknowledge the financial support from the Natural Sciences and Engineering Research Council of Canada (NSERC), Rio Tinto Alcan (RTA) and NRCAluminium Technology Centre (NRC-ATC) through the NSERC Industrial Research Chair in Metallurgy of Aluminium Transformation at the University of Quebec at Chicoutimi.

Grateful acknowledgement is also sent to Mrs. H. Grégoire, Ms. G. Simard, Mrs. M. Poliquin, Ms E. Brideau, Ms. Y. Han, Mr. M. Larouche, Mr. M. Patry, Mr. F. Nadeau, Mr. M. Perron, Mr. M. Bouchard and Dr. D. Gallant for their technical support and helpful discussion.

Finally, the author wants to express his special thanks to his wife Linlin and his son William for their unconditional love and support without which this work would not have been possible. 


\section{Publications}

1. J.F. Guo, P. Gougeon, X.-G. Chen, "Microstructure evolution and mechanical properties of dissimilar friction stir welded joints between $\mathrm{AA} 1100-\mathrm{B}_{4} \mathrm{C} M \mathrm{MMC}$ and Al 6063 alloy", Journal paper, in preparation.

2. J.F. Guo, P. Gougeon, F. Nadeau, X.-G. Chen, "Joining of AA1100-16vol.\% B 4 C Metal Matrix Composite Using Laser Welding and Friction Stir Welding", Canadian Metallurgical Quarterly, 2012, online published, DOI: 10.1179/1879139512Y.0000000003.

3. J.F. Guo, P. Gougeon, X.-G. Chen, "Study on Laser Welding of AA1100-16\% vol.B ${ }_{4} \mathrm{C}$ Metal Matrix Composites", Composites Part B: Engineering, 2012, online published, DOI:10.1016/j.compositesb.2011.11.044.

4. J.F. Guo, P. Gougeon, X.-G. Chen, "Characterization of Welded Joints Produced by Friction Stir Welding in AA1100- $\mathrm{B}_{4} \mathrm{C}$ Metal Matrix Composites", Science and Technology of Welding \& Joining, 2012, Vol. 17, No.2, pp. 85-91.

5. J.F. Guo, P. Gougeon, X.-G. Chen, "Effect of surface preparation techniques on EBSD analysis of a friction stir welded AA1100-16 vol.\% $\mathrm{B}_{4} \mathrm{C}$ composite", Materials Characterization, 2011, Vol. 62, pp. 865-877.

6. J.F. Guo, P. Gougeon, F. Nadeau, X.-G. Chen, "Potential of Laser Welding and Friction Stir Welding for Joining AA1100-16vol.\% B 4 C Metal Matrix Composite", Proceedings of The $50^{\text {th }}$ Conference Of Metallurgists: Innovations in Joining of Advanced Materials, P. Wanjara, M. Brochu and J. Kang, Eds., Oct. 2-5 2011, Montreal, Canada, pp. 15-26.

7. J.F. Guo, P. Gougeon, X.-G. Chen, "Joining of AA1100-16vol.\% B ${ }_{4}$ C MMCs by Laser Welding and Friction Stir Welding" The Encyclopedia of Research on Aluminium in Quebec, 2011 edition, Les Presses de l'aluminium (PRAL).

8. J.F. Guo, P. Gougeon, X.-G. Chen, "Characterization of Friction Stir Welded Joints of AA1100-B ${ }_{4} \mathrm{C}$ Metal Matrix Composites", The Encyclopedia of Research on Aluminium in Quebec, 2010 edition, Les Presses de l'aluminium (PRAL), pp. 45.

9. J.F. Guo, P. Gougeon, X.-G. Chen, "Microstructural evolution of $\mathrm{Al-B}$ - C MMCs during laser welding", The Encyclopedia of Research on Aluminium in Quebec, 2009 edition, Les Presses de l'aluminium (PRAL), Presented Orally in École Technique Supérieur (ETS) de Montreal, pp. 67.

10. J.F. Guo, P. Gougeon, X.-G. Chen, "Interfacial Reaction in Laser Welding of $\mathrm{Al}^{-\mathrm{B}_{4} \mathrm{C}}$ Metal Matrix Composites", The Encyclopedia of Research on Aluminium in Quebec, 2008 edition, Les Presses de l'aluminium (PRAL), pp.25. 


\section{Table of Content}

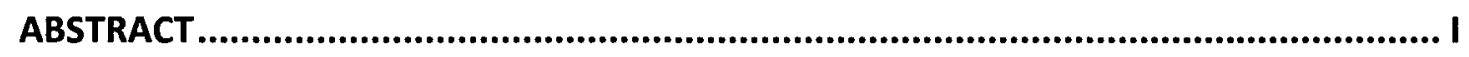

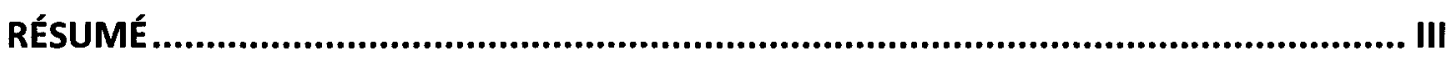

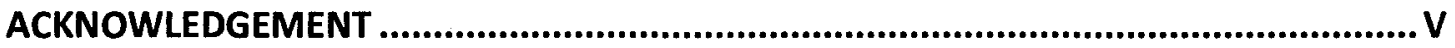

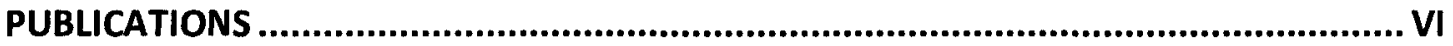

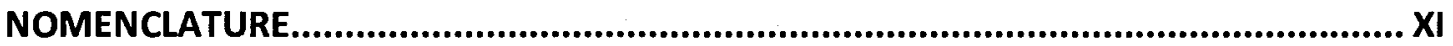

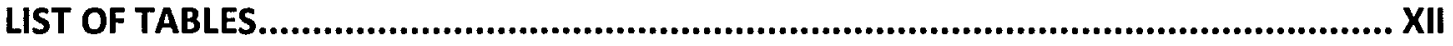

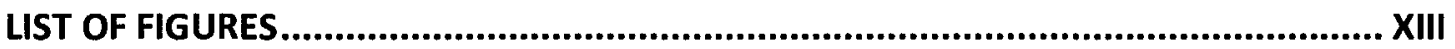

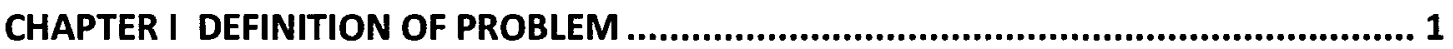

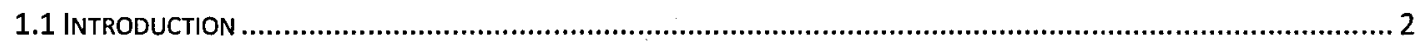

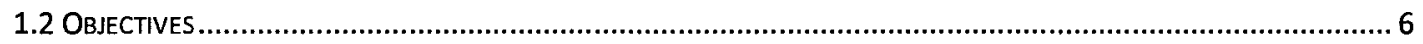

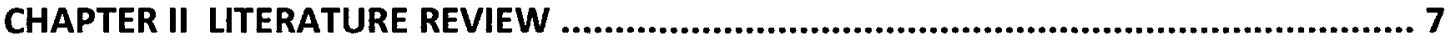

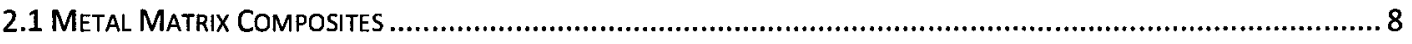

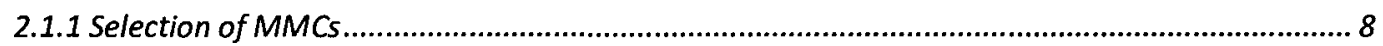

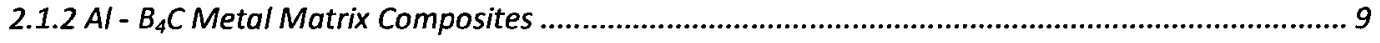

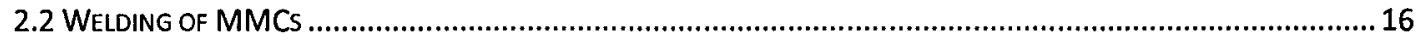

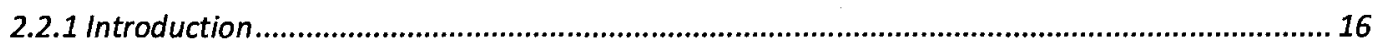

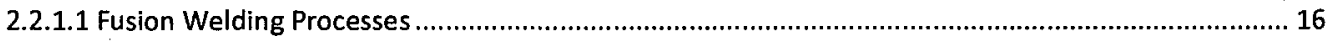

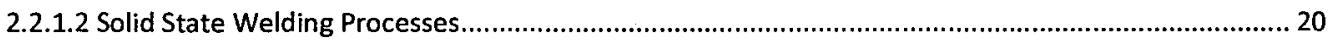

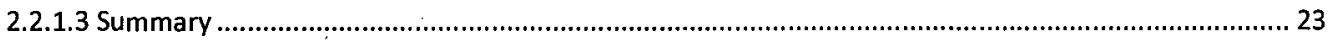

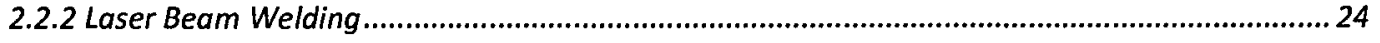




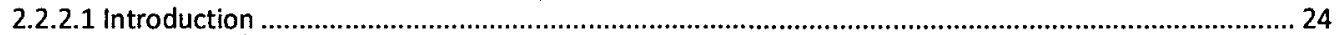

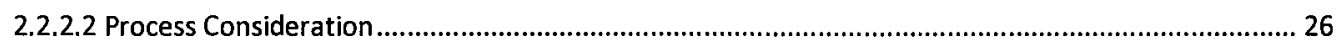

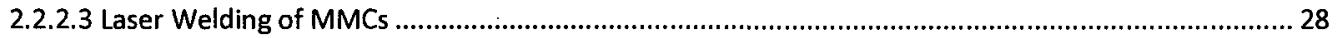

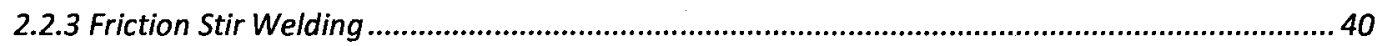

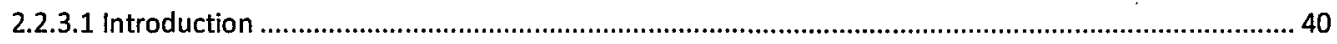

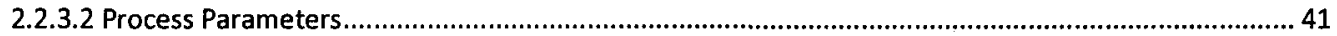

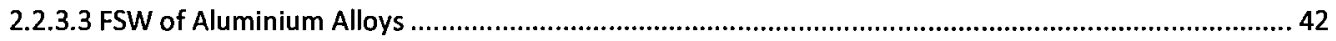

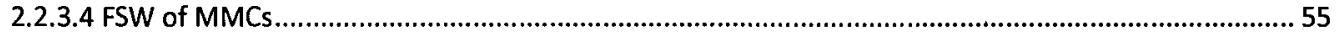

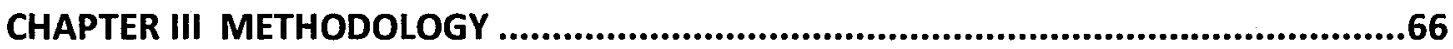

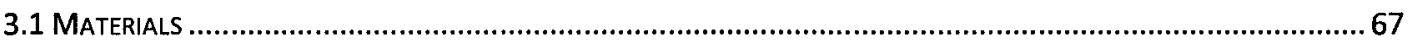

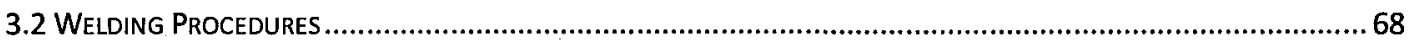

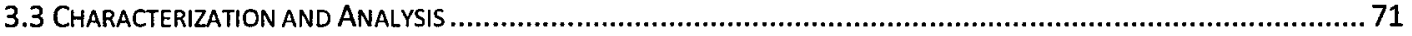

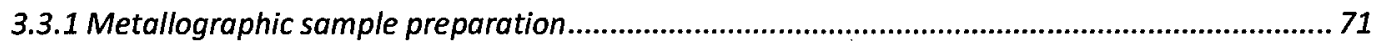

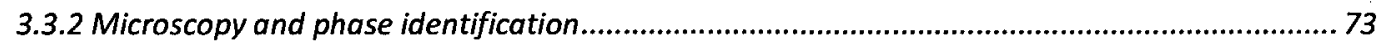

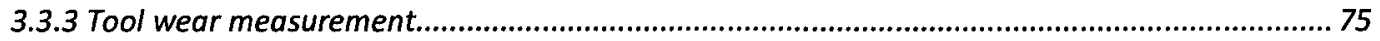

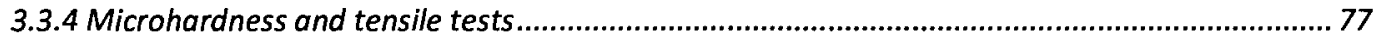

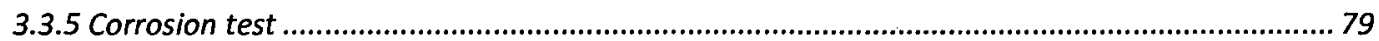

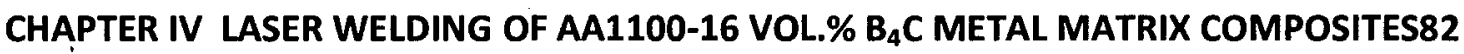

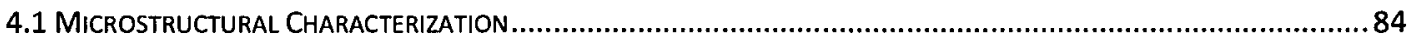

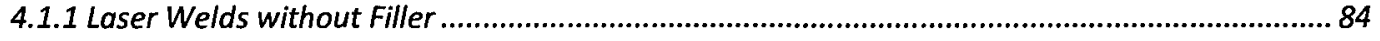

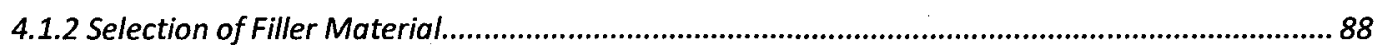

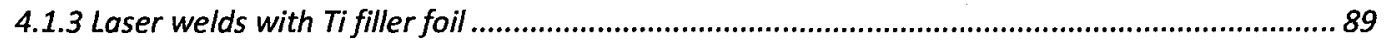

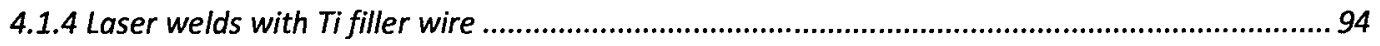

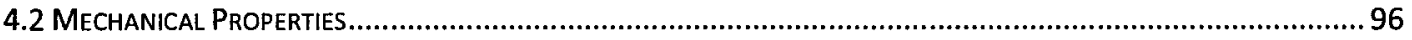

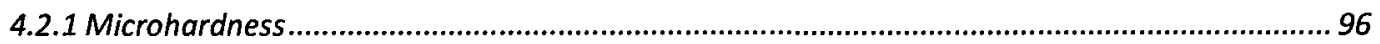


4.2.2 Tensile Results .......................................................................................................................97

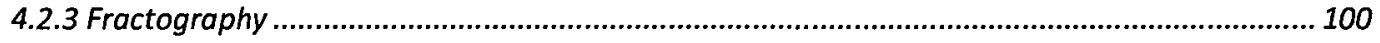

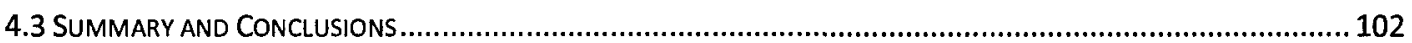

CHAPTER V FRICTION STIR WELDING OF AA1100-B ${ }_{4}$ C METAL MATRIX COMPOSITES 103

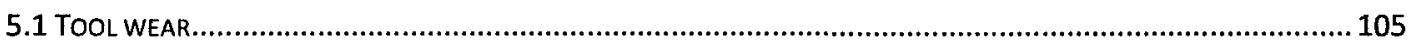

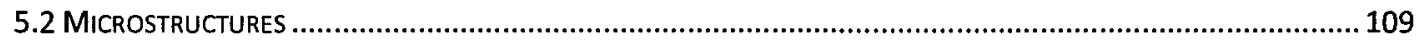

5.2.1 $B_{4} C$ particle characterization ............................................................................................ 112

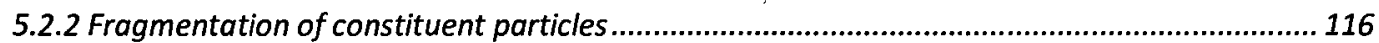

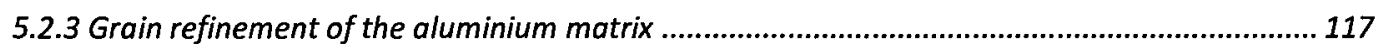

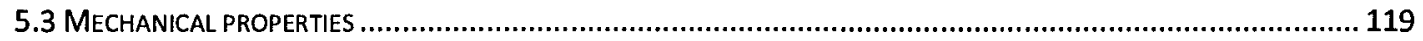

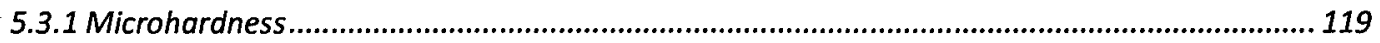

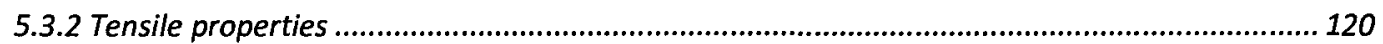

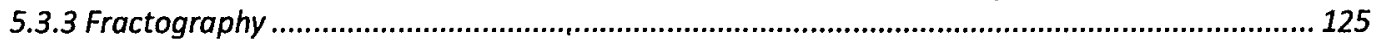

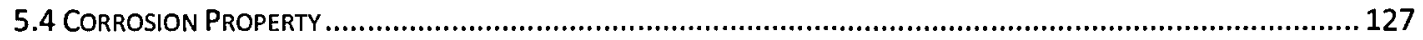

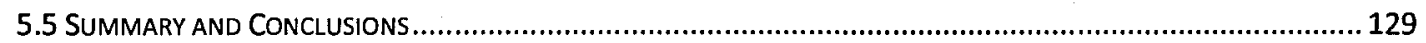

\section{CHAPTER VI MICROSTRUCTURE EVOLUTION AND MECHANICAL PROPERTIES OF

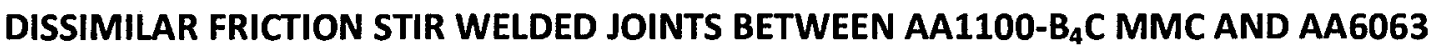
ALLOY

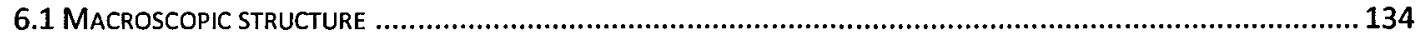

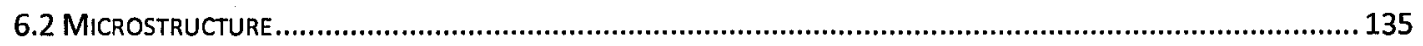

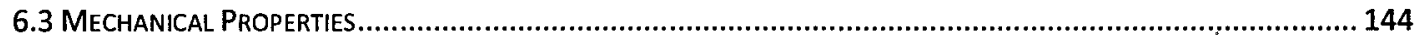

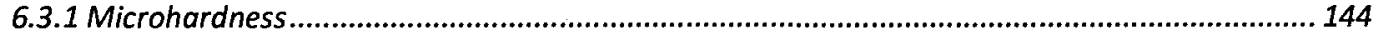

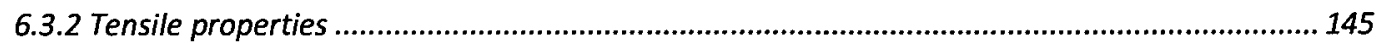

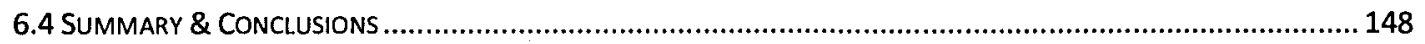

CHAPTER VII CONCLUSIONS AND RECOMMENDATIONS.........................................150

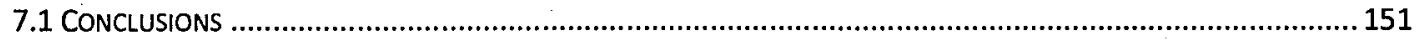




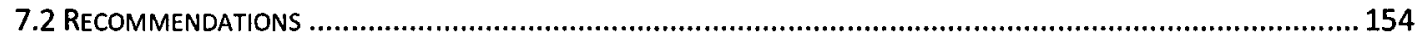

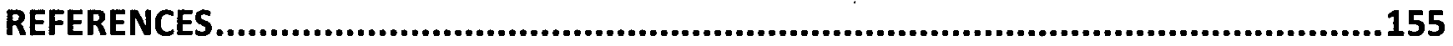

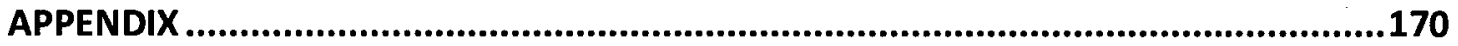




\section{Nomenclature}

\begin{tabular}{lll} 
Symbol & \multicolumn{1}{c}{ Definition } & Unit \\
\hline$\alpha[\mathrm{Si}]$ & Activity of Si in liquid Al & - \\
$\mathrm{A}$ & Absorptivity of material at laser wavelength & -- \\
$\mathrm{E}_{\mathrm{corr}}$ & Corrosion potential & $\mathrm{mV}$ \\
$\Delta \mathrm{G}$ & Gibbs free energy & $\mathrm{J} / \mathrm{mol}^{-}$ \\
$\mathrm{HV}$ & Vickers hardness & -- \\
$\mathrm{j}_{\text {corr }}$ & Corrosion current density & $\mu \mathrm{Acm}$ \\
$\mathrm{R}_{\mathrm{p}}$ & Polarisation resistance & $\mathrm{k \Omega cm}$ \\
$\mathrm{T}$ & Temperature & $\mathrm{K}$
\end{tabular}




\section{List of Tables}

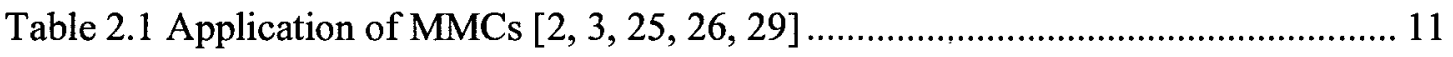

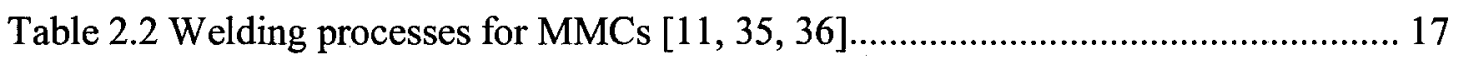

Table 2.3 Absorptivity of metals for Nd:YAG and $\mathrm{CO}_{2}$ laser [10]............................ 27

Table 2.4 Process parameters of LBW and their effects on the welding process $[8-10,52-$

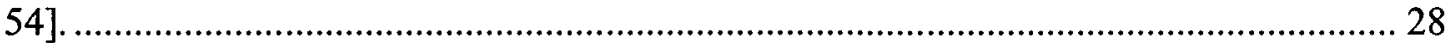

Table 2.5 Summary of recent studies on laser welding of MMCs * ............................... 30

Table 2.6 Summary of major FSW parameters and their effects on the process $[37,72] 41$

Table 2.7 Tensile properties of friction stir welds in as-welded condition...................... 53

Table 2.8 Summary of technical information in FSW of MMCs * ............................... 57

Table 2.9 Summary of mechanical properties of FSW MMCs * ..................................6 60

Table 3.1 Chemical composition of AA6063 (wt.\%) measured by OES ........................ 67

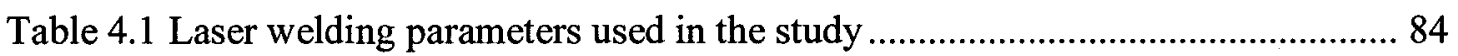

Table 4.2 Tensile results of the base material and laser welded joints of $\mathrm{Al}-\mathrm{B}_{4} \mathrm{C}$ MMCs $( \pm$

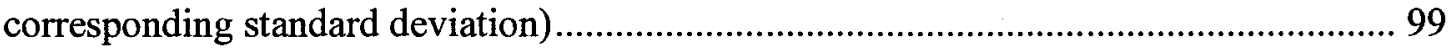

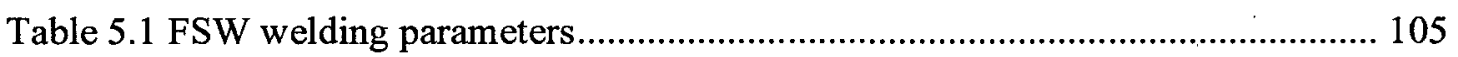

Table 5.2 Tool wear rate comparison for both tool materials................................... 108

Table 5.3 Particle size and aspect ratio before and after FSW of Al-16\% $\mathrm{B}_{4} \mathrm{C} \ldots \ldots \ldots \ldots . . .115$

Table 5.4 Tensile tests of the base materials and FSW joints for Al-B ${ }_{4} \mathrm{C}$ MMCs......... 121

Table 5.5 Electrochemical parameters for the polarisation curves shown in Fig. 5.13 .. 128

Table 6.1 Main welding parameters for different conditions .................................. 133

Table 6.2 Tensile tests results of dissimilar friction stir welded joints*..................... 147 


\section{List of Figures}

Fig. 2.1 SEM photographs of $\mathrm{Al}-\mathrm{B}_{4} \mathrm{C}(5 \%)$ reacted at $1000 \mathrm{~K}$ for (a): $15 \mathrm{~h}$ and (b): $48 \mathrm{~h}$, showing the growth of $\mathrm{Al}_{3} \mathrm{BC}$ and $\mathrm{AlB}_{2}$ crystals [34].

Fig. 2.2 a) Micrograph showing aluminium carbide in TIG weld, and b) chemical analysis

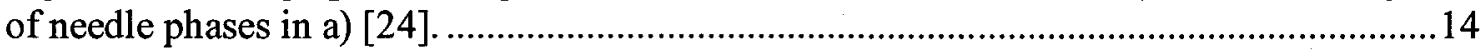

Fig. 2.3 Principle of laser welding keyhole (butt welding configuration)..........................25

Fig. 2.4 Optical micrograph of laser weld zone of $\mathrm{SiC}$ reinforced materials [51]................34

Fig. 2.5 Free energy of formation for several metallic carbides in welding of Al-SiC MMC

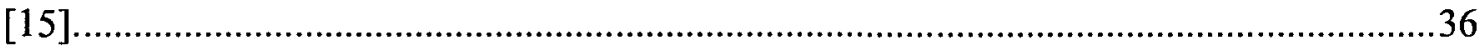

Fig. 2.6 Schematic drawing of friction stir welding [37] ..........................................40

Fig. 2.7 A typical macrograph showing various microstructural regions in aluminium

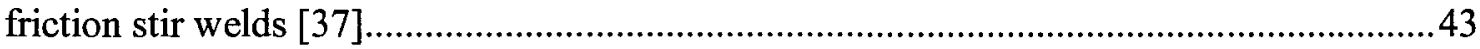

Fig. 2.8 Schematic diagram showing dissolution and reprecipitation in age hardenable

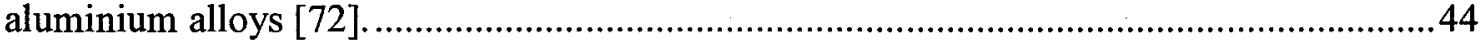

Fig. 2.9 TEM micrographs showing precipitate distribution in different FSW weld regions:

(a) Parent metal, (b) HAZ, (c) TMAZ I, (d) TMAZ II, (e) Nugget zone [74] ...................45

Fig. 2.10 EBSD maps showing the grain structures in the nugget zones of FSW welds with different rotation speeds but a constant welding speed. (a) and (c) at the center, (b) and (d)

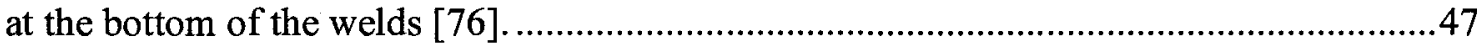

Fig. 2.11 Effect of rotation speed on onset temperature of abnormal grain growth [79]....49

Fig. 2.12 Hardness profiles in the welds made with the same weld pitch (ratio of welding

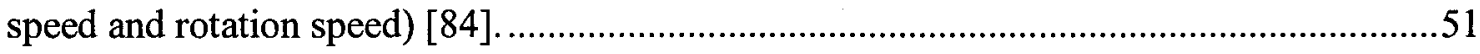

Fig. 2.13 Effect of weld pitch and welding speed on the average hardness in FSW nugget [84].

Fig. 2.14 Average Vickers microhardness of the unprocessed base metal and friction stir welded zone [90]. FZ: friction stir processed zone, UZ: unprocessed zone. 
Fig. 2.15 Hardness profiles $\left(\mathrm{HV}_{0.02}\right)$ on the cross-section of a FSW composite [20].

Fig. 2.16 Pin tool wear as a percent of initial pin shape projections versus corresponding MMC-/FSW traverse distance at various welding speeds noted. (Tool rotation constant at $1000 \mathrm{rpm})[21]$.

Fig. 3.1 The robotized Nd:YAG laser welding machine at NRC-ATC.

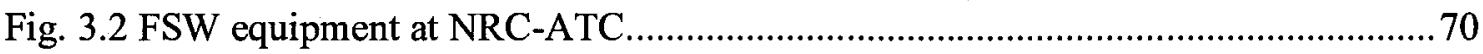

Fig. 3.3 Schematic of laser welding with Ti filler foil.................................................. 70

Fig. 3.4 Automatic polishing machine at ATC (Struers TegraPol-31) ..............................72

Fig. 3.5 Ion beam cross section polishing machine at ATC (Cross Section Polisher: SM09010).

Fig. 3.6 Optical microscope equipped with image analyzer at ATC.................................74

Fig. 3.7 Scanning electron microscope used in the study............................................. 74

Fig. 3.8 Distribution of fields throughout the thickness of plate for image analysis.......75

Fig. 3.9 Noncontact optical profilometer for FSW tool shape measurement (STIL

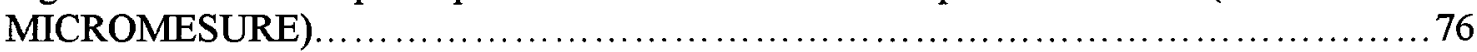

Fig. 3.10 Example of outline profile of a new FSW steel tool ........................76

Fig. 3.11 Vickers microhardness testing machine at ATC (CMT, Clemex) .............78

Fig. 3.12 Sketch of a typical tensile sample showing various dimensions...............78

Fig. 3.13 Schematic of a specimen for corrosion test $\ldots \ldots \ldots \ldots \ldots \ldots \ldots \ldots \ldots \ldots \ldots \ldots$

Fig. 3.14 Schematic of the three electrode system for corrosion testing.................80

Fig. 3.15 Example of a polarization curve for the base material of $\mathrm{Al}-16 \% \mathrm{~B}_{4} \mathrm{C}$ MMC $\ldots . .81$

Fig. 4.1 Images showing typical microstructures of: (a) macro-view of the laser joint (condition B), (b) base material, (c) weld zone under OM, and (d) weld zone under SEM..

Fig. 4.2 Element mapping results showing the formation of Al-B-C and Al-B compounds. 
Fig. 4.3 XRD results showing the presence of $\mathrm{AlB}_{2}$ and $\mathrm{Al}_{3} \mathrm{BC}$ in the weld zone of $\mathrm{Al}-\mathrm{B}_{4} \mathrm{C}$

Fig. 4.4 Standard Gibbs free energy of formation of possible reaction products 89

Fig. 4.5 Optical images showing typical macro-views of laser joints made with (a) $150 \mu \mathrm{m}$ and (b) $300 \mu \mathrm{m}$ Ti foils.

Fig. 4.6 SEM micrographs showing the typical microstructure of the weld zone with (a) $150 \mu \mathrm{m}$ Ti and (b) $300 \mu \mathrm{m} \mathrm{Ti}$

Fig. 4.7 Element mapping results showing the formation of Al-B, Al-B-C and Ti-B compounds

Fig. 4.8 XRD results showing the presence of $\mathrm{AlB}_{2}, \mathrm{Al}_{3} \mathrm{BC}$ and $\mathrm{TiB}_{2}$ in the weld zone of joints made with $150 \mu \mathrm{m}$ Ti foil

Fig. 4.9 Element mapping results showing the formation of Ti-B, Ti-C and $\mathrm{Al}-\mathrm{Ti}$ compounds

Fig. 4.10 XRD results showing the presence of $\mathrm{TiB}_{2}, \mathrm{TiC}$ and $\mathrm{Al}_{3} \mathrm{Ti}$ in the weld zone of joints made with $300 \mu \mathrm{m}$ Ti foil

Fig. 4.11 Optical images showing typical macro-view of laser joints made with Ti filler (zone 1with light color: insufficient Ti, zone 2 with dark gray color: excessive Ti).

Fig. 4.12 SEM micrographs showing typical microstructures with various local $\mathrm{Ti}$ concentrations, a) and b) insufficient $\mathrm{Ti}$ zones, c) adequate $\mathrm{Ti}$ zone and d) excessive $\mathrm{Ti}$ zone

Fig. 4.13 Vickers microhardness profiles across the laser weld: (a) without filler, (b) with $150 \mu \mathrm{m}$ Ti foil and (c) with $300 \mu \mathrm{m}$ Ti foil

Fig. 4.14 Tensile results of the base material and laser welded joints for $\mathrm{Al}^{-\mathrm{B}_{4} \mathrm{C}}$ MMCs

Fig. 4.15 Tensile fracture surface of the (a) as-rolled base material and (b) laser joints without filler, (c) with $150 \mu \mathrm{m}$ Ti foil, and (d) with $300 \mu \mathrm{m} \mathrm{Ti}$ foil 101

Fig. 5.1 Shape changes of the FSW tools, $(a \sim c)$ H13 steel and $(d \sim f)$ WC-Co 107

Fig. 5.2 Tool shape measurement of (a) H13 steel tool and (b) WC-Co tool 108

Fig. 5.3 Typical micrographs showing (a) the steel debris, and (b) WC-Co debris at the top edge of the weld cross-sections 
Fig. 5.4 Typical ultrasonic inspection images of FSW joints of AA1 100-16 vol.\% $\mathrm{B}_{4} \mathrm{C}$ MMCs. a) Defect free FSW joint. b) FSW joint with discontinuous worm hole.

Fig. 5.5 Typical macrograph of FSW joint of AA1100-16 vol. $\% \mathrm{~B}_{4} \mathrm{C}$ composite. Weld zone on the retreating side cannot be clearly identified.

Fig. 5.6 Typical optical micrographs of (a) base material and (b) nugget zone of Al$16 \% \mathrm{~B}_{4} \mathrm{C}$ MMCs (LR3); (c) base material and (d) nugget zone of $\mathrm{Al}-30 \% \mathrm{~B}_{4} \mathrm{C}$ MMCs (HA1)

Fig. 5.7 Particle area and aspect ratio histograms measured in the base material and FSW nugget of both $\mathrm{Al}-16 \%$ and $\mathrm{Al}-30 \% \mathrm{~B}_{4} \mathrm{C} \mathrm{MMCs}$.

Fig. 5.8 Typical backscattered images of the intermetallic distribution in AA1100-16\% $\mathrm{B}_{4} \mathrm{C}$ MMCs before (a) and after (b) FSW

Fig. 5.9 EBSD maps showing the typical grain structure in (a) the as-rolled base material and (b) its weld nugget zone. The black color indicates $\mathrm{B}_{4} \mathrm{C}$ particles while the other colors display different orientations of aluminium grains.

Fig. 5.10 Microhardness profiles across the FSW joints of (a) as-rolled AA1 100-16\% $\mathrm{B}_{4} \mathrm{C}$ MMCs (LR3), (b) annealed AA1 100-16\% B 4 C MMCs (LA3) .......................................120

Fig. 5.11 Tensile properties of $\mathrm{AA1} 100-\mathrm{B}_{4} \mathrm{C}$ MMCs and their FSW joints.

Fig. 5.12 EBSD maps from the as-rolled base material (a) and the HAZ (b), showing the recovery to take place in the $\mathrm{HAZ}$ where most dislocation networks (low angles $2-5^{\circ}$ ) disappear. The black regions are $\mathrm{B}_{4} \mathrm{C}$ particles while other color regions represent the aluminium grains with different orientations. The black lines are the boundary angles $>15^{\circ}$, while the green lines display the boundaries between 5 and $15^{\circ}$ and the grey lines between 2 and $5^{\circ}$, respectively.

Fig. 5.13 Failure locations of FSW joints (FA2)

Fig. 5.14 SEM micrographs of tensile fracture surfaces of (a) the as-rolled base material, (b) the FSW joint (LA1) and (c) the annealed base material.. 126

Fig. 5.15 Potentiodynamic polarisation curves of the base material and its friction stir welds 128

Fig. 6.1 Macroscopic images showing the cross-section of the dissimilar FSW joints produced under condition: (a) DF1, (b) DF2, (c) DF3, (d) DF4. Red dashed lines mark the original interfaces. 
Fig. 6.2 Typical microstructure of the base material and the weld nugget zone on the MMCs side (DF4)

Fig. 6.3 SEM images showing the interfaces of the weld at positions marked in Fig. 6.1 (a, $\mathrm{b}$ for condition DF1; $\mathrm{c}, \mathrm{d}$ for condition DF4).

Fig. 6.4 Typical grain structure of the base materials before welding: (a) AA6063 aluminium alloy, (b) AA1100-16 vol.\% $\mathrm{B}_{4} \mathrm{C}$ MMC. Black color area in (a) represents $\mathrm{B}_{4} \mathrm{C}$ particles; black lines: $>10^{\circ}$, green lines: between $10^{\circ}$ and $5^{\circ}$, grey lines: between $5^{\circ}$ and $2^{\circ}$.

Fig. 6.5 Typical grain structures of the area around interface in the weld nugget of condition; (a) DF1 (advancing side: 6063 alloy), (b) DF4 (advancing side: $\mathrm{Al}-\mathrm{B}_{4} \mathrm{C} \mathrm{MMC}$ ). Black color areas represent $\mathrm{B}_{4} \mathrm{C}$ particles; black lines: $>10^{\circ}$, green lines: between $10^{\circ}$ and $5^{\circ}$, grey lines: between $5^{\circ}$ and $2^{\circ}$.

Fig. 6.6 Typical grain structure along different weld zones (a-d on the $6063 \mathrm{Al}$ side, e-f on the MMC side): (a) $2 \mathrm{~mm}$ from the nugget center, (b) $3.6 \mathrm{~mm}$ from the nugget center (TMAZ), (c) $4.4 \mathrm{~mm}$ from the nugget center (TMAZ), (d) $5.2 \mathrm{~mm}$ from the nugget center (HAZ), (e) $3 \mathrm{~mm}$ from the nugget center, (f) $4.8 \mathrm{~mm}$ from the nugget center. Black color areas represent $\mathrm{B}_{4} \mathrm{C}$ particles; black lines: $>10^{\circ}$, green lines: between $10^{\circ}$ and $5^{\circ}$, grey lines: between $5^{\circ}$ and $2^{\circ}$.

Fig. 6.7 Typical microhardness profiles across the dissimilar friction stir welds: (a) DF1, (b) DF4

Fig. 6.8 Tensile test results of dissimilar friction stir welded joints.

Fig. 6.9 Fractured tensile samples of the dissimilar joints showing the failure locations and the distribution of elongation (DF1). 148 
Chapter I

\section{Definition of Problem}




\section{Chapter I Definition of Problem}

\subsection{Introduction}

Metal matrix composites (MMCs) reinforced with ceramic particulate have been used in a wide range of structural and functional applications, especially in automotive, aerospace, and defense industries due to their superior properties compared to monolithic metallic alloys [1-3]. However, barriers to their wide applications concerning manufacturing and processing still exist. Particularly, challenges of welding technique for joining complex structure must be overcome to enhance the engineering usage of these metal matrix composite materials.

The joining of MMCs was first explored by using conventional fusion welding techniques such as Tungsten Inert Gas (TIG) or Metal Inert Gas (MIG) because they are relatively well developed and have good affordability. Although problems such as reinforcement segregation, porosity, chemical reaction may arise during fusion welding of MMCs, sound welds can be obtained with special attention to the joint preparation and design, selection of welding methods, process parameters and filler metals [4-7]. Successful TIG and MIG welding for Al-SiC MMCs were obtained with ER4043 filler wire [4]. DURALCAN has also successfully applied both TIG and MIG welding processes to 
foundry and wrought aluminium MMCs for surface defect correction and some structural applications [6]. Some precautions and tips need to be followed carefully to produce sound welds. For instance, proper joint preparation and good joint design are the base lines for welding MMCs. Welding practice with low heat input and high silicon content filler wire could minimize the formation of $\mathrm{Al}_{4} \mathrm{C}_{3}$ phase during the welding of $\mathrm{SiC}$ reinforced aluminium MMCs, and the use of magnesium-containing filler could inhibit the dewetting and clumping effects of $\mathrm{Al}_{2} \mathrm{O}_{3}$ particles during the arc welding of $\mathrm{Al}_{2} \mathrm{O}_{3}$ reinforced aluminium MMCs [6].

Compared with arc welding processes, laser beam welding (LBW) has great advantages by using a controllable high intensity heat source. First, the deep and narrow fusion zones associated with laser welding result in a much smaller heat affected zone in comparison with arc welding techniques [8]. Thus, less thermal distortion and mechanical property reduction can be expected. Furthermore, laser welding has advantages for welding smaller components and for welding heat sensitive components due to its precise control [9]. In addition, laser welding has very good process flexibility as the laser heat input can be delivered through optical fibers [10]. It can be performed in various environments and welding can even be realized in locations inaccessible to other welding processes. Application of laser welding for joining $\mathrm{Al}-\mathrm{MMCs}$ reinforced with $\mathrm{SiC}$ and $\mathrm{Al}_{2} \mathrm{O}_{3}$ particles has been investigated. The majority of investigations have emphasized the effects of chemical reaction between the matrix and reinforcement on the joint quality. Researchers have gained some understanding of reaction mechanisms and skills to control these 
undesirable reactions in laser welding of MMCs, mainly concentrated on Al-SiC and Al$\mathrm{Al}_{2} \mathrm{O}_{3}$ systems. The formation of needle-like $\mathrm{Al}_{4} \mathrm{C}_{3}$ and spinel phase $\left(\mathrm{MgAl}_{2} \mathrm{O}_{4}\right)$ can be observed in laser welding of $\mathrm{Al}-\mathrm{SiC}$ and $\mathrm{Al}-\mathrm{Al}_{2} \mathrm{O}_{3} \mathrm{MMCs}$ respectively [11-12]. These phases may act as stress concentration source and thus have a negative influence on mechanical properties. It is suggested that minimum superheating and short melting time [12-13], the use of silicon filler or silicon containing matrix alloy [14], and the use of titanium filler [15-16] would be recommended for Al-SiC MMCs; while aluminium matrix with magnesium content lower than $1 \mathrm{wt} \%$ would be preferred for $\mathrm{Al}-\mathrm{Al}_{2} \mathrm{O}_{3}$ MMCs [17]. However, complete elimination of these harmful phases is difficult and the chemical reaction problem is material specific. Therefore, any change of the reinforcement or the matrix could result in a completely different issue to resolve.

On the other hand, friction stir welding (FSW), as a solid state process, seems to be promising as it provides the opportunity of joining MMCs components without typical problems encountered during fusion welding. A number of research works have been reported showing the feasibility of FSW for joining Al-based MMCs reinforced with various ceramic particles. The tensile strength of FSW joints could reach $60-84 \%$ of the parent metal strength [18-20]. An appropriate post-weld artificially aging treatment may further improve this joint efficiency depending on the matrix alloy and its initial temper [18]. These behaviors can be attributed to the concurrent effects of different microstructural modifications induced by the FSW process such as the refinement of grain structure, and the overaging of the matrix alloy. Nonetheless, an important issue is the severe welding 
tool wear which occurs during FSW of the composite materials. This tool wear may not only reduce lifetime of welding tool and thus increase the cost; but may also affect the performance of FSW joints. It is remarkable that a self optimization phenomenon of tool shape was observed in the study of FSW of AA6061- $\mathrm{Al}_{2} \mathrm{O}_{3} \mathrm{MMCs}$ [21]. No additional tool wear can be detected after a sufficient welding distance for the same set of welding parameters.

In order to overcome challenges in joining $\mathrm{Al}-\mathrm{B}_{4} \mathrm{C} \mathrm{MMCs}$, the present study is intended to evaluate the weldability of $\mathrm{AA} 1100-\mathrm{B}_{4} \mathrm{C}$ MMCs by laser beam welding and friction stir welding. $\mathrm{Al}-\mathrm{B}_{4} \mathrm{C}$ MMCs are principally used as neutron absorber in spent nuclear fuel storage and transportation due to its high boron $\left({ }^{10} \mathrm{~B}\right)$ concentration and thus high neutron absorption capability [22-23]. Increasing demand for joining components of Al- $\mathrm{B}_{4} \mathrm{C}$ MMCs has been posed in applications with complex structure. The achievement of sound joints is considered as one of the important milestones for widespread application of $\mathrm{Al}-\mathrm{B}_{4} \mathrm{C} \mathrm{MMCs}$ as engineering materials. However, the investigation of welding techniques for $\mathrm{Al}-\mathrm{B}_{4} \mathrm{C} \mathrm{MMCs}$ is still in its initial stage. Studies on the feasibility of welding technique for the material have been rarely reported in the literature [5, 18, 24]. Therefore, systematical research works were carried out in the present study in order to understand the welding mechanism and to improve the mechanical performances of joined assemblies made of $\mathrm{Al}-\mathrm{B}_{4} \mathrm{C}$ MMCs. The effects of the LBW and FSW on the microstructural and mechanical properties of $\mathrm{Al}-\mathrm{B}_{4} \mathrm{C}$ MMCs welds were studied. 


\subsection{Objectives}

The objectives of this study are detailed as follows.

1. To evaluate the feasibility of laser beam welding and friction stir welding for joining $\mathrm{Al}-\mathrm{B}_{4} \mathrm{C} \mathrm{MMCs}$;

2. To optimize the mechanical performances of $\mathrm{Al}-\mathrm{B}_{4} \mathrm{C} \mathrm{MMCs}$ through adjusting the process parameters of these two welding techniques;

3. To study the effects of the LBW process parameters on microstructure and mechanical properties of the $\mathrm{Al}-\mathrm{B}_{4} \mathrm{C}$ MMCs

4. To investigate the effects of the FSW process parameters on microstructure and mechanical properties of the $\mathrm{Al}-\mathrm{B}_{4} \mathrm{C} \mathrm{MMCs}$;

5. To study the effects of FSW on microstructure and mechanical properties of dissimilar joints between the monolithic aluminium alloys and the $\mathrm{Al}-\mathrm{B}_{4} \mathrm{C} \mathrm{MMCs}$; 


\section{Chapter II}

\section{Literature Review}




\section{Chapter II Literature Review}

\subsection{Metal Matrix Composites}

Metal Matrix Composites are important engineering materials for their property advantages compared to monolithic metals. These materials provide us the opportunity to combine various properties coming from ceramics and metals including higher specific modulus, better wear resistance, increased specific strength, and superior properties at elevated temperatures, into one material [25, 26]. Therefore, MMCs have very high potential in a wide range of structural and functional applications, especially in automotive, aerospace, and defense industries [11]. A general overview about the technological consideration of MMCs is provided in the following parts. Emphasis is put on the welding techniques of MMCs. More detailed information about the constitution, fabrication and processing of MMCs is available elsewhere in the literature [2, 25-27].

\subsubsection{Selection of MMCs}

MMC is a mixture of metal matrix and reinforcement. A suitable matrix alloy could provide the intended application with interesting properties such as light weight, high corrosion resistance and thermal conductivity, and sufficient mechanical properties at room 
or elevated temperatures. Various light metal alloys such as aluminium, magnesium, titanium are usually desirable matrix candidates [27]. Other metals such as copper, iron may be also used in some special applications. For instance, copper based MMCs are used in applications that require extremely high thermal conductivity and high strength at elevated temperatures simultaneously $[2,26]$. On the other hand, the addition of the reinforcement aims to bring some special improvements to the properties of material. Thus, they usually have a specific property profile. The most common used reinforcements are silicon carbide $(\mathrm{SiC})$, aluminium oxide $\left(\mathrm{Al}_{2} \mathrm{O}_{3}\right)$, graphite $(\mathrm{C})$, boron $(\mathrm{B})$, and boron carbide $\left(\mathrm{B}_{4} \mathrm{C}\right)[2,27]$. Low density, mechanical and chemical compatibility, thermal stability, good mechanical properties and economic efficiency should be thoroughly considered when selecting reinforcement for MMC [25].

The selection of reinforcement is material specific and complicated, detailed instruction is hence beyond the scope of this study. A balance of physical and mechanical properties of these materials can be achieved to meet the applications needs by varying the matrix alloy, the reinforcement, the volume fraction, shape, distribution of the reinforcement, and even the manufacture processes [28]. Table 2.1 gives a list of MMCs applications and the main design considerations.

\subsection{2 $\mathrm{Al}-\mathrm{B}_{4} \mathrm{C}$ Metal Matrix Composites}

Al- $\mathrm{B}_{4} \mathrm{C}$ MMCs have been mainly used in spent nuclear fuel storage and transportation applications owing to their good corrosion resistance, excellent thermal conductivity and 
the specific capability of ${ }^{10} \mathrm{~B}$ to capture neutrons [22]. They have also been successfully applied in applications of bicycle frames and automotive brake components, thanks to their low density, high wear resistance and good mechanical properties [30, 31]. Aluminium matrix provides superior thermal conductivity, excellent mechanical properties, and lightweight, while boron carbide reinforcement offers high neutron absorption capability for the product. Generally, AA6xxx-B 4 C composites with a $\mathrm{T} 4$ or $\mathrm{T} 6$ temper are produced for structural parts in the container; $\mathrm{AA} 1100-\mathrm{B}_{4} \mathrm{C}$ composites are prepared for nonstructural components and can incorporate the highest $\mathrm{B}_{4} \mathrm{C}$ concentration while keeping good formability. If the casting has complex geometries, $\mathrm{Al}-\mathrm{Si}-\mathrm{B}_{4} \mathrm{C}$ composites with excellent castability can be selected [23].

Currently, five suppliers in North America including DWA Technologies, METAMIC LLC, Talon Industries, Ceradyne Inc. and Rio Tinto Alcan have demonstrated their capability of producing aluminium boron carbide MMCs. The former four suppliers are actually using powder metallurgy processes, while Rio Tinto Alcan is applying a so called "liquid mixing process" by mechanically blending boron carbide into the molten aluminium and then going directly to Direct Chill (DC) casting [22, 23]. The liquid mixing process has shown numerous advantages in terms of efficiency and cost control, and thus it is currently the dominating process for the production of most common commercial aluminium MMCs [32]. 
Table 2.1 Application of MMCs [2, 3, 25, 26, 29]

\begin{tabular}{|c|c|c|}
\hline Materials & Application examples & Properties of main concern \\
\hline Al-SiC & $\begin{array}{l}\text { Brake components on } \\
\text { passenger vehicle }\end{array}$ & $\begin{array}{l}\text { Good wear resistance, high thermal conductivity, } \\
\text { reduced braking distance }\end{array}$ \\
\hline $\mathrm{Al}-\mathrm{Al}_{2} \mathrm{O}_{3}$ & $\begin{array}{l}\text { Piston, various components } \\
\text { in cylinder head }\end{array}$ & $\begin{array}{l}\text { Improved wear and fatigue resistance, reduced } \\
\text { thermal expansion coefficient }\end{array}$ \\
\hline $\mathrm{Al}-\mathrm{B}$ & $\begin{array}{l}\text { Frames and rib truss } \\
\text { members in mid-fuselage } \\
\text { section of space shuttle }\end{array}$ & High specific strength and stiffness \\
\hline $\mathrm{Al}-\mathrm{C}$ & $\begin{array}{l}\text { High-gain antenna boom } \\
\text { for Hubble space telescope }\end{array}$ & $\begin{array}{l}\text { Increased stiffness, low thermal expansion } \\
\text { coefficient, excellent electrical conductivity and } \\
\text { high dimensional stability }\end{array}$ \\
\hline $\mathrm{Al}-\mathrm{B}_{4} \mathrm{C}$ & $\begin{array}{l}\text { Nuclear transport } \\
\text { containers }\end{array}$ & $\begin{array}{l}\text { High neutron absorption capability, superior } \\
\text { thermal conductivity and high specific strength }\end{array}$ \\
\hline $\mathrm{Mg}-\mathrm{SiC}$ & Electronic packaging & $\begin{array}{l}\text { Low thermal expansion coefficient, high thermal } \\
\text { conductivity }\end{array}$ \\
\hline $\mathrm{Mg}-\mathrm{Al}_{2} \mathrm{O}_{3}$ & $\begin{array}{l}\text { Automotive engine } \\
\text { components }\end{array}$ & $\begin{array}{l}\text { High specific strength and stiffness, low thermal } \\
\text { expansion coefficient }\end{array}$ \\
\hline $\mathrm{Mg}-\mathrm{C}$ & Large space mirrors & $\begin{array}{l}\text { High modulus of elasticity, near - zero coefficient } \\
\text { of thermal expansion, low density, and high } \\
\text { thermal conductivity }\end{array}$ \\
\hline $\mathrm{Ti}-\mathrm{SiC}$ & $\begin{array}{l}\text { Nozzle actuator links in } \\
\text { General Electric F110 } \\
\text { engine }\end{array}$ & $\begin{array}{l}\text { Elevated temperature strength, high corrosion } \\
\text { resistance }\end{array}$ \\
\hline Ti-TiB & $\begin{array}{l}\text { Intake and exhaust valves } \\
\text { in Toyota Altezza engine }\end{array}$ & $\begin{array}{l}\text { Elevated temperature strength, high corrosion } \\
\text { resistance, good wear resistance, high hardness }\end{array}$ \\
\hline $\mathrm{Cu}-\mathrm{W}$ & Spot welding electrodes & Burn up resistance \\
\hline $\mathrm{Cu}-\mathrm{C}$ & Electric carbon brushes & $\begin{array}{l}\text { High electrical and thermal conductivity, good } \\
\text { wear resistance }\end{array}$ \\
\hline $\mathrm{Fe}-\mathrm{TiC}$ & $\begin{array}{l}\text { Cutting, rolling, piercing, } \\
\text { punching components }\end{array}$ & Ultra hardness, high wear resistance \\
\hline
\end{tabular}

As an important issue of $\mathrm{Al}-\mathrm{B}_{4} \mathrm{C}$ MMCs, the chemical compatibility of the reinforcement in a specified matrix should be thoroughly considered. Interfacial reactions between aluminium and boron carbide have been reported in the literature [32-34]. Many binary or ternary compounds containing $\mathrm{Al}, \mathrm{B}$ and $\mathrm{C}$ were identified under different 
conditions. Nevertheless, the reaction mechanism of $\mathrm{Al}-\mathrm{B}_{4} \mathrm{C}$ system is still not well understood, especially at relatively high temperatures $\left(>1000^{\circ} \mathrm{C}\right)$.

According to D.C. Halverson et al. [33] in an earlier study of $\mathrm{B}_{4} \mathrm{C}-\mathrm{Al}$ composites, at temperatures between 800 and $900^{\circ} \mathrm{C}, \mathrm{AlB}_{2}$ and phase $\mathrm{Al}_{3} \mathrm{BC}$ are the major reaction products after $24 \mathrm{~h}$ heat-treatment; $\mathrm{AlB}_{12}$ will form instead of $\mathrm{AlB}_{2}$ with the increase of heat-treatment time and they also indicated that $\mathrm{AlB}_{12}$ and $\mathrm{Al}_{4} \mathrm{C}_{3}$ would be the final stable phases given a sufficient heat-treatment time. For temperatures between 900 and $1000^{\circ} \mathrm{C}$, $\mathrm{AB}_{12} \mathrm{C}_{2}$ is thermodynamically more stable than $\mathrm{AlB}_{12}$. Between 1200 and $1400^{\circ} \mathrm{C}, \mathrm{Al}_{4} \mathrm{C}_{3}$ and $\mathrm{AlB}_{24} \mathrm{C}_{4}$ will become the stable phases. To avoid this undesirable phase of $\mathrm{Al}_{4} \mathrm{C}_{3}$, they suggested that the $\mathrm{B}_{4} \mathrm{C}-\mathrm{Al}$ composites should be processed at temperatures below $1200^{\circ} \mathrm{C}$. In another fundamental investigation, J.C. Viala et al. [34] extensively studied the reaction mechanism in the mixture of $\mathrm{Al}-\mathrm{B}_{4} \mathrm{C}$ composites at temperatures ranging from 900 to $1273 \mathrm{~K}$. A sharp increase of the reaction rate was noticed at the melting point of aluminium. At temperatures between 933 and $1141 \mathrm{~K}, \mathrm{Al}_{3} \mathrm{BC}$ and $\mathrm{AlB}_{2}$ phases will form, as shown in Fig. 2.1. Above $1141 \mathrm{~K}$, a new phase of $\mathrm{Al}_{3} \mathrm{~B}_{48} \mathrm{C}_{2}\left(\beta-\mathrm{AlB}_{12}\right)$ and the ternary phase of $\mathrm{Al}_{3} \mathrm{BC}$ were observed as the final reaction products; $\mathrm{AlB}_{2}$ no longer existed. Recently, X.-G. Chen [32] reported that the reaction between aluminium and boron carbide could lead to rapid loss of liquid fluidity in a very short holding time, and thus degrade the melt to unusable level. They also developed a new method to control the interfacial reaction by the addition of $\mathrm{Ti}$ into the casting melt. $\mathrm{A}$ dense protective layer of $\mathrm{TiB}_{2}$ and $\mathrm{TiC}$ was formed on $\mathrm{B}_{4} \mathrm{C}$ particle surfaces and has effectively improved the castability of the MMC melt. 
Although some progress has been made in the production processes, further application of $\mathrm{Al}-\mathrm{B}_{4} \mathrm{C}$ MMCs is still limited due to the cost of these materials and the lack of suitable joining techniques to fully benefit the advantages of the materials. Earlier attempts have been made to weld these materials by using TIG or MIG welding processes $[5,24]$. Problems of porosity and inhomogeneous distribution of $\mathrm{B}_{4} \mathrm{C}$ particles were observed in the fusion zone, and these problems cannot be avoided despite the fact that the level of porosity might be decreased by reducing the cooling rate of welding pool [5]. According to T.W. Nelson et al. [24], significant amounts of undesirable needle-like phase were also detected in the fusion zone as shown in Fig. 2.2. In the same study, they also examined the feasibility of FSW technique for joining aluminium boron carbide MMCs. Problems associated with fusion welding processes were totally eliminated because of the solid state feature of FSW technique. Tensile test results indicated that FSW is a superior joining process compared to TIG when welding AA6061- $\mathrm{B}_{4} \mathrm{C}$ composite materials [24]. The same tendency was confirmed later in the investigation of X.-G. Chen et al. [18]; a further increase of joint efficiency was also obtained by applying an artificially aging heat treatment. The problem of FSW technique was the severe tool wear during welding of MMCs [18, 24], which will be discussed later. 


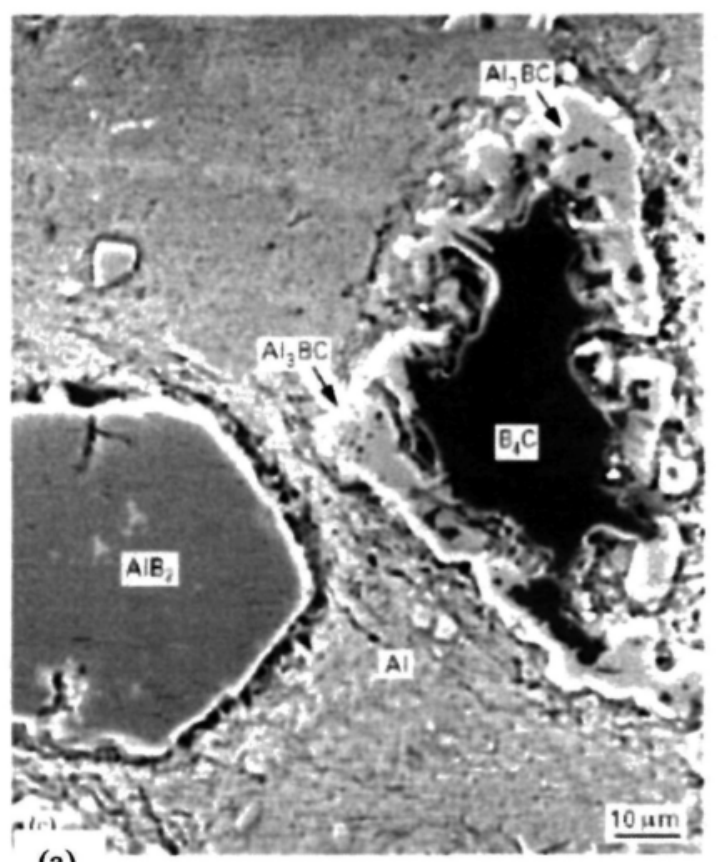

(a)

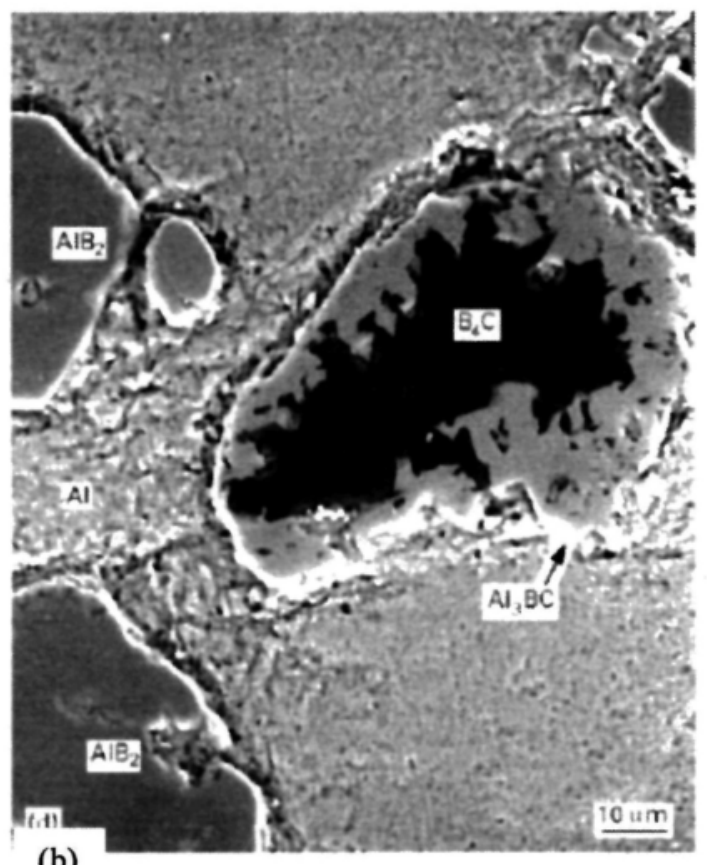

(b)

Fig. 2.1 SEM photographs of $\mathrm{Al}-\mathrm{B}_{4} \mathrm{C}(5 \%)$ reacted at $1000 \mathrm{~K}$ for (a): $15 \mathrm{~h}$ and (b): 48 $h$, showing the growth of $\mathrm{Al}_{3} \mathrm{BC}$ and $\mathrm{AlB}_{2}$ crystals [34].

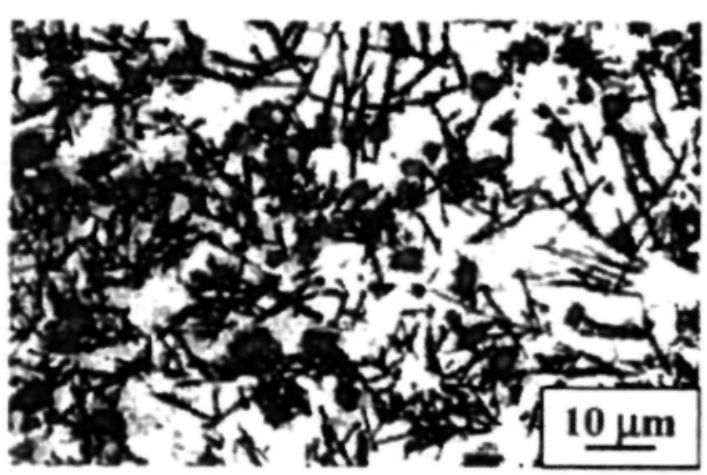

a)

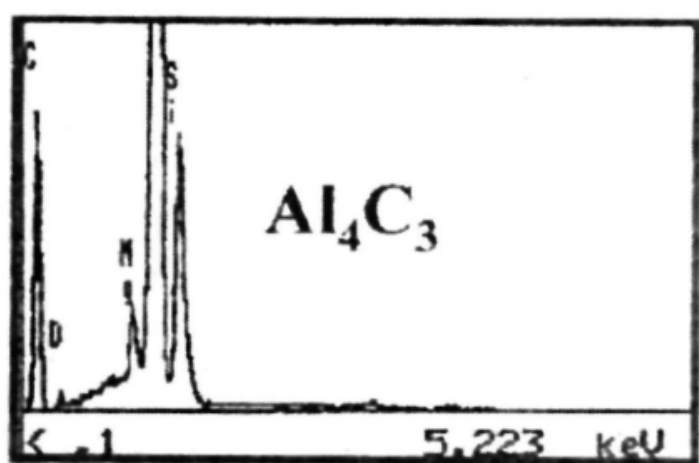

b)

Fig. 2.2 a) Micrograph showing aluminium carbide in TIG weld, and b) chemical analysis of needle phases in a) [24]. 
In general, it is extremely difficult to produce high quality welds of $\mathrm{Al}-\mathrm{B}_{4} \mathrm{C} M \mathrm{MCs}$ by using TIG or MIG processes [5], while some preliminary success by using FSW has been found in the field. The searching of appropriate welding techniques for these materials is still in its initial stage. Therefore, the present study is intended to find effective and reliable welding techniques for aluminium boron carbide MMCs. 


\subsection{Welding of MMCs}

\subsubsection{Introduction}

The welding of MMCs is always a challenge though these materials can with great care be welded by a range of welding processes including fusion and solid state techniques. The addition of particle reinforcement has made the welding of MMCs more complex than for monolithic alloys due to the physical and chemical property differences of metal matrix and ceramic reinforcement. Researchers and engineers have put a lot of efforts in the study for joining MMCs and have gained some experience and knowledge. Table 2.2 summarizes advantages and disadvantages of the welding processes for MMCs. Several extensive reviews on welding of MMCs can be found elsewhere [11, 35-38].

\subsubsection{Fusion Welding Processes}

Fusion welding technologies were first applied for the joining of MMCs because they usually had good affordability and were relatively well developed. Fusion welding includes all welding processes that need to melt materials to be joined. Appropriate joint preparation and design, selections of welding methods, process parameters and filler metals are of great importance for sound welds. Nevertheless, the high temperatures associated with fusion processes could make a number of problems take place during welding of MMCs. First, the solid ceramic reinforcement could result in high viscosity of the melt, which made it difficult to have a fully mixed welding pool; viscous melt also led to a lower heat transfer by convection in the welding pool and hence affects final microstructures and stress 
distributions $[11,35,38]$. In addition, the reinforcement could be rejected by the solidification front if the solidification rate was below a critical value, which could produce unreinforced regions $[11,38]$. Moreover, undesirable chemical reactions between metal matrix and reinforcements could cause serious degradation of weld quality such as low joint strength and ductility [11,35-38]. For example, brittle phase $\mathrm{Al}_{4} \mathrm{C}_{3}$ could form in $\mathrm{Al}-\mathrm{C}$ or Al-SiC MMCs, spinel phase of $\mathrm{MgAl}_{2} \mathrm{O}_{4}$ arises in $\mathrm{Mg}-\mathrm{Al}_{2} \mathrm{O}_{3}$ or $\mathrm{Al}-\mathrm{Mg}-\mathrm{Al}_{2} \mathrm{O}_{3} \mathrm{MMCs}$ [4, 38]. In a similar way, $\mathrm{TiC}$, and $\mathrm{AlB}_{2}$ might be produced correspondingly in $\mathrm{Ti}-\mathrm{SiC}$ and $\mathrm{Al}$ B MMCs system $[39,40]$.

Table 2.2 Welding processes for MMCs $[11,35,36]$

\begin{tabular}{|l|l|l|}
\hline Welding process & Advantages & Disadvantages \\
\hline TIG or MIG & $\begin{array}{l}\text { Standard equipment, filler wire can be } \\
\text { easily used to facilitate welding process }\end{array}$ & $\begin{array}{l}\text { Possibility of chemical } \\
\text { reaction, low weld strength } \\
\text { with unreinforced filler wire }\end{array}$ \\
\hline $\begin{array}{l}\text { Electron Beam } \\
\text { Welding (EBW) }\end{array}$ & $\begin{array}{l}\text { Relatively high speed, deep and narrow } \\
\text { welds }\end{array}$ & $\begin{array}{l}\text { Possibility of chemical } \\
\text { reaction, vacuum required }\end{array}$ \\
\hline $\begin{array}{l}\text { Laser Beam } \\
\text { Welding (LBW) }\end{array}$ & $\begin{array}{l}\text { High speed welding, no vacuum required, } \\
\text { deep and narrow welds, low distortion, } \\
\text { greater accuracy }\end{array}$ & $\begin{array}{l}\text { Possibility of chemical } \\
\text { reaction, shielding gas } \\
\text { required, high beam coupling }\end{array}$ \\
\hline $\begin{array}{l}\text { Resistance } \\
\text { Welding }\end{array}$ & $\begin{array}{l}\text { Short therral cycle and thus less } \\
\text { dissolution / reaction of reinforcement }\end{array}$ & $\begin{array}{l}\text { Possible segregation of } \\
\text { reinforcing particles, } \\
\text { geometry limitations }\end{array}$ \\
\hline Diffusion Bonding & $\begin{array}{l}\text { Interlayer may be required for optimum } \\
\text { bond properties, no particle-matrix } \\
\text { interaction }\end{array}$ & $\begin{array}{l}\text { Insufficient or excessive mass } \\
\text { transport may produce poor } \\
\text { bond, long thermal cycle }\end{array}$ \\
\hline $\begin{array}{l}\text { Magnetically } \\
\text { Impelled Arc Butt } \\
\text { Welding (MIAB) }\end{array}$ & Suitable for tubular components only \\
\hline Friction Welding & $\begin{array}{l}\text { No particle-matrix interaction, full bond } \\
\text { strength achievable after heat-treatment }\end{array}$ & $\begin{array}{l}\text { Small axis-symmetric parts } \\
\text { required, high stress applied, } \\
\text { flash requires removal }\end{array}$ \\
\hline $\begin{array}{l}\text { Friction Stir } \\
\text { Welding }\end{array}$ & $\begin{array}{l}\text { No particle-matrix interaction, cracking, } \\
\text { porosity, filler metals, and shielding gas; } \\
\text { simple weld preparation, shrinkage and } \\
\text { distortion; full bond strength achievable } \\
\text { after heat-treatment }\end{array}$ & $\begin{array}{l}\text { Large and expensive } \\
\text { equipment, limited to flat } \\
\text { plate, severe tool wear }\end{array}$ \\
\hline
\end{tabular}




\subsection{Arc welding}

TIG and MIG welding are two of the most common arc welding processes. TIG uses a non-consumable tungsten electrode, while MIG uses a continuous consumable metal electrode to produce the weld. Both processes are protected with inert gas shielding. Successful TIG and MIG welding for Al-SiC MMCs were obtained with 4043 filler wire given that the powder metallurgy manufactured MMCs were well degassed [4]. T.M. Stantz et al. [5] examined the weldability of $\mathrm{Al}-\mathrm{B}_{4} \mathrm{C}$ MMCs by using TIG and MIG processes. Problems of porosity and inhomogeneous distribution of $\mathrm{B}_{4} \mathrm{C}$ particles were observed in the fusion zone, and these problems cannot be avoided despite the fact that the level of porosity might be decreased by reducing the cooling rate of welding pool [5]. DURALCAN has also successfully applied both TIG and MIG welding processes to foundry and wrought aluminium MMCs (A356 and 6061 based) for surface defect correction and some structural applications [6]. Some precautions and tips need to be followed carefully for sound welds. For instance, proper joint preparation and good joint design are the base lines for welding MMCs. Welding practice with low heat input and high silicon content filler wire could minimize the formation of $\mathrm{Al}_{4} \mathrm{C}_{3}$ phase during the welding of $\mathrm{SiC}$ reinforced aluminium MMCs, and the use of magnesium-containing filler could inhibit the dewetting and clumping effects of $\mathrm{Al}_{2} \mathrm{O}_{3}$ particles during the arc welding of $\mathrm{Al}_{2} \mathrm{O}_{3}$ reinforced aluminium MMCs [6]. Y. Coo [41] reported that the addition of Ti filler could effectively restrain the formation of brittle $\mathrm{Al}_{4} \mathrm{C}_{3}$ phases in TIG welding of $\mathrm{Al} 356-20 \% \mathrm{SiC}$ MMCs. In another investigation, J. Grabian et al. [42] reported that correct selection of beveling type may help 
to produce visibly defect-free TIG welds of AlSi9-SiC MMC and that the presence of $\mathrm{Al}_{4} \mathrm{C}_{3}$ phase was not detected in the weld produced with a $\mathrm{Mg}$ containing filler (5356). In a comparative study of the MIG welding of Al-TiC composites by using direct and indirect electric arc, the composite materials exhibited a good degree of weldability [43]. Negligible dissolution of TiC occurred in welding using indirect electric arc, while some dissolution was observed by using indirect electric arc [43]. In comparison with aluminium based MMCs, fewer studies can be found in arc welding of MMCs with other metal matrix. Z.Z. Xuan et al. [7] reported that TIG welds of an $\mathrm{Mg}-10 \% \mathrm{TiC} \mathrm{MMC}$ were susceptible to porosity and chemical reaction between $\mathrm{Mg}$ and $\mathrm{TiC}$ reinforcement was not detected.

\subsection{Electron beam welding}

As a high energy beam technique, electron beam welding uses a narrow beam of high energy electrons to produce a weld joint in vacuum. The welded joint has advantages such as narrow heat affected zone, low distortion and contamination. However, electron beam process requires a vacuum chamber, and only very few papers could be found in the literature. In the work of T.J. Lienert et al [44], it was found that electron beam welding produced less $\mathrm{Al}_{4} \mathrm{C}_{3}$ than laser welding with the same powers and travel speeds. They attributed this phenomenon to the preferential energy absorption by the $\mathrm{SiC}$ reinforcement during laser welding process, and suggested that sharp focus of the electron beam and high welding speed should be used to minimize the formation of $\mathrm{Al}_{4} \mathrm{C}_{3}$. 


\subsection{Laser beam welding}

Laser beam welding is a fusion welding process that uses a concentrated high energy laser beam to produce the weld. Compared with other fusion processes, laser beam welding has received more attention for joining MMCs over the past two decades. This is mainly because of its advantages of high energy density, greater position accuracy, feasibility for automated 3D welding, low distortion and no requirement of vacuum chamber which may be beneficial for joining MMCs [35]. Laser welding represents one of the advanced fusion techniques and has become widely accepted in many industries [9-10]. Detailed discussion on laser welding of MMCs will be given in later parts following an introduction of laser welding technique.

\subsubsection{Solid State Welding Processes}

Compared to fusion welding, solid-state welding techniques seem to be more suitable for joining MMCs. The disappearance of molten welding pool can eliminate various problems encountered in fusion process. In particular, friction stir welding has been emerging as a competitive alternative for joining MMCs. A summary of several solid-state welding techniques is provided below. 


\subsection{Diffusion bonding}

Diffusion bonding is a welding process that produces a solid state bond between two components under a certain load at a temperature below the melting point of the materials to be joined. At present, diffusion bonding has found some applications for welding MMCs, though restrictions may be imposed on the process. In general, surface preparation, interlayer and other parameters such as processing time, temperature and pressure are of significant importance for optimum bond properties [35, 38]. The major concern of diffusion bonding of MMCs is the use of suitable interlayer to improve the joining quality. X.-P. Zhang et al. [45] reported that good joints of an Al-SiC MMCs were successfully produced by vacuum diffusion bonding. A soft active layer of $\mathrm{Al}-\mathrm{Si}-\mathrm{Mg}$ and a pure copper foil were actually used as interlayer in their study. It was found that the use of suitable interlayer could benefit to the interface bonding and lead to increasing of joint strength. In another investigation of diffusion bonding of an $\mathrm{Al}_{-} \mathrm{Al}_{2} \mathrm{O}_{3} \mathrm{MMCs}$, the joining process was favored by the use of an Al-Li alloy which accelerates the breakup of protective aluminium oxide [46]. It needs to be noticed that the diffusion bonding process is usually conducted above the solution treatment temperature of the matrix of base materials, and further postweld heat treatment is thus required to recover the mechanical properties [35]. Another limitation of diffusion bonding is that the process is incapable of joining some MMCs that have lower hot strength to withstand the bonding pressure without excessive macrodeformation [35]. Besides, it can be difficult to achieve reproducibly satisfactory bonds in aluminium based MMCs [11]. 


\subsection{Friction welding}

Friction welding is a solid state process that uses friction heat generated between a moving workpiece and a stationary one to produce the weld. Although high pressures should be applied during friction welding of MMCs since the reinforcement has substantially increased the flow stress of the material [38], friction welding seems to be very attractive for joining small MMCs components with axis-symmetric feature. In fact, different types of MMCs have been friction welded with good results. M.J. Cola et al. [47] conducted an investigation of friction welding on $\mathrm{AA} 6061-\mathrm{Al}_{2} \mathrm{O}_{3} \mathrm{MMCs}$ in $\mathrm{T} 6$ temper condition. Sound welds without any discontinuity were produced though the ductility of the weld zone was not good. More recently, A.A.M. Silva et al. [48] have examined the feasibility of friction welding on a titanium based MMCs. Satisfactory joints with high tensile properties could be obtained in a wider operating window. Similar to diffusion bonding technique, a further concern is the possible decrease of strength in the heat affected zone due to dissolution of hardening precipitates, although this can be recovered by applying the proper post weld heat treatment [49].

\subsection{Friction stir welding}

The advantages of solid state welding over fusion welding process have been widely recognized $[11,35]$. However, the application of diffusion bonding or friction welding is limited due to their low productivity. The development of FSW process provides the opportunity of welding MMCs components with flat geometry at much higher productivity. 
The feasibility of FSW of MMCs has been demonstrated in some investigations over the past decade $[24,50,51]$. It was identified that high quality welds of MMCs reinforced with ceramic particles could be produced by FSW. Like for laser welding technique, FSW of MMCs will also be reviewed later in a separated section.

\subsubsection{Summary}

Based on the above discussion, it is clear that MMCs components can be welded by most of the existing welding techniques. Although fusion welding processes may experience various problems such as viscous welding pool, reinforcement segregation, interfacial reaction and porosity, sound welds can still be produced with more careful attention in terms of joint preparation, process parameters and selection of filler metal. On the other hand, solid state welding processes seem to be more promising for joining MMCs and should always be preferred when applicable. It needs to be realized that the welding of MMCs is a really tough challenge, especially with the development of new types of MMCs. Based on above literature review, laser beam welding and friction stir welding are selected in the study to evaluate the weldability of $\mathrm{AA} 1100-\mathrm{B}_{4} \mathrm{C}$ MMCs since they are two very promising techniques and also because these two processes are available at Aluminium Technology Centre (NRC-ATC). Reviews of these two processes and their application for welding MMCs will be provided in the following parts. 


\subsubsection{Laser Beam Welding}

\subsubsection{Introduction}

Laser beam welding is a high energy beam process that is used to join multiple workpieces through the use of a laser. As shown in Fig. 2.3, the laser beam is focused on or very near the surface of the workpieces to be joined. The laser energy initially absorbed by the workpiece surface quickly heats the material, causing production of an energy absorbing ionized vapor $[10,52]$. This ionized vapor rapidly accelerates the absorption of laser energy and initiates a keyhole into the workpiece. Due to multiple reflections on the keyhole walls, the laser energy is entrapped in the keyhole which increases the coupling of laser energy into the workpiece. In the keyhole, the vapor cavity surrounded by molten material is maintained through equilibrium between forces from material ablation, plasma formation, surface tension and hydrostatic pressure of the molten pool $[53,54]$. As the laser beam moves forward, material is progressively melted at the edge of the molten pool and flows around the vapor cavity to the rear of the pool. The keyhole will collapse at excessive welding speed, whereas a wide weld bead will be produced at insufficient speed [54]. The laser welding practice must therefore be conducted in a certain speed range. 


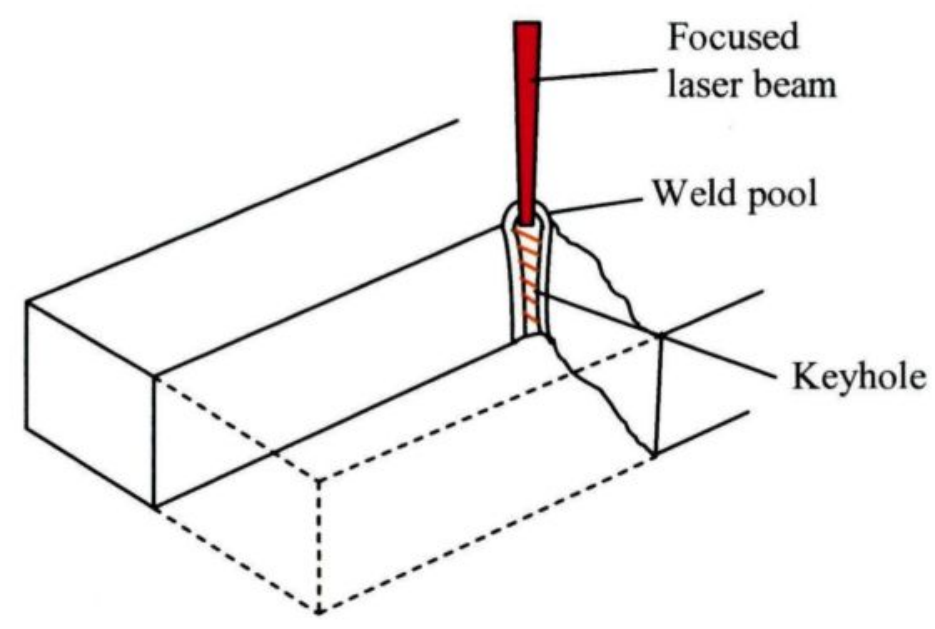

Fig. 2.3 Principle of laser welding keyhole (butt welding configuration).

Laser beam welding has been increasingly used in many industries such as automotive and defense industries because of its great advantages by using a controllable high intensity heat source. With this process, a deep and narrow fusion zone with almost parallel fusion boundaries $[8,52]$ could be produced with a single pass. The lower heat input feature for a given penetration results in a much smaller heat affected zone in comparison with arc welding techniques, thus less thermal distortion and mechanical property reduction can be expected [10]. LBW also has advantages for welding small components and for welding heat sensitive components due to its high accuracy and precise heat control $[9,52]$. In addition, LBW has very good process flexibility for 3D welding as the laser heat input can be delivered through optical fibers. It can be performed in various environments and even welding can be realized in locations inaccessible for other techniques [55]. Besides, laser 
welding technique can produce welds at high welding speed which may compensate the high equipment cost in long term for instance in car manufacturing industries $[8,10]$.

\subsubsection{Process Consideration}

Currently, $\mathrm{CO}_{2}$ and $\mathrm{Nd}$ :YAG lasers are two main high power laser systems being used in laboratories and industries. The big difference between them is the shorter wavelength of $\mathrm{Nd}$ :YAG compared with that of $\mathrm{CO}_{2}$ laser, which are 1.06 and $10.6 \mu \mathrm{m}$ correspondingly $[10,52]$. This shorter wavelength allows fiber optic delivery of Nd:YAG laser beam while it is not possible for the $\mathrm{CO}_{2}$ laser beam $[8,53]$, which is probably the most attractive feature of Nd:YAG laser for industrials. On the other hand, the $\mathrm{CO}_{2}$ laser has the advantage of higher output efficiency (the ratio of output laser power to input electrical power), which is very competitive in industrial applications though less power is needed for Nd:YAG laser for the same weld performance due to much lower reflectivity of metals at short wavelength $[8,10]$. Recently, new laser technologies (disc laser and fiber laser) have been put in the market but no significant work seems to have been done on MMCs.

As a high energy beam process, laser welding is quite different to conventional arc welding which solely depends on Joule effect and heat conduction to achieve a weld. The energy transfer from an incident laser beam to the workpiece is completed through optical absorption by the material and plasma and multiple reflections of the laser beam at walls of the keyhole [54]. Laser energy absorption by a material is affected by many factors like 
type of laser, incident power density, temperature, type of material and materials surface condition [10, 52-54]. The absorptivity (A) of several metals for laser radiation at normal incidence on a metal surface at room temperature is listed in Table 2.3. Careful considerations of these factors can be very useful in tailoring laser profiles for particular welding operations. However, detailed discussion on these factors is out of the scope of the present study.

Table 2.3 Absorptivity of metals for $\mathrm{Nd}: \mathrm{YAG}$ and $\mathrm{CO}_{2}$ laser [10].

\begin{tabular}{|l|l|l|}
\hline \multirow{2}{*}{ Metal } & \multicolumn{2}{|c|}{ Absorptivity (A) } \\
\cline { 2 - 3 } & Nd:YAG laser & $\mathbf{C O}_{\mathbf{2}}$ laser \\
\hline $\mathrm{Al}$ & 0.06 & 0.02 \\
\hline $\mathrm{Cu}$ & 0.05 & 0.015 \\
\hline $\mathrm{Fe}$ & 0.1 & 0.03 \\
\hline $\mathrm{Ni}$ & 0.15 & 0.05 \\
\hline $\mathrm{Ti}$ & 0.26 & 0.08 \\
\hline $\mathrm{Zn}$ & 0.16 & 0.03 \\
\hline Carbon steel & 0.09 & 0.03 \\
\hline Stainless steel & 0.31 & 0.09 \\
\hline
\end{tabular}

In addition to the factors above, high quality laser welds require a precise control of various process parameters such as laser power, spot size, welding speed and shielding gas. The major process parameters of LBW and their effects on the welding process are listed in Table 2.4. Comprehensive reviews on the subject can be found elsewhere in the literature $[8-10,52-54]$ 
Table 2.4 Process parameters of LBW and their effects on the welding process [8-10, 52-54].

\begin{tabular}{|l|l|}
\hline Process parameter & Comments \\
\hline Laser power & Greater power, higher penetration at a set welding speed \\
\hline $\begin{array}{l}\text { Continuous wave (CW) or } \\
\text { pulsed wave }\end{array}$ & $\begin{array}{l}\text { CW: high speed welding, pulsed wave: precision welding of } \\
\text { small components }\end{array}$ \\
\hline Spot size & $\begin{array}{l}\text { Smaller spot size results in higher power density at a given laser } \\
\text { power }\end{array}$ \\
\hline Beam spatial mode & $\begin{array}{l}\text { TEM } \\
\text { Higher order modes: larger focal spots }\end{array}$ \\
\hline Focal length & $\begin{array}{l}\text { The shorter the focal length, the smaller the beam waist diameter } \\
\text { and the depth of focus, and the larger the convergence angle }\end{array}$ \\
\hline Depth of focus (DOF) & $\begin{array}{l}\text { Larger DOF indicates larger vertical distance for acceptable weld } \\
\text { quality }\end{array}$ \\
\hline Focal plane position & $\begin{array}{l}\text { Important for laser beam coupling, and adjustable for maximum } \\
\text { penetration }\end{array}$ \\
\hline Welding speed & Higher welding speed, lower penetration at a given laser power \\
\hline Shield gas & $\begin{array}{l}\text { Important to prevent oxidation, to control plasma plume, and to } \\
\text { protect optic lenses from weld spattering and fumes }\end{array}$ \\
\hline
\end{tabular}

\subsubsection{Laser Welding of MMCs}

Laser welding technique has been applied in joining MMCs over the past two decades due to its various advantages. Investigations were carried out trying to control the microstructure of weld and thus the mechanical properties of joints. As summarized below in Table 2.5, most of the investigations on welding MMCs focused on aluminium based MMCs, only very few studies can be found for other types of MMCs. Sound laser welds of MMCs could be successfully obtained with appropriate welding parameters and filler materials. The high energy feature of laser welding could benefit some properties such as 
distortion and residual stress of MMCs joints. As any other fusion welding processes, laser welding technique may also suffer possible problems such as reinforcement segregation, porosity and undesirable chemical reaction between matrix and reinforcement in welding of MMCs $[39,56,57]$. Although these problems can, to some extent, be lessened through adjusting the laser process parameter, complete prevention of them, especially interfacial reaction between matrix and reinforcement, is almost impossible by only changing the process parameter [58-60]. The use of different types of filler metals seems to be a promising method to solve these problems [14-16, 61], which is detailed in the following sections.

\subsection{Microstructure Evolution}

The microstructure of a metallic material mainly depends on the experienced thermal cycle. In comparison with arc welding processes, the distinction of laser welding is the high energy density of laser beam and the rapid cooling rate of the workpiece after welding. Thus narrower weld zones and finer microstructure can be expected in laser welding [55]. Consequently, laser welds usually have reduced thermal distortion and improved metallurgical properties in comparison with that produced by arc welding techniques. On the other hand, this high energy density and the rapid cooling rate may also cause problems like cracking and possible loss of some volatile elements [10]. The addition of ceramic reinforcement into the metallic matrix further complicates the microstructure evolution of MMCs during laser welding. 
Table 2.5 Summary of studies on laser welding of MMCs *

\begin{tabular}{|c|c|c|c|}
\hline Materials & Laser types & Process parameter & Ref. \\
\hline $\mathrm{A} 354-5-15 \% \mathrm{SiC}$ & $\mathrm{CO}_{2}: \mathrm{CW}$ & $\begin{array}{l}\text { Power: } 4 \mathrm{~kW} \text {, filler: ER } 4043 \text { and ER4047, spot size: } 0.8 \mathrm{~mm} \text {, } \\
\text { shielding: } \mathrm{N}_{2} \text {, speed: } 15-61.7 \mathrm{~mm} / \mathrm{s}\end{array}$ & 14 \\
\hline $\begin{array}{l}\mathrm{A} 356-10 \% \mathrm{SiC} \text { and } \\
\mathrm{A} 356-20 \% \mathrm{SiC}\end{array}$ & $\mathrm{CO}_{2}: \mathrm{CW}$ & $\begin{array}{l}\text { Power: } 1.2-2.7 \mathrm{~kW} \text {, filler: } \mathrm{Ti} \text {, mode: } \mathrm{TEM}_{10} \text {, focal position: } 0.5 \\
\text { mm below surface, shielding: Ar at } 4 \mathrm{~L} / \mathrm{min} \text {, speed: } 25 \mathrm{~mm} / \mathrm{s}\end{array}$ & 16 \\
\hline $\begin{array}{l}\mathrm{A} 356-10 \% \mathrm{SiC} \text { and } \\
\mathrm{A} 356-20 \% \mathrm{SiC}\end{array}$ & $\mathrm{CO}_{2}$ : pulsed & $\begin{array}{l}\text { Power: } 1.6-2.9 \mathrm{~kW} \text {, mode: } \mathrm{TEM}_{10} \text {, focal position: } 0.5 \mathrm{~mm} \text { below } \\
\text { surface, shielding: Ar at } 4 \mathrm{~L} / \mathrm{min} \text {, speed: } 25 \mathrm{~mm} / \mathrm{s}\end{array}$ & 58 \\
\hline $\mathrm{A} 356-15 \% \mathrm{SiC}$ & $\begin{array}{l}\mathrm{CO}_{2}: \mathrm{CW} \\
\mathrm{Nd}: Y A G: \text { pulsed }\end{array}$ & $\begin{array}{l}\mathrm{CO}_{2} \text { power: } 1.0-1.5 \mathrm{~kW} \text {, focal length: } 127 \mathrm{~mm} \text {, focal position: } \\
0.64 \mathrm{~mm} \text { below the surface, spot size: } 0.56 \mathrm{~mm} \text {, shielding: He at } \\
19 \mathrm{~L} / \mathrm{min} \text {, speed: } 36-97.4 \mathrm{~mm} / \mathrm{s} \\
\mathrm{Nd}: Y A G \text { power: } 200 \mathrm{~W} \text {, focal length: } 127 \mathrm{~mm} \text {, focal position: } \\
\text { workpiece surface, shielding: He at } 19 \mathrm{~L} / \mathrm{min} \text {, speed: } 3.2-8.5 \\
\mathrm{~mm} / \mathrm{s}\end{array}$ & 57 \\
\hline $\mathrm{A} 359-20 \% \mathrm{SiC}$ & $\begin{array}{l}\mathrm{CO} 2: \mathrm{CW} \\
\text { Diode laser: } \mathrm{CW}\end{array}$ & $\begin{array}{l}\text { Power 1: } 2.4-4 \mathrm{~kW} \text {, focal length: } 200 \mathrm{~mm} \text {, focal position: } \\
\text { workpiece surface, spot size: } 0.6 \mathrm{~mm} \text {, shielding: } \mathrm{N}_{2} \text {, speed: } 30- \\
50 \mathrm{~mm} / \mathrm{s} \\
\text { Power } 2: 2 \mathrm{~kW} \text {, mode: } \mathrm{TEM}_{00}, \text { focal length: } 66 \mathrm{~mm} \text {, shielding: } \\
\mathrm{N}_{2} \text {, speed:15-35 mm/s }\end{array}$ & 13 \\
\hline $\mathrm{A} 359-20 \% \mathrm{SiC}$ & Nd-YAG: pulsed & $\begin{array}{l}\text { Power : } 2-5 \mathrm{~kW} \text {, shielding: } \mathrm{N}_{2}, \mathrm{He}, \text { Ar at } 5 \mathrm{~L} / \mathrm{min} \text {, speed: } 25-33.3 \\
\mathrm{~mm} / \mathrm{s}\end{array}$ & 12 \\
\hline AA1 $100-15 \% \mathrm{SiC}$ & $\mathrm{CO}_{2}: \mathrm{CW}$ & $\begin{array}{l}\text { Power: } 2 \mathrm{~kW} \text {, filler: ER } 4043 \text { and ER4047, spot size: } 0.8 \mathrm{~mm} \text {, } \\
\text { shielding: } \mathrm{N}_{2} \text {, speed: } 15-25 \mathrm{~mm} / \mathrm{s} \text {, }\end{array}$ & 14 \\
\hline AA2124-17\% SiC & $\begin{array}{l}\text { Nd-YAG: } \mathrm{CW} \\
\text { and pulsed }\end{array}$ & $\begin{array}{l}\text { Power: } 400-1400 \mathrm{~W} \text {, filler: } \mathrm{Ni} \text {, focal length: } 100 \mathrm{~mm} \text {, focal } \\
\text { position: workpiece surface, spot size: } 0.5 \mathrm{~mm} \text {, shielding: Ar at } \\
10 \mathrm{~L} / \mathrm{min} \text {, speed: } 25 \mathrm{~mm} / \mathrm{s}\end{array}$ & 62 \\
\hline AA6061-20\%SiC & Nd:YAG: pulsed & Power: $300-600 \mathrm{~W}$ & 63 \\
\hline $\begin{array}{l}\text { AA6061-20wt.\% } \\
\text { SiC }\end{array}$ & $\begin{array}{l}\mathrm{CO}_{2}: \mathrm{CW} \text { and } \\
\text { pulsed }\end{array}$ & $\begin{array}{l}\text { Power: } 1.5 \mathrm{~kW} \text {, filler: Ti, Beam mode: } \mathrm{TEM}_{00} \text {, Focal length: } \\
6.35 \mathrm{~mm} \text {, spot size: } 120 \mu \mathrm{m}\end{array}$ & 15 \\
\hline AA6061-25\% $\%$ SiC & $\mathrm{CO}_{2}: \mathrm{CW}$ & Power: $2.5-4.5 \mathrm{~kW}$, shielding: Ar at $4 \mathrm{~L} / \mathrm{min}$, speed: $9-20 \mathrm{~mm} / \mathrm{s}$ & 59 \\
\hline AA6061-25\% $\mathrm{SiC}$ & $\mathrm{CO}_{2}: \mathrm{CW}$ & Power: $2.5 \mathrm{~kW}$, speed: $5-8.3 \mathrm{~mm} / \mathrm{s}$ & 61 \\
\hline AA6063-15\% & $\mathrm{CO}_{2}:$ pulsed & Peak power: $1 \mathrm{~kW}$, speed: $20 \mathrm{~mm} / \mathrm{s}$ & 60 \\
\hline $\begin{array}{l}\mathrm{AA} 2618-20 \% \mathrm{Al}_{2} \mathrm{O}_{3} \\
\mathrm{AA} 6061-20 \% \mathrm{Al}_{2} \mathrm{O}_{3}\end{array}$ & Nd-YAG: pulsed & $\begin{array}{l}\text { Power : } 2-5 \mathrm{~kW} \text {, shielding: } \mathrm{N}_{2}, \mathrm{He}, \text { Ar at } 5 \mathrm{~L} / \mathrm{min} \text {, speed: } 25-33.3 \\
\mathrm{~mm} / \mathrm{s}\end{array}$ & 12 \\
\hline $\begin{array}{l}\mathrm{AA} 2681-20 \% \mathrm{Al}_{2} \mathrm{O}_{3} \\
\mathrm{AA} 6061-20 \% \mathrm{Al}_{2} \mathrm{O}_{3}\end{array}$ & $\mathrm{CO}_{2}: \mathrm{CW}$ & $\begin{array}{l}\text { Power: } 4 \text { and } 6 \mathrm{~kW} \text {, filler: ER5356, focal position: workpiece } \\
\text { surface, spot size: } 0.5 \mathrm{~mm} \text {, shielding: } \mathrm{N}_{2}, \mathrm{H}_{\mathrm{e}}, \mathrm{Ar} \text { at } 5 \mathrm{~L} / \mathrm{min} \text {, } \\
\text { speed: } 66.7-133.3 \mathrm{~mm} / \mathrm{s} \text { without filler and } 41.7-66.7 \mathrm{~mm} / \mathrm{s} \text { with } \\
\text { filler }\end{array}$ & 56 \\
\hline $\begin{array}{l}\mathrm{AA} 2681-20 \% \mathrm{Al}_{2} \mathrm{O}_{3} \\
\mathrm{AA} 6061-20 \% \mathrm{Al}_{2} \mathrm{O}_{3}\end{array}$ & $\mathrm{CO}_{2}: \mathrm{CW}$ & $\begin{array}{l}\text { Power: } 6 \mathrm{~kW} \text {, mode: } \mathrm{TEM}_{02} \text {, spot size: } 0.5 \mathrm{~mm} \text {, shielding: } \mathrm{N}_{2} \\
\text { and } \mathrm{H}_{\mathrm{e}} \text {, speed: } 50-83.3 \mathrm{~mm} / \mathrm{s} \text {, }\end{array}$ & 65 \\
\hline AA $6061-30 \% \mathrm{Al}_{2} \mathrm{O}_{3}$ & Nd:YAG: pulsed & $\begin{array}{l}\text { Power: } 50-375 \mathrm{~W} \text {, shielding: } \mathrm{N}_{2} \text {, frequency: } 15-50 \mathrm{~Hz} \text {, speed: } 5 \\
\mathrm{~mm} / \mathrm{s} \text {, }\end{array}$ & 66 \\
\hline AISi7Mg-20\%SiCp & Nd-YAG: pulsed & $\begin{array}{l}\text { Laser fluence energy: } 2 \mathrm{~J} \text {, filler: Ti, mode: } \mathrm{TEM}_{00} \text {, spot size: } 1.26 \\
\text { mm, frequency: } 25 \mathrm{~Hz} \text {, pulse duration: } 4 \mathrm{~ms} \text {, speed: } 5 \mathrm{~mm} / \mathrm{s} \text {, }\end{array}$ & 64 \\
\hline $\begin{array}{l}\mathrm{ZC} 71(\mathrm{Mg}-7 \mathrm{Zn}- \\
1 \mathrm{Cu})-12 \% \mathrm{SiC}\end{array}$ & Nd:YAG: pulsed & $\begin{array}{l}\text { Power: } 300-400 \mathrm{~W} \text {, shielding: Ar at } 20 \mathrm{~L} / \mathrm{min} \text {, speed: } 0.83-5 \\
\mathrm{~mm} / \mathrm{s} \text {, }\end{array}$ & 67 \\
\hline
\end{tabular}

* The concentration of reinforcement refers to volume fraction unless otherwise specified. 


\section{Reinforcement Segregation}

The segregation of $\mathrm{Al}_{2} \mathrm{O}_{3}$ particles inside the fusion zone can be observed during laser welding of $\mathrm{Al}-\mathrm{Al}_{2} \mathrm{O}_{3} \mathrm{MMCs}$. This behavior would be less severe when the laser power was reduced or a higher welding speed was used $[12,56]$. The reinforcement segregation could also be reduced by using a matrix with higher magnesium content since magnesium may enhance the wettability of the reinforcement particles in the matrix melt [12]. In addition, the use of Ar as shielding gas was reported to be the most effective, compared with $\mathrm{N}_{2}$ and $\mathrm{He}$, to reduce the $\mathrm{Al}_{2} \mathrm{O}_{3}$ segregation $[12,56]$. However, no explanation was provided. The segregation of $\mathrm{SiC}$ reinforcement in aluminium or titanium matrix has not been reported, probably because of the severe chemical reaction taking place in the laser melt pool. In the laser welding of a $12 \% \mathrm{SiC}$ particulate reinforced magnesium composite, welds with microstructures even similar to the original material were obtained. This behavior could be explained by the lower reactivity of $\mathrm{Mg}$ with carbides when compared to $\mathrm{Al}$. However, severe burning and evaporation of magnesium might occur if the laser beam density was too high due to the lower vaporizing temperature of magnesium [67].

\section{Porosity}

Porosity is always a challenge during liquid processing of aluminium and its alloys due to the large solubility difference of hydrogen in it. Surprisingly, it was not widely discussed or clarified in laser welding of aluminium based MMCs. F. Bonollo et al. [14] pointed out that the use of a silicon-rich aluminium filler wire during laser welding of $\mathrm{Al}-\mathrm{SiC} \mathrm{MMCs}$ could reduce the porosity content of the weld. In another study on laser welding of Al- 
$\mathrm{Al}_{2} \mathrm{O}_{3} \mathrm{MMCs}$, it was reported that $\mathrm{Ar}$ shielding gas is more effective for avoiding the porosity than $\mathrm{N}_{2}$ and $\mathrm{He}[12]$.

\section{Chemical Reaction}

One of the most important issues during laser welding of MMCs is the chemical reactions which may occur between reinforcement and matrix. In fact, the majority of investigations on laser welding of MMCs have emphasized the effects of these chemical reactions on the joint quality. Researchers have gained some understanding of reaction mechanisms and skills to control these undesirable reactions in laser welding of MMCs, mainly concentrated on $\mathrm{Al}-\mathrm{Al}_{2} \mathrm{O}_{3}$ and $\mathrm{Al}-\mathrm{SiC}$ systems. However, the chemical reaction problem is really material specific, and any change of the reinforcement or the matrix could result in a completely different issue to resolve. A review of chemical reaction in some $\mathrm{Al}$ MMCs during laser welding is provided below.

Chemical reaction takes place in $\mathrm{Al}-\mathrm{Al}_{2} \mathrm{O}_{3} \mathrm{MMCs}$ only when the magnesium element is present in the $\mathrm{Al}$ alloy matrix or filler material. $\mathrm{MgO}$ and $\mathrm{MgAlO}_{3}$ precipitate according to the following equations $[12,65]$ :

$$
\begin{gathered}
3 \mathrm{Mg}(l)+\mathrm{Al}_{2} \mathrm{O}_{3}(s) \rightarrow 3 \mathrm{MgO}(s)+2 \mathrm{Al}(l) \\
3 \mathrm{Mg}(l)+4 \mathrm{Al}_{2} \mathrm{O}_{3}(s) \rightarrow 3 \mathrm{MgAl}_{2} \mathrm{O}_{4}(s)+2 \mathrm{Al}(l)
\end{gathered}
$$

These products, especially the $\mathrm{MgAl}_{2} \mathrm{O}_{4}$ spinel phase, may act as stress concentration source, and thus have a negative influence on mechanical properties $[12,65]$. It was reported that the alumina particles could react with magnesium producing either $\mathrm{MgAl}_{2} \mathrm{O}_{4}$ 
for $1 \%<\mathrm{Mg}<4 \mathrm{wt} \%$ or $\mathrm{MgO}$ at $\mathrm{Mg}>4 \mathrm{wt} \%$ in the $\mathrm{Al}$ matrix [17]. Thus, aluminium matrix with magnesium content lower than $1 \mathrm{wt} \%$ would be preferred for $\mathrm{Al}_{2} \mathrm{O}_{3}$ reinforcement when the MMC is considered for welding.

The chemical reaction problem during laser welding of Al-SiC MMCs is quite typical. Fig. 2.4 shows an example micrograph of weld zone of $\mathrm{SiC}$ reinforced materials. Needlelike $\mathrm{Al}_{4} \mathrm{C}_{3}$ phases were formed during laser welding process, which deteriorated the properties of the weld in terms of ductility, fracture toughness and corrosion resistance [11, 38]. In principle, needle-like $\mathrm{Al}_{4} \mathrm{C}_{3}$ and blocky $\mathrm{Si}$ phase precipitate out during fusion welding according to the following reaction [38]:

$$
3 S i C(s)+4 A l(l) \rightarrow A l_{4} C_{3}(s)+3 S i(s)
$$

The Gibbs free energy change of this reaction has been reported by A.S. Isaikin et al. [68] and can be used as a criterion to establish the stability of products formed by chemical reaction:

$$
\Delta G(J / m o l)=113900-12.06 T \ln T+8.92 \times 10^{-3} T^{2}+7.53 \times 10^{-4} T^{-1}+21.5 T+3 R T \ln (\alpha[S i])
$$

where (s) and (1) denote solid and liquid, while $\alpha[S i]$ is the activity of $\mathrm{Si}$ in liquid aluminium. From this equation, the free energy of the reaction will become negative above a critical temperature value, which is depending on the activity of $\mathrm{Si}$ in the melt. Accordingly, several possible methods were pointed out to limit the formation of $\mathrm{Al}_{4} \mathrm{C}_{3}$. 


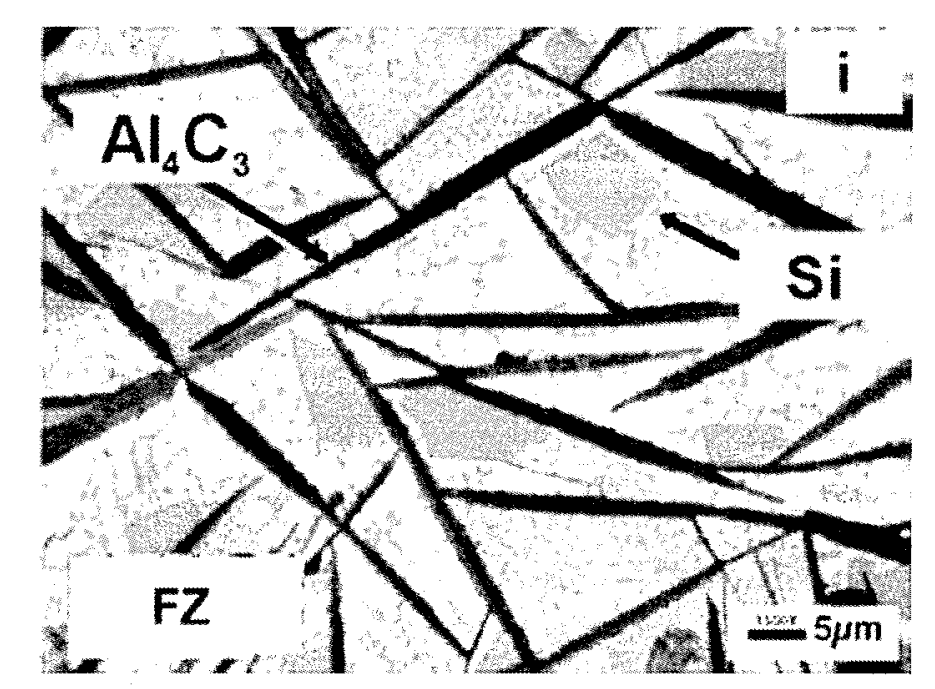

Fig. 2.4 Optical micrograph of laser weld zone of SiC reinforced materials [51].

First, the welding practice should always be performed with minimum superheating and short melting time. According to P. Bassani et al. [13], the formation of $\mathrm{Al}_{4} \mathrm{C}_{3}$ was moderately reduced by simply decreasing the laser power. It is possible to avoid this by using a laser in conduction mode [13]. However, laser welding in conduction mode has a very limited penetration and would not be an ideal solution. While I. Calliari et al. [12] reported that during laser welding a similar microstructure to the base material can be obtained at a relative low laser power under pulsed mode though, some trace of $\mathrm{Al}_{4} \mathrm{C}_{3}$ phase was also observed. It seems that pulsed laser was more effective than continuous wave laser in lowering the total heat input while ensuring the same penetration [62]. The effects of pulse frequency and pulse duty cycle on the formation of $\mathrm{Al}_{4} \mathrm{C}_{3}$ were also studied $[58,60]$. It was demonstrated that reasonably lowering the duty cycle or increasing the laser power frequency could suppress the formation of $\mathrm{Al}_{4} \mathrm{C}_{3}$. However, a complete elimination of $\mathrm{Al}_{4} \mathrm{C}_{3}$ phase was not achieved in their studies. It can be concluded that any measure 
reducing superheating and melting time of the weld pool would suppress the formation of brittle $\mathrm{Al}_{4} \mathrm{C}_{3}$ phase.

Another way to prevent the formation of $\mathrm{Al}_{4} \mathrm{C}_{3}$ is to artificially increase the activity of silicon in the welding pool through the use of silicon filler or silicon containing matrix alloy. Interestingly, F. Bonollo et al. [14] attributed this behavior to the temperature difference of the molten pool. A complete prevention of $\mathrm{Al}_{4} \mathrm{C}_{3}$ formation could be achieved if the pre-saturation of silicon was satisfied in the melt.

The third method to suppress or eliminate the formation of the needle-like harmful $\mathrm{Al}_{4} \mathrm{C}_{3}$ phase is to find a filler metal that has much greater affinity to carbon than aluminium has. This concept was first proposed by K.C. Meinert Jr. et al [15] based on thermodynamic calculation. As shown in Fig. 2.5, titanium and zirconium showed much higher affinity to carbon under standard condition. In their investigation, the addition of titanium filler was made to the fusion zone by placing thin foils of the material between the edges of two sheets of the composite in a butt weld. The results showed that the formation of harmful $\mathrm{Al}_{4} \mathrm{C}_{3}$ phase had been suppressed. A very fine dendritic structure of titanium carbide was observed in the weld instead of the needle-like aluminium carbide. The idea of Ti filler for Al-SiC MMCs was further confirmed in some later investigations $[16,61,64]$. In the study of H.M. Wang et al. [61], two amounts of Ti filler were used to investigate the reaction mechanism. It was shown that a complete prevention of $\mathrm{Al}_{4} \mathrm{C}_{3}$ phase could be achieved, but excessive $\mathrm{Ti}$ content might lead to the formation of $\mathrm{Ti}_{5} \mathrm{Si}_{3}$ and $\mathrm{Al}_{3} \mathrm{Ti}$ besides $\mathrm{TiC}$. Unfortunately, the amount of necessary titanium filler was not optimized in the study [16, 
61]. Recently, K.W. Guo studied the influence of in-situ reaction during laser welding of $\mathrm{SiCp} / \mathrm{AlSi} \mathrm{Mg}$ with Ti filler [64]. The results showed that the laser welding with in-situ reaction could effectively restrain the pernicious $\mathrm{Al}_{4} \mathrm{C}_{3}$ forming reaction in the interface between aluminium matrix and reinforcement particles. Simultaneously, the reaction formed $\mathrm{TiC}$ phase distributed uniformly in the weld. In a very similar way, T.M. Yue et al. [62] utilized another filler metal by brush plating of nickel on the joining surfaces before laser welding. Laser welds without $\mathrm{Al}_{4} \mathrm{C}_{3}$ were also produced in the study. They indicated that there is a relationship between the thickness of nickel coating and the laser parameters to guarantee an aluminium carbide free weld. Several Al-Ni intermetallic phases were identified by energy dispersive spectroscopy. However, they did not give any explanation about the principle and some longitudinal cracks were observed in the joints.

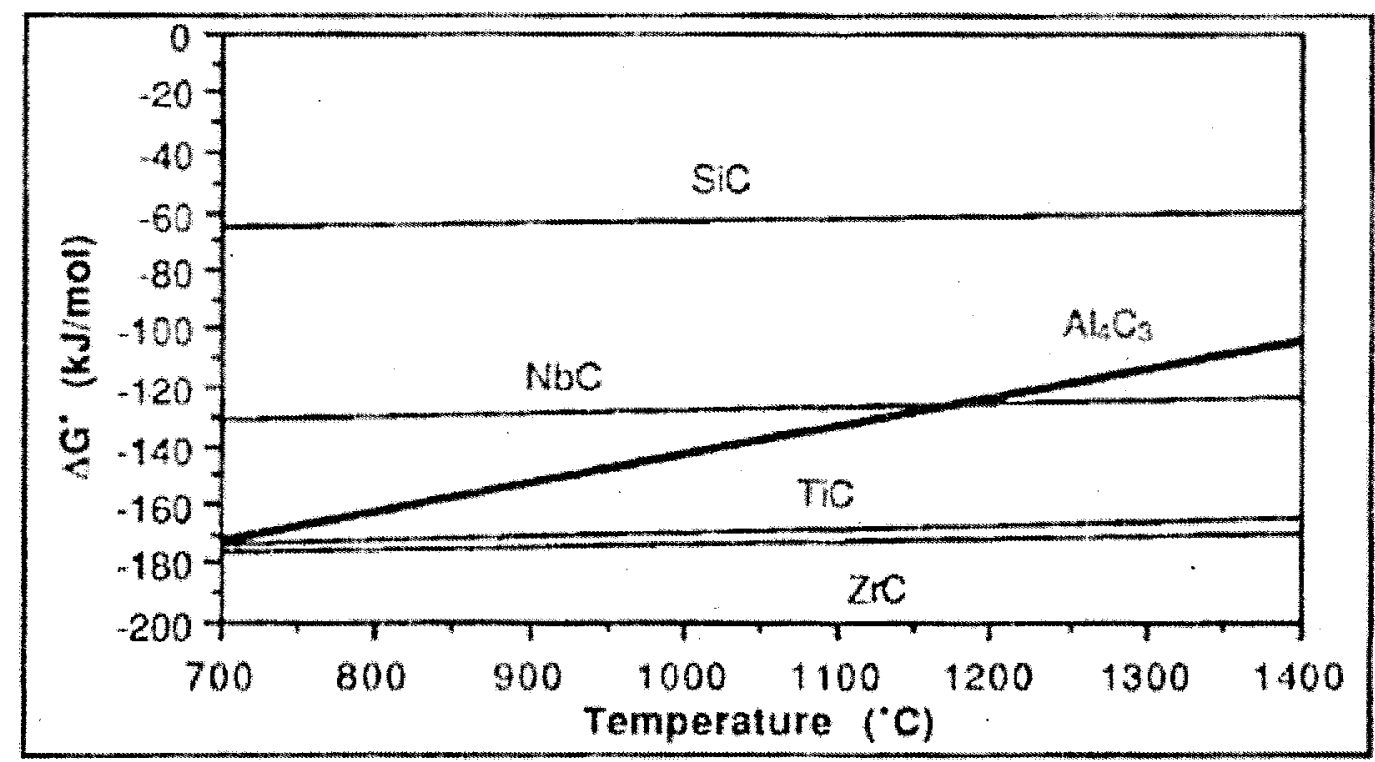

Fig. 2.5 Free energy of formation for several metallic carbides in welding of Al-SiC MMC [15]. 
Chemical reaction during laser welding of $\mathrm{SiC}$ fibre reinforced $\mathrm{Ti}$ based MMCs was also reported by A. Hirose et al. [39]. Small particles of TiC were formed by chemical reaction between the $\mathrm{Ti}$ matrix and the $\mathrm{SiC}$ fibres. It was reported that this chemical reaction was promoted by excess heat input at higher. laser power. Consequently, laser welding should always be carried out at the lower possible power to reduce the formation of TiC particles. However, it is worth noting that post-weld heat treatment at $1173 \mathrm{~K}$ could decompose these TiC particles and homogenize the weld [39].

\subsubsection{Mechanical Properties}

In contrast with the microstructural aspects, the mechanical properties of laser welds of MMCs were less documented. An increase of microhardness was generally observed inside the welding beads due to the chemical reaction between the reinforcement and the matrix producing hard phases such as $\mathrm{Al}_{4} \mathrm{C}_{3}$ and $\mathrm{MgAl}_{2} \mathrm{O}_{4}$ in $\mathrm{Al}-\mathrm{SiC}$ and $\mathrm{Al}^{-} \mathrm{Al}_{2} \mathrm{O}_{3}$ systems respectively $[12-14,56]$. Accordingly, any methods suppressing chemical reactions should be able to reduce this hardness increase. With the use of Si containing filler, F. Bonollo et al. [14] obtained more homogenized microhardness profiles in laser welding of $\mathrm{Al}-15 \% \mathrm{SiC}$ MMCs. P. Bassani et al. [13] indicated that the structure refinement due to rapid solidification may also account for this hardness increase. It should be realized that the hardness increase does not mean good properties of laser welds. Actually, these reaction 
products often have a negative influence for other mechanical properties especially fracture toughness and ductility.

The tensile properties of laser welds can only be found in several investigations. It was reported that laser power, welding speed, pulse frequency and duty cycle were of great importance to the final tensile properties of the welds $[58,60,64,67,69]$. Generally, the as-welded tensile properties are significantly lower (as low as 35\%) than that of the base materials if no specific care is taken during welding.

W. Guo et al. [66] studied the tensile properties of $\mathrm{AA} 6061-30 \% \mathrm{Al}_{2} \mathrm{O}_{3} \mathrm{MMCs}$ by varying laser power and laser pulse frequency. It was shown that the tensile strength of laser welds was lower than that of base material but remained stable with different laser powers as long as the composite material was fully penetrated; further increasing the laser power would however lead to a decrease of weld strength since excessive power input had promoted the formation of $\mathrm{MgAl}_{2} \mathrm{O}_{4}$. The effect of laser pulse frequency on tensile strength was also identified in the same work at a selected laser power. It was found that increasing the pulse frequency could improve the reinforcement distribution and significantly increase the tensile strength of joints.

The tensile properties of laser welded Al-SiC MMCs are mainly affected by the extent of interfacial reaction. According to equation (4), the chemical reaction in the system can only proceed at temperatures higher than a critical value. Thus controlling the laser heat input by adjusting various process parameters could effectively optimize the tensile strength of the welds. The effects of laser power and welding speed have been 
demonstrated in two different investigations $[63,69]$. It was found that the properties of joints could be improved by decreasing the laser power or increasing the welding speed. In an extensive study of laser welding A356-SiC MMCs conducted by N.B. Dahotre et al. [58], optimized tensile properties were obtained under the condition of intermediate duty cycle (67-74\%). This effect was later confirmed in the laser welding of AA6063-SiC MMCs [60]. Recently, K.W. Guo studied the influence of in-situ reaction during laser welding of $\mathrm{SiCp} / \mathrm{AlSi} 7 \mathrm{Mg}$ with Ti filler [64]. The results showed that the laser welding with Ti filler could improve the tensile strength of welded joints. Different amount of Ti filler was tried by adjusting the thickness of filler metal $(0.15$ to $0.75 \mathrm{~mm})$ in the study and the optimized tensile strength was obtained with $0.3 \mathrm{~mm}$ thick Ti filler addition.

\subsection{Summary}

Laser welding is a competitive welding technique for MMCs, though various difficulties may be encountered. The weld quality could be optimized through adjusting the process parameters or the use of proper filler material. Chemical reaction is a serious problem in laser welding of most MMCs system since the reaction products are usually harmful to weld properties. Among others, the thermodynamic approach could prevent these reactions, which has been validated in laser welding of Al-SiC MMCs. This approach may be borrowed in laser welding of other types of MMCs such as $\mathrm{Al}-\mathrm{B}_{4} \mathrm{C}$ composite material which is being studied in the present work. Up to present, laser welding of $\mathrm{Al}-\mathrm{B}_{4} \mathrm{C}$ MMCs has never been reported. 


\subsubsection{Friction Stir Welding}

\subsubsection{Introduction}

Friction stir welding process, as illustrated in Fig. 2.6, involves a rotating tool that is inserted into the joint edges and moves forward along the joint line. As a result of the local friction between the tool and the workpiece, the material is heated and transferred from the front to the back of the pin. Consequently, a sound weld is produced in solid state $[37,70]$.

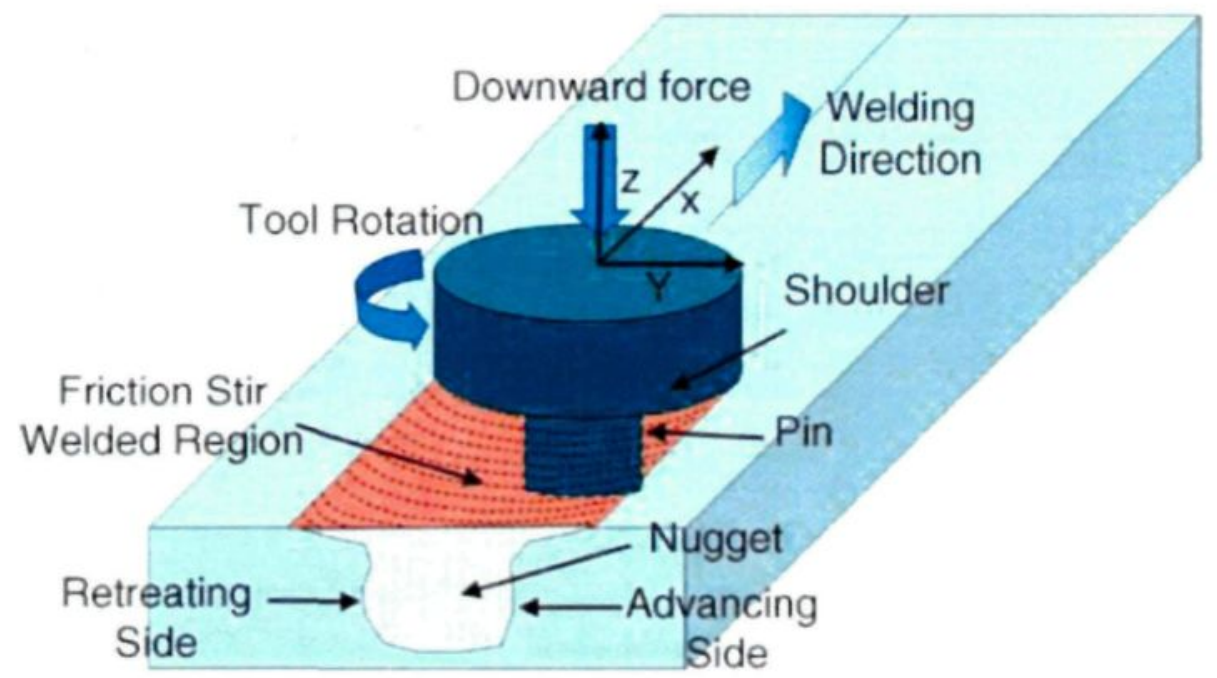

Fig. 2.6 Schematic drawing of friction stir welding [37].

FSW is a relatively new welding technique [71] that has demonstrated its great potential in joining materials that are traditionally considered to be unweldable or difficult to weld. Compared with fusion welding processes, the solid state feature of FSW prevents many metallurgical problems such as porosity and formation of brittle phases and enables us to produce welds with a minimum distortion and shrinkage that result from the melting 
and solidification $[19,37]$. In addition, a much finer microstructure can be obtained owning to a dynamic recrystallization process, which will benefit the mechanical properties of the welds. Furthermore, FSW also eliminates the needs of shielding gas and filler metal because of the elimination of the liquid welding pool. With these interesting advantages, FSW has gained wide acceptance for welding aluminium alloys and is becoming an important technique in many industries [70].

\subsubsection{Process Parameters}

Various process parameters including the tool rotational speed, welding speed, tilt angle and the vertical pressure on the tool can be changed to control the FSW process. The resulted material flow and temperature profile during the process further determine the microstructural evolution and the subsequent mechanical properties of the welds $[37,72]$. Thus, the major FSW parameters and their effects on the process are listed in Table 2.6 to facilitate the selection during the present study.

Table 2.6 Summary of major FSW parameters and their effects on the process $[37,72]$

\begin{tabular}{|l|l|}
\hline Process parameter & Effects on FSW process \\
\hline Tool rotation speed & Peak temperature increases with increasing rotation speed. \\
\hline Welding speed & Peak temperature decreases with increasing welding speed. \\
\hline Tilt angle & $\begin{array}{l}\text { Suitable tilt angle may help the tool hold the stirred material and } \\
\text { transfer the material efficiently from the front to the back. }\end{array}$ \\
\hline $\begin{array}{l}\text { Vertical pressure or } \\
\text { insertion depth of pin } \\
\text { shoulder }\end{array}$ & $\begin{array}{l}\text { Too high pressure leads to overheating, excessive flash and joint } \\
\text { thinning; while too low pressure may cause insufficient heating and } \\
\text { inner voids or surface groove. }\end{array}$ \\
\hline Preheating & May help high melting point materials soften and plasticize. \\
\hline Cooling & $\begin{array}{l}\text { Could help low melting point materials avoid too much grain growth } \\
\text { and dissolution of strengthening precipitates. }\end{array}$ \\
\hline
\end{tabular}




\subsubsection{FSW of Aluminium Alloys}

In order to understand the FSW process, microstructural evolution and mechanical property aspects of friction stir welded aluminium alloys are reviewed below. Aluminium

alloys are selected here for two reasons: first, most of the information on FSW is related to aluminium alloys. Second, the present study is to be conducted on $\mathrm{Al}-\mathrm{B}_{4} \mathrm{C}$ MMCs. Some background knowledge in aluminum alloys are expected to help us understand the behaviors of $\mathrm{Al}-\mathrm{B}_{4} \mathrm{C}$ MMCs during FSW.

\subsection{Microstructural Evolution}

The microstructural evolution is one of the most important issues since it further determines various properties of the materials. In the case of FSW, the microstructural aspect has been extensively documented in the literature. Generally, three distinct regions shown in Fig. 2.7 can be identified in aluminium friction stir welds as nugget zone, thermomechanically affected zone (TMAZ), and heat affected zone (HAZ) $[37,73]$. According to J.C. Lippold et al. [73], the nugget zone is a recrystallized region associated with the passage of the tool. The TMAZ is a region unique to FSW in which the material has undergone some macroscopic deformation without grain refinement since the force and temperature are not high enough to promote dynamic recrystallization, while the HAZ is a region without deformation but may undergo some metallurgical change. In fact, apart from the grain structure difference, metallurgical changes are happening simultaneously in all these three regions depending on the temperature profile and alloy composition. 


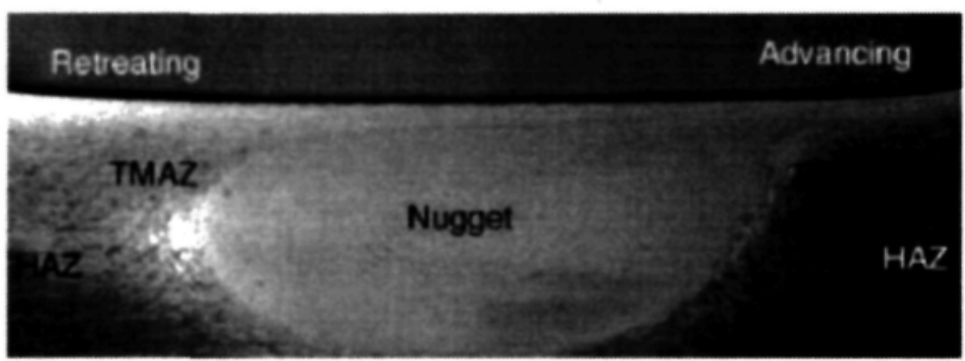

Fig. 2.7 A typical macrograph showing various microstructural regions in aluminium friction stir welds [37].

\section{Precipitate Behavior during FSW}

FSW process exerts a thermal cycle on the workpiece in solid state. For many aluminium alloys strengthened by precipitation hardening mechanism, it can be predicted that FSW would cause a soften region within and around the weld nugget. As illustrated in Fig. 2.8, R. Nandan et al [72] used a schematic diagram to interpret this softening process. $\mathrm{HV}_{\min }$ and $\mathrm{HV}_{\max }$ represent the hardness in the solution-treated and precipitation hardened states. They described that the precipitates may experience coarsening, dissolution and reprecipitation during FSW depending on the localized temperature. The heat produced during FSW causes a drop in hardness from $\mathrm{HV}_{\max }$ to $\mathrm{HV}_{\min }$, curve (a) in Fig. 2.8. Some reprecipitation may occur during the cooling part of the thermal cycle, resulting in a hardness value beyond $\mathrm{HV}_{\min }$, curve (b) in Fig. 2.8. The minimum hardness would thus appear at somewhere in $\mathrm{HAZ}$ as a result of the competing effect of dissolution and reprecipitation. 


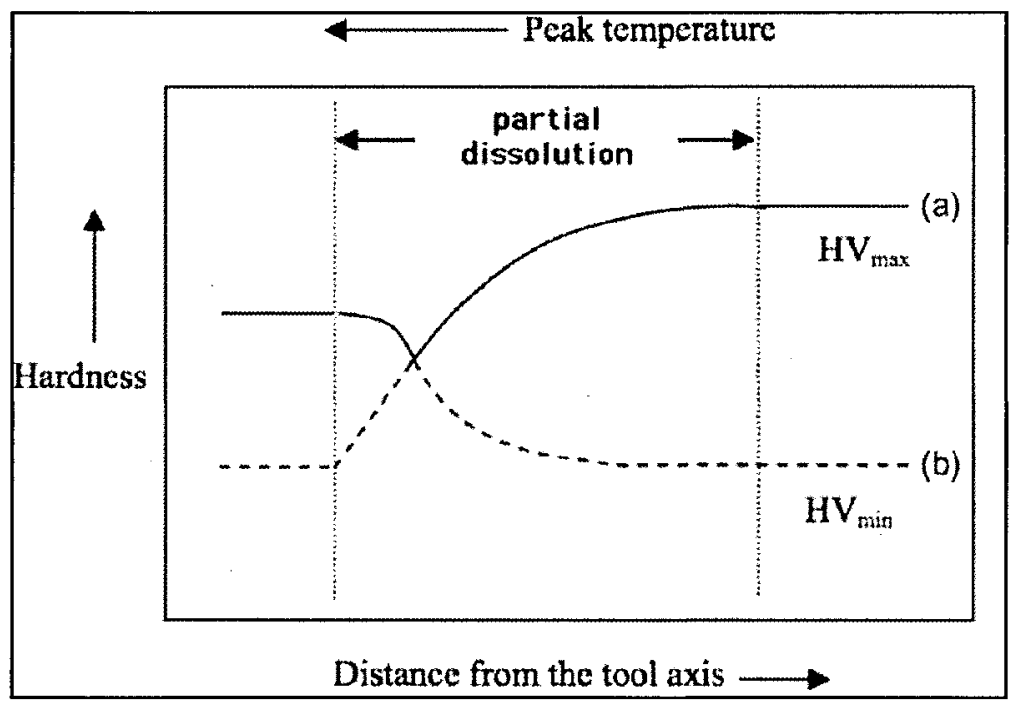

Fig. 2.8 Schematic diagram showing dissolution and reprecipitation in age hardenable aluminium alloys [72].

In fact, the above theory has been proven in several studies on microstructure evolution of FSW [74-75]. In the work of J.Q. Su et al. [74], the typical precipitate distribution in each weld region of an AA7050-T651 alloy was illustrated by transmission electron micrographs as shown in Fig. 2.9, which corresponds very well to the above interpretation. Similarly, a comparison between AA6063 friction stir welds and isothermal aging samples has been made by Y.S. Sato et al. [75] according to simulated thermal cycles, which also confirmed again the precipitation sequences in heat-treatable aluminium friction stir welds. 

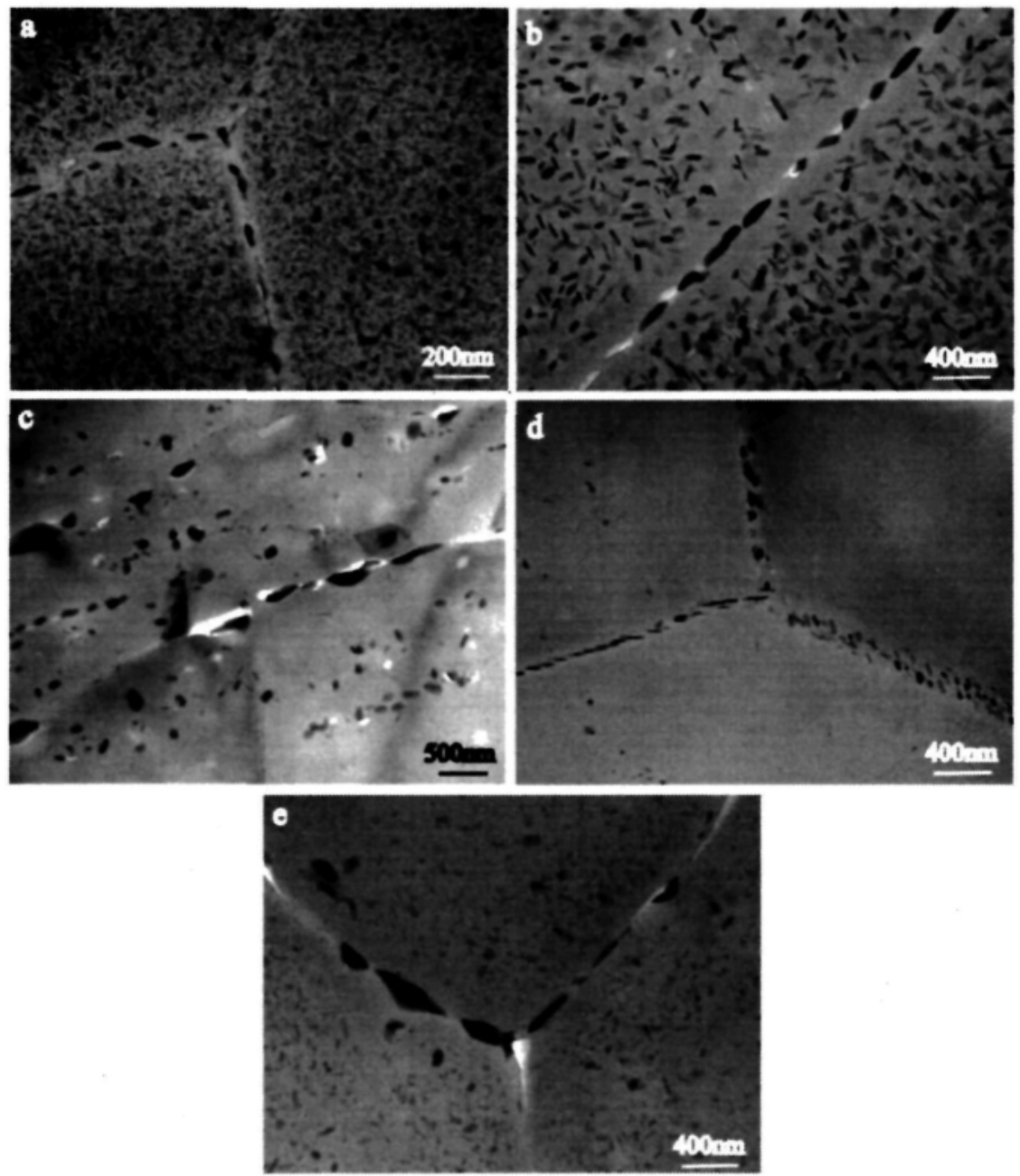

Fig. 2.9 TEM micrographs showing precipitate distribution in different FSW weld regions: (a) Parent metal, (b) HAZ, (c) TMAZ I, (d) TMAZ II, (e) Nugget zone [74].

\section{Effects of Process Parameters}

The thermal cycle experienced by the workpiece is the main factor that determines the microstructure evolution and the final property of friction stir welds. Any change in process parameters will undoubtedly lead to variation in the thermal cycle and hence in the microstructure and properties. 
For both heat-treatable and non-heat-treatable aluminium alloys, it was recorded that the grain size in the nugget zone increased with increasing rotation speed or decreasing welding speed [76-79]. Fig. 2.10 gives a good example of micrographs showing the effects of rotation speed on grain structure. At $180 \mathrm{rpm}$, the average grain size in the nugget was extremely fine, around $1.7 \mu \mathrm{m}$, compared with $6 \mu \mathrm{m}$ in the welds made at $450 \mathrm{rpm}$. These results can be explained by the thermo-mechanical cycle in the weld. As mentioned earlier in Table 2.6, the peak temperature during FSW could be controlled by varying the rotation speed and the welding speed, which in turn determines the resultant grain structure of a dynamic recrystallization process. In a different way, S. Benavides et al. [80] obtained finer grain size of about $0.8 \mu \mathrm{m}$ compared to the original of $10 \mu \mathrm{m}$ through lowering the starting temperature from 30 to $-30^{\circ} \mathrm{C}$, which effectively decreases the peak temperature from 330 to $140{ }^{\circ} \mathrm{C}$.

It is worth noting that Kh.A.A. Hassan et al. [76] observed a grain size decrease from the top to bottom in the nugget of AA7010 alloy and the effect was less remarked with higher rotation speed. In another work, Y.S. Sato et al. [79] observed the opposite behavior in FSW of AA1100 alloy. However, none of them gave any explanation. 

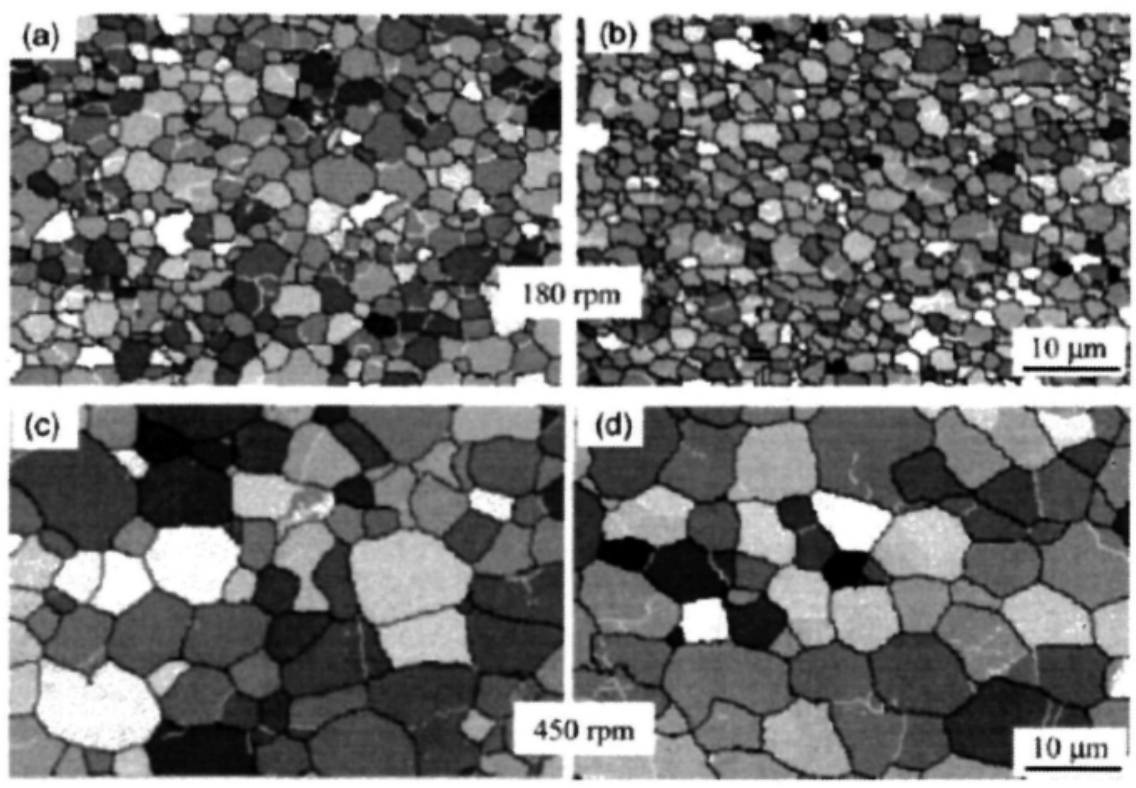

Fig. 2.10 EBSD maps showing the grain structures in the nugget zones of FSW welds with different rotation speeds but a constant welding speed. (a) and (c) at the center, (b) and (d) at the bottom of the welds [76].

\section{Abnormal Grain Growth}

Abnormal grain growth sometimes known as secondary recrystallization, usually takes place in recrystallized materials at high temperatures. This process may lead to the formation of large grains of even greater than several millimeters [81], which causes negative effects for mechanical property. Its occurrence during the post weld heat treatment (PWHT) of friction stir welds has been reported in the literature [76, 79, 82, 83]. A good review of this phenomenon in FSW could also be found in the work of Y.S. Sato et al. [79]. Kh.A.A. Hassan et al. [76] studied the stability of friction stir welded AA7010 alloy during solution treatment. It was concluded that the abnormal grain growth might be promoted by the fine grain structure in nugget zone and the partial dissolution of second phase particles during solution treatment. The welds made with higher heat input seem to be more stable 
since only a few large grains developed at the base of the weld on its advancing side. M. M. Attallah [83] also revealed that the rotation speed and the welding speed can be used as a tool to control abnormal grain growth during subsequent heat treatment. It was found that the welding parameter determines the extent of abnormal grain growth and the welds made with lower rotation speed and higher welding speed have higher tendency to abnormal grain growth. Nevertheless, none of the above two investigations was able to completely avoid abnormal grain growth. Recently, Y.S. Sato et al. [79] conducted a more systematic research work with AA1100 alloy. Different rotation speeds and heat treatment temperatures were used in FSW and PWHT respectively. The peak temperatures experienced during FSW were measured by placing alumel-chromel thermocouples at the bottom of the stirred zone. As shown in Fig. 2.11, the abnormal grain growth was only observed in conditions with PWHT temperature higher than the peak temperature experienced during FSW. For instance, the peak temperature measured during FSW with 1800 rpm was $755 \mathrm{~K}$, PWHT were carried out under different temperatures of 573, 623, $643,673,773,873 \mathrm{~K}$. Only the materials heat-treated at 773 and $873 \mathrm{~K}$, which are higher than $755 \mathrm{~K}$, experienced abnormal grain growth. 


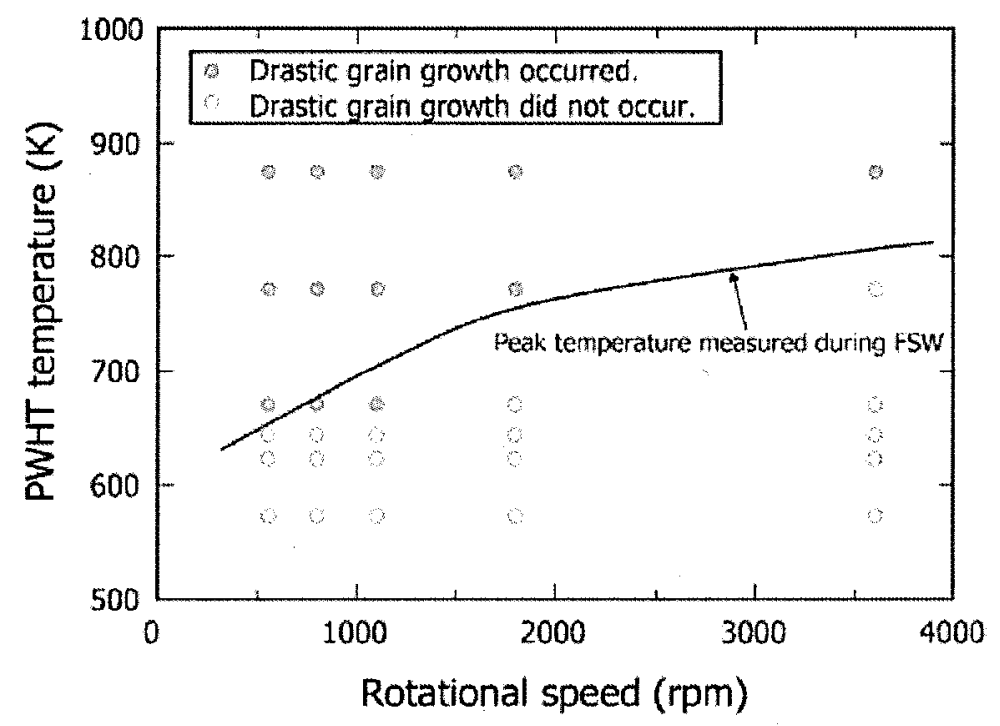

Fig. 2.11 Effect of rotation speed on onset temperature of abnormal grain growth [79].

\subsection{Mechanical Properties}

As discussed above, FSW has produced significant microstructural changes in the workpiece, which have substantial influences on the weld mechanical properties. A review of hardness and tensile properties of friction stir welds will be provided below as a reference for FSW of MMCs.

\section{Hardness}

Hardness data were usually measured as an initial evaluation of mechanical properties across the FSW weld zone. Although it was reported that the hardness responses to FSW are dependent on the materials' composition, initial temper and also the welding process parameters, these materials can generally be classified into heat-treatable and non-heattreatable alloys. The commonly reported hardness plots for heat-treatable alloys usually have "W" shapes, which consist of a local maximum central plateau with two minimum on 
both sides in HAZ, but the overall hardness values in the weld zone are much lower than that in the base materials $[75,78,84,85]$. For non-heat-treatable alloys, the hardness distribution seems to be controversial though the same principle was used to explain the different results.

The hardness of heat-treatable alloys is dominated by precipitation behavior. As discussed in the previous part, the precipitate experiences a process of coarsening, dissolution and reprecipitation during FSW depending on the localized temperature. Thus, it is not surprising to have a "W" shaped hardness profile in the weld of heat-treatable alloys, and an example is shown in Fig. 2.12. It is important to note that the welding process parameters have some influences on the hardness profile of the weld. A.P. Reynolds et al. [84] did an elegant work to build the relationship between welding parameters and hardness distribution in AA7050 alloy. It was found that the average hardness in the weld nugget is closely related to welding process parameters. As shown in Fig. 2.13, the average hardness increases with increasing welding speed at a constant weld pitch (ratio of welding speed and rotation speed). Furthermore, higher hardness was achieved at higher rotation speed for a given welding speed. It can thus be concluded that the average nugget hardness level increases with increasing the heat input during welding [84]. It was also observed that the hardness minimum on both sides increases with increasing weld power [84]. Kh.A.A. Hassan et al. [78] investigated the effect of welding parameters on the hardness of the nugget zone. Similar results were obtained except that the hardness minimum did not change with welding parameters as in the nugget. 


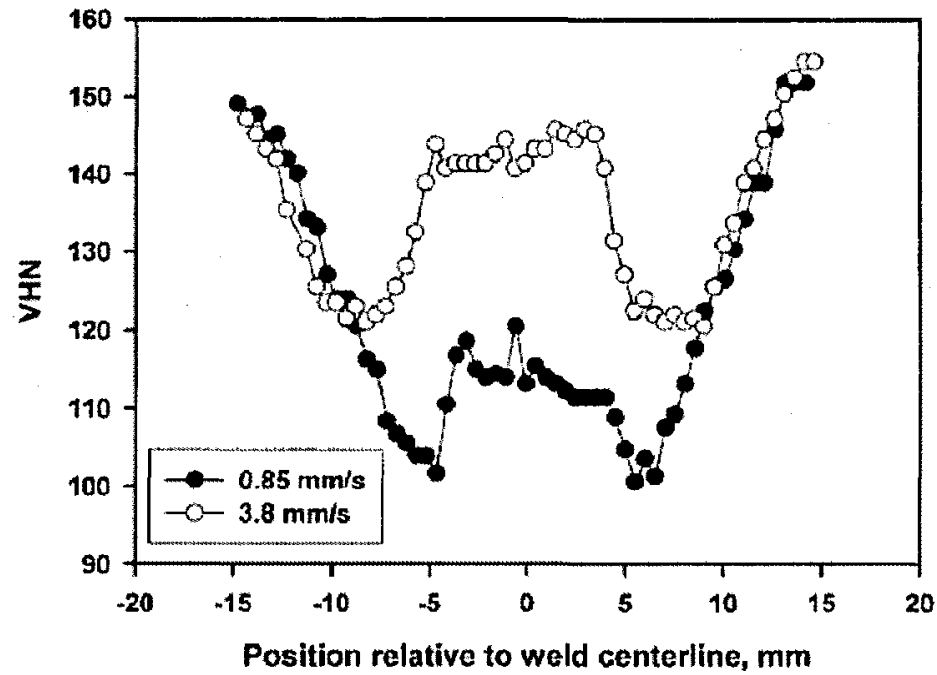

Fig. 2.12 Hardness profiles in the welds made with the same weld pitch (ratio of welding speed and rotation speed) [84].

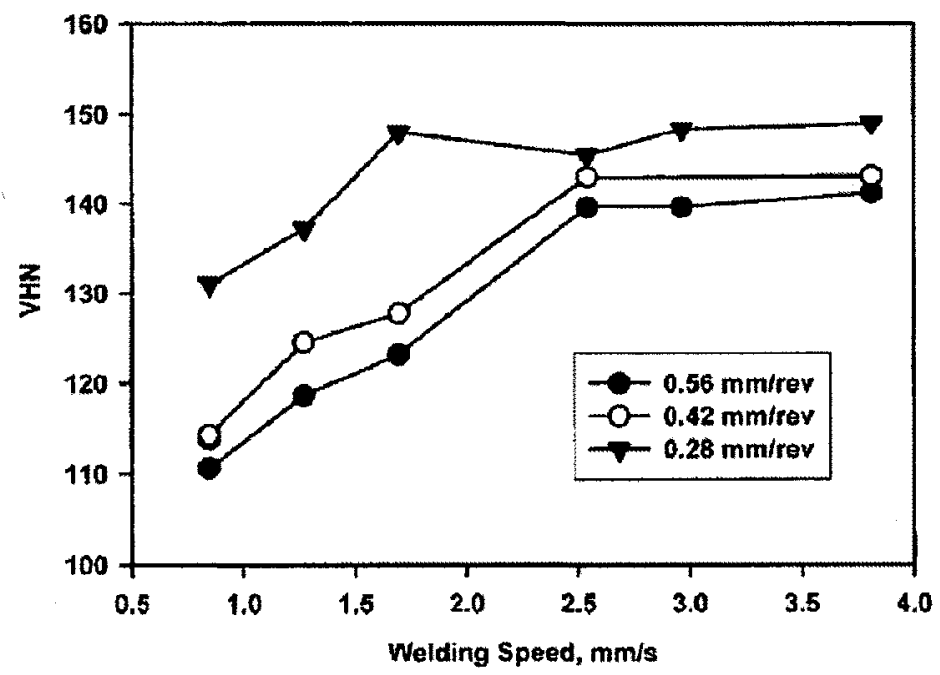

Fig. 2.13 Effect of weld pitch and welding speed on the average hardness in FSW nugget [84].

On the other hand, the hardness of non-heat-treatable aluminium alloys is mainly dependent on grain size and dislocation density. It was generally reported that FSW did not 
cause too much changes in hardness of the weld for annealed alloys [85, 87], while an obvious softened region could be observed in the weld of strain hardened alloys [87, 88]. However, N. Saito et al. [89] observed higher microhardness in the weld zone for both the rolled and annealed AA1050 alloy samples. Recently, Y. J. Kwon et al. [90] examined the average hardness across the weld of a cold rolled AA1050 alloy after welding at different rotation speeds from 560 to $1840 \mathrm{rpm}$. It was reported that the average hardness of the weld increased significantly with decreased tool rotation speed, as shown in Fig. 2.14. Fifty percent increase of the average hardness in the weld was observed by adjusting the rotation speed from 1840 to $560 \mathrm{rpm}\left(32\right.$ vs. $48 \mathrm{HV}_{0.1}$ ). They suggested that the weld zone have much finer grain size and lower dislocation density than the base metal. Therefore, at lower rpm (560-1350) the grain size contributes more to the hardness than dislocation, while for $1840 \mathrm{rpm}$ the effect of the grain size cannot overcomes the negative influence of dislocation decrease.

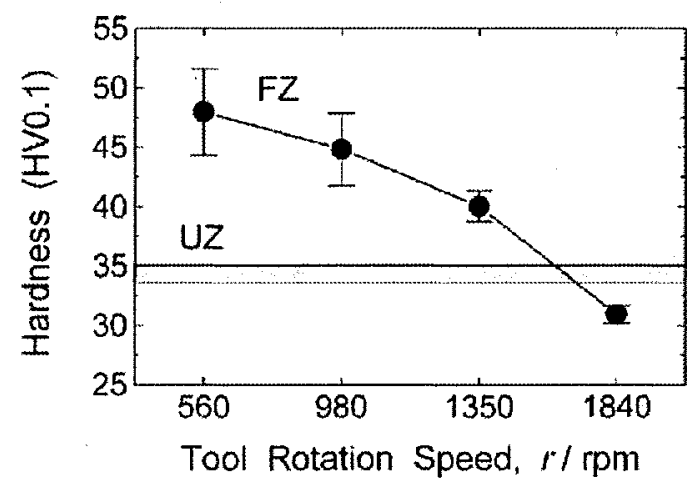

Fig. 2.14 Average Vickers microhardness of the unprocessed base metal and friction stir welded zone [90]. FZ: friction stir processed zone, UZ: unprocessed zone. 


\section{Tensile Properties}

Like the hardness, tensile properties are also determined by the microstructure of the materials. Compared with fusion welds, friction stir welds are generally characterized by finer grain microstructure and less reduction of mechanical properties. The tensile properties of some friction stir welds are summarized in Table 2.7. Most of the data focused on alloys in strain-hardened or aging hardened conditions. It can be seen that the joint efficiency is generally higher than $60 \%$, but lower than $100 \%$. Higher efficiency could be achieved through adjusting the process parameters. It should be noted that extremely high joint efficiency of about $146 \%$ has been obtained in FSW of a cold rolled 1050 alloy [90].

Table 2.7 Tensile properties of friction stir welds in as-welded condition

\begin{tabular}{|l|l|l|l|l|l|}
\hline \multirow{2}{*}{ Base alloy } & \multicolumn{5}{|c|}{ Friction stir welds properties } \\
\cline { 2 - 6 } & UTS (MPa) & YS (MPa) & Elongation (\%) & $\begin{array}{l}\text { Efficiency (\%, } \\
\text { UTS) }\end{array}$ & Ref. \\
\hline AA1050-H24 & $72-85$ & $38-51$ & $9.5-20.5$ & $62.3-73.6$ & 87 \\
\hline Cold rolled AA1050 & $125-202$ & -- & -- & $90.6-146$ & 90 \\
\hline AA2219-T6 & $225-336$ & -- & $5-7.3$ & $54-80.8$ & 91 \\
\hline Overaged AA2095 & $188-211$ & -- & -- & $95-100$ & 83 \\
\hline AA5083-O & $303-344$ & -- & -- & -- & 92 \\
\hline \multirow{2}{*}{ AA6061-T651 } & $186-217$ & $114-141$ & $8.5-11.8$ & $60-70$ & 93 \\
\cline { 2 - 6 } & $211-243$ & -- & $8.1-8.8$ & $69-79$ & 94 \\
\hline \multirow{2}{*}{ AA6082-T6 } & $226-254$ & -- & -- & -- & 92 \\
\cline { 2 - 6 } & $210-270$ & $136-185$ & $10-11.6$ & -- & 95 \\
\hline AA7010-T7651 & $375-518$ & -- & $3.5-22$ & -- & 78 \\
\hline AA7050-T7451 & 427 & 303 & 5.7 & 76.5 & 96 \\
\hline
\end{tabular}


As already mentioned, the thermal cycle experienced by the workpiece is the main factor that determines the microstructure and the final mechanical properties of friction stir welds. It can be controlled by varying the process parameters such as the tool rotation speed and the welding speed. The effect of process parameters on tensile properties of heat treatable alloys has been investigated in several studies $[78,92-96]$. Kh.A.A. Hasson et al. [78] found that there is an optimum FSW condition that gives the best tensile properties for AA7010-T7651. They explained that the tensile properties of the materials are dominated by the behavior of precipitates. Relatively higher heat input could lead to more dissolution of coarsened precipitate particles, and thus more solutes are available for natural aging process for $7 \mathrm{xxx}$ series alloys. However, too high heat input will deteriorate the weld properties due to reprecipitation occurring during the cooling process after welding, which would reduce the natural aging response of the welds. Similar trends of tensile properties for AA6082-T6 alloy were also observed in another study [95]. On the other hand, the effect of process parameters on tensile properties of non-heat-treatable alloys has also been reported in the literature. Y.J. Kwon et al. [90] examined the mechanical properties of a cold rolled AA1050 plates after FSW by using different tool rotation speeds. It was shown that the average tensile strength of the welds increased significantly with decreased tool rotation speed (from 123 to $202 \mathrm{MPa}$ ), which has a similar tendency to the average hardness results (from 32 to $46 \mathrm{HV}_{0.1}$ ). They attributed this behavior to the much finer grain size in spite of lower dislocation density. Meanwhile, H. Liu et al. [87] reported a similar study of FSW for AA1050-H24 plates by varying the welding speed from $1.7-13.3 \mathrm{~mm} / \mathrm{s}$ with constant rotation speed of $1500 \mathrm{rpm}$. It was observed that the yield strength increased 
slightly with increased welding speed, and the ultimate strength however showed a peak value at $6.7 \mathrm{~mm} / \mathrm{s}$. Unfortunately, the authors did not give any explanation for this phenomenon.

Post weld heat treatment is sometimes applied to recover the mechanical properties of friction stir welds. It can easily be understood that solution treatment followed by artificial aging could probably completely restore the base metal tensile strength [82]. However, attention needs to be paid to the occurrence of abnormal grain growth, which is believed to be very harmful to mechanical properties. As described previously, the mechanism of abnormal grain growth has been understood to some extent. Nevertheless, its effects on tensile properties were not reported in these studies probably because the mechanical properties of the joints have been degraded to unacceptable level $[76,82,83]$.

\subsubsection{FSW of MMCs}

The feasibility of FSW for MMCs has been identified in some investigations. The technical information of these studies is summarized in Table 2.8. According to T.W. Nelson et al. [24], FSW joints of AA6061-B ${ }_{4} \mathrm{C}$ MMCs showed superior tensile strength (205 MPa) compared with that produced by TIG welding technique (157 MPa). Generally, the tensile strength of FSW joints could reach $60-84 \%$ of the parent metal strength [18-20, 50]. An appropriate post-weld artificially aging treatment could further restore them to 81 $93 \%$ of the parent metal strength $[18,50]$. However, the elongation of these joints exhibited significant decrease after FSW and could not be recovered through post-weld heat treatment. It is worth noting that a post-weld T6 treatment does not necessarily increase the 
tensile strength of AA6xxx based MMC. An abnormal grain growth was observed in the investigation of X.-G. Chen et al. [18] and thus resulted in an obvious decrease of mechanical properties. It was reported that FSW could lead to more uniform particle distribution if any cluster or regular orientation of particles was present in the base metal $[18,50]$. The breakage of $\mathrm{Al}_{2} \mathrm{O}_{3}$ particles was noticed by L.M. Marzoli et al. [19] and L. Ceschini et al. [20]. Another important issue of FSW is the excessive tool wear occurring during the process. Detailed investigations of tool wear were conducted by R.A. Prado et al. [21]. It is remarkable that a self optimization phenomenon was observed in their study of FSW of $\mathrm{AA} 6061-\mathrm{Al}_{2} \mathrm{O}_{3}$ MMCs. No additional tool wear can be detected after a sufficient welding distance for the same set of welding parameters. This tool shape optimization was further confirmed in the FSW of A359-SiC MMCs [97].

\subsection{Microstructural Aspects}

The microstructure response of MMCs during FSW is essentially similar to that of the matrix alloy. Fine and equiaxed grains are also generated by a dynamic recrystallization process. Porosity and chemical reaction are generally absent in FSW of MMCs. In addition, redistribution and breakage of particles were observed in some studies. However, the effect of welding process parameters on the microstructure of MMCs has been rarely reported in the literature. 
Table 2.8 Summary of technical information in FSW of MMCs *

\begin{tabular}{|c|c|c|c|c|c|}
\hline Welding Materials & $\begin{array}{l}\text { Thickness of } \\
\text { materials (mm) }\end{array}$ & \begin{tabular}{|l|} 
Rotation \\
rate (rpm) \\
\end{tabular} & $\begin{array}{l}\text { Welding } \\
\text { speed }(\mathrm{mm} / \mathrm{s})\end{array}$ & Tool materials & Ref. \\
\hline AA6061-15, 20\% $\mathrm{B}_{4} \mathrm{C}$ & 2.5 & 670 & $1.9-2.3$ & H13 tool steel & 24 \\
\hline AA6063-6, $10.5 \% \mathrm{~B}_{4} \mathrm{C}$ & 4.5 & 1500 & 10 & AISI 4340 steel & 18 \\
\hline AA356-15\% SiC & 6 & 1200 & 0.5 & D2 tool steel & 98 \\
\hline \multirow[b]{3}{*}{$\mathrm{AA} 359-20 \% \mathrm{SiC}$} & 4 & $500-1000$ & $1-11$ & $\begin{array}{l}\text { AISI oil-hardened, } \\
\text { RC62 }\end{array}$ & 97 \\
\hline & 4 & $500-1000$ & $1-11$ & RC62 tool steel & 99 \\
\hline & 3 & 1000 & 5 & $\begin{array}{l}\text { AISI } 1040 \text { steel } \\
\text { coated with } \\
\text { multilayer PVD } \\
\text { AlSiCrN or AlSiTiN }\end{array}$ & 100 \\
\hline AA2009-15\% SiC & 8 & $400-1000$ & 0.83 & Tool steel & 101 \\
\hline AA2009-15\% SiC & 8 & 600 & 0.83 & Tool steel & 102 \\
\hline AA2124-20\% SiC & 4 & 500 & 0.83 & Tool steel & 51 \\
\hline $\mathrm{AA} 2124-25 \% \mathrm{SiC}$ & 6 & 800 & 2 & $\begin{array}{l}\text { TiAlN coated HSS } \\
\text { steel }\end{array}$ & 103 \\
\hline AA6092-17.5\% SiC & 3.2 & 1350 & 0.17 & H13 coated with $\mathrm{B}_{4} \mathrm{C}$ & 70 \\
\hline AA7093-25\% SiC & -- & -- & -- & -- & 104 \\
\hline $\mathrm{AA} 6061-10,20 \% \mathrm{Al}_{2} \mathrm{O}_{3}$ & 4 & $500-3000$ & $1.7-41.7$ & -- & 50 \\
\hline \multirow{4}{*}{ AA6061-20\% $\mathrm{Al}_{2} \mathrm{O}_{3}$} & 4 & 500 & 0.83 & Tool steel & 51 \\
\hline & 7 & $400-700$ & $2.5-8.3$ & -- & 19 \\
\hline & 5 & 1000 & $1-9$ & RC62 tool steel & 21 \\
\hline & 7 & 800 & 0.93 & - & 105 \\
\hline \multirow{3}{*}{ AA7005-10\% $\mathrm{Al}_{2} \mathrm{O}_{3}$} & 7 & 800 & 0.93 & -- & 105 \\
\hline & 7 & 600 & 5 & RC 63 steel & 20 \\
\hline & 7 & 600 & 4.2 & - & 106 \\
\hline Al-10\%wt.TiB & 6 & 2000 & 0.5 & HCHCr steel & 107 \\
\hline $\begin{array}{l}\text { AA6061-3\%wt.TiC to } \\
7 \% \text { wt.TiC }\end{array}$ & 6 & -- & $0.5-2.25$ & $\begin{array}{l}\text { high carbon high } \\
\text { chromium steel }\end{array}$ & 108 \\
\hline $\mathrm{Al}-15 \%$ wt. $\mathrm{Mg}_{2} \mathrm{Si}$ & 6 & $710-1400$ & 2.1 & H13 tool steel & 109 \\
\hline AZ91 Mg- $10 \% \mathrm{SiC}$ & 4 & 1250 & 0.53 & $\begin{array}{l}\text { SKD } 11 \text { (JS) tool } \\
\text { steel }\end{array}$ & 110 \\
\hline
\end{tabular}

* The concentration of reinforcement refers to volume fraction unless otherwise specified. 


\section{Particle redistribution}

Clusters, regular orientation of particles and particle-free regions could be found in the parent materials. While after the FSW process, it seems that the particle distribution in the nugget zone became more uniform due to intense plastic deformation and materials mixing $[18,50,98,102]$. This behavior is believed to be somewhat beneficial to the mechanical properties such as modulus of elasticity and hardness. S.C. Baxter et al. [102] reported that the percentage of extremely small particles within the weld increased significantly, which was attributed to the breakage of $\mathrm{SiC}$ particles. A.H. Feng et al. [102] and H. Uzun [103] confirmed similar results in FSW of Al-SiC MMCs. On the other hand, the breakage of $\mathrm{Al}_{2} \mathrm{O}_{3}$ particles was also observed in several investigations $[50,20,105]$. However, X.G. Chen et al. [18] did a research work to investigate if similar modifications occurred in their

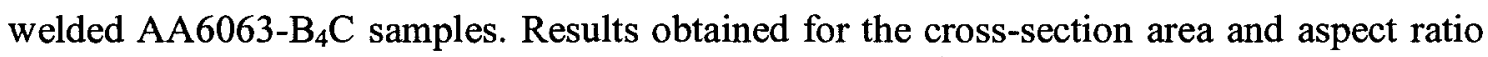
of the particles revealed that the particle size and shape was not significantly modified in the welded zone for the $6 \%$ and $10.5 \% \mathrm{~B}_{4} \mathrm{C}$ materials, this phenomenon may be attributed to much higher hardness of $\mathrm{B}_{4} \mathrm{C}$ particles.

\section{Post weld heat treatment}

Although much finer grain structure could also be obtained in FSW nugget of MMCs, the materials in as-welded condition usually have reduced mechanical properties compared with the base metal. The use of PWHT is expected to recover the reduced properties and has shown some positive effects in FSW of $\mathrm{Al}-\mathrm{Al}_{2} \mathrm{O}_{3} \mathrm{MMCs}$ [50] and $\mathrm{Al}-\mathrm{SiC} \mathrm{MMCs}$ [70, 102]. However, as discussed previously, there is a risk that the abnormal grain growth may 
take place, which will significantly reduce the mechanical properties of the welds. X.G. Chen et al. [18] observed an average grain size of $940 \mu \mathrm{m}$ in the nugget of $\mathrm{AA} 6063-\mathrm{B}_{4} \mathrm{C}$ MMCs after the solution treatment of T6 compared to approximately $13 \mu \mathrm{m}$ in as welded condition. According to Y.S. Sato et al. [79], the abnormal grain growth in AA1100 alloy was only observed in conditions with PWHT temperature higher than the peak temperature experienced during FSW of aluminium alloys. Therefore, the PWHT temperature should be carefully selected according to the process parameters used in FSW.

\subsection{Mechanical Properties}

A number of studies have been carried out over the past decade to evaluate the mechanical properties of friction stir welded MMCs. The tensile properties of the friction stir welds and the initial temper of base materials reported in the literature are summarized in Table 2.9 .

\section{Hardness}

Generally, the hardness of the welds also exhibited corresponding decreases after FSW of aging hardened MMCs like that in aluminium matrix alloys. This is mainly because of that the coarsening and dissolution of the precipitates during the FSW welding thermal cycle $[18,103,109]$. It is interesting that $L$. Ceschini et al. [20] observed two peak hardness in the TMAZ of friction stir welded AA7005/10\%vol. $\mathrm{Al}_{2} \mathrm{O}_{3}$ composite, as illustrated in Fig 2.15. They suggested that the maximum microhardness in TMAZ is probably a subsequence of strain hardening, reprecipitation of second phase and formation of GuinierPreston zones after natural aging. In contrast, the relatively lower hardness in nugget zone 
is due to the presence of coarsened precipitates formed during reprecipitation. It is also worth noting if the base materials are welded as fabricated without any heat-treatment, there will be a distinct microhardness increase in the nugget zone [101]. They attributed this to the precipitate hardening effect caused by FSW thermal cycle. It is regretful that none of these studies discussed the effect of reinforcement particles on the hardness profile.

Table 2.9 Summary of mechanical properties of FSW MMCs *

\begin{tabular}{|c|c|c|c|c|c|c|}
\hline Composites & \begin{tabular}{|l|} 
Initial \\
temper
\end{tabular} & UTS(MPa) & YS(MPa) & $\begin{array}{l}\text { Elong. } \\
(\%)\end{array}$ & $\begin{array}{l}\text { Joint } \\
\text { efficiency }\end{array}$ & Ref. \\
\hline $\mathrm{AA} 6061-21 \% \mathrm{~B}_{4} \mathrm{C}$ & - & 205 & 135 & 4.5 & 83 & 24 \\
\hline AA6063-6\% $\% B_{4} \mathrm{C}$ & T5 & 172 & 125 & 2.5 & 62 & 18 \\
\hline AA6063-10.5\%B $\mathrm{B}_{4} \mathrm{C}$ & T5 & 176 & 125 & 2.5 & 62 & 18 \\
\hline $\mathrm{A} 356-15 \% \mathrm{SiC}$ & Cast & 186 & -- & - & 134 & 98 \\
\hline AA2009-15\% SiC & Extruded & 325 & 225 & 2 & 105.5 & 101,102 \\
\hline AA6092-17.5\% SiC & $\mathrm{T} 6$ & 300 & 189 & 2.72 & 72.5 & 70 \\
\hline $\mathrm{AA} 6061-10 \% \mathrm{Al}_{2} \mathrm{O}_{3}$ & $\mathrm{~T} 6$ & 250 & -- & 3.3 & 78 & 50 \\
\hline \multirow{4}{*}{$\mathrm{AA} 6061-20 \% \mathrm{Al}_{2} \mathrm{O}_{3}$} & \multirow{4}{*}{ T6 } & 232 & - & 1.5 & 74 & 50 \\
\hline & & 251 & 234 & - & 70.7 & 19 \\
\hline & & 329 & 280 & 1.3 & 86.8 & 105 \\
\hline & & 262 & 193 & 2.8 & 72.0 & 111 \\
\hline $\mathrm{AA} 7005-10 \% \mathrm{Al}_{2} \mathrm{O}_{3}$ & T6 & 299 & 263 & 1.2 & 80.8 & 20 \\
\hline Al-10\%wt.TiB 2 & Cast & $240-282$ & -- & $3.4-6.7$ & $79-99$ & 107 \\
\hline $\begin{array}{l}\text { AA6061-3\%wt.TiC to } \\
\text { 7\%wt.TiC }\end{array}$ & $\mathrm{T} 6$ & $138-235$ & -- & - & $73-114$ & 108 \\
\hline Al-15\%wt. $\mathrm{Mg}_{2} \mathrm{Si}$ & Cast & $95-115$ & - & - & -- & 109 \\
\hline
\end{tabular}

* The concentration of reinforcement refers to volume fraction unless otherwise specified. 


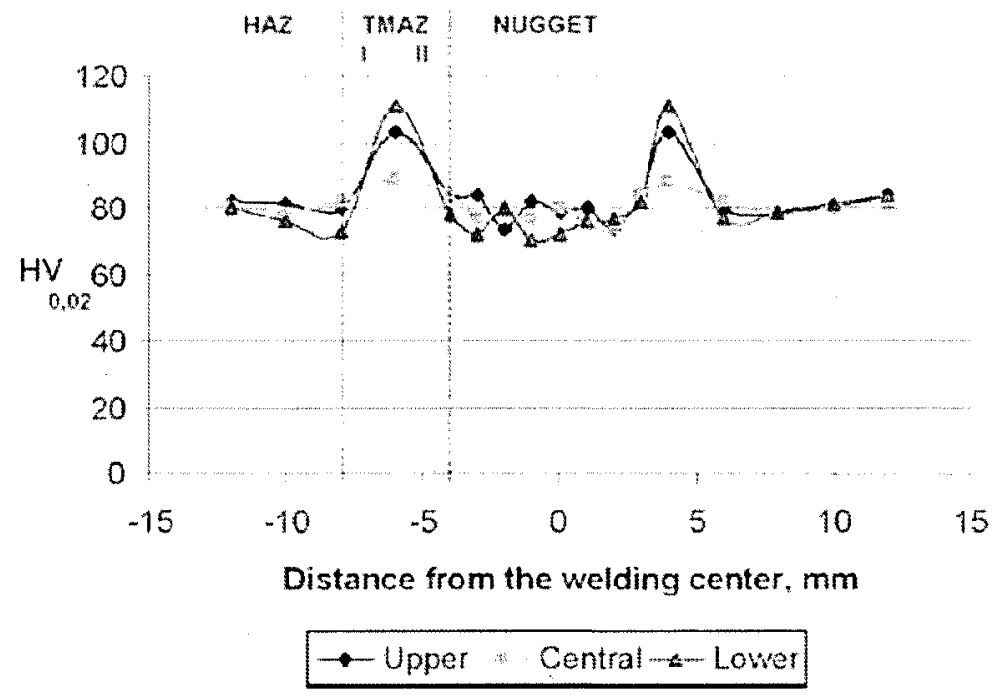

Fig. 2.15 Hardness profiles $\left(\mathrm{HV}_{0.02}\right)$ on the cross-section of a FSW composite [20].

\section{Tensile properties}

The FSW process has caused a decrease in tensile properties since most of the materials used in these studies has an aging hardened initial temper. According to $\mathrm{L}$. Ceschini et al. [111], this behavior can be attributed to the concurrent effects of different microstructural modifications induced by the FSW process such as the refinement of grain structure, the particle redistribution and the overaging of the matrix alloy. Nevertheless, these FSWs still have a joint efficiency around 62-87\%. T.W. Nelson et al. [24] conducted a comparison between fusion welding and $\mathrm{FSW}$ with $\mathrm{Al}-\mathrm{B}_{4} \mathrm{C} \mathrm{MMCs}$, and reported that the FSW welds exhibited a $22 \%$ increase in tensile strength over GTAW welds. On the other hand, if the base materials were as-extruded condition without aging heat-treatment, an improvement in tensile properties can be observed due to the precipitation strengthening resulted from the FSW thermal cycles [102]. As mentioned above, PWHT has shown 
positive effects on the mechanical properties of the welds, but that is not always the case as the abnormal grain growth may take place in some conditions. X.G. Chen et al. [18] performed a T6 heat treatment after FSW of Al- ${ }_{4} \mathrm{C}$ composite. The obtained tensile results even showed some decrease compared with that in as-welded condition though an increase of microhardness was observed in the nugget zone. S. Gopalakrishnan et al. [108] studied the effects of various welding parameters and tool pin profile on the mechanical properties of joints in FSW of Al-TiC MMCs. The FSW specimens without any post-weld heat treatment belonging to a different set of parameters tested, exhibited a high joint efficiency (most of them ranging from $90 \%$ to $98 \%$ ) with respect to the ultimate tensile strength of the base material of AA6061-MMC. It was found that the tool pin profile and the welding speed have more significant effects on tensile strength and the joints produced using tapered square tool present maximum joint efficiency [108]. However, in the study of S.J. Vijay et al. [107], the joint welded by square pin profiled tool exhibits highest tensile strength when compared to joints produced by other tools. The joint fabricated by tapered square pin profiled tool has the least tensile strength. The reason for the opposite results on the effect of tool pin profile may be related to the different matrix alloy and more work needs to be done before concluding.

\subsection{Tool Wear}

Excessive tool wear is a serious problem during FSW of MMCs because of the presence of very hard ceramic reinforcement. Such tool wear significantly reduces the lifetime of the FSW tool and may also affect the quality of joints. J.A. Lee et al. [70] recorded the tool wear behavior in FSW of AA6092-17.5\% SiC MMCs. A tool made of 
$\mathrm{H} 13$ with $\mathrm{B}_{4} \mathrm{C}$ coating was actually used in this work. The pin diameter was reduced by $0.83 \mathrm{~mm} / \mathrm{m}$ and had to be replaced from the welding head for every $1.5 \mathrm{~m}$ welding. T.W. Nelson et al. [24] used threaded $\mathrm{H} 13$ steel tools for welding AA6061-21\%B 4 C composite. The threads were completely removed in less than $254 \mathrm{~mm}$ of welding. D. Contorno et al. [100] investigated the wear behavior of uncoated and coated steel tools in friction stir processing of extruded AA359-20\%SiC MMC. However, a definitive advantage of the coatings on the hardened tool was not found.

R.A. Prado et al. $[21,112]$ used a simple technique to calculate the wear rate of the welding tool by measuring the relationship between the original tool and the worn tool. This is accomplished by weighing the photograph of the worn tool in $2 \mathrm{D}$ projection and comparing the relative percentage change to the original tool photograph. They reported that the tool wear and the rate of wear for hardened steel decreased with increasing welding speed in the FSW of AA6061-20\% $\mathrm{Al}_{2} \mathrm{O}_{3} \mathrm{MMCs}$, as illustrated in Fig. 2.16. It can be readily observed that $20 \%$ tool wear has been reached in less than $100 \mathrm{~cm}$ of welding. Interestingly, a self optimization phenomenon of tool shape was noticed in the study. When this optimized tool shape was achieved, tool wear as determined by shape change essentially ceased and this shape was slightly different at different welding speeds. It was found the optimized tool could produce porosity free welds with a narrower HAZ. Thus, it was suggested that the use of threaded tools for the FSW of MMC is not required since the self-optimized tools yield better quality welds with fewer drops in hardness than the threaded pin tools. Self-optimizing wear phenomena may provide a basis for designing 
optimized tools for other FSW practices, especially those involving appreciable tool wear where tool wear reduction becomes important.

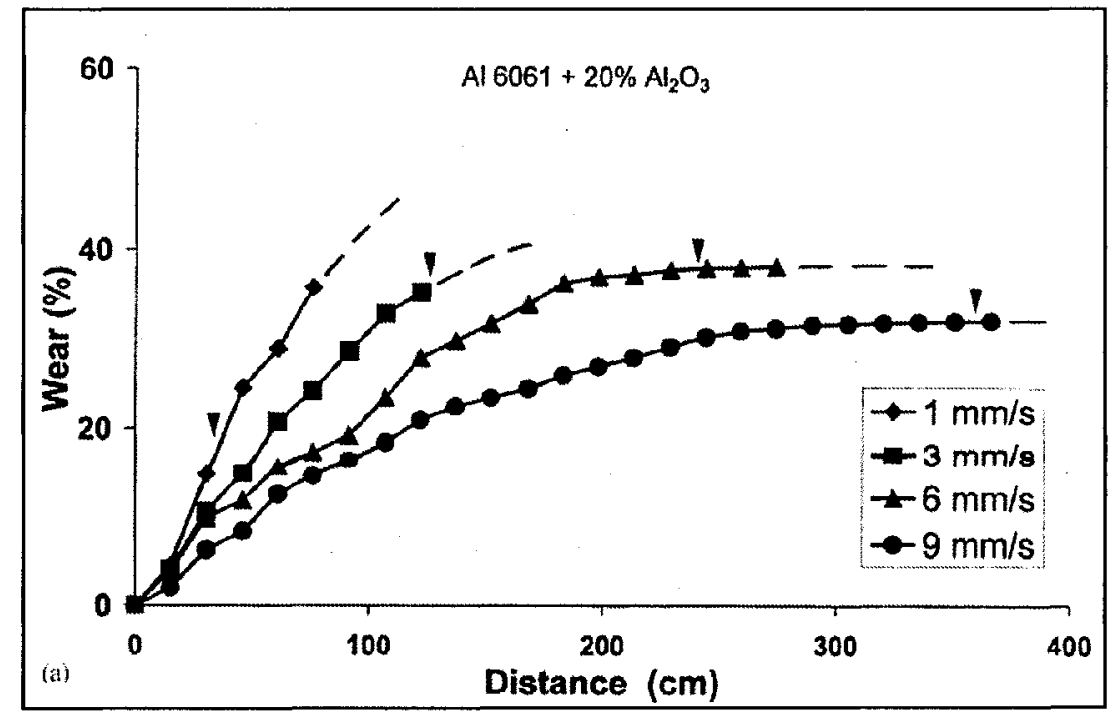

Fig. 2.16 Pin tool wear as a percent of initial pin shape projections versus corresponding MMC-/FSW traverse distance at various welding speeds noted. (Tool rotation constant at $1000 \mathrm{rpm}$ ) [21].

G.J. Fernandez et al. [97] and D.J. Shindo et al. [99] confirmed the same phenomenon in the FSW of A359-20\% SiC MMCs using the same welding tools. However, much less tool wear was recorded in their studies in comparison with the work of R.A. Prado et al. [21]. In the case of $1000 \mathrm{rpm}$ and $9 \mathrm{~mm} / \mathrm{s}$, only $15 \%$ tool wear was observed after selfoptimization compared to $30 \%$ tool wear during FSW of $\mathrm{AA} 6061-20 \% \mathrm{Al}_{2} \mathrm{O}_{3} \mathrm{MMCs}$. It is probably because the relatively harder aluminium matrix AA6061 needs more deformation force to flow. It was also reported that welds made after the pin optimization, are more homogeneous and have less particle comminution. There is only a $7 \%$ reduction in the mean $\mathrm{SiC}$ particle size in the weld zone for self-optimized pin tool without threads as 
compared to a $25 \%$ variation for threaded tools wearing significantly at the beginning of the welding. It is especially interesting to note that the rate of tool optimization apparently decreases with increasing welding speeds, and the speeds used in these studies were as high as 9 and $11 \mathrm{~mm} / \mathrm{s}$ which are very favorable in commercial welding application.

\subsection{Summary}

The feasibility of FSW has been demonstrated in different types of MMCs. It seems to be a very promising technique for welding MMCs in terms of mechanical properties. However, the exploration of FSW of MMCs is still at its initial stage. Further study is definitely needed for several aspects. First, the effects of process parameters such as tool. rotation speed and welding speed on the microstructural and mechanical properties of MMCs welds have not been studied yet. Furthermore, a better way is needed to monitor the tool wear condition. Although a self-optimization phenomenon was noticed in FSW of Al$\mathrm{Al}_{2} \mathrm{O}_{3}[21,112]$ and $\mathrm{Al}-\mathrm{SiC}$ MMCs $[97,99]$, the exact reason for this behavior has not been provided in literature. The present study is to be conducted to clarify these experimental facts for $\mathrm{FSW}$ of $\mathrm{Al}-\mathrm{B}_{4} \mathrm{C}$ MMCs. 


\section{Chapter III}

\section{Methodology}




\section{Chapter III Methodology}

\subsection{Materials}

Three materials are used in this study: extruded plates of AA6063 aluminium alloy (4.5 mm thick, T5 temper) and rolled plates of AA1 100-16\% $\mathrm{B}_{4} \mathrm{C}$ MMC (4.4 mm thick) and AA1 $100-30 \% \mathrm{~B}_{4} \mathrm{C}$ MMC (2.5 mm thick). The median particle size of boron carbide in the MMCs is around $11 \mu \mathrm{m}$ for AA1100-16vol.\% $\mathrm{B}_{4} \mathrm{C}$ and $15 \mu \mathrm{m}$ for AA1100-30vol. $\% \mathrm{~B}_{4} \mathrm{C}$ MMCs. The matrix of the MMCs is an AA1100 aluminium alloy. The chemical composition of the AA6063 plate analyzed by Optical Emission Spectroscopy (OES) is given in Table 3.1. The AA1100- $\mathrm{B}_{4} \mathrm{C}$ composite was fabricated by Rio Tinto Alcan via an ingot metallurgy route [23]. The cast ingots were subsequently preheated and hot-rolled with multi-passes of cross-rolling to the final shape. For laser welding, commercially pure titanium of grade 1 in the form of foils (thickness: $150 \mu \mathrm{m}$ ) and filler wire (diameter: $1 \mathrm{~mm}$ ) were used as filler metal. For FSW, some plates of the $16 \%$ vol. $\mathrm{B}_{4} \mathrm{C}$ composite were annealed $\left(400^{\circ} \mathrm{C}\right.$ for $1 \mathrm{~h}$ ) before welding in order to study the effect of initial temper of the materials on the mechanical properties of the joints.

Table 3.1 Chemical composition of AA6063 plate (wt.\%) measured by OES

\begin{tabular}{lccccccc}
\hline Alloy & $\mathrm{Si}$ & $\mathrm{Fe}$ & $\mathrm{Cu}$ & $\mathrm{Mg}$ & $\mathrm{Mn}$ & $\mathrm{Ti}$ & $\mathrm{Al}$ \\
\hline AA6063 & 0.44 & 0.19 & 0.01 & 0.50 & 0.03 & 0.01 & Bal. \\
\hline
\end{tabular}




\subsection{Welding Procedures}

The plates of $\mathrm{AA} 1100-\mathrm{B}_{4} \mathrm{C} \mathrm{MMCs}$ and aluminium alloy were shear-cut into plates with dimensions of $150 \mathrm{~mm}$ (rolling direction) $\times 100 \mathrm{~mm}$. For laser welding, the plate edges were machined into flat; while for FSW the shear cut plates were used directly without machining. All plates were carefully degreased with liquid acetone and dried in air. For laser welding, a steel brush or sand paper was used to remove the possible smudges and oxide films on the plate edges. This surface preparation is critical for a sound laser joint and good surface finish since any moisture or excessive gap between the two welding surfaces would cause laser energy loss and defects in the weld [52]. All plates were butt welded along the rolling direction. As shown in Fig. 3.1, a robotized Nd:YAG laser welding equipment (HL4006D, Trumph) in continuous emission mode was used for fusion joining, whereas a MTS I-Stir PDS FSW machine in force control mode (max force: $90 \mathrm{kN}$ ) was used for solid state joining (Fig. 3.2). For laser welding, no gap was left between the two plates to butt weld. A schematic of laser welding with Ti filler foil between the two plates is shown in Fig. 3.3 as an example. During laser welding with a Ti foil, an aluminium backing plate was used to keep the Ti foil layers in position. The amount of Ti added was controlled by adjusting the number of foil layers or the feeding rates of the filler wire. An argon shielding gas was used at a constant flow rate of $20 \mathrm{~L} / \mathrm{min}$ backward from the vertical axis at about 40 degrees. The optical fibre transmitting the laser beam energy had a $600 \mu \mathrm{m}$ core diameter. The laser welding head was used in the configuration with a focal length of $200 \mathrm{~mm}$ and was pushed at 10 degrees backward from the vertical axis to avoid 
possible damage to the laser optics from the beam reflection. Finally, an electric heat-gun (at $2.5 \mathrm{~kW}$ ) was used for $20 \mathrm{~s}$ at a distance of $\sim 10 \mathrm{~cm}$ in order to eliminate the possible humidity on the welding plates. For FSW tests, the welding parameters were selected to avoid macro-defects in the weld and excessive flash on the surface. Preliminary tests were carried out in position control mode in order to find out the appropriate vertical force for the specific welding condition. Conical unthreaded tools made of WC-15\% Co and $\mathrm{H} 13$ tool steel were used. The outline profiles of these tools are described later in the section on tool wear measurement in the same chapter.

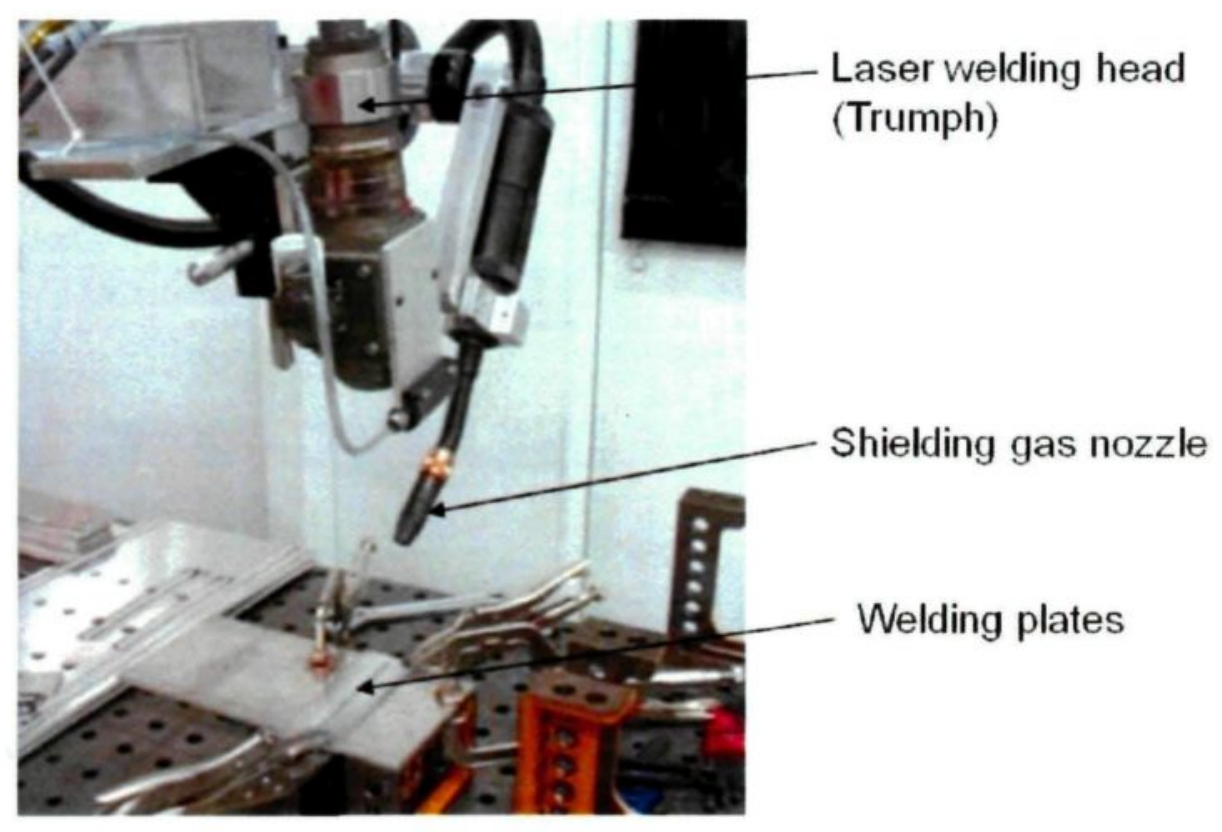

Fig. 3.1 The robotized Nd:YAG laser welding machine at NRC-ATC. 


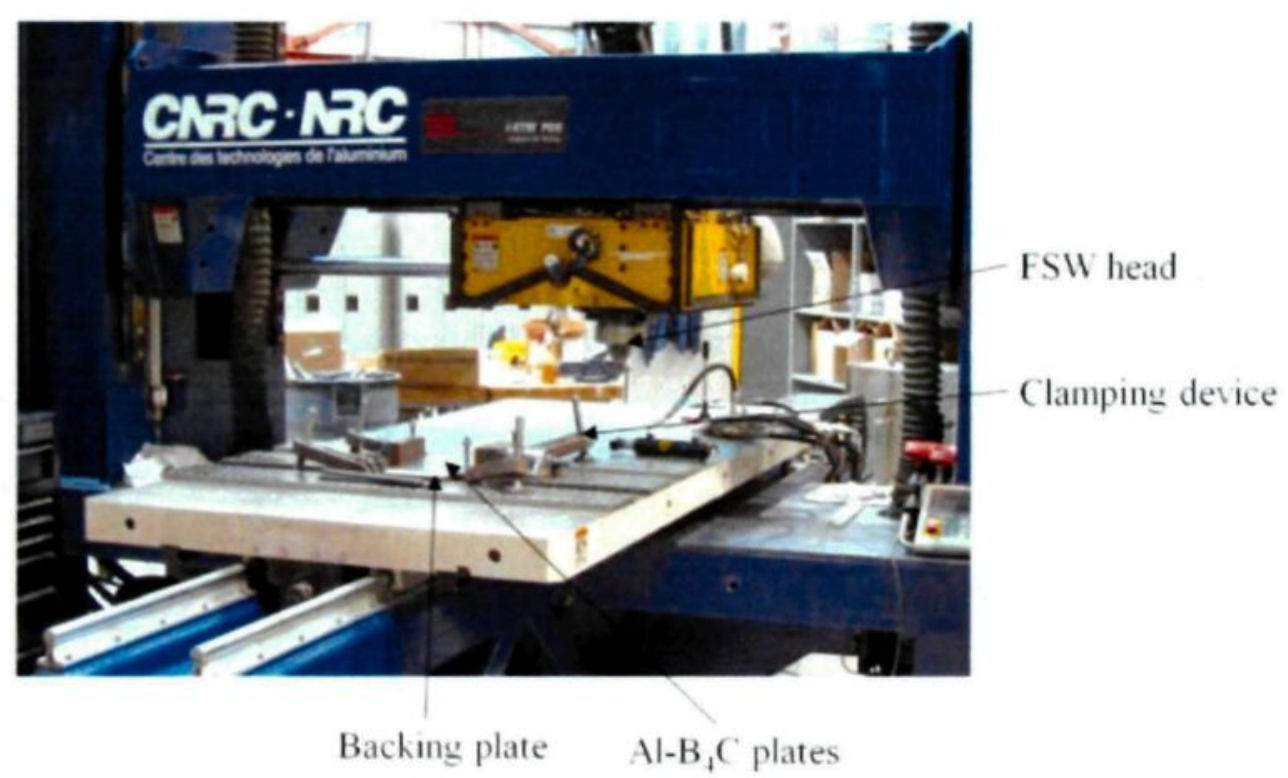

Fig. 3.2 FSW equipment at NRC-ATC.

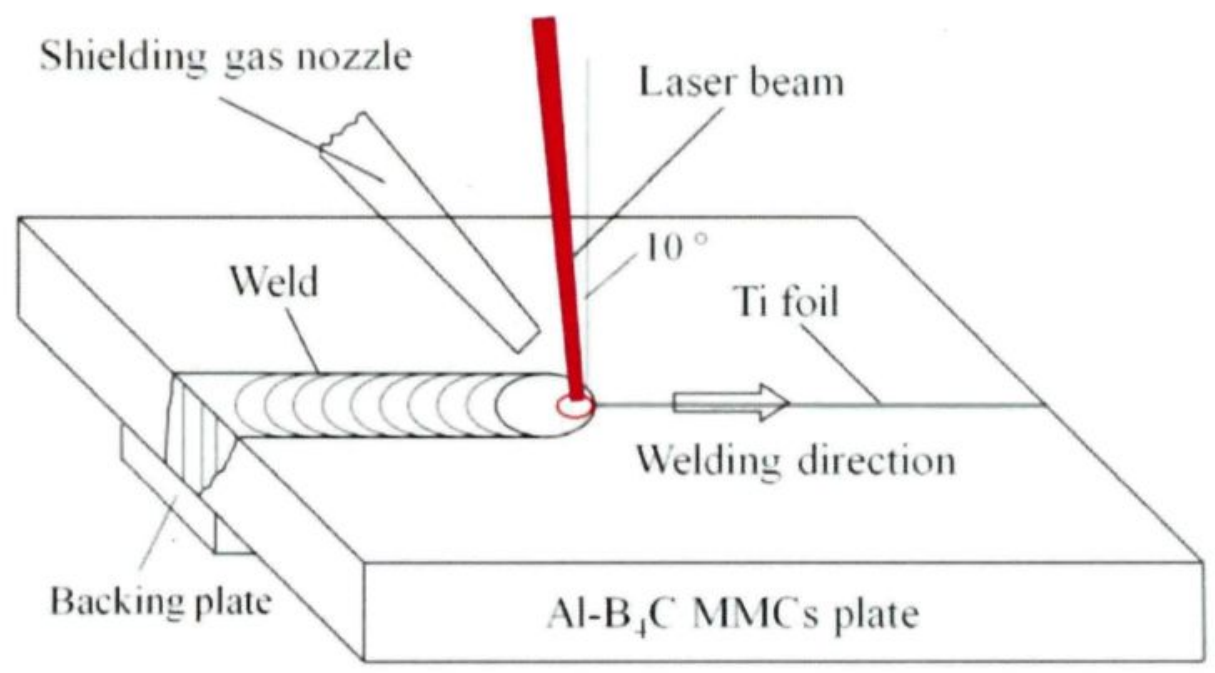

Fig. 3.3 Schematic of laser welding with Ti filler foil. 


\subsection{Characterization and Analysis}

\subsubsection{Metallographic sample preparation}

The welded samples were transversely sectioned and polished using conventional mechanical polishing method. A polishing procedure adapted for MMCs is used as the composite consists of a very soft aluminium matrix and a very hard $\mathrm{B}_{4} \mathrm{C}$ reinforcement. Grinding and polishing were carried out using an automatic grinding / polishing machine (Fig. 3.4) according to the following procedures. Sectioned samples were first hot mounted in epoxy resin and ground with grained diamond disc down to $40 \mu \mathrm{m}$. The specimen was polished with diamond pastes of $15,9,6,3$ and $1 \mu \mathrm{m}$ granulation for a few minutes each. Finally, polishing with a $0.05 \mu \mathrm{m}$ colloidal silica solution was done for 15 minutes. Water and Struers DP-suspension were used as the lubricant for grinding and polishing respectively. It is important to wash the sample surface and change the washing water before going to the next polishing step. On the other hand, samples for electron backscattered diffraction (EBSD) analysis were prepared using ion beam polishing method. It was performed using a Cross Section Polisher (Fig. 3.5). For generating the ion beam, the argon pressure was selected at $170 \mathrm{kPa}$. The specimen was polished for eight hours with 5 $\mathrm{kV}$ accelerating voltage and approximately $100 \mathrm{~mA}$ beam current. 


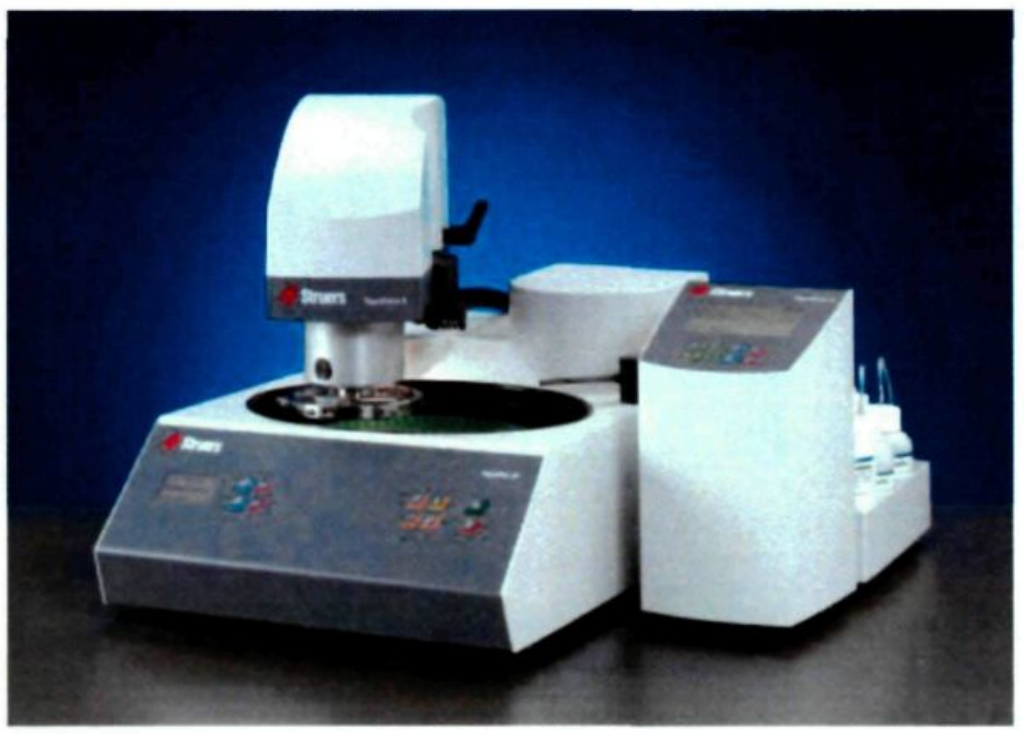

Fig. 3.4 Automatic polishing machine at ATC (Struers TegraPol-31).

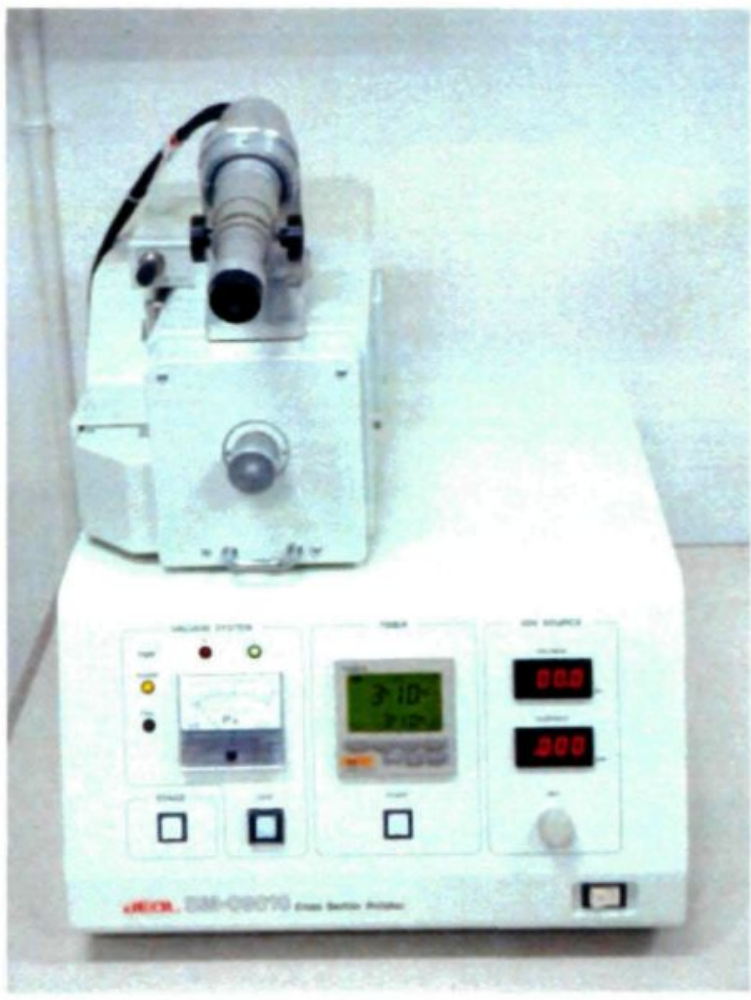

Fig. 3.5 Ion beam cross section polishing machine at UQAC (Cross Section Polisher: SM-09010). 


\subsubsection{Microscopy and phase identification}

The microstructure observation was performed using an optical microscope (OM, Olympus BX51M) with an image analyzer (Clemex JS-2000) and a scanning electron microscope (SEM, Hitachi SU-70) equipped with energy dispersive spectrometer (EDS). The two microscopes are shown in Figs. 3.6 and 3.7. For laser welds, microstructure observation was mainly performed at 2000 5000x magnification under SEM. For friction stir welds, microstructure observation was mainly made at $200 \mathrm{x}$ and $500 \mathrm{x}$ magnifications under OM. For particle measurement, image analysis was conducted under OM at 500x magnification. As shown in Fig. 3.8, a total of 64 fields $\left(190 \times 140 \mu \mathrm{m}^{2} /\right.$ field, 8 fields by 8 fields) uniformly distributed in the analyzed zone ( $\sim 3 \mathrm{~mm}$ wide) were actually measured to increase the statistical accuracy. For the purpose of comparison, all EBSD analyses were performed at $800 \mathrm{x}$ magnification and a step size between 0.25 and $0.5 \mu \mathrm{m}$ was used. Regardless of polishing method, the specimen was directly used for the EBSD analysis without any etching. The phase identification was carried out under SEM using EDS spectrum and element mapping. Some $\mathrm{x}$-ray diffraction (XRD) tests were also performed on laser welds to confirm the phases compositions. Fracture surfaces of tensile samples were observed at 1000x magnification under SEM. 


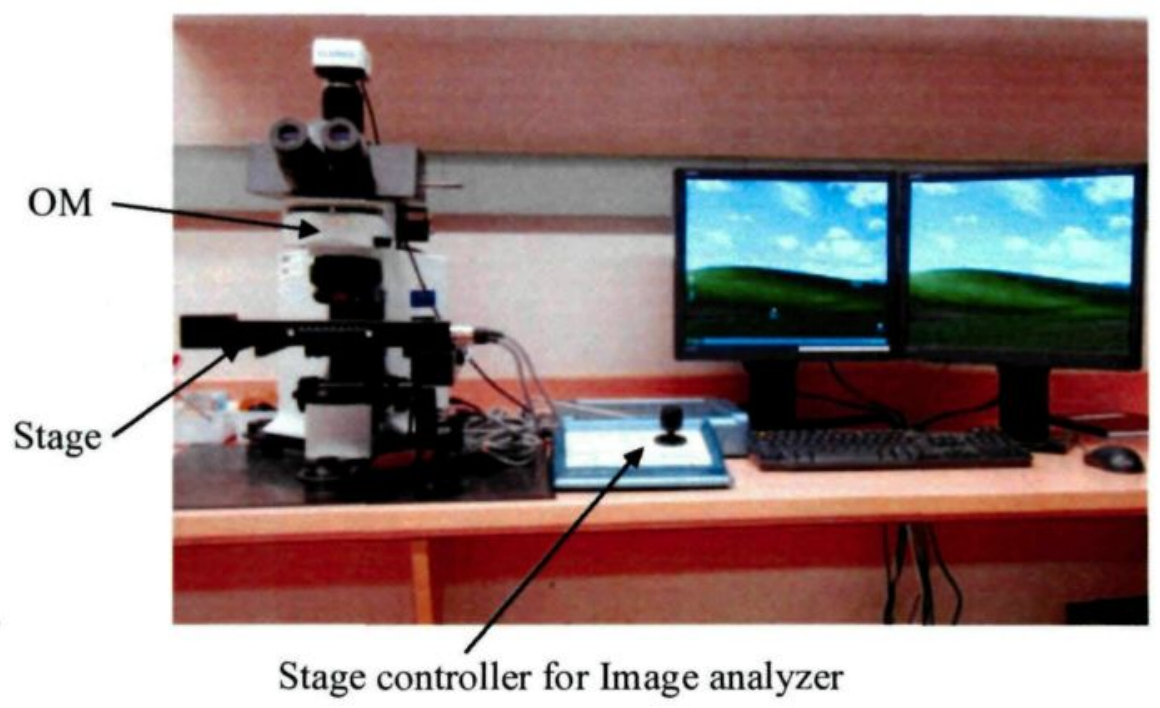

Fig. 3.6 Optical microscope (Olympus BX51M) equipped with image analyzer at ATC.

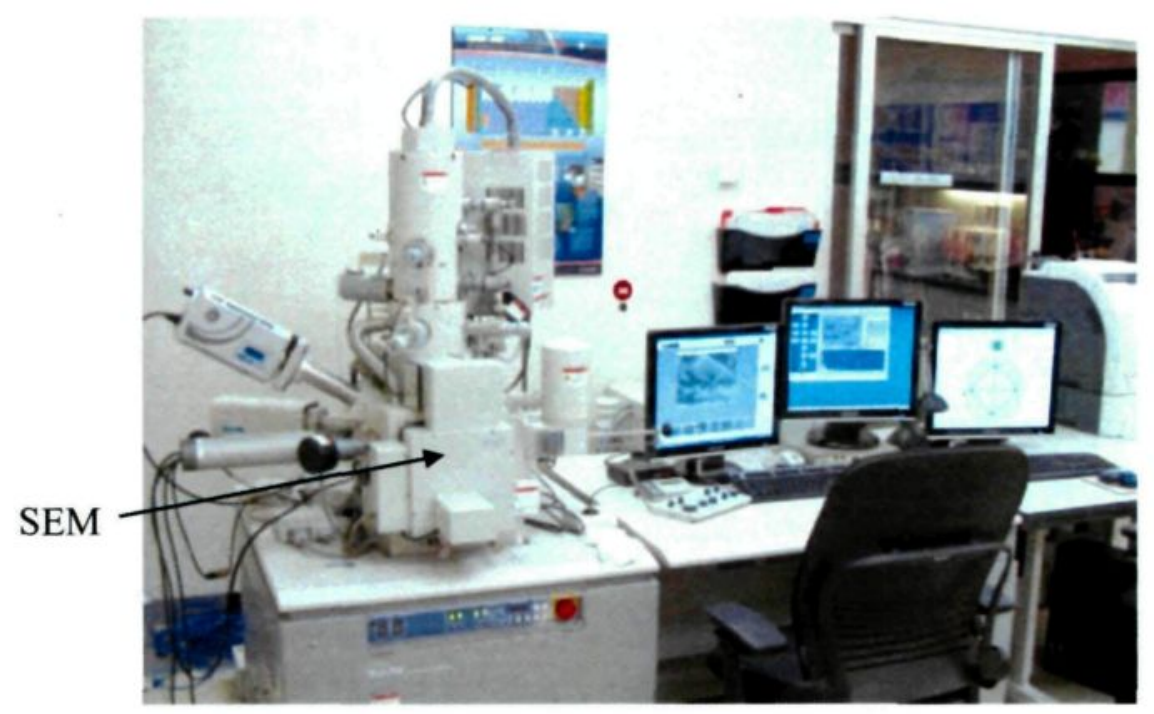

Fig. 3.7 Scanning electron microscope (SEM, Hitachi SU-70) at ATC. 


\begin{tabular}{|c|c|}
\hline $\begin{array}{l}\text { Cross section } \\
\text { of sample }\end{array}$ & 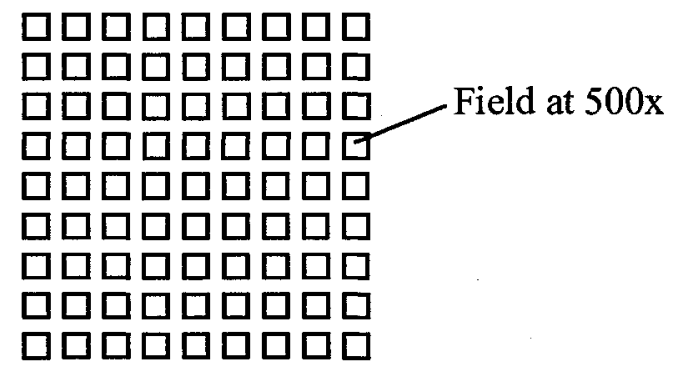 \\
\hline
\end{tabular}

Fig. 3.8 Distribution of fields throughout the thickness of plate for image analysis.

\subsubsection{Tool wear measurement}

Tool wear is one of the problems which prevent application of FSW for joining MMCs. The tool weight loss can be measured to calculate the actual volume loss. However, this method only gives us the overall tool wear rate and does not provide any information on tool profile changes. In order to better characterize the tool wear occurred during FSW of MMCs, a three dimensional method was used to construct the outline profile of FSW tool. One tool made of WC-Co and one made of H13 steel was selected for comparison. It involves a series of topographical measurement by means of the interferometry technique after a specific distance of welding using a noncontact optical profilometer (STIL MICROMESURE, Fig. 3.9). This equipment has a vertical resolution of $57 \mathrm{~nm}$ and a horizontal resolution of $1 \mu \mathrm{m}$. It is assumed that the conical tool has a symmetrical wear rate and thus two-dimensional outline profiles across the tool axis were used to illustrate tool shapes. Fig. 3.10 provides an example of the measurement on a new steel tool. 


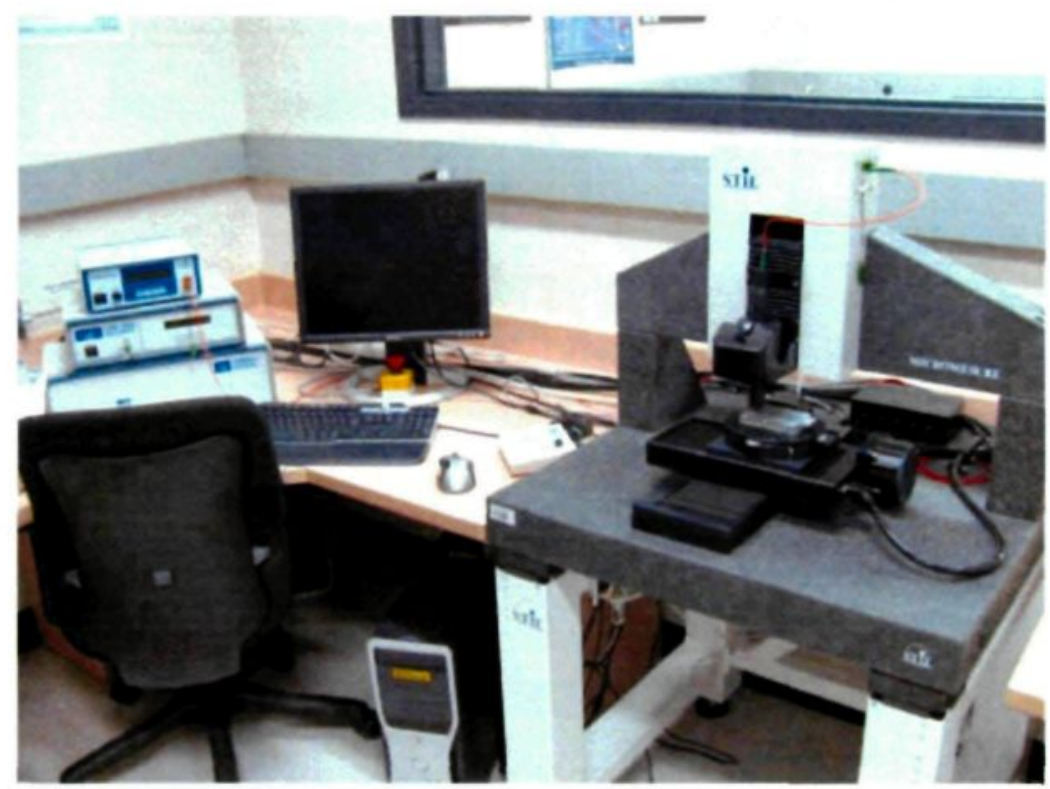

Fig. 3.9 Noncontact optical profilometer for FSW tool shape measurement (STIL MICROMESURE)

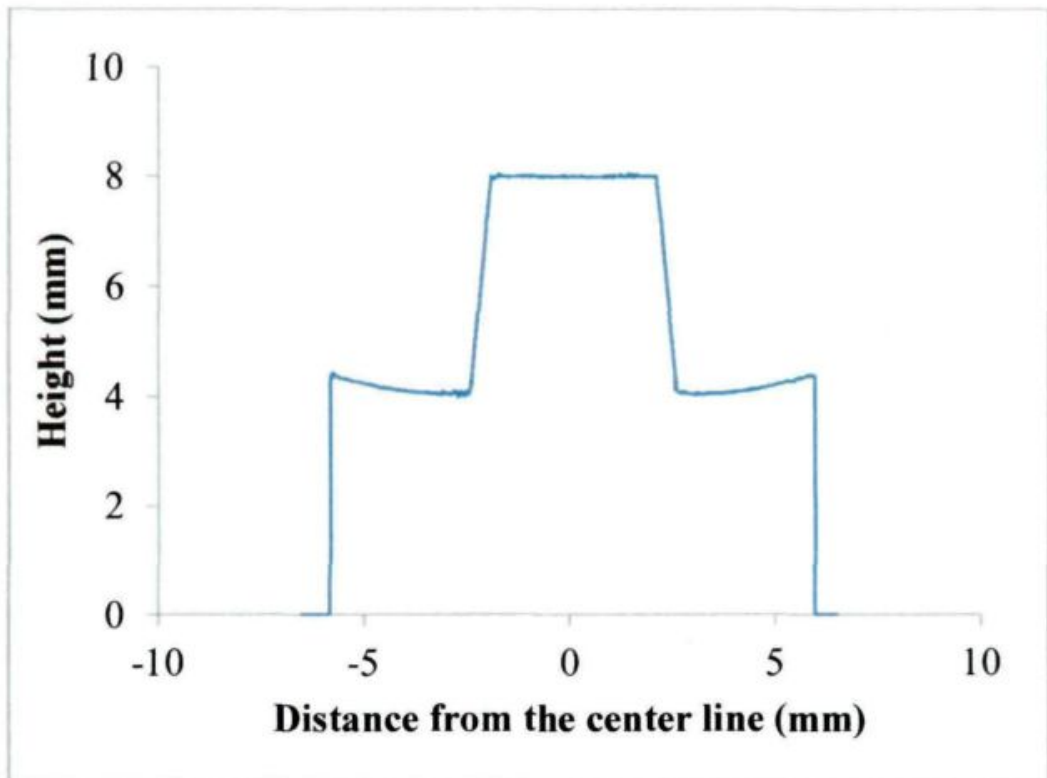

Fig. 3.10 Example of outline profile of a new FSW steel tool. 


\subsubsection{Microhardness and tensile tests}

Vickers microhardness of the matrix was measured at two locations on the cross section after metallographic preparation: $1 \mathrm{~mm}$ from the top surface and $1 \mathrm{~mm}$ from the bottom surface. Fig. 3.11 shows the equipment used for Vickers microhardness testing (CMT, Clemex). For AA6063 aluminium alloy, a load of $100 \mathrm{~g}$ was applied and measurements were made automatically at intervals of $0.5 \mathrm{~mm}$. For MMCs, a load of $10 \mathrm{~g}$ was used because the AA1100 aluminium matrix is very soft and the ceramic concentration is relatively high. Measurements were made manually at intervals of about $0.5 \mathrm{~mm}$ to avoid indentation on $\mathrm{B}_{4} \mathrm{C}$ particles. The tensile tests were carried out according to the ASTM E804 standard at a test speed of $1 \mathrm{~mm} / \mathrm{min}$ [113]. Rectangular flat specimens of $200 \mathrm{~mm}$ long with $50 \mathrm{~mm}$ long and $12.5 \mathrm{~mm}$ wide gauge in the reduced section were used (Fig. 3.12). Tensile samples of the joints were prepared without any change of surface condition after welding (e.g. no machining). The tensile properties of each joining condition, namely the ultimate tensile strength (UTS), the yield strength (YS) and the fracture elongation ( $(\varepsilon)$, are the average values of a minimum of three tensile samples, and the standard deviation is also calculated for each condition. 


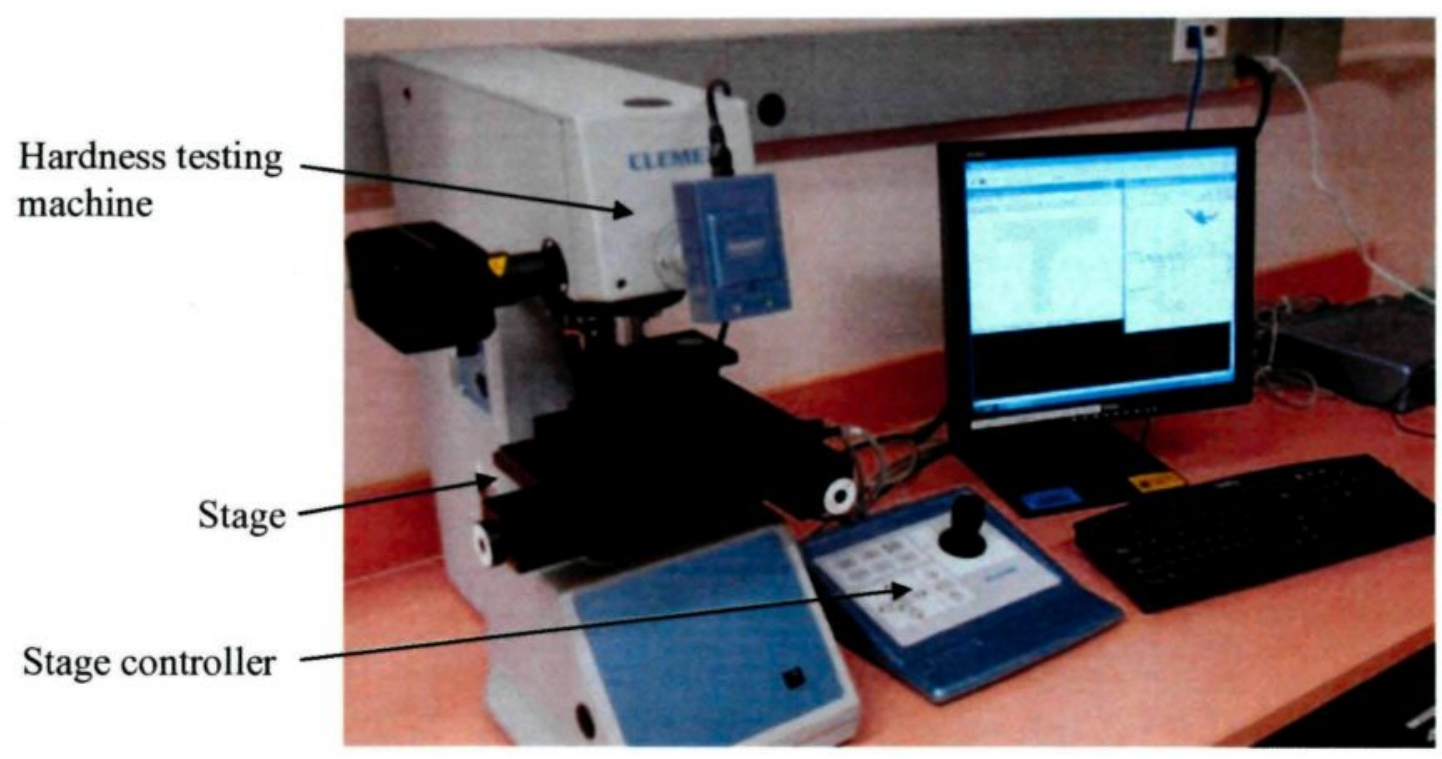

Fig. 3.11 Vickers microhardness testing machine at ATC (CMT, Clemex)

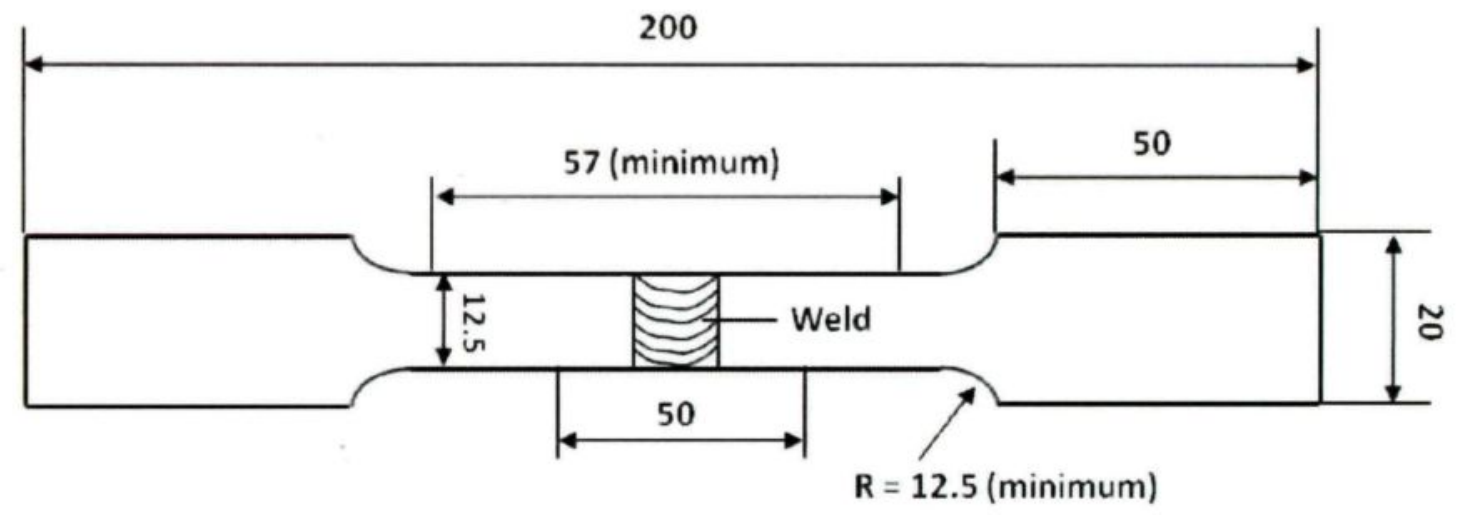

Fig. 3.12 Sketch of a typical tensile sample (unit: $\mathbf{m m}$ ) 


\subsubsection{Corrosion test}

The effect of FSW on the corrosion properties of the material surface was studied by using a $3.5 \mathrm{wt} \% \mathrm{NaCl}$ solution at room temperature. As shown in Fig. 3.13, the top surface of specimen with a rectangular shape $(20 \mathrm{~mm} \times 20 \mathrm{~mm})$ was ground with $\mathrm{SiC}$ paper down to 1200 grit in order to remove the welding flash and then cleaned with isopropyl $\left(\mathrm{C}_{3} \mathrm{H}_{8} \mathrm{O}\right)$. The top surface of the weld was not touched. A Teflon cylinder $(\sim 5 \mathrm{~mm}$ high $)$ with $0.5 \mathrm{~cm}^{2}$ cross section area was positioned on the top surface to be tested using pliers. An epoxy primer was then applied manually around the cylinder on the edges of specimens and dried in air for one day. The specimens with the cylinder and epoxy primer were ground again with $\mathrm{SiC}$ paper down to 1200 grit in order to obtain a flat epoxy surface and thus to avoid crevices of solution during corrosion testing. The residual Teflon cylinder was then removed from the specimens' surface. The specimens were then cleaned with distilled water and dried in air. Therefore, an area of approximately $0.5 \mathrm{~cm}^{2}$ of the top surface which was covered with Teflon during preparation, was exposed to $1000 \mathrm{ml}$ of the $\mathrm{NaCl}$ solution during testing. The open circuit potential (OCP) and the potentiodynamic polarization curves were measured using a Reference 600 Potentiostat (Gamry Instruments, USA). As shown in Fig. 3.14, the tests were performed using a three electrode system with a platinum mesh as counter electrode and $\mathrm{Ag} / \mathrm{AgCl}$ as reference electrode. The OCP of the specimens was monitored until it stabilized for a period of approximately $1 \mathrm{~h}$. The potentiodynamic polarization curves were recorded by scanning from $250 \mathrm{mV}$ below the OCP at $1 \mathrm{mV} / \mathrm{s}$ 
until the current reached $1 \mathrm{~mA}$. Fig. 3.15 shows an example of a polarization curve for the base material of $\mathrm{Al}-16 \% \mathrm{~B}_{4} \mathrm{C} \mathrm{MMC}$.

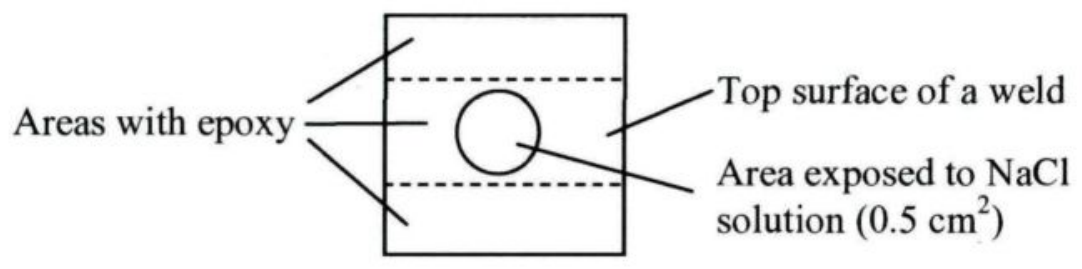

Fig. 3.13 Schematic of a specimen for corrosion test.

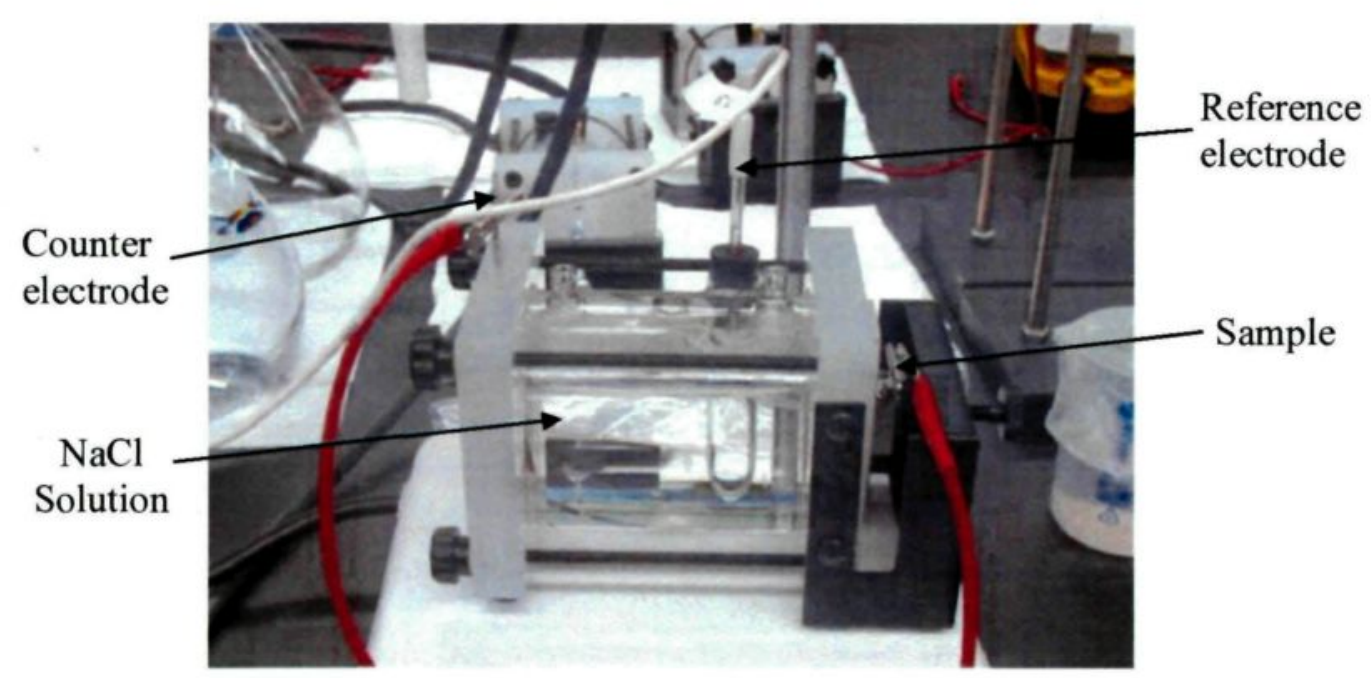

Fig. 3.14 Schematic of the three electrode system for corrosion testing. 


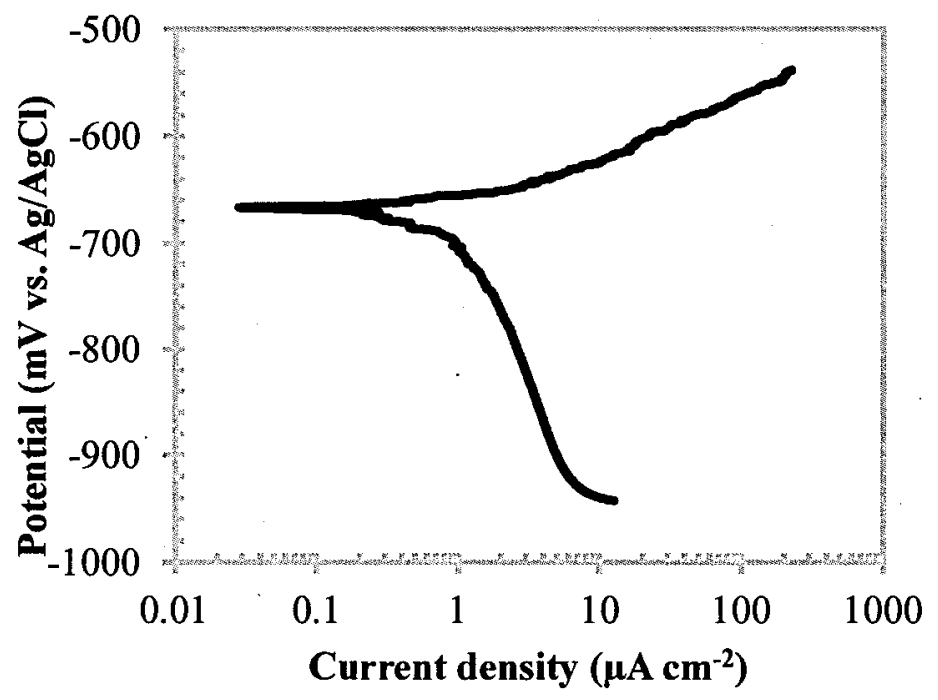

Fig. 3.15 Example of a polarization curve for the base material of $\mathrm{Al}-16 \% \mathrm{~B}_{4} \mathrm{C} \mathrm{MMC}$. 


\section{Chapter IV}

\section{Laser Welding of AA1100-16 vol.\% $\mathrm{B}_{4} \mathrm{C}$ Metal Matrix Composites}




\section{Chapter IV Laser Welding of AA1100-16 vol.\% B $_{4}$ C Metal}

\section{Matrix Composites}

Laser welding of AA1 100-16 vol.\% $\mathrm{B}_{4} \mathrm{C}$ Metal Matrix Composites was explored in this chapter. As shown in Table 4.1, the welding conditions are generally divided into three groups: without any filler, with $\mathrm{Ti}$ foil and with $\mathrm{Ti}$ filler wire. Welding parameters were selected based on visual inspection and microstructure observation. It was found that most $\mathrm{B}_{4} \mathrm{C}$ particles were decomposed and that needle-like $\mathrm{AlB}_{2}$ and $\mathrm{Al}_{3} \mathrm{BC}$ phases were substantially formed during the welding process without filler. A relatively low joint efficiency of $63 \%$ (UTS) was obtained due to needle-like phases in the weld. The addition of Ti with $150 \mu \mathrm{m}$ thick foil increased the joint efficiency to $75 \%$ due to the decrease of needle-like phase formations. On the other hand, the addition of Ti with filler wire did not show significant tensile property improvement due to the Ti segregation and microstructure inhomogeneity in the weld zone. The fracture surfaces of laser welded joints were investigated to understand the fracture mechanisms.

The main content of this chapter is published in: J.F. Guo, P. Gougeon, X.-G. Chen, "Study on Laser Welding of AA1 100-16\% vol.B ${ }_{4}$ C Metal Matrix Composites", Composites Part B: Engineering, 2012, online published, DOI:10.1016/j.compositesb.2011.11.044. 
Table 4.1 Laser welding parameters used in the study

\begin{tabular}{llllll}
\hline Code & Power $(\mathrm{kW})$ & $\begin{array}{l}\text { Welding speed } \\
(\mathrm{m} / \mathrm{min})\end{array}$ & $\begin{array}{l}\text { Conditions } \\
\text { (foil layers or wire } \\
\text { feeding rates }(\mathrm{m} / \mathrm{min}))\end{array}$ & $\begin{array}{l}\text { Defocus* } \\
(\mathrm{mm})\end{array}$ & $\begin{array}{l}\text { Backing } \\
\text { plate }\end{array}$ \\
\hline B & 3.2 & 1.0 & - & -3 & no \\
F1 & 3.0 & 1.5 & 1 layer & 0 & yes \\
F2 & 3.0 & 1.8 & 2 layers & 0 & yes \\
W1 & 4 & 0.6 & 0.3 & 0 & no \\
W2 & 4 & 0.75 & 0.5 & 0 & no \\
W3 & 4 & 0.75 & 0.6 & 0 & no \\
W4 & 4 & 0.75 & 0.75 & 0 & no \\
\hline
\end{tabular}

* Defocus $<0$ when the focal point is set into the material.

\subsection{Microstructural Characterization}

\subsubsection{Laser Welds without Filler}

Fig. 4.1 a shows a typical macro-view of joints without filler indicating that a sound joint can be obtained. The base material consists of aluminium matrix and $\mathrm{B}_{4} \mathrm{C}$ particles which are uniformly distributed in the matrix (Fig. 4.1b), while the laser weld zone consists of a large number of needle-like phases and some $\mathrm{B}_{4} \mathrm{C}$ residues (Fig. 4.1c and d). The EDS analysis under SEM reveals that these needle-like phases are Al-B-C and Al-B compounds (Fig. 4.2) and the $\mathrm{XRD}$ results confirm that both phases are $\mathrm{Al}_{3} \mathrm{BC}$ and $\mathrm{AlB}_{2}$ respectively (Fig. 4.3). In the weld pool, the following chemical reaction took place:

$$
9 A l(l)+2 B_{4} C(s) \rightarrow 3 A l B_{2}(s)+2 A l_{3} B C(s)
$$


Two intermetallic phases, $\mathrm{AlB}_{2}$ and $\mathrm{Al}_{3} \mathrm{BC}$, are produced at the expense of the $\mathrm{B}_{4} \mathrm{C}$ decomposition which is similar to the interfacial reaction occurring under conventional casting conditions [114] although the peak temperature in the laser weld pool is reported to be much higher (above $980^{\circ} \mathrm{C}$ ) [115-116]. The needle-like phases can promote high stress concentrations at the interface between the matrix and the needles and can be very harmful to the mechanical properties of the material. Thus, the prevention of the needle-like phases is preferable to improve the mechanical properties. During the tests, different energy inputs were then applied by varying the laser power from 2 to $4 \mathrm{~kW}$ and the welding speed from 1 to $2.5 \mathrm{~m} / \mathrm{min}$. However, the needle-like morphology of both intermetallic phases was not changed to a noticeable level. In the laser welding of Al-SiC MMCs, it was reported that the size and the amount of the needle-like reaction product, aluminium carbide, could be modified by varying the laser energy input [117]. Formation of the needle-like phase was constrained in both size and quantity by decreasing the laser energy input. The formation of needle-like phases in $\mathrm{Al}-\mathrm{B}_{4} \mathrm{C}$ MMCs does not seem sensitive to the welding process parameters in conditions tested. Therefore, an alternative method must be found to effectively limit the harmful needle-like phases. 


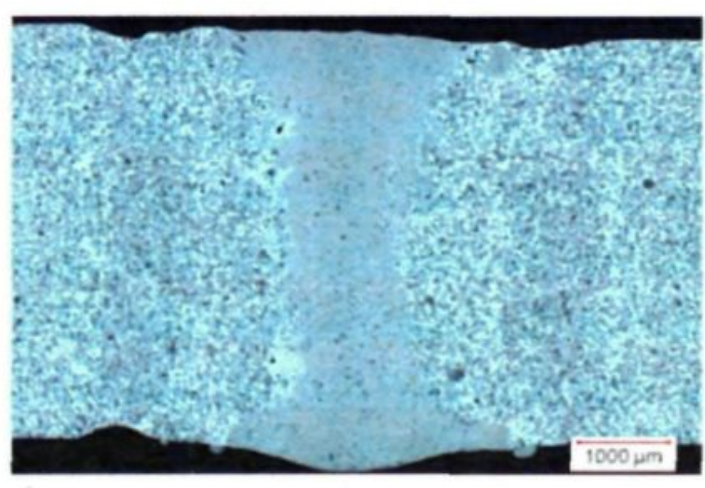

(a)

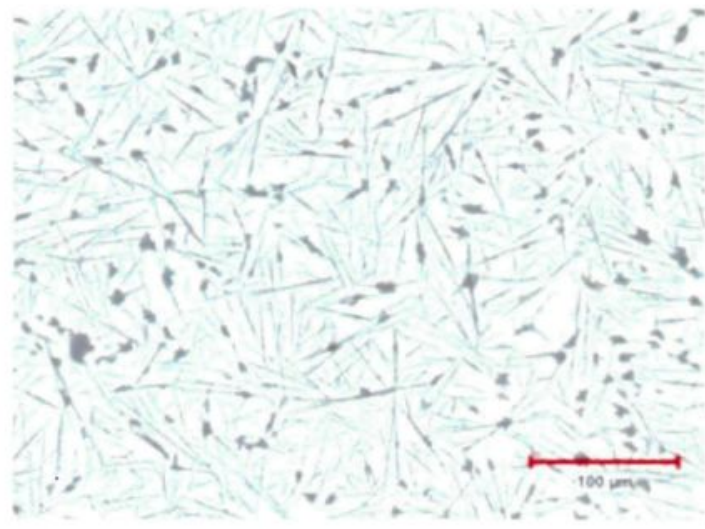

(c)

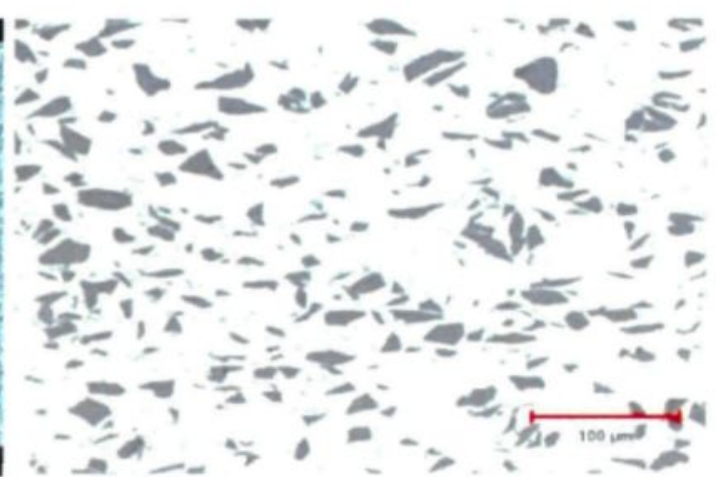

(b)

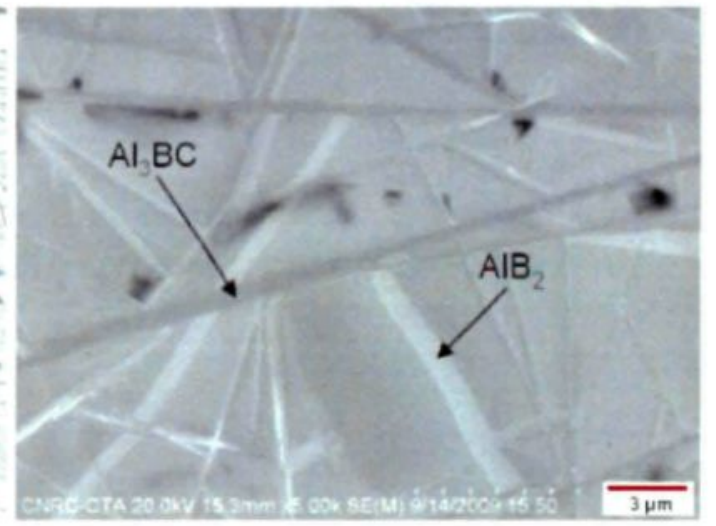

(d)

Fig. 4.1 Images showing typical microstructures of: (a) macro-view of the laser joint (condition B), (b) base material, (c) weld zone under OM, and (d) weld zone under SEM. 

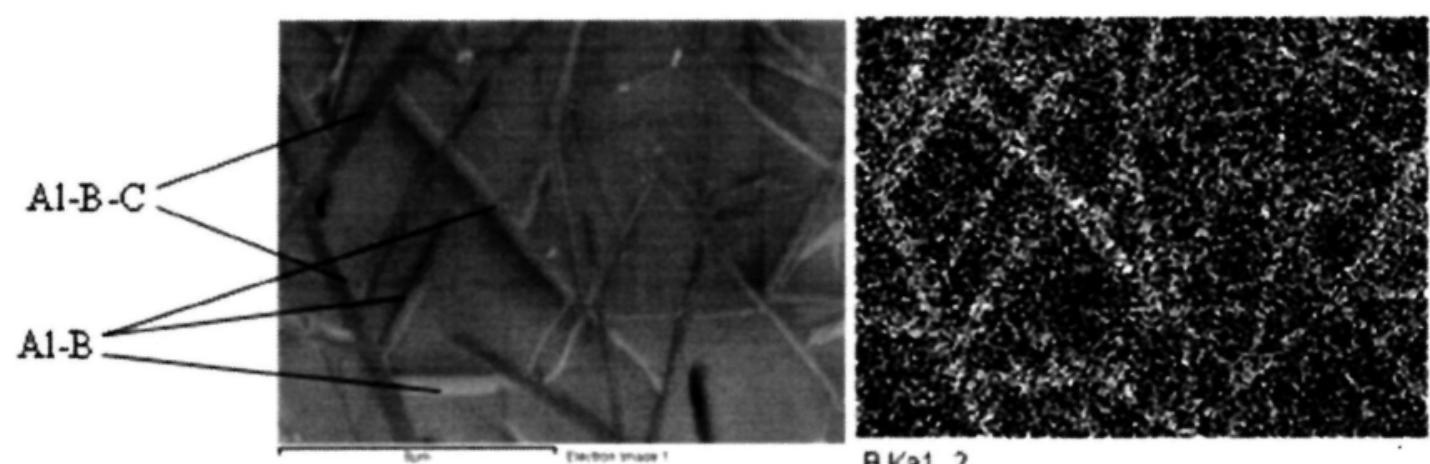

BKa1_2
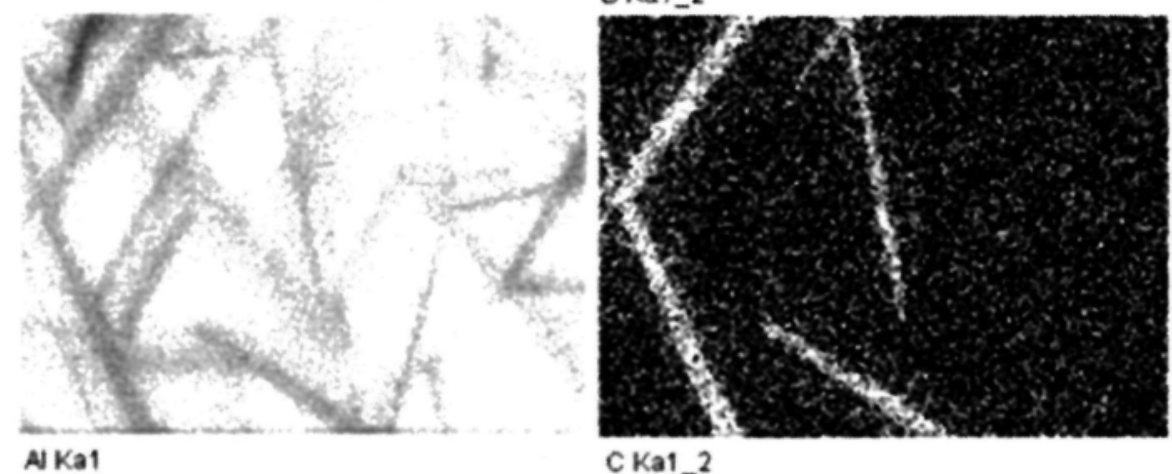

CKa1_2

Fig. 4.2 Element mapping results showing the formation of Al-B-C and Al-B compounds

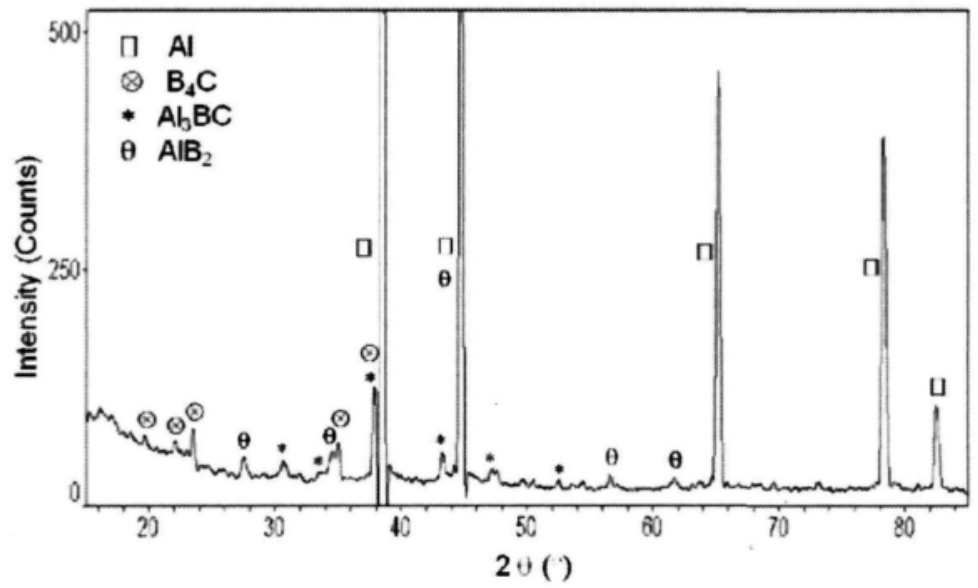

Fig. 4.3 XRD results showing the presence of $\mathrm{AlB}_{2}$ and $\mathrm{Al}_{3} \mathrm{BC}$ in the weld zone of $\mathrm{Al}$ $\mathrm{B}_{\mathbf{4}} \mathrm{C}$ MMCs 


\subsubsection{Selection of Filler Material}

A method to modify the microstructure of the weld zone is to find an effective filler material that has a higher affinity to the specific elements than that of $\mathrm{Al}$. As indicated in [114], addition of Ti filler seems promising to modify the microstructural compounds in the Al- $\mathrm{B}_{4} \mathrm{C}$ system. The standard Gibbs free energy formation of possible carbides and borides in the $\mathrm{Al}-\mathrm{B}_{4} \mathrm{C}$ system are calculated from data [118] and the results are illustrated in Fig. 4.4. An approximate comparison could be made if both carbon and boron atoms could be balanced. Compared to aluminium, it is obvious that titanium has shown a much greater affinity to boron and carbon under standard conditions. It can therefore be expected that the titanium addition would change the microstructure of the $\mathrm{Al}-\mathrm{B}_{4} \mathrm{C}$ MMCs laser weld zone. The ideal amount of $\mathrm{Ti}$ addition should be adequate to capture all the boron and carbon elements while avoiding the formation of other unnecessary intermetallic phases. In the present study, $\mathrm{Ti}$ is used as the filler material aiming to improve the properties of laser joints. 


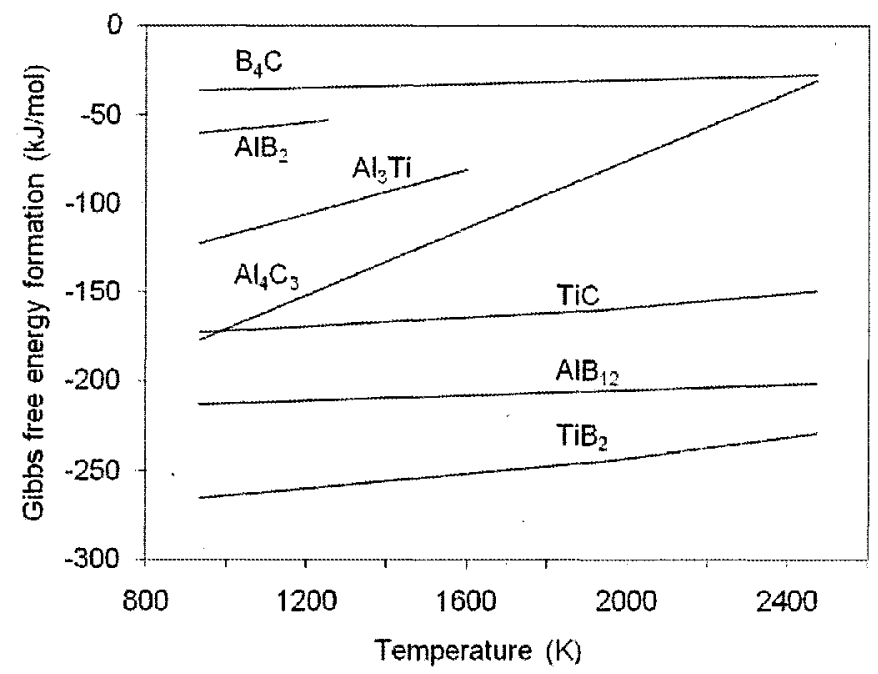

Fig. 4.4 Standard Gibbs free energy of formation of possible reaction products

\subsubsection{Laser welds with Ti filler foil}

Two different amounts of $\mathrm{Ti}$ foil (150 and $300 \mu \mathrm{m}$ thick) were used to evaluate the effect of Ti addition on the laser welding of $\mathrm{Al}-\mathrm{B}_{4} \mathrm{C}$ MMC. Typical macro-views of joints welded under these two conditions are shown in Fig. 4.5 (the brighter parts at the bottom of images are backing plates). Some undercuts on the top surface and a few porosities smaller than $100 \mu \mathrm{m}$ at the boundary of fusion zone can be observed. The formation of porosity is due to the imperfect alignment of $\mathrm{Ti}$ foils between the two welding plates. The dimension of the $\mathrm{Ti}$ foils should be more precisely controlled during preparation. Zones with a dark gray color are due to their higher local Ti concentration. The typical microstructures in the weld zone of the joints can be seen in Fig. 4.6. With a $150 \mu \mathrm{m}$ thick Ti foil addition (one layer of foil), the needle-like phases $\mathrm{AlB}_{2}$ and $\mathrm{Al}_{3} \mathrm{BC}$ have been significantly reduced both 
in size and quantity (Fig. 4.6a). A new fine rod-like phase was found and the EDS analysis indicated that this phase was a Ti-B compound (Fig. 4.7). The XRD results further confirmed the rod-like phase as being $\mathrm{TiB}_{2}$ (Fig. 4.8). As illustrated in Fig. 4.4, the microstructural change in the weld zone could be explained by the fact that $\mathrm{TiB}_{2}$ is the most stable phase in the $\mathrm{Al}-\mathrm{B}_{4} \mathrm{C}-\mathrm{Ti}$ system. In the case of a $300 \mu \mathrm{m}$ thick Ti foil addition (two layers of foil), the needle-like phases completely disappeared in the weld zone as shown in Fig. $4.6 \mathrm{~b}$ and three new phases i.e. one rod-like, one fine particle-like, and a large amount of thick plate-like phases were produced. The SEM mapping identified them as the Ti-B (rod-like), Ti-C (fine particle-like) and Al-Ti (thick plate-like) compounds respectively (Fig. 4.9) and these phases are confirmed to be $\mathrm{TiB}_{2}, \mathrm{TiC}$ and $\mathrm{Al}_{3} \mathrm{Ti}$ by the $\mathrm{XRD}$ analysis shown in Fig. 4.10. As discussed in the previous paragraph, the ideal amount of Ti addition should be sufficient to capture all the boron and carbon elements while avoiding the formation of other intermetallic phases. The ideal Ti addition (uniform distribution) is calculated to be $19 \%$ volume fraction of the fusion zone in the $\mathrm{Al}-16 \% \mathrm{~B}_{4} \mathrm{C}$ composite according to the following chemical reaction:

$$
3 T i(l)+B_{4} C(s) \rightarrow 2 T i B_{2}(s)+T i C(s)
$$

As the average width of the weld zone in this study is around $1 \mathrm{~mm}$, the additions of 150 and $300 \mu \mathrm{m} \mathrm{Ti}$ foils correspond approximately to $15 \%$ and $30 \% \mathrm{Ti}$ (volume fraction) respectively. Obviously, the optimum Ti foil thickness should be between 150 and $300 \mu \mathrm{m}$ for eliminating needle-like $\mathrm{AlB}_{2}$ and $\mathrm{Al}_{3} \mathrm{BC}$ phases while avoiding large $\mathrm{Al}_{3} \mathrm{Ti}$ intermetallics. 


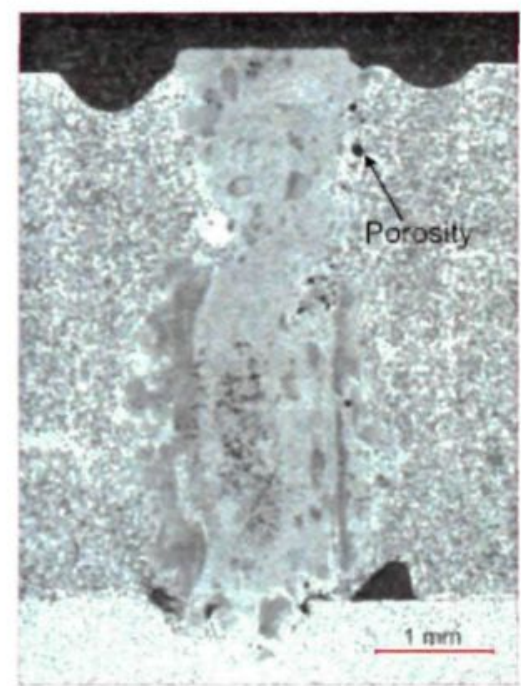

(a)

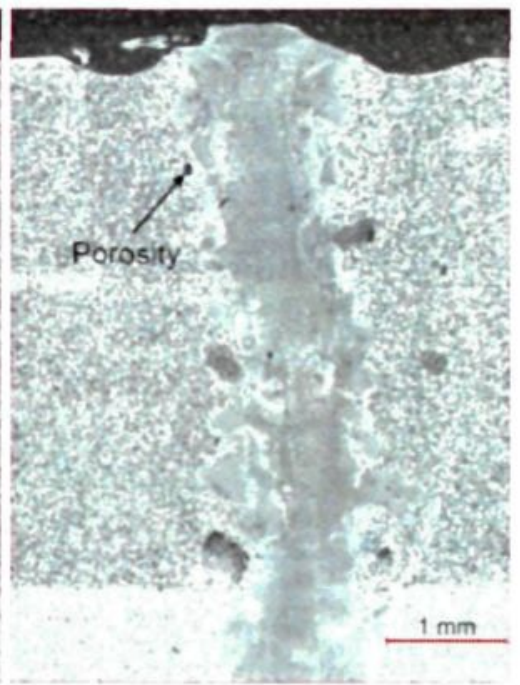

(b)

Fig. 4.5 Optical images showing typical macro-views of laser joints made with (a) 150 $\mu \mathrm{m}$ and (b) $300 \mu \mathrm{m}$ Ti foils

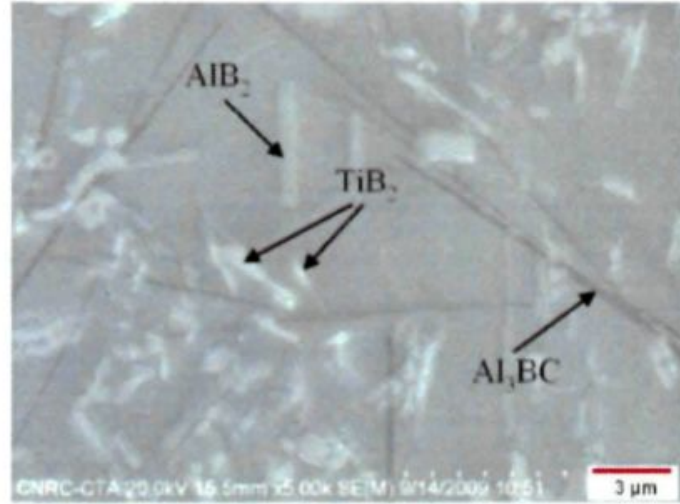

(a)

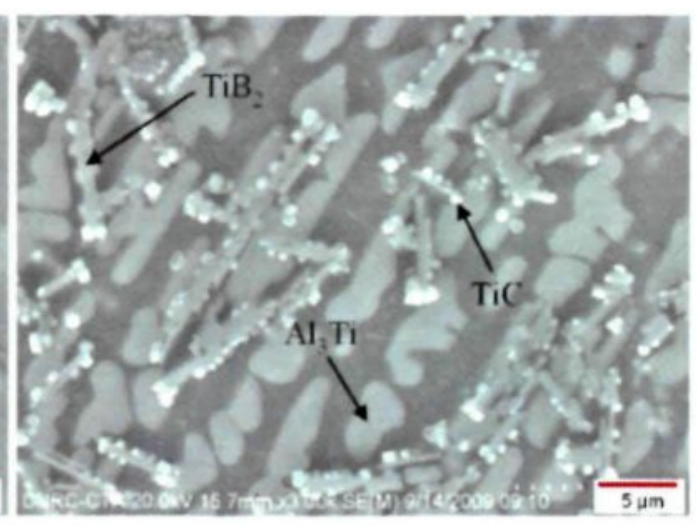

(b)

Fig. 4.6 SEM micrographs showing the typical microstructure of the weld zone with (a) $150 \mu \mathrm{m} \mathrm{Ti}$ and (b) $300 \mu \mathrm{m} \mathrm{Ti}$ 

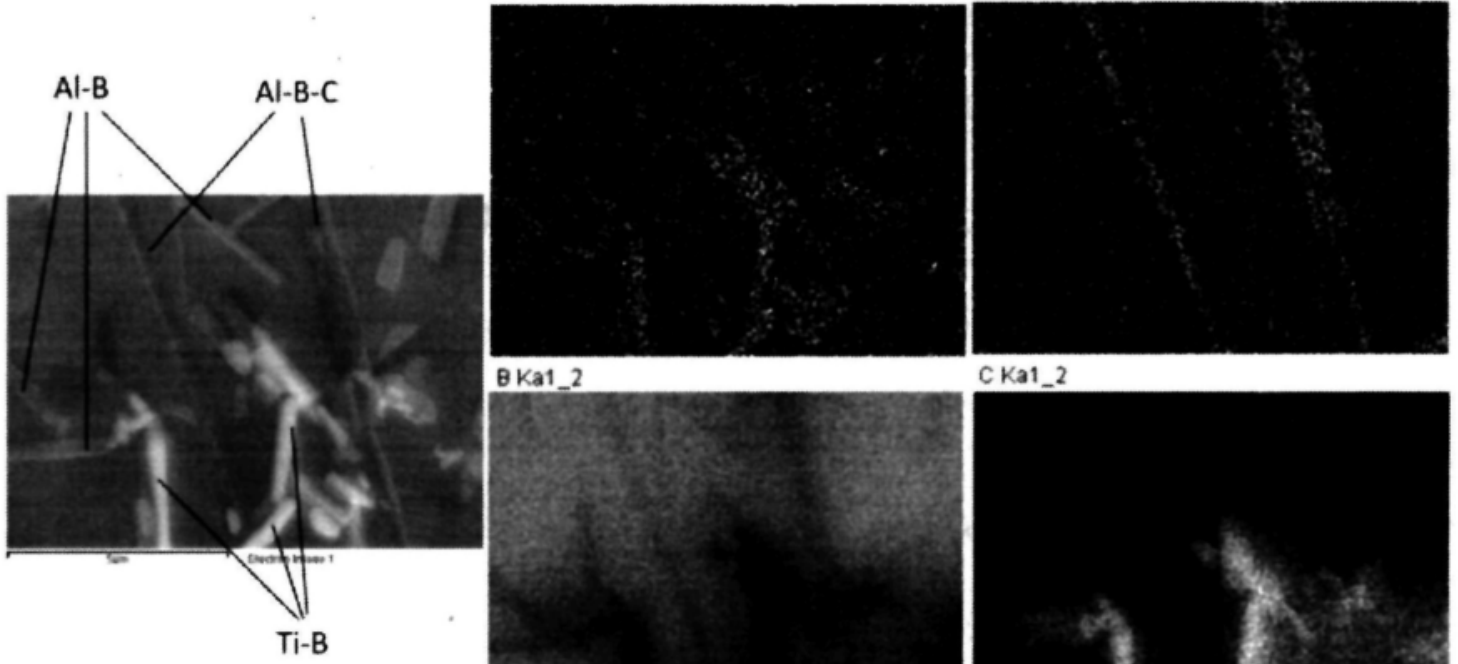

BKa1_2

CKa1_2
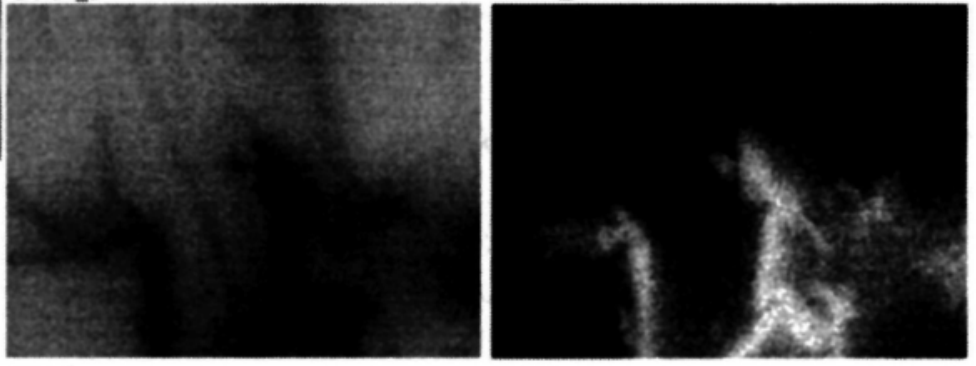

N Ka1

nKa1

Fig. 4.7 Element mapping results showing the formation of Al-B, Al-B-C and Ti-B compounds

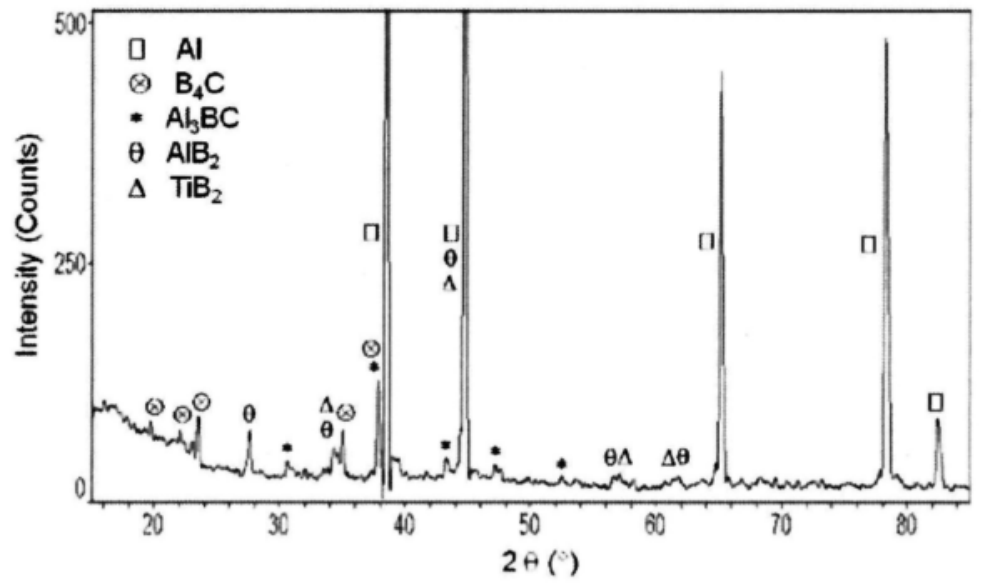

Fig. 4.8 XRD results showing the presence of $\mathrm{AlB}_{2}, \mathrm{Al}_{3} \mathrm{BC}$ and $\mathrm{TiB}_{2}$ in the weld zone of joints made with $150 \mu \mathrm{m}$ Ti foil 


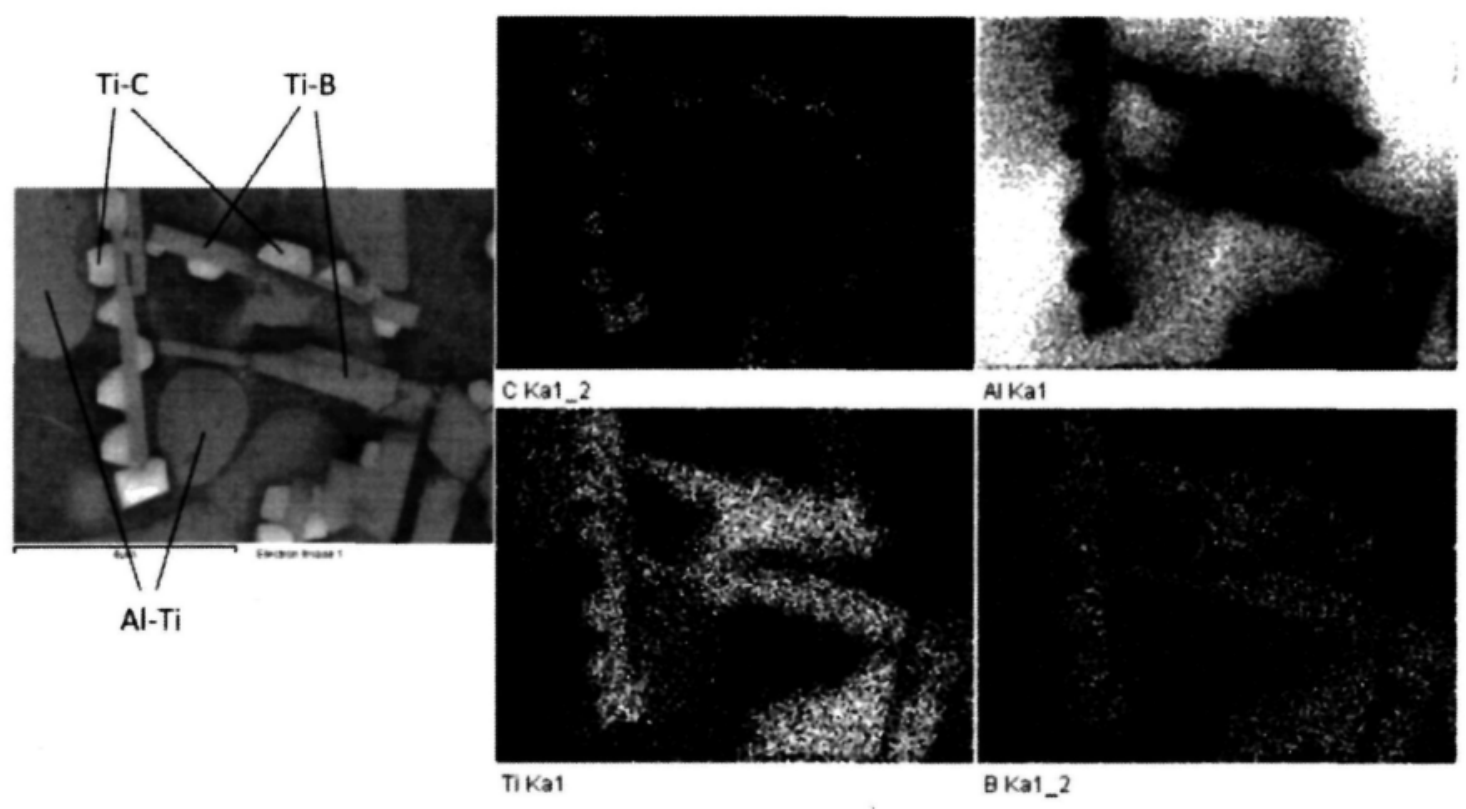

Fig. 4.9 Element mapping results showing the formation of Ti-B, Ti-C and Al-Ti compounds

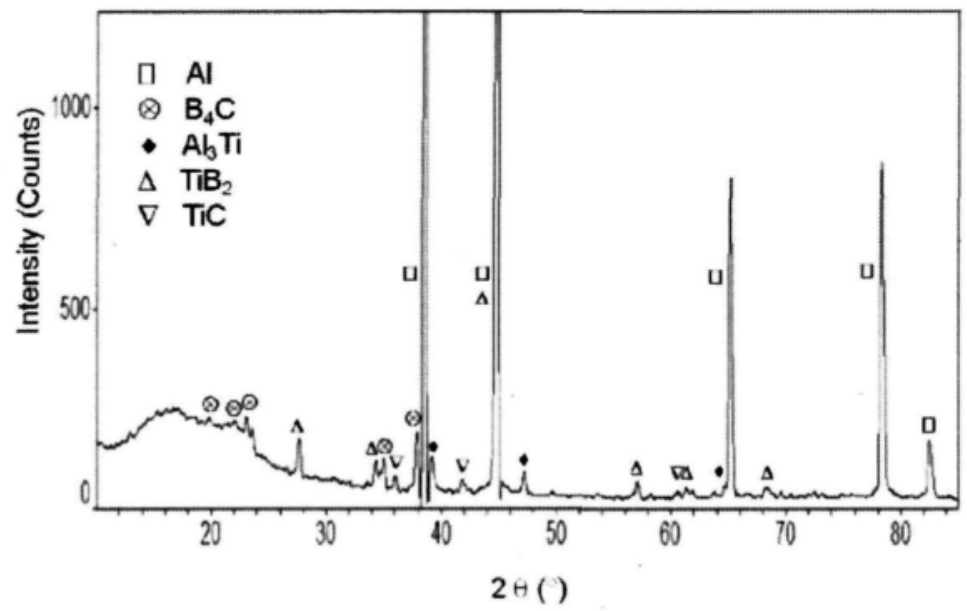

Fig. 4.10 XRD results showing the presence of $\mathrm{TiB}_{2}, \mathrm{TiC}$ and $\mathrm{Al}_{3} \mathrm{Ti}$ in the weld zone of joints made with $300 \mu \mathrm{m}$ Ti foil 


\subsubsection{Laser welds with Ti filler wire}

Four wire feeding rates (W1 - W4 listed in Table 4.1), corresponding to $9 \%, 13 \%, 15 \%$ and $19 \% \mathrm{Ti}$ (volume fraction) respectively were tested. It was observed, however, that microstructures of the laser joints in all four conditions were not as uniform as for the joints made with the Ti filler foils. A typical macro-view of the laser joint is shown in Fig. 4.11 and the Ti segregation in the weld zone is very severe. Various microstructures with insufficient, adequate or excessive Ti concentrations are simultaneously found in the same weld for all four feeding conditions. Figs. 4.12a and $\mathrm{b}$ display typical microstructures with insufficient $\mathrm{Ti}$ and show large need-like $\mathrm{AlB}_{2}, \mathrm{Al}_{3} \mathrm{BC}$ and $\mathrm{Al}_{4} \mathrm{C}_{3}$ phases. Fig. $4.12 \mathrm{c}$ shows the zone consisting only of titanium boride and titanium carbide $\left(\mathrm{TiB}_{2}\right.$ and $\left.\mathrm{TiC}\right)$ that corresponds to the adequate Ti content, while Fig. 4.12d represents an excessive Ti zone with a large amount of $\mathrm{Al}_{3} \mathrm{Ti}$ intermetallic phases. The microstructural inhomogeneity of the joints is due to the non-uniform intermixing in liquid state before the bulk solidification of the welding pool. Unlike the Ti foil that was uniformly placed along the joint before welding, the Ti wire first had to be melted and then redistributed through diffusion and convection within the entire weld pool. Due to the narrow weld pool and the high cooling rate, it appears very difficult to reach a uniform $\mathrm{Ti}$ distribution in the weld zone. The Ti segregation, and hence the inhomogenous microstructure, would undoubtedly have a negative effect on the mechanical properties of the joints. 


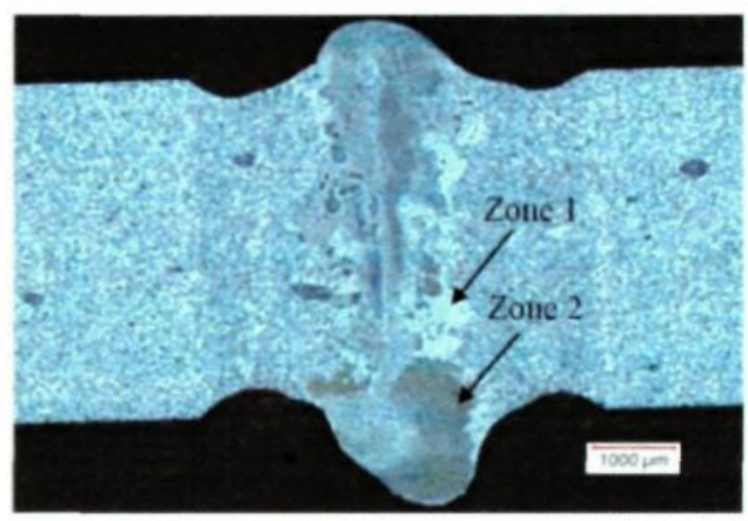

Fig. 4.11 Optical images showing typical macro-view of laser joints made with Ti filler (zone 1with light color: insufficient $\mathrm{Ti}$, zone 2 with dark gray color: excessive $\mathrm{Ti}$ )

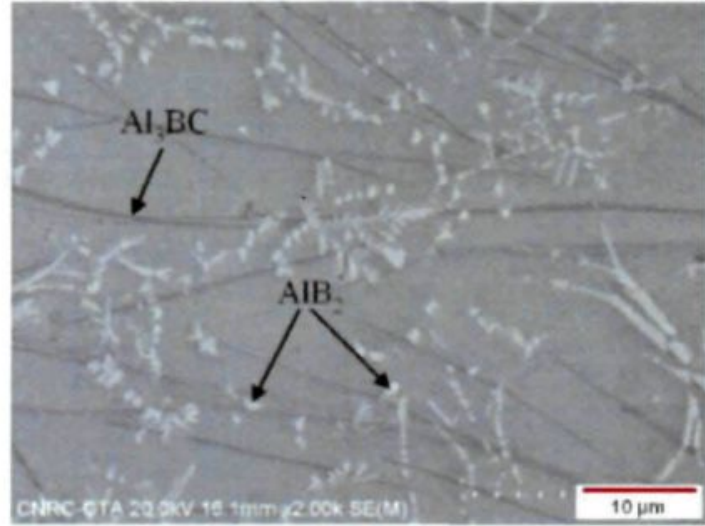

(a)

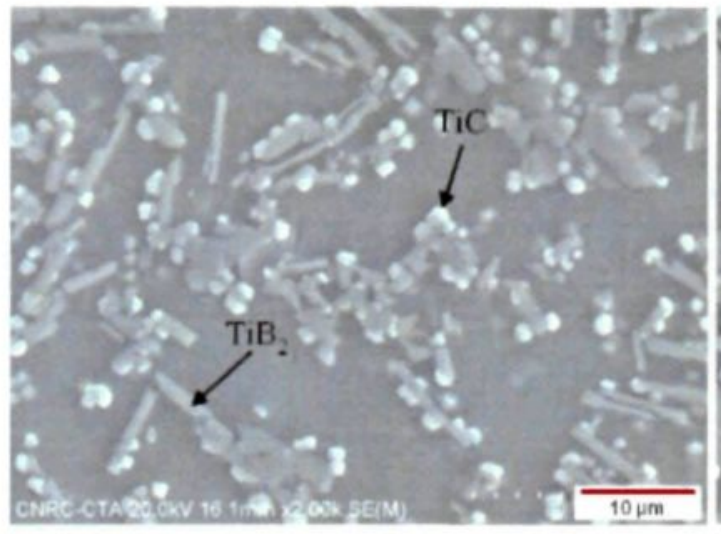

(c)

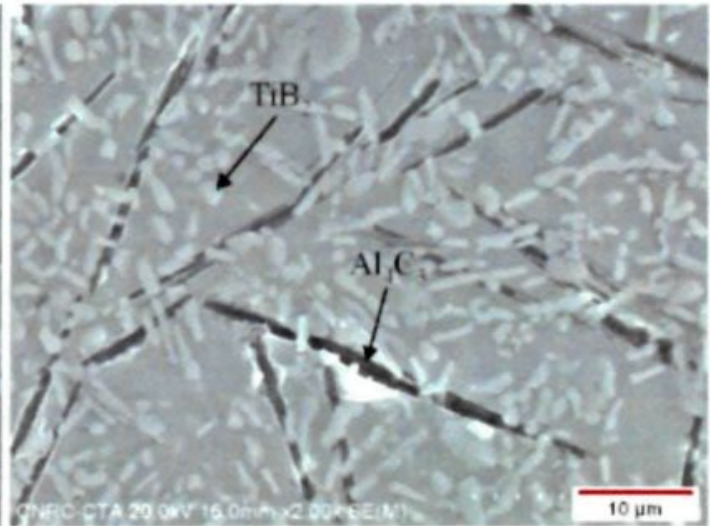

(b)

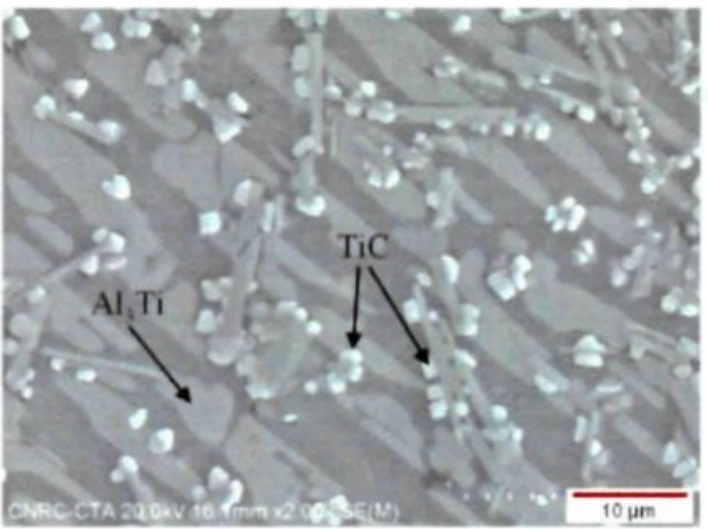

(d)

Fig. 4.12 SEM micrographs showing typical microstructures with various local Ti concentrations, a) and b) insufficient $\mathrm{Ti}$ zones, c) adequate $\mathrm{Ti}$ zone and d) excessive $\mathrm{Ti}$ zone 
It is interesting to notice that there are zones with an optimum Ti amount consisting of only titanium boride and titanium carbide (Fig. 4.12c). Further improvement of the microstructure and hence the mechanical properties would be possible if the problem of the Ti segregation could be resolved in the weld process.

\subsection{Mechanical Properties}

\subsubsection{Microhardness}

Fig. 4.13 shows the Vickers microhardness profiles of the welds produced without filler and with $\mathrm{Ti}$ filler foils. All these welds demonstrated a sharp increase of microhardness in the fusion zone. This is due to a large amount of reaction-induced intermetallic phases formed in the fusion zone. In addition, a slight decrease of microhardness could be observed in the HAZ owing to the annealing effect of the laser heat input. A comparison between these curves reveals that the weld made with one layer Ti foil presents a relatively small hardness increase in the fusion zone compared to the base material, while the welds made with other two conditions exhibit large microhardness increases. This is because the intermetallics in the weld using one layer Ti foil were finer and less brittle compared to that in the other two conditions. 

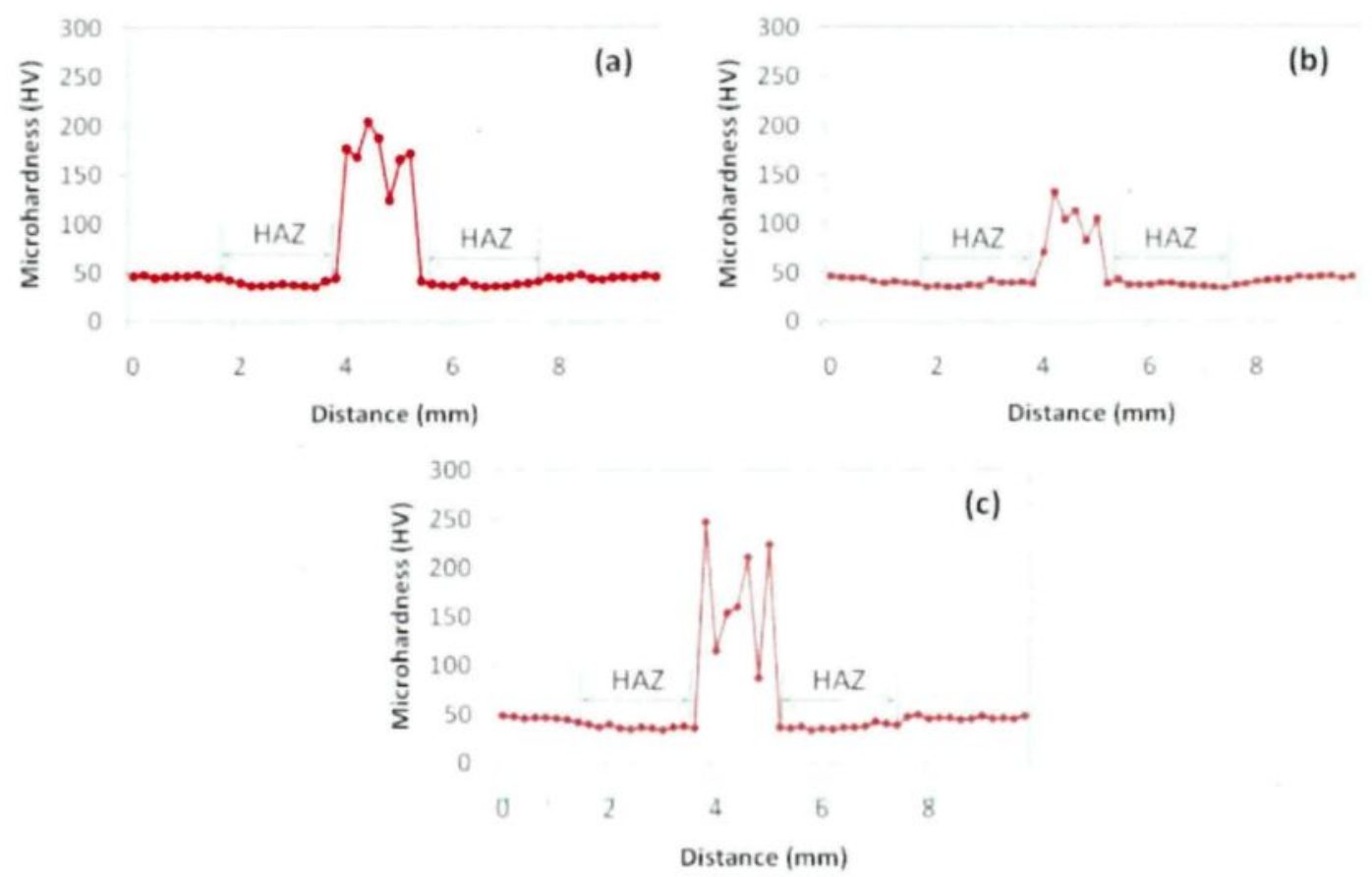

Fig. 4.13 Vickers microhardness profiles across the laser weld: (a) without filler, (b) with $150 \mu \mathrm{m}$ Ti foil and (c) with $300 \mu \mathrm{m}$ Ti foil

\subsubsection{Tensile Results}

The tensile results of the base material and the laser welded joints of $\mathrm{Al}-\mathrm{B}_{4} \mathrm{C}$ MMCs at different conditions are presented in Table 4.2 and are illustrated in Fig. 4.14. All the welded joints failed in the fusion zone which had the highest microhardness (Fig. 4.13) in the welds. This is explained by the presence of a large number of brittle intermetallics and by the stress concentration effect which was rather intense in the fusion zone. For laser joints without $\mathrm{Ti}$ addition, a joint efficiency (UTS) of $63 \%$ was obtained. The low value of the tensile properties was due to the large amount of needle-like phases formed in the joint 
during laser welding. With $150 \mu \mathrm{m}$ Ti foil addition, the joint efficiency (UTS) of the joints increased to $75 \%$. This is attributed to the reduced amount and size of the needle-like

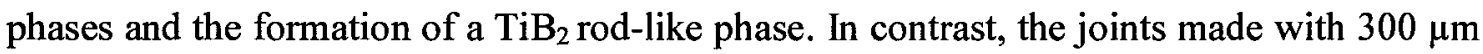
Ti foil showed a decrease of joint efficiency compared with the one obtained for welds produced with a $150 \mu \mathrm{m}$ Ti foil addition. According to the microstructural observation, the formation of a large amount of plate-like $\mathrm{Al}_{3} \mathrm{Ti}$ intermetallics may account for the decline of mechanical properties. On the other hand, the Ti addition in the form of filler wire did not show remarkable improvement of the tensile properties and the tensile strengths were almost the same as the joints without Ti addition. The conditions W2 and W4 exhibited a slight enhancement of joint efficiencies (66-68\% compared to $63 \%$ without Ti). Although the amounts of $\mathrm{Ti}$ addition with filler wire were varied from 9 to $19 \%$ by adjusting the wire feeding rates, the relative insensitivity of the mechanical properties with the $\mathrm{Ti}$ filler wire was mainly attributed to the $\mathrm{Ti}$ segregation and resultant microstructural inhomogeneity and defects.

In a practical point of view, the addition of Ti foil along the joint is a simple method that produced a uniform $\mathrm{Ti}$ distribution in the entire welding zone. Selection of an appropriate foil thickness corresponding to the optimum Ti concentration of the joint would further improve the joint efficiency as long as uniform intermixing is obtained in the welding pool. It should also be mentioned that in all the above weld conditions, elongation of the laser joints remained relatively low (less than $1 \%$ ) compared to the base composite material $(3,8 \%)$. This is mainly because of the formation of brittle intermetallics during laser welding. In addition, the welding defects such as undercut and porosity may also play 
an important role in the degradation of the ductility. It should be pointed out that the composition of $\mathrm{B}_{4} \mathrm{C}$ under all conditions does not affect the capability of neutron absorption of the MMC because the amount of ${ }^{10} \mathrm{~B}$ isotope remains unchanged no matter what compound it forms.

Table 4.2 Tensile results of the base material and laser welded joints of $\mathrm{Al}-\mathrm{B}_{4} \mathrm{C} \mathrm{MMCs}$ ( \pm corresponding standard deviation)

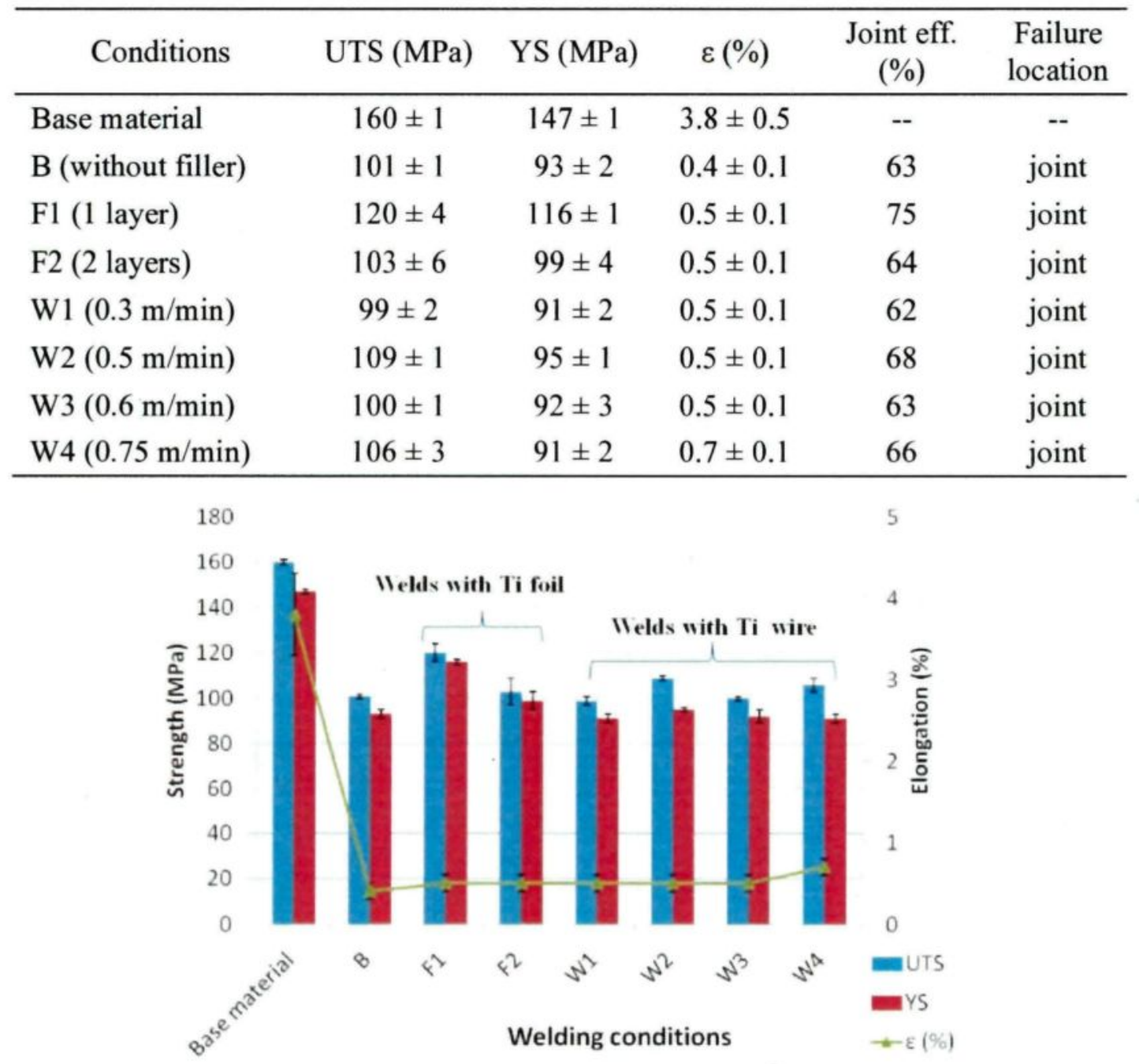

Fig. 4.14 Tensile results of the base material and laser welded joints for $\mathrm{Al}-\mathrm{B}_{4} \mathrm{C}$ MMCs 


\subsubsection{Fractography}

The fracture surfaces of the base material and the laser joints of the AA1100-16 vol.\% $\mathrm{B}_{4} \mathrm{C}$ MMCs were examined by SEM to study the fracture mechanisms involved during tensile testing. For laser joints with $\mathrm{Ti}$ addition, only those with $\mathrm{Ti}$ foils were selected for fractography as the maximum tensile strength was obtained with one layer Ti foil. The typical micrographs of the fracture surfaces are shown in Fig. 4.15. In the base material (Fig. 4.15a), large interfacial voids resulting from decohesion between $\mathrm{B}_{4} \mathrm{C}$ particles and the matrix, and some ductile dimples in the matrix were the main characteristics of the fracture. In joints without the $\mathrm{Ti}$ addition (Fig. 4.15b), the fracture surface was characterized as a brittle fracture with some large cleavage planes. As previously mentioned, the addition of $150 \mu \mathrm{m}$ Ti foil remarkably reduced the size and quantity of the needle-like phases. Consequently, the fracture surfaces of joints made under this condition (Fig. 4.15c) showed a smaller scale of cleavage planes than that of joints without the filler (Fig. 4.15b) and a higher tensile strength was recorded when $150 \mu \mathrm{m}$ of Ti foil was added. However, the fracture surfaces of joints made with $300 \mu \mathrm{m}$ Ti foil (Fig. 4.15d) showed coarser cleavage planes when the microstructure of the joints contained a great number of plate-like $\mathrm{Al}_{3} \mathrm{Ti}$ intermetallics which decreased the tensile strength of the joints. 


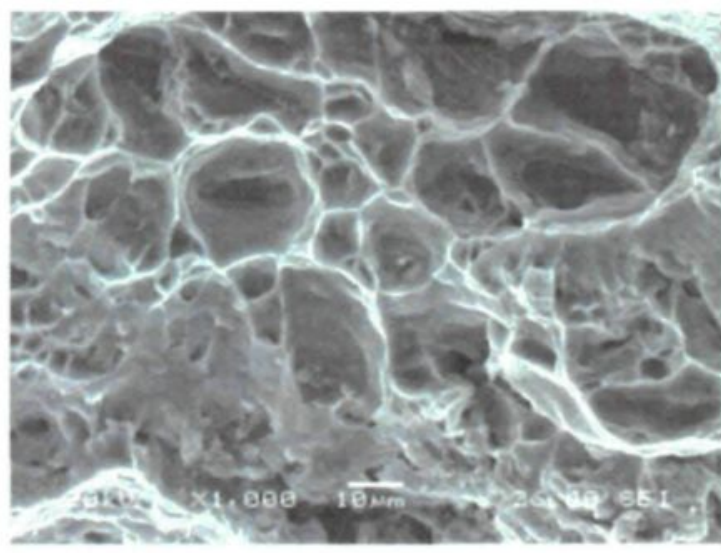

(a)

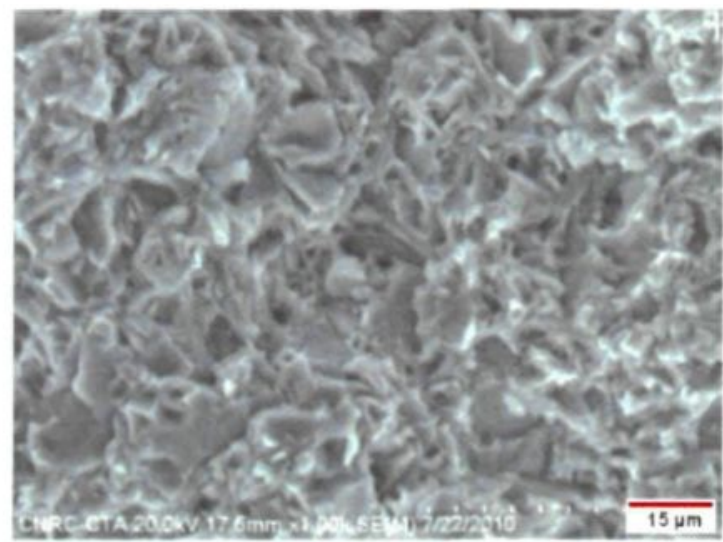

(c)

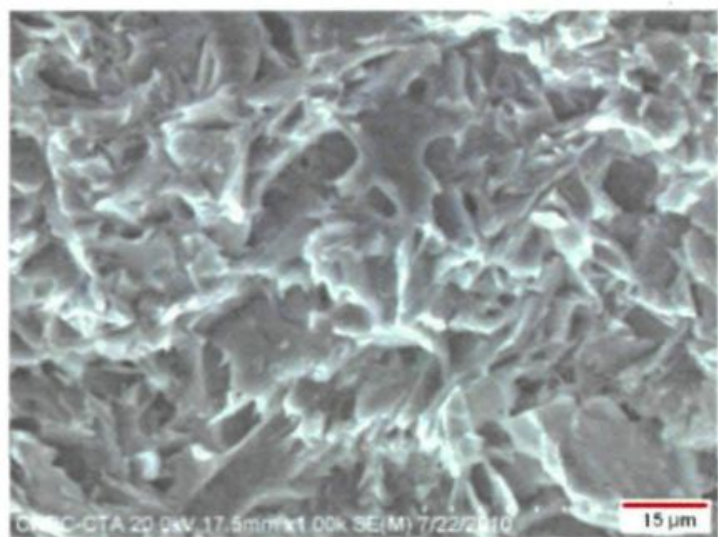

(b)

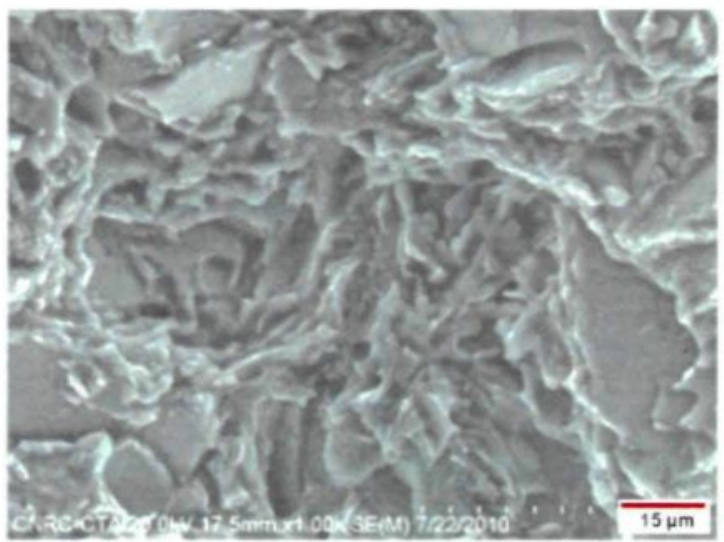

(d)

Fig. 4.15 Tensile fracture surface of the (a) as-rolled base material and (b) laser joints without filler, (c) with $150 \mu \mathrm{m}$ Ti foil, and (d) with $300 \mu \mathrm{m}$ Ti foil

It is worth mentioning that in all laser joints produced in the three conditions, the fracture surfaces were characterized as brittle although some differences could be seen amongst the corresponding surfaces. This explains why the tensile properties of the laser joints, particularly the elongation, decreased in comparison to that of the base material. 


\subsection{Summary and Conclusions}

1. A joint efficiency (UTS) of $63 \%$ is obtained for the laser welding of $\mathrm{AA} 1100-\mathrm{B}_{4} \mathrm{C}$ MMCs without filler material. In the weld zone, most $\mathrm{B}_{4} \mathrm{C}$ particles are decomposed into needle-like $\mathrm{AlB}_{2}$ and $\mathrm{Al}_{3} \mathrm{BC}$ phases.

2. The joint efficiency of the laser welded joints can be increased to $75 \%$ with the addition of $150 \mu \mathrm{m}$ Ti foil. An appropriate addition of Ti concentration may further improve the mechanical properties of the joints. With $\mathrm{Ti}$ addition, $\mathrm{TiB}_{2}, \mathrm{TiC}$ and $\mathrm{Al}_{3} \mathrm{Ti}$ phases are formed in the laser weld zone instead of needle-like $\mathrm{AlB}_{2}$ and $\mathrm{Al}_{3} \mathrm{BC}$ phases.

3. Addition of the $\mathrm{Ti}$ in form of filler wire did not show significant improvement of the tensile properties due to the $\mathrm{Ti}$ segregation and microstructural inhomogeneity in the laser weld zone.

4. The ductility of all laser joints remains lower than $1 \%$ even with Ti addition. 


\section{Chapter V}

Friction stir welding of $\mathrm{AA1100-B_{4 }}$ C Metal Matrix

Composites 


\section{Chapter V Friction stir welding of $\mathrm{AA1100}_{-} \mathrm{B}_{4} \mathrm{C}$ Metal}

\section{Matrix Composites}

The feasibility of friction stir welding for joining AA 1100 based metal matrix composites reinforced with $\mathrm{B}_{4} \mathrm{C}$ particulate was studied for 16 and $30 \% \mathrm{~B}_{4} \mathrm{C}$ volume concentrations. The wear behavior of FSW tools made of WC-Co and H13 steel were compared. Most of the joints were produced using the WC-Co tool except otherwise specified. For the $16 \% \mathrm{~B}_{4} \mathrm{C}$ composite, the material received from the manufacturer is in the as-rolled condition. Some plates of the $16 \% \mathrm{~B}_{4} \mathrm{C}$ composite were annealed $\left(400{ }^{\circ} \mathrm{C}\right.$ for $1 \mathrm{~h})$ before FSW to study the effect of the initial temper of the materials on the mechanical properties of the joints. For the $30 \% \mathrm{~B}_{4} \mathrm{C}$ composite, only the annealed temper was used. The welding parameters were selected to avoid macro-defects in the weld and excessive flash on the surface, as listed in Table 5.1. It was found that the welding tool made of WC showed much better durability than the steel tool for which the tool wear occurred mainly on the shoulder edges. For both composites, friction stir welding has a significant influence on the particle size distribution and the matrix grain size. For the $16 \%$ composite, the average particle size decreases after welding by $\sim 20 \%$ and the grain size from 15 to $5 \mu \mathrm{m}$

The major part of this chapter is published in: J.F. Guo, P. Gougeon, X.-G. Chen, "Characterization of Welded Joints Produced by Friction Stir Welding in AA1100-B $\mathrm{C}_{4}$ Metal Matrix Composites", Science and Technology of Welding \& Joining, 2012, Vol. 17, No.2, pp. 85-91. 
as measured in the weld nugget. Tensile testing of welded joints showed up to $100 \%$ joint efficiency for both annealed $\mathrm{AA} \quad 1100-16 \% \mathrm{~B}_{4} \mathrm{C}$ and $\mathrm{AA} \quad 1100-30 \% \mathrm{~B}_{4} \mathrm{C}$ composite materials. However, the ultimate tensile strength values of all the studied composites are similar at $\sim 130 \mathrm{MPa}$, and the weld ductility is higher for the annealed materials. Furthermore, it was observed that varying the welding speed between 100 and $275 \mathrm{~mm}$ $\min ^{-1}$ does not influence the tensile properties and the particle size distribution in the nugget.

Table 5.1 FSW welding parameters

\begin{tabular}{ccccc}
\hline Code & $\begin{array}{c}\mathrm{B}_{4} \mathrm{C}(\mathrm{vol} . \\
\text { fraction) }\end{array}$ & Temper & $\begin{array}{c}\text { Rotation } \\
\text { speed (rpm) }\end{array}$ & $\begin{array}{c}\text { Welding speed } \\
(\mathrm{mm} / \mathrm{min})\end{array}$ \\
\hline LR1 & $16 \%$ & As-rolled & 1500 & 100 \\
LR2 & $16 \%$ & As-rolled & 1500 & 200 \\
LR3 & $16 \%$ & As-rolled & 1500 & 275 \\
LA1 & $16 \%$ & Annealed & 1500 & 100 \\
LA2 & $16 \%$ & Annealed & 1500 & 200 \\
LA3 & $16 \%$ & Annealed & 1500 & 275 \\
HA1 & $30 \%$ & Annealed & 1500 & 100 \\
HA2 & $30 \%$ & Annealed & 1500 & 200 \\
HA3 & $30 \%$ & Annealed & 1500 & 275 \\
S1 (steel tool) & $16 \%$ & Annealed & 1500 & 100 \\
S2 (steel tool) & $16 \%$ & Annealed & 1500 & 275 \\
\hline
\end{tabular}

\subsection{Tool wear}

The tool wear of conical unthreaded tools made of $\mathrm{H} 13$ steel and WC-15 wt.\% Co were compared. As can be seen in Fig. 5.1a to c, the tool made of $\mathrm{H} 13$ tool steel has been worn out in one meter FSW of Al-16\%vol. ${ }_{4} \mathrm{C}$ MMC. The tool wear occurs mainly on the tool shoulder edge as the concave shape has become completely convex. The tool profiles 
measured by the optical profilometer are provided in Fig. 5.2a, which confirms this wear behaviour. The preferential wear on the shoulder edge can be explained by two reasons. First, the materials under the outer part of the tool have lower temperature and thus higher viscosity [119] which makes the friction experienced by the outer part of the tool much higher. In addition, the outer part of the tool passed longer distance than the inner part did. In contrast, the tool made of WC-Co displayed excellent durability (Fig. 5.1d-f) in FSW of Al-16\%vol. $\mathrm{B}_{4} \mathrm{C}$ MMC. Only a limited wear can be observed on both of the tool shoulder and pin after six meters' FSW (Fig. 5.2b). This is promising as the WC-Co tool with unthreaded geometry can significantly reduce the tool wear during FSW. It was reported that an appreciable tool wear was observed in the FSW of a Al-30 vol.\% SiC MMC by using a threaded tool made of WC-Co material [120]. The average wear rate was calculated according to the mass loss measured by using a high precision balance. As shown in Table 5.2 , the results demonstrate that the WC-Co tool is significantly more durable than the steel tool. The results obtained on the wear tests could be very useful for the future tool design and material selection. For instance, composite tools with different combination of pin and shoulder materials may be an attractive option for prolonging tool life and reducing tool cost.

The presence of the tool wear debris in the welded microstructure was examined in the nugget zones for both tool materials. Most debris was concentrated at the top part of the nugget. Fig. 5.3 shows the typical micrographs taken at the top of nugget zones. Numerous particles of steel debris were observed close to the top of the joint (less than $0.5 \mathrm{~mm}$ from the top) when welded by the steel tool (Fig. 5.3a). On the contrary, only few and tiny WC- 
Co debris could be observed at the corresponding area of the joint made by the WC-Co tool (Fig. 5.3b). The fact that the debris was mainly found in the top part of the nugget corresponds well to the preferential wear on the shoulder edge, especially in the case of using steel tool. In the presence of numerous hard ceramic particles, the tool wear through abrasion is considered as the main wear mechanism in the $\mathrm{FSW}$ of $\mathrm{Al}-\mathrm{B}_{4} \mathrm{C}$ composites.

It should be noted that self-optimization of tool geometry was not observed on either tool. Little tool wear can hardly be noticed on the pins of both tools. This can be attributed to the absence of threads on the tool pins and thus much less vertical driving force was generated to create translational turbulence. According to R.A. Prado et al. [21], the resulting flow of ceramic particles from the turbulence would erode the threads. The tool became self-optimized when there is no threads left.

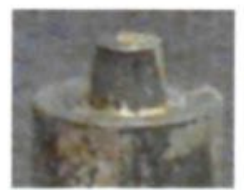

a) Initial (steel)

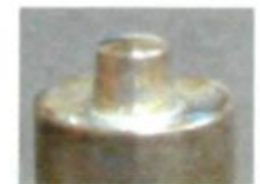

d) Initial (WC-Co)

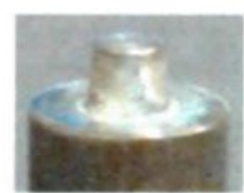

b) After $0.45 \mathrm{~m}$ (steel)

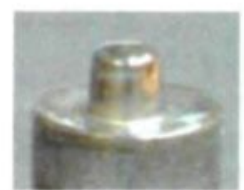

e) After $3.8 \mathrm{~m}$ (WC-Co)

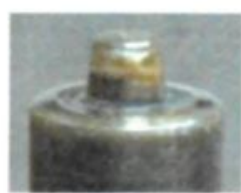

(c) After $1 \mathrm{~m}$ (steel)

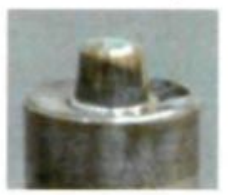

(f) After 6 m (WC-Co)

Fig. 5.1 Shape changes of the FSW tools, $(\mathrm{a} \sim \mathrm{c}) \mathrm{H13}$ steel and $(\mathrm{d} \sim \mathrm{f}) \mathrm{WC}-\mathrm{Co}$ 


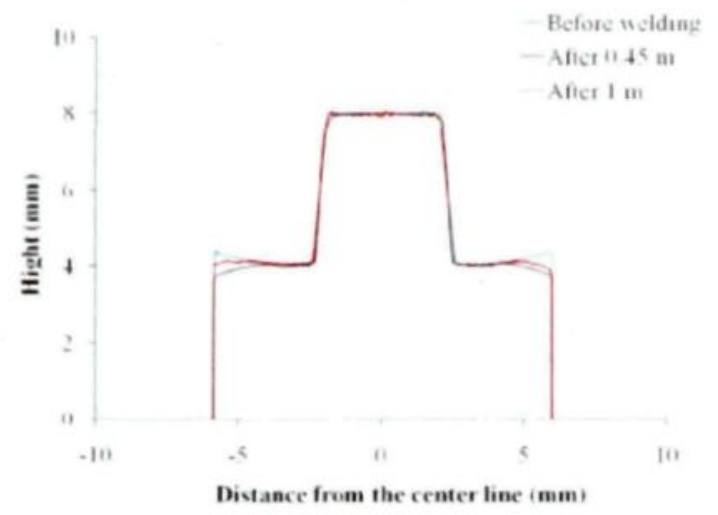

(a)

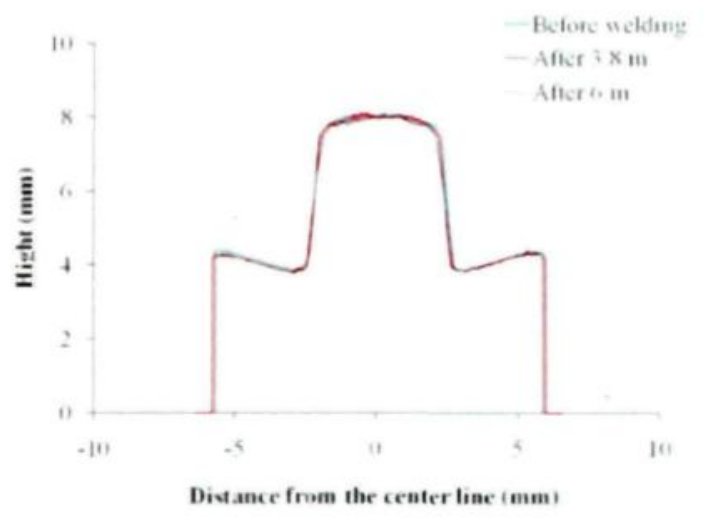

(b)

Fig. 5.2 Tool shape measurement of (a) H13 steel tool and (b) WC-Co tool

Table 5.2 Tool wear rate comparison for both tool materials

\begin{tabular}{|c|c|c|c|c|c|c|}
\hline \multirow{2}{*}{$\begin{array}{l}\text { Wear } \\
\text { properties }\end{array}$} & \multicolumn{3}{|c|}{ WC tool } & \multicolumn{3}{|c|}{ Steel tool (H13) } \\
\hline & Initial & After $3.8 \mathrm{~m}$ & After $6 \mathrm{~m}$ & Initial & After $0.45 \mathrm{~m}$ & After $1 \mathrm{~mm}$ \\
\hline $\operatorname{Mass}(\mathrm{g})$ & $39.91 \pm 0.01$ & $39.87 \pm 0.01$ & $39.84 \pm 0.01$ & $21.46 \pm 0.01$ & $21.38 \pm 0.01$ & $21.31 \pm 0.01$ \\
\hline $\begin{array}{l}\text { Volume } \\
\left(\mathrm{mm}^{3}\right)\end{array}$ & $2526.0 \pm 0.1$ & $2523.6 \pm 0.1$ & $2521.4 \pm 0.1$ & $2750.9 \pm 0.1$ & $2740.7 \pm 0.1$ & $2731.7 \pm 0.1$ \\
\hline $\begin{array}{l}\text { Tool wear } \\
\text { rate }\left(\mathrm{mm}^{3} / \mathrm{m}\right)\end{array}$ & $\mathrm{N} / \mathrm{A}$ & 0.632 & 0.768 & N/A & 22.7 & 19.23 \\
\hline
\end{tabular}




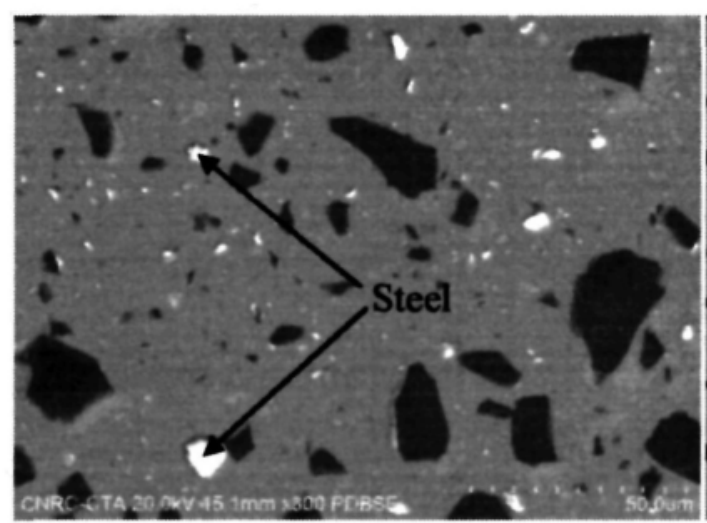

(a)

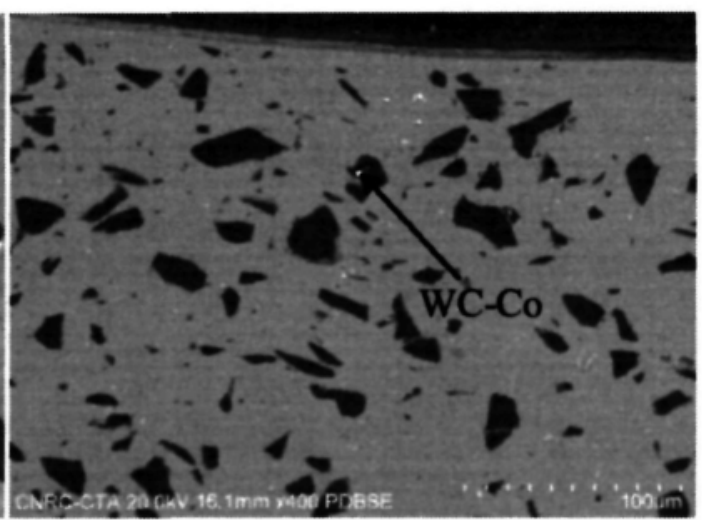

(b)

Fig. 5.3 Typical micrographs showing (a) the steel debris, and (b) WC-Co debris at the top edge of the weld cross-sections

\subsection{Microstructures}

All FSW joints of AA1 $100-\mathrm{B}_{4} \mathrm{C}$ materials were inspected from the bottom side by ultrasound in an immersion bath prior to further analyses to ensure they were sound and free of macro defects. The ultrasonic inspections were performed with a focused shape transducer operating at $30 \mathrm{MHz}$. The inspection results for a defect-free weld and for a weld with discontinuous defects are presented in Fig. 5.4 (a) and (b), respectively. It should be noted that any non-uniformity in the inspected materials (larger than $\sim 120 \mu \mathrm{m}$ ) will cause a change in the ultrasonic wave propagation and generate a different color from the blue background color. Therefore, some welding defects and particle clusters in the AA1100- $\mathrm{B}_{4} \mathrm{C}$ composite materials could behave in a similar way during ultrasonic inspection. Careful analysis of discontinuities has to be made with the inspection software 
to distinguish between welding defects and particle clusters. According to the analysis, most of the spots (change of color) outside of the welded zone are due to particle clusters. It is remarkable that the FSW process significantly reduced the number of particle clusters in the stirred zone, as shown in Fig. 5.4a. The discontinuous defects in the welded zone (Fig. 5.4b) are usually caused by insufficient forging force and can be avoided by setting the welding parameters accordingly.

A typical macroscopic overview of sound weld cross-section is shown in Fig. 5.5. The stirred zone (nugget), TMAZ, and HAZ, as well as the base material (BM), can be roughly identified by color change due to the different thermo-mechanical histories of the materials. The typical defects found in the fusion welding joints, such as particle segregation, porosity and chemical reaction, are not observed in the FSW joints. 


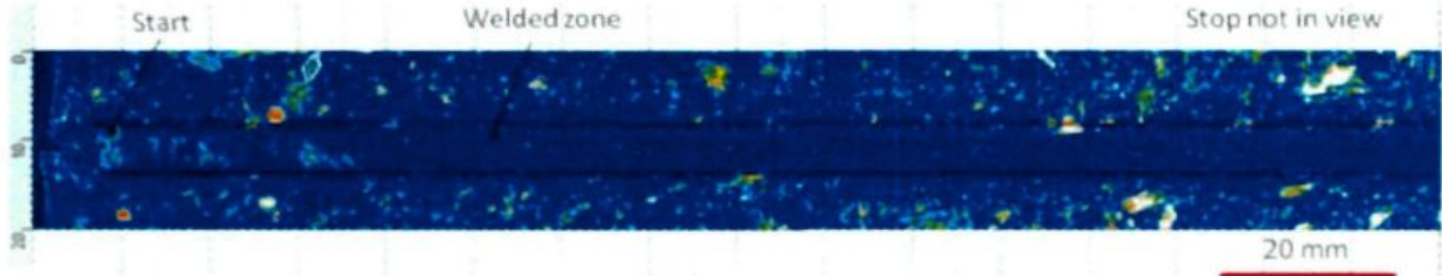

(a)

(a) Defect free FSW joint

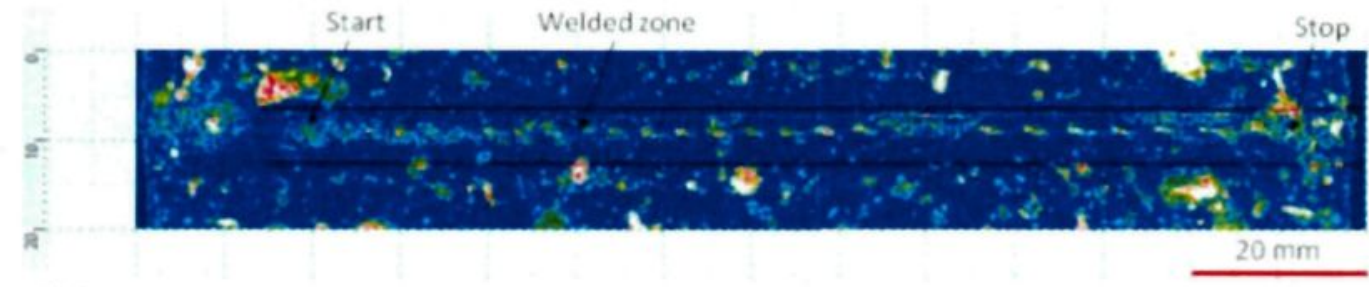

(b)

(b) FSW joint with discontinuous worm hole

Fig. 5.4 Typical ultrasonic inspection images of FSW joints of AA1100-16 vol.\% $\mathrm{B}_{4} \mathrm{C}$ MMCs. a) Defect free FSW joint. b) FSW joint with discontinuous worm hole.

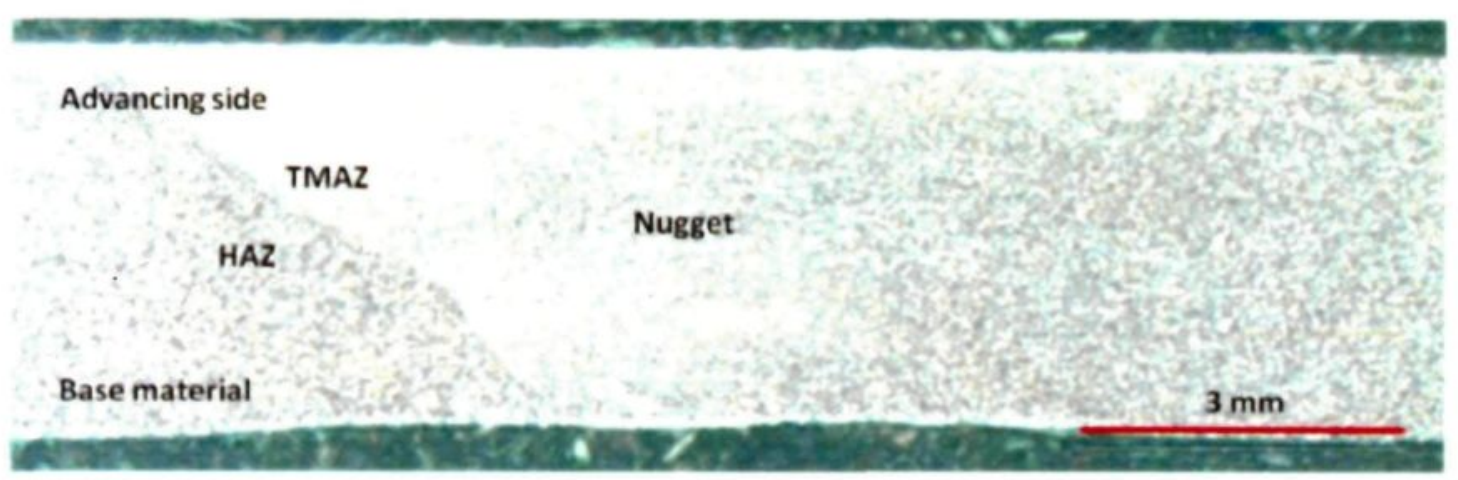

Fig. 5.5 Typical macrograph of FSW joint of AA1100-16 vol. $\% \mathrm{~B}_{4} \mathrm{C}$ composite. Weld zone on the retreating side cannot be clearly identified. 


\subsection{1 $\mathrm{B}_{4} \mathrm{C}$ particle characterization}

Image analyzer results show similar average volume concentrations of $\mathrm{B}_{4} \mathrm{C}$ particles in the nugget zones and base materials. The measured $\mathrm{B}_{4} \mathrm{C}$ concentrations are $15 \pm 1 \%$ in the nugget and $16 \pm 1 \%$ in the base material for $\mathrm{Al}-16$ vol. $\% \mathrm{~B}_{4} \mathrm{C}$ MMCs, and $32 \pm 1 \%$ in the nugget and $33 \pm 1 \%$ in the base material for $\mathrm{Al}-30$ vol. $\% \mathrm{~B}_{4} \mathrm{C} \mathrm{MMCs}$.

Although the FSW process does not affect the $\mathrm{B}_{4} \mathrm{C}$ volume concentration, it should be noted that significant particle size and shape changes are observed in the weld zone. As illustrated in Fig. 5.6, breakage of $\mathrm{B}_{4} \mathrm{C}$ particles occurs in both materials, and typical micrographs of the base and welded materials clearly show this feature.

Typical $\mathrm{B}_{4} \mathrm{C}$ particle size and shape histograms are plotted in Fig. 5.7 for both materials. Particle size analyses were carried out with great care using the image analysis software to avoid counting intermetallics (fine and grey particles) as $\mathrm{B}_{4} \mathrm{C}$ particles (black particles). Furthermore, particles for which the cross section area is smaller than $2 \mu \mathrm{m}^{2}$ are not counted due to measurement uncertainties. Obviously, the amount of finer $\mathrm{B}_{4} \mathrm{C}$ particles increases significantly in the nugget for both materials. For $\mathrm{Al}-16 \% \mathrm{~B}_{4} \mathrm{C}$ MMCs (LR3), the average particle area decreased from $86 \pm 5 \mu \mathrm{m}^{2}$ (base material) to $60 \pm 5 \mu \mathrm{m}^{2}$ (nugget), while for $\mathrm{Al}-30 \% \mathrm{~B}_{4} \mathrm{C}$ MMCs (HA1), this average value decreased from $186 \pm 5 \mu \mathrm{m}^{2}$ to 109 $\pm 5 \mu \mathrm{m}^{2}$. Similar results were also obtained in the FSW of $\mathrm{Al}-\mathrm{SiC}$ and $\mathrm{Al}-\mathrm{Al}_{2} \mathrm{O}_{3} \mathrm{MMCs}[19$, 98]. On the other hand, the particle aspect ratio is significantly reduced (from $2.53 \pm 0.02$ to $2.13 \pm 0.02$ ) in the $\mathrm{Al}-16 \% \mathrm{~B}_{4} \mathrm{C}$ MMCs. This rounding effect may be due to the breaking 
and possible abrasion of the $\mathrm{B}_{4} \mathrm{C}$ particles during $\mathrm{FSW}$ of this $\mathrm{Al}$-composite. However, the particle aspect ratio for $\mathrm{Al}-30 \% \mathrm{~B}_{4} \mathrm{C}$ MMCs does not change significantly (constant average value of $1.92 \pm 0.02$ ). The reason for this different behavior is unclear, but the smaller aspect ratio of $\mathrm{B}_{4} \mathrm{C}$ particles, the difference in the initial particle distribution, and the higher viscosity of the material during FSW surely play a role. In our study, the influence of welding speed on particle breakage and aspect ratio was investigated in Al-16\% $\mathrm{B}_{4} \mathrm{C} \mathrm{MMCs}$, and the results are given in Table 5.3. Similar behavior of the particle breakage was observed in both as-rolled and annealed conditions and the welding speed did not have a significant influence on the particle breakage and roundness.

Optical microscopy showed that the distribution of $\mathrm{B}_{4} \mathrm{C}$ particles in the stirred zone is more homogenous than that of the base material. Particle clusters and alignment along the rolling direction found in the base material have completely disappeared in the stirred zone. A similar phenomenon was also reported in $\mathrm{FSW}$ of $\mathrm{Al}-\mathrm{SiC}$ [103] and $\mathrm{Al}-\mathrm{B}_{4} \mathrm{C}$ MMCs [18]. This can be attributed to the physical stirring effect of the FSW tool and is very favorable here since homogenous $\mathrm{B}_{4} \mathrm{C}$ particle distribution is of primary importance in nuclear applications. 


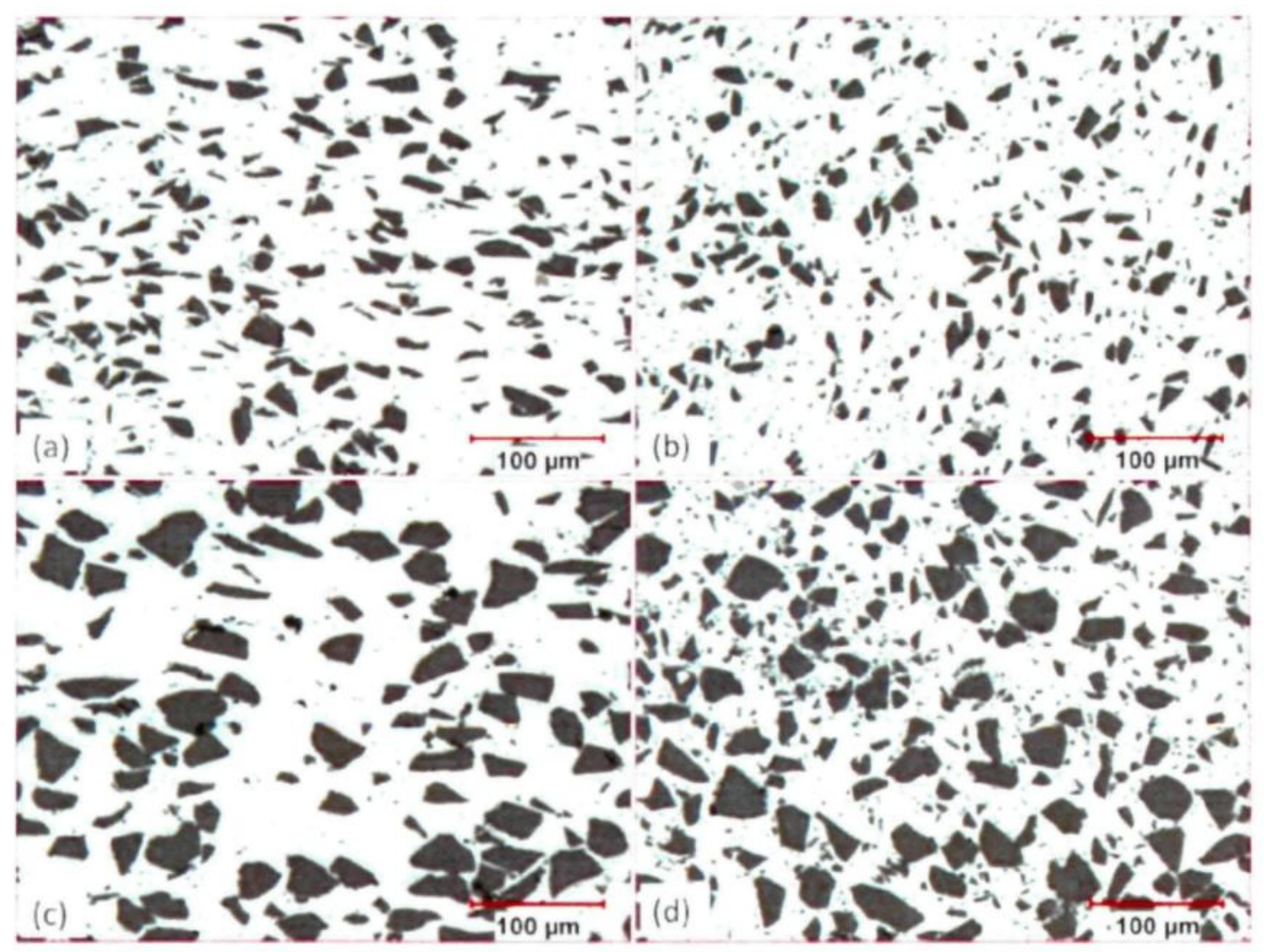

Fig. 5.6 Typical optical micrographs of (a) base material and (b) nugget zone of Al$16 \% \mathrm{~B}_{4} \mathrm{C}$ MMCs (LR3); (c) base material and (d) nugget zone of $\mathrm{Al}-30 \% \mathrm{~B}_{4} \mathrm{C} \mathrm{MMCs}$ (HA1) 

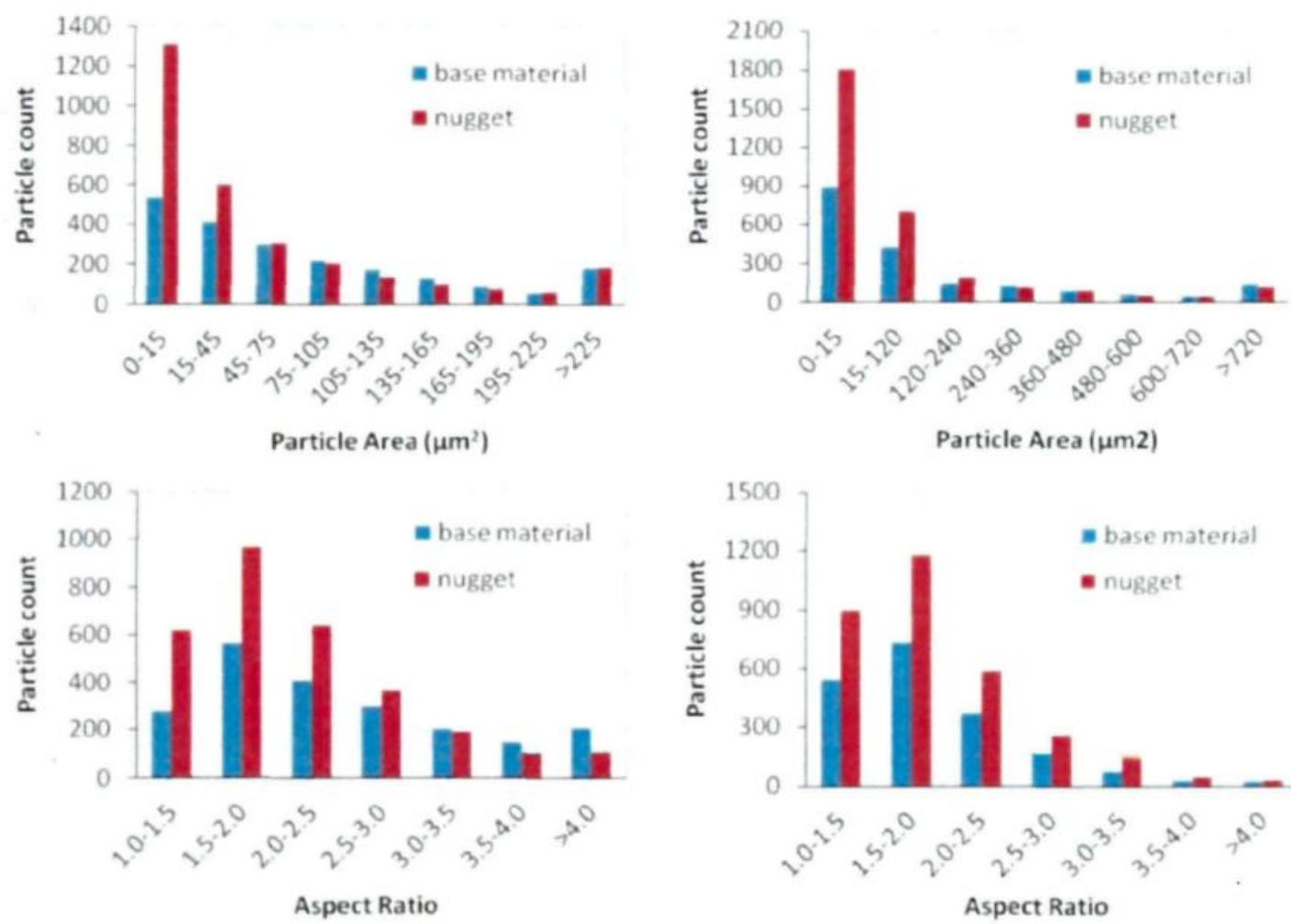

(a) AA1100-16\% vol Ba CMMCs (LR3)

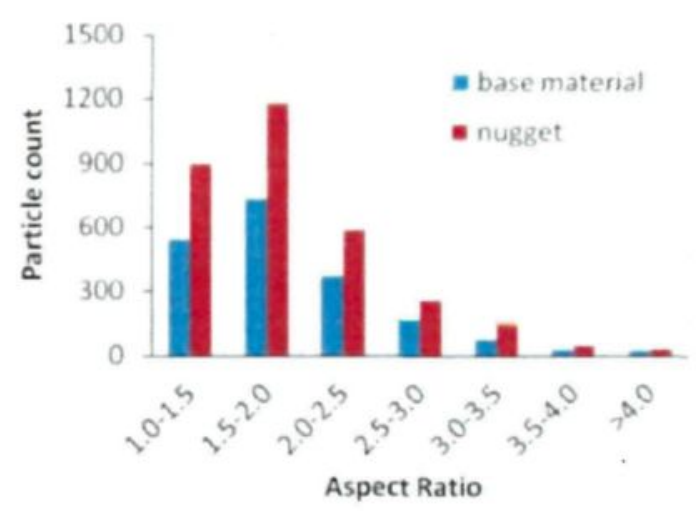

(b) AA1100-30\% vol. B, C MMCS (HA1)

Fig. 5.7 Particle area and aspect ratio histograms measured in the base material and FSW nugget of both $\mathrm{Al}-16 \%$ and $\mathrm{Al}-30 \% \mathrm{~B}_{4} \mathrm{C}$ MMCs

Table 5.3 Particle size and aspect ratio before and after FSW of $\mathrm{Al}-16 \% \mathrm{~B}_{4} \mathrm{C}$

\begin{tabular}{ccccc}
\hline Conditions & \multicolumn{2}{c}{ Base material } & \multicolumn{2}{c}{ Nugget } \\
\cline { 2 - 5 } (welding speed & $\begin{array}{c}\text { Particle area } \\
\text {-mm/min) }^{2}\end{array}$ & Aspect ratio & $\begin{array}{c}\text { Particle area } \\
\mu \mathrm{m}^{2}\end{array}$ & Aspect ratio \\
\hline LR1 (100) & 85 & 2.56 & 55 & 2.04 \\
LR2 (200) & 83 & 2.42 & 59 & 2.11 \\
LR3 (275) & 86 & 2.53 & 60 & 2.13 \\
\hline
\end{tabular}




\subsubsection{Fragmentation of constituent particles}

To facilitate the fabrication of $\mathrm{Al}-\mathrm{B}_{4} \mathrm{C}$ MMCs cast ingots during the liquid mixing cast process, a certain amount of $\mathrm{Ti}$ was added to the aluminium matrix to avoid the degradation of $\mathrm{B}_{4} \mathrm{C}$ particles. By adding $\mathrm{Ti}$, a protective layer consisting of fine $\mathrm{TiB}_{2}$ and $\mathrm{Al}_{3} \mathrm{BC}$ formed around the $\mathrm{B}_{4} \mathrm{C}$ particles [114]. Therefore, in the microstructure of rolled base materials, several reaction-induced fine particles such as $\mathrm{TiB}_{2}, \mathrm{Al}_{3} \mathrm{BC}$ and $\mathrm{AlB}_{2}$ are often found around $\mathrm{B}_{4} \mathrm{C}$ particles. Furthermore, some $\mathrm{Al}-\mathrm{Fe}$ intermetallic particles from the impurities of the AA1100 alloy are distributed in the aluminium matrix.

As illustrated in Fig. 5.8a, many $\mathrm{TiB}_{2}$ and $\mathrm{Al}_{3} \mathrm{BC}$ fine crystals around $\mathrm{B}_{4} \mathrm{C}$ surfaces were generally recognized before FSW, while such particles can no longer be found around the $\mathrm{B}_{4} \mathrm{C}$ particles in the stirred zone, as seen in Fig. 5.8b. It is evident that most of the reaction-induced particles are broken down and stirred away from $\mathrm{B}_{4} \mathrm{C}$ particles, and redistributed in the aluminium matrix. The fragmentation of $\mathrm{Al}-\mathrm{Fe}$ intermetallic phases was also observed in the nugget zone. The fragmentation and redistribution of these constituent particles are believed to be beneficial for grain structure refinement of the matrix since the fine intermetallic particles may act as nucleation sites during dynamic recrystallization induced by FSW. It is also reasonable to believe that these fine particles can have a dispersion strengthening effect on the aluminium matrix. 

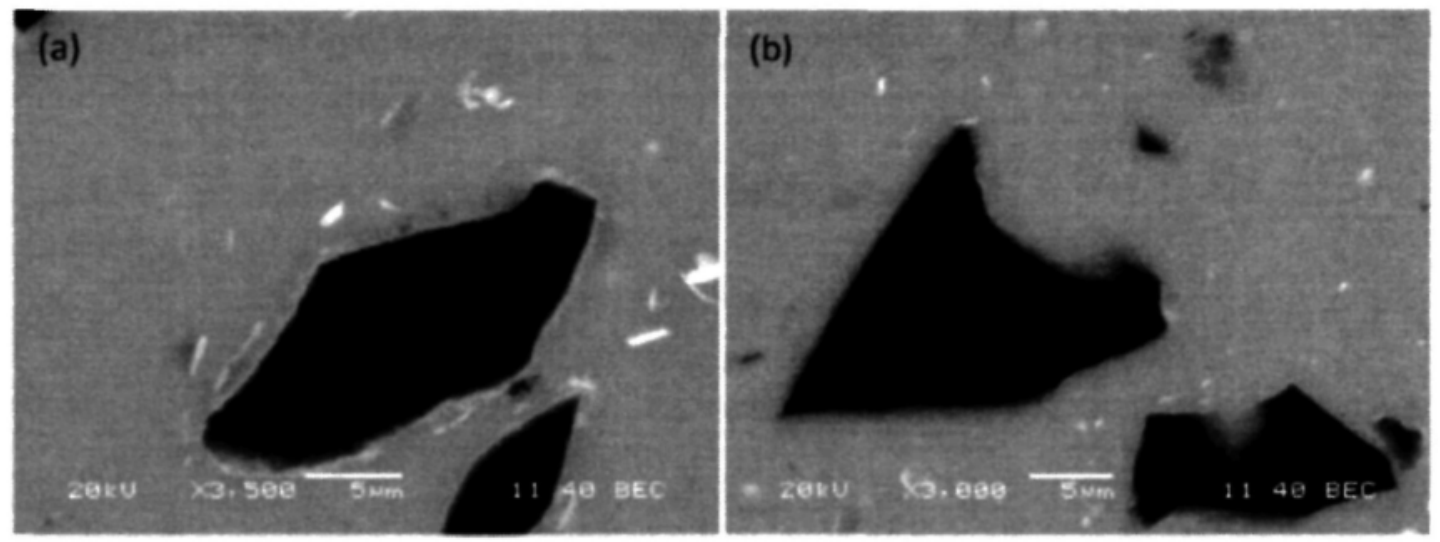

Fig. 5.8 Typical backscattered images of the intermetallic distribution in AA1100-16\% $B_{4}$ C MMCs before (a) and after (b) FSW

\subsubsection{Grain refinement of the aluminium matrix}

Significant grain refinement of the aluminium matrix was observed in the stirred zones of both $16 \%$ and $30 \% \mathrm{~B}_{4} \mathrm{C}$ composite materials. Comparing the base material and nugget zone grain structures in Fig. 5.9 (a) and (b) reveals the grain refinement effect in an example of the $16 \% \mathrm{~B}_{4} \mathrm{C}$ composite material. As shown in Fig. 5.9, the average grain size of $16 \% \mathrm{~B}_{4} \mathrm{C}$ composite material is reduced from about $15 \mu \mathrm{m}$ in the base material to about $5 \mu \mathrm{m}$ in the nugget zone. Refinement of the grain structure is mainly attributed to the effects of plastic deformation and thermo-mechanical cycle during FSW. Similar grain refinement in the nugget has also been reported in the literature for different aluminium alloys [74, 121]. In the case of metal matrix composites, other authors have confirmed a similar recrystallization process for $\mathrm{FSW}$ of $\mathrm{Al}-\mathrm{SiC}$ [103], $\mathrm{Al}-\mathrm{B}_{4} \mathrm{C}$ [18] and other MMCs. 


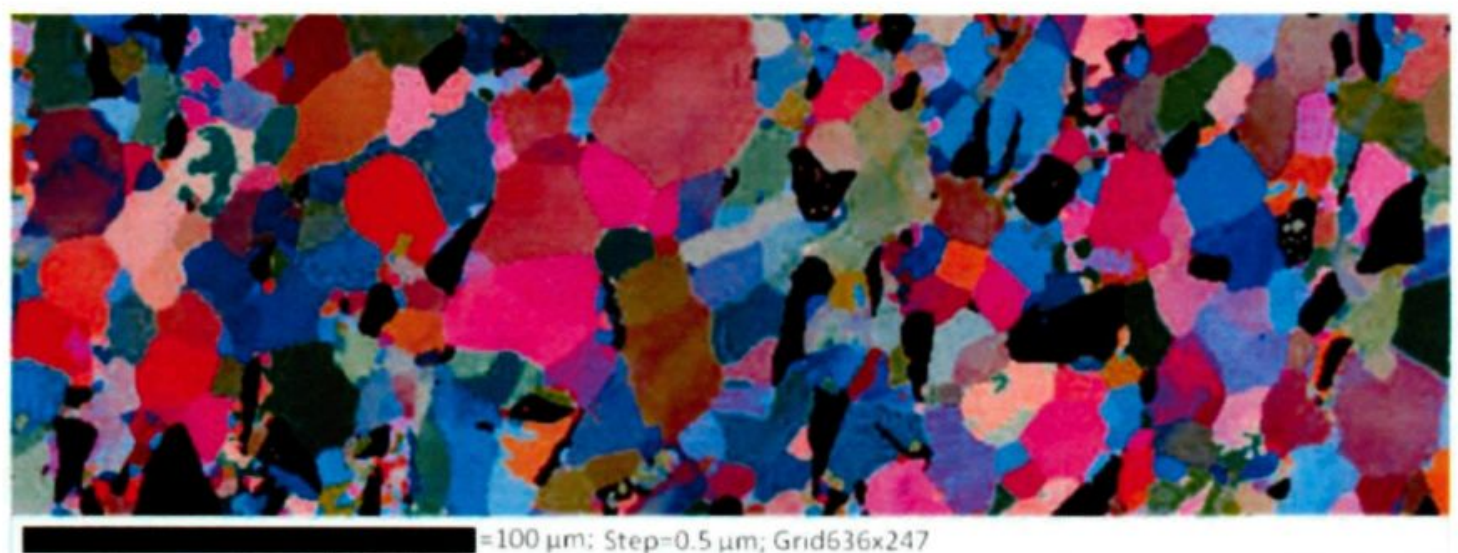

(a)

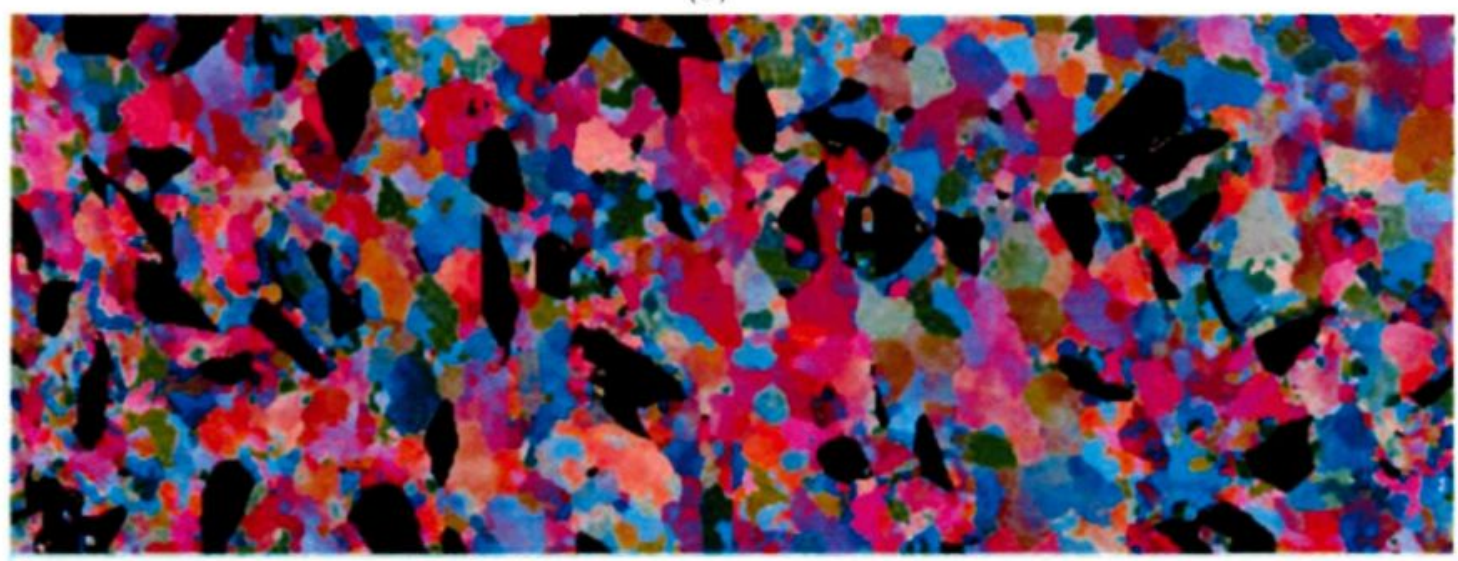

$=100$ um: Step $=0.5 \mu \mathrm{m} ;$ Grid $636 \times 238$

(b)

Fig. 5.9 EBSD maps showing the typical grain structure in (a) the as-rolled base material and (b) its weld nugget zone. The black color indicates B4C particles while the other colors display different orientations of aluminium grains. 


\subsection{Mechanical properties}

\subsubsection{Microhardness}

The microhardness profiles measured in the FSW joint of as-rolled AA1100-16\% $\mathrm{B}_{4} \mathrm{C}$ MMCs show an increase of hardness in the nugget zone for all welding conditions, as shown in Fig. 5.10a. This can be related to the much finer grain size in the nugget and the hardening effect of the fine broken particles embedded in the matrix. A softened region can be observed in the weld of strain hardened monolithic alloys, as previously reported [8788]. However, in this study the hardening effect of grain refinement and the fine broken particles embedded in the matrix overcome the softening effect. It is important to note that the minimum hardness for as-rolled $\mathrm{Al}-16 \% \mathrm{~B}_{4} \mathrm{C}$ is observed in the transition zone of the weld, where there is an annealing effect by the FSW thermal cycle. Such minimum does not exist in the microhardness profiles of the annealed material (Fig. 5.10b). Moreover, the hardening effect in the stirred zone is also confirmed for the annealed material.

The microhardness in the FSW joints of AA1100-30\% $\mathrm{B}_{4} \mathrm{C}$ MMCs has not been measured since the inter-particle distance is not sufficient to allow the implementation of an effective indent even with $10 \mathrm{gf}$. 


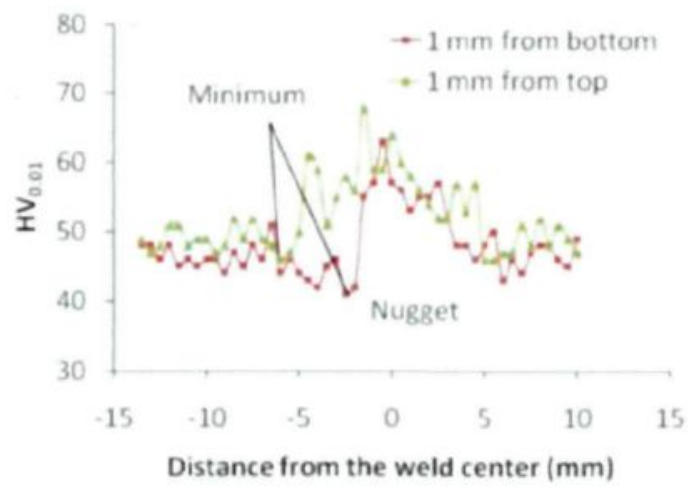

(a) As-rolled material (LR3)

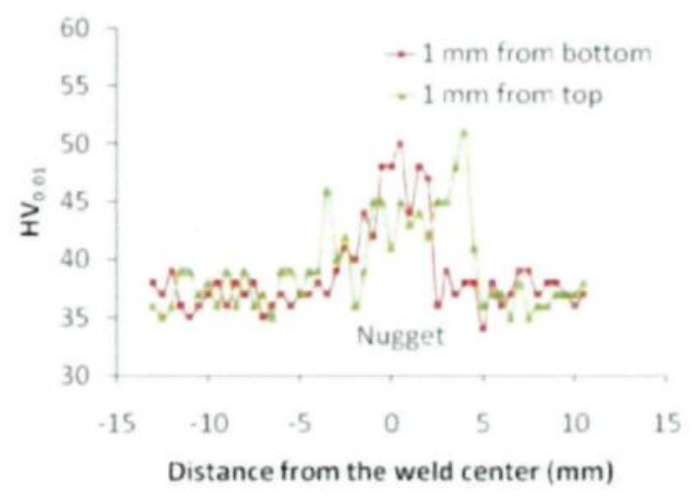

(b) Annealed material (HA3)

Fig. 5.10 Microhardness profiles across the FSW joints of (a) as-rolled AA1100-16\% $B_{4}$ C MMCs (LR3), (b) annealed AA1100-16\% B H $_{4}$ MMCs (LA3)

\subsubsection{Tensile properties}

The transverse tensile tests of all FSW joints were carried out to examine the effects of FSW parameters on the mechanical properties of welded assemblies. For comparison purposes, the base materials in the corresponding temper were also tested perpendicular to the rolling direction. The tensile properties of the base materials and their FSW joints are listed in Table 5.4 and are illustrated graphically in Fig. 5.11. Generally, tensile results show high joint efficiency for both composite materials, up to $100 \%$ for the joints made from annealed materials. 
Table 5.4 Tensile tests of the base materials and $\mathrm{FSW}$ joints for $\mathrm{Al}-\mathrm{B}_{4} \mathrm{C}$ MMCs

\begin{tabular}{|c|c|c|c|c|c|c|}
\hline Material & $\begin{array}{l}\text { UTS } \\
(\mathrm{MPa})\end{array}$ & $\begin{array}{l}\text { Standard } \\
\text { deviation } \\
\text { (UTS) }\end{array}$ & $\begin{array}{l}\text { YS } \\
(\mathrm{MPa})\end{array}$ & $\varepsilon(\%)$ & $\begin{array}{l}\text { Joint eff. } \\
(\%)\end{array}$ & $\begin{array}{l}\text { Failure } \\
\text { location }\end{array}$ \\
\hline $\begin{array}{l}\text { As rolled } \\
\text { Al- } 16 \% \mathrm{~B}_{4} \mathrm{C}\end{array}$ & 160 & 0.86 & 148 & 3.8 & -- & -- \\
\hline $\mathrm{LR} 1(100 \mathrm{~mm} / \mathrm{min})$ & 129 & 3.9 & 101 & 2.9 & 81 & TMAZ/HAZ \\
\hline LR2 $(200 \mathrm{~mm} / \mathrm{min})$ & 133 & 0.87 & 100 & 3.9 & 83 & TMAZ/HAZ \\
\hline LR3 (275 mm/min) & 132 & 0.82 & 94 & 4.3 & 83 & TMAZ/HAZ \\
\hline $\begin{array}{l}\text { Annealed } \\
\mathrm{Al}-16 \% \mathrm{~B}_{4} \mathrm{C}\end{array}$ & 126 & 1.9 & 61 & 12.6 & -- & -- \\
\hline LA1 (100 mm/min) & 129 & 0.69 & 70 & 11.9 & 100 & $\begin{array}{l}\text { Base } \\
\text { material/HAZ }\end{array}$ \\
\hline LA2 (200 mm/min) & 131 & 0.80 & 71 & 14.6 & 100 & Base material \\
\hline LA3 (275 mm/min) & 127 & 0.86 & 77 & 10.1 & 100 & $\begin{array}{l}\text { Base } \\
\text { material/HAZ }\end{array}$ \\
\hline $\begin{array}{l}\text { Annealed } \\
\mathrm{Al}-30 \% \mathrm{~B}_{4} \mathrm{C}\end{array}$ & 128 & 0.86 & 91 & 7.8 & -- & -- \\
\hline $\mathrm{HA} 1(100 \mathrm{~mm} / \mathrm{min})$ & 132 & 0.42 & 93 & 6.4 & 100 & Base material \\
\hline HA2 (200 mm/min) & 129 & 1.6 & 90 & 6.4 & 100 & Base material \\
\hline HA3 (275 mm/min) & 130 & 1.2 & 88 & 7.0 & 100 & Base material \\
\hline
\end{tabular}

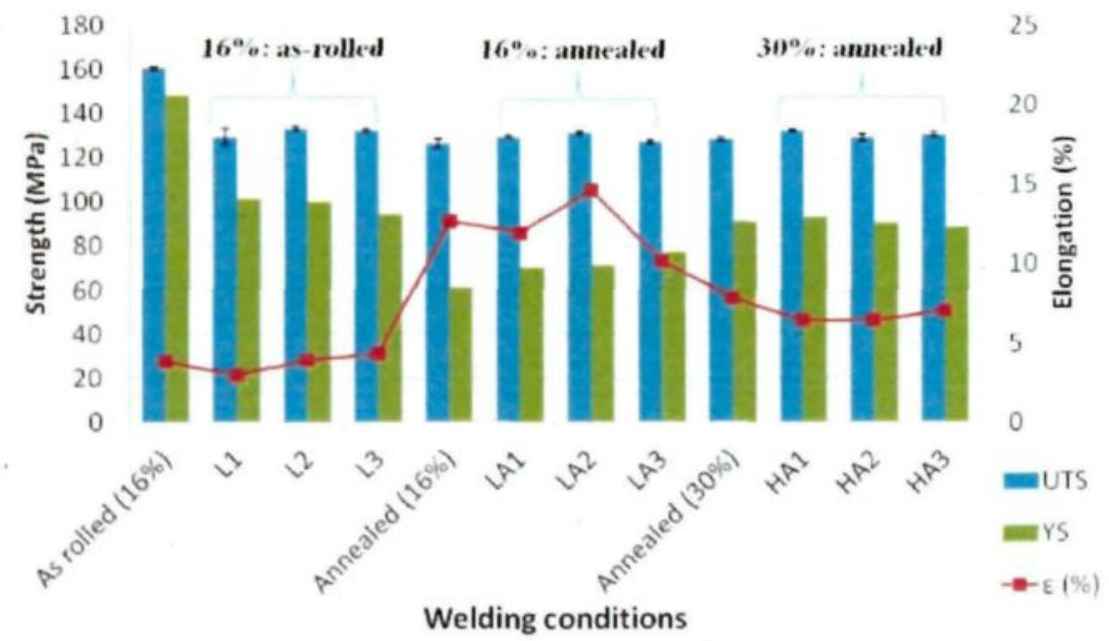

Fig. 5.11 Tensile properties of AA1100-B ${ }_{4} \mathrm{C}$ MMCs and their FSW joints. 
The decrease of the ultimate tensile strength and yield strength of the as-rolled AA1100-16\% vol. $\mathrm{B}_{4} \mathrm{C}$ MMCs is due to the annealing effect induced by the thermal cycle during FSW. As shown in Table 5.4, the failure location of the joints occurs in the transition zone (TMAZ/HAZ), which is also the position for the minimum value in the microhardness profile. Figure 5.12 shows the EBSD maps from the base material and the HAZ. In the as-rolled base material, there are a number of dislocation networks (low angles $2-5^{\circ}$ ), while in the HAZ, the heat generated during welding causes the recovery to take place and most dislocation networks to disappear, resulting in a drop in the strength and hardness.

For this material, the increase of welding speed from $100 \mathrm{~mm} / \mathrm{min}$ to $275 \mathrm{~mm} / \mathrm{min}$ does not have a significant effect on the UTS and YS, which is somewhat unexpected according to the literature on FSW of strain hardened pure aluminium [87, 90]. The noneffect of welding speed on the mechanical properties of welded as-rolled MMC materials compared to monolithic strain hardened aluminium alloys may be attributed to higher heat generation during FSW of MMCs. Indeed, higher temperature is expected during FSW of Al- $\mathrm{B}_{4} \mathrm{C}$ composites due to their higher flow stress and lower thermal conductivity (173 $\mathrm{W} \cdot \mathrm{m}^{-1} \cdot \mathrm{K}^{-1}$ for $\mathrm{Al}-15 \% \mathrm{~B}_{4} \mathrm{C}$ and $222 \mathrm{~W} \cdot \mathrm{m}^{-1} \cdot \mathrm{K}^{-1}$ for $\left.\mathrm{AA} 1100-\mathrm{O}\right)$ [122-123].

On the other hand, the FSW joints of the annealed MMC materials, for both $\mathrm{B}_{4} \mathrm{C}$ concentrations, show UTS, YS and elongation values comparable to those of the corresponding base materials. The variation of welding speed from $100 \mathrm{~mm} / \mathrm{min}$ to 275 $\mathrm{mm} / \mathrm{min}$, as expected, does not show significant effect. This is understandable as the 
materials are already in fully annealed condition, which negates the softening effect of the FSW thermal cycle.

It is worthwhile to highlight the fact that all tensile samples made of MMCs with $30 \%$ vol. $\mathrm{B}_{4} \mathrm{C}$ and most of the tensile samples made of MMCs with $16 \%$ vol. $\mathrm{B}_{4} \mathrm{C}$ in annealed condition failed in the base materials. This indicates that the FSW joints of these MMCs are stronger than the base materials, which is very unusual for aluminium based material welding. This is related to the grain refinement of the matrix resulting of the FSW process. It is interesting to note that the FSW joints of as-rolled samples show good consistency in terms of tensile properties, as indicated by the low standard deviation values on repeated measurements.

Comparison of the tensile data between the FSW joints of as-rolled and annealed AA1 100-16\% $\mathrm{B}_{4} \mathrm{C}$ MMCs indicates that the starting temper of the materials does not have much influence on the final UTS of the joints, but has a significant effect on elongation $\varepsilon$. The annealed starting temper is recommended as far as tensile property values are concerned as for similar UTS the welded samples give higher elongation. It is worthwhile to highlight the fact that most of the tensile samples made of MMCs with $16 \%$ vol. $\mathrm{B}_{4} \mathrm{C}$ in annealed conditions failed in the base materials, as shown in Fig. 5.13. This indicates that the FSW joints of these MMCs were stronger than the base materials, which is very promising for joining aluminium metal matrix composites. 

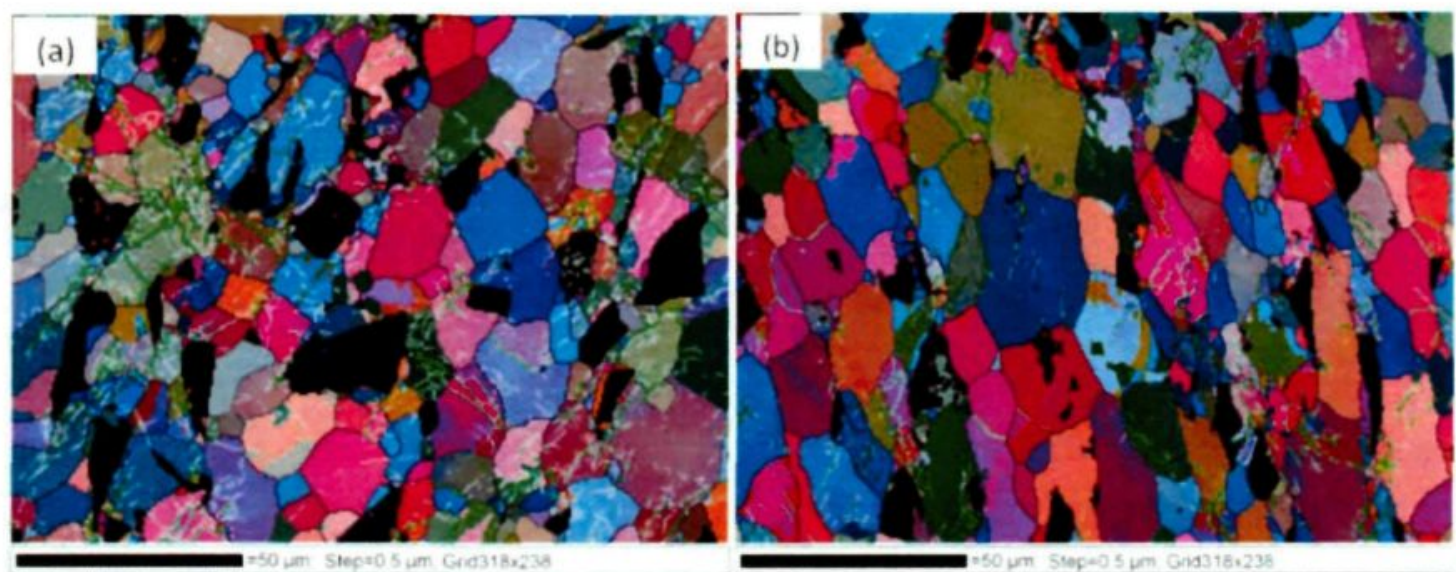

Fig. 5.11 EBSD maps from the as-rolled base material (a) and the HAZ (b), showing the recovery to take place in the HAZ where most dislocation networks (low angles 2$5^{\circ}$ ) disappear. The black regions are $\mathrm{B}_{4} \mathrm{C}$ particles while other color regions represent the aluminium grains with different orientations. The black lines are the boundary angles $>15^{\circ}$, while the green lines display the boundaries between 5 and $15^{\circ}$ and the grey lines between 2 and $5^{\circ}$, respectively.

Original joint line

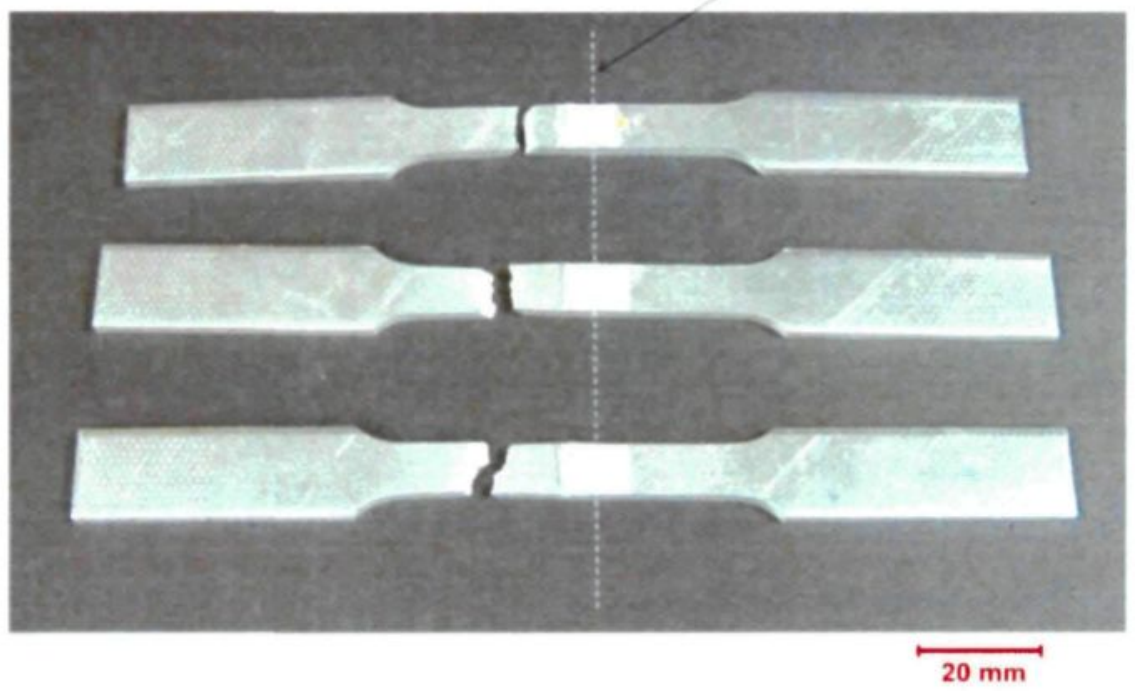

Fig. 5.13 Failure locations of FSW joints (FA2) 


\subsubsection{Fractography}

After tensile testing, the fracture surfaces of the base material and the FSW joints of the AA1 100-16\% $\mathrm{B}_{4} \mathrm{C}$ MMCs were examined by SEM to investigate the effects of FSW on fracture behavior. The results of typical SEM micro-images are shown in Fig. 5.14. The fracture of particulate reinforced MMCs under tensile loading is controlled by three main mechanisms depending upon the nature of the matrix, reinforcement and interface [124125]: i) If the matrix is very strong and the local stress exceeds the fracture stress of the reinforcement particle, particle fracture will occur; ii) If the local stress is lower than the particle fracture strength but is higher than interfacial strength, interfacial decohesion occurs; iii) If both the interface and the reinforcement are stronger than the matrix, then fracture takes place by void coalescence of the matrix.

In the as-rolled materials, large interfacial voids, resulting from decohesion between $\mathrm{B}_{4} \mathrm{C}$ particles and matrix, are the main characteristics of the fracture (Fig. 5.14a). Particle fracture was occasionally observed but a large portion of the fracture consisted of interfacial decohesion. The local stresses were not large enough to fracture the majority of the particles but exceeded the interface strength, which resulted in interfacial voiding.

In the FSW joints of the as-rolled material, failure occurs in the transition zone (TMAZ/HAZ). The fractograph (Fig. 5.14b) shows extensive ductile dimpling in the matrix with occasional small interfacial voids between particles and matrix. As the tensile strength decreased significantly after FSW of the as-rolled material, the void coalescence of the 
matrix became the dominant feature. The rupture surface is due to the finer particles in the TMAZ zone compared to the base materials, and easier plastic deformation of the aluminium matrix annealed by FSW.
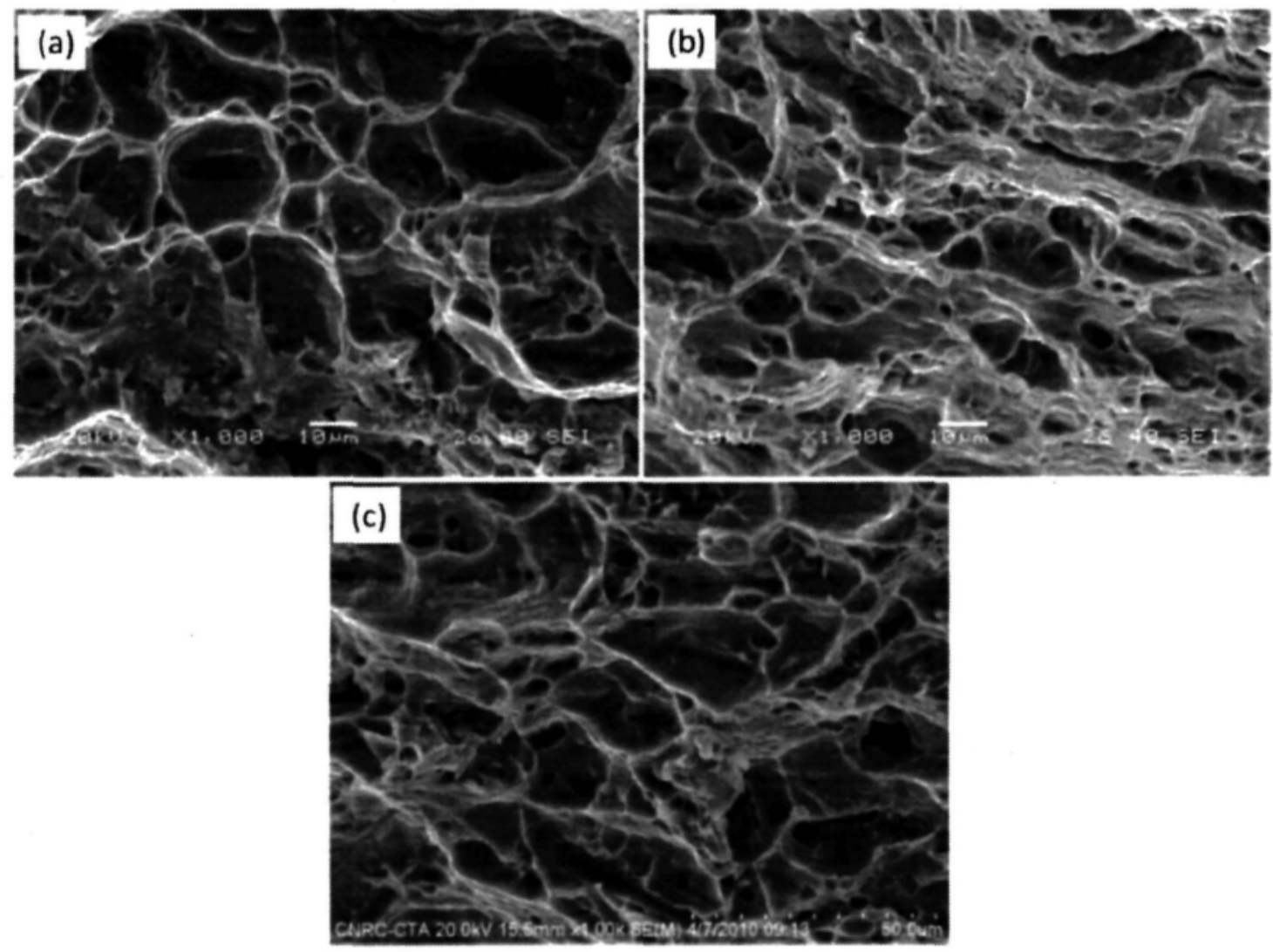

Fig. 5.12 SEM micrographs of tensile fracture surfaces of (a) the as-rolled base material, (b) the FSW joint (LA1) and (c) the annealed base material

On the other hand, the fracture surfaces of the annealed base material and the corresponding FSW joints are very similar, and the morphology can be characterized as major ductile dimpling in the matrix with a small fraction of interfacial decohesion (Fig. 5.14c). The scale of the matrix dimples and interfacial voids is coarser than that found in 
the FSW joints of the as-rolled material, as shown in Fig. 5.14b. This is because the failures of the FSW joints of the annealed materials are located in the HAZ or the base material where there was no refinement of both particles and matrix. In both cases (annealed base material and its FSW joints), the materials were already fully annealed and the tensile strengths were low. The annealed AA1100 matrix is very soft, and therefore, it is understandable that the AA1 100 aluminium matrix tends to fail before the fracture of $\mathrm{B}_{4} \mathrm{C}$ particles and interfacial decohesion.

\subsection{Corrosion Property}

To distinguish the corrosion resistance of the base materials and the friction stir welds, potentiodynamic polarization measurement was carried out [126]. Fig. 5.15 shows the typical polarisation curves for the base material and the friction stir welds in $3.5 \mathrm{wt}$ \% $\mathrm{NaCl}$ solution. The corrosion potential (Ecorr), the corrosion current density (jcorr) and the polarization resistance $(\mathrm{Rp})$ are summarized in Table 5.5. The corrosion current density jcorr was obtained from the extrapolation of the cathodic Tafel slopes to the respective corrosion potentials and the polarization resistance $(\mathrm{Rp})$ values were calculated from the slope of linear $\mathrm{E}-\mathrm{j}$ curves found by varying $\pm 10 \mathrm{mV}$ around the Ecorr. As can be seen in Table 5.5, the base material displays the highest corrosion potential (Ecorr $=-667 \mathrm{mV}$ ) and the highest polarization resistance $\left(\mathrm{Rp}=19.91 \mathrm{k} \Omega \mathrm{cm}^{2}\right)$. Consequently, the base material has better corrosion resistance than the welds made with both tools. 
On the other hand, welds produced by steel tool showed lower corrosion potentials and polarization resistances than those produced by WC-Co tools at the same welding speed condition. This indicates that the joints produced by steel tool possess the worst corrosion resistance. The difference of the corrosion resistance between two types of joints may be attributed to the fact that a large amount of steel tool debris was embedded in the top part of the welds and thus increased the corrosion initiation sites (Fig. 5.3).

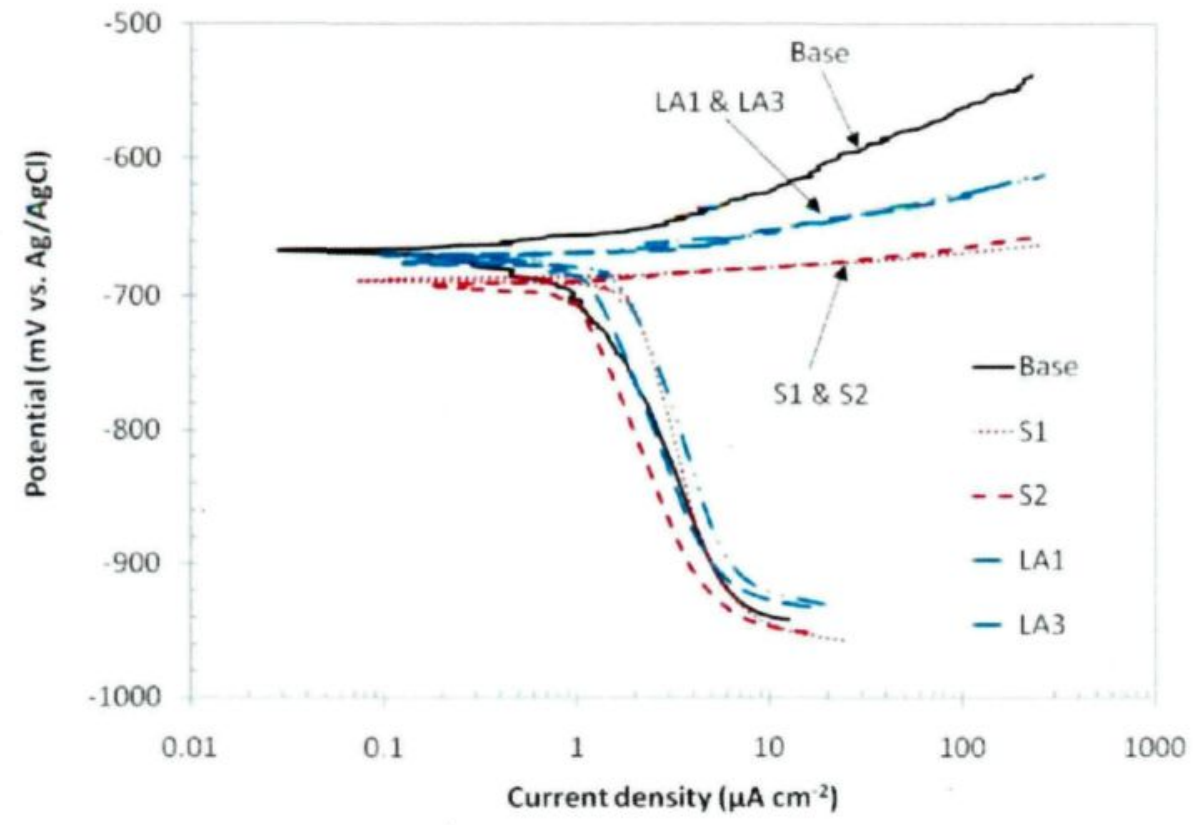

Fig. 5.13 Potentiodynamic polarisation curves of the base material and its friction stir welds

Table 5.5 Electrochemical parameters for the polarisation curves shown in Fig. 5.13

\begin{tabular}{llllll}
\hline Conditions & Base & S1 & S2 & LA1 & LA3 \\
\hline $\mathrm{E}_{\text {corr }}(\mathrm{mV})$ & -667 & -689 & -693 & -670 & -675 \\
$\mathrm{j}_{\text {corr }}\left(\mu \mathrm{A} \mathrm{cm} \mathrm{cm}^{-2}\right)$ & 0.898 & 1.921 & 0.999 & 1.501 & 1.142 \\
$\mathrm{R}_{\mathrm{p}}\left(\mathrm{k} \Omega \mathrm{cm}^{2}\right)$ & 19.91 & 1.74 & 4.27 & 4.68 & 6.03 \\
\hline
\end{tabular}




\subsection{Summary and Conclusions}

1. Friction stir welding is a good welding technique for joining AA1100-based metal matrix composites reinforced with $\mathrm{B}_{4} \mathrm{C}$ particles up to $30 \%$ volume fraction. Joint efficiencies (UTS) higher than $81 \%$ are obtained for the as-rolled AA1100-16 vol.\% $\mathrm{B}_{4} \mathrm{C}$ composite, and up to $100 \%$ for both the annealed AA1100-16 vol.\% and AA110030 vol. $\% \mathrm{~B}_{4} \mathrm{C}$ composite materials.

2. Breakage and fragmentation of ceramic and constituent particles during FSW are noted. While the particle size distribution stays monomodal after FSW, the average particle cross section area decreases from 86 to $60 \mu^{2}$ for the $16 \% \mathrm{~B}_{4} \mathrm{C}$ composite and from 186 to $109 \mu \mathrm{m}^{2}$ for the $30 \% \mathrm{~B}_{4} \mathrm{C}$ composite, respectively. Some rounding has also been observed after welding, with a particle aspect ratio varying from 2.5 to 2.1 after welding of the $16 \% \mathrm{~B}_{4} \mathrm{C}$ concentration composite.

3. The annealed starting temper is generally recommended for AA1100-based metal matrix composites, as their FSW joints have equal UTS at about $130 \mathrm{MPa}$ and higher elongation compared with those of the as-rolled condition.

4. The grain refinement of the aluminium matrix (15 to $5 \mu \mathrm{m}$ for $\mathrm{AA} 1100-16 \% \mathrm{~B}_{4} \mathrm{C}$ ) induced by FSW contributes to the high tensile properties of FSW joints. 
5. The FSW joint surfaces produced by both tools exhibited lower corrosion resistance than that of the base material. But the joints made by the WC-15wt.\%Co tool showed a better corrosion resistance than those made by the steel tool. 


\section{Chapter VI}

\section{Microstructure evolution and mechanical}

properties of dissimilar friction stir welded joints

between $\mathrm{AA1100-B}$ C MMC and AA6063 alloy 


\section{Chapter VI Microstructure evolution and mechanical properties of dissimilar friction stir welded joints between $\mathrm{AA1100}^{-\mathrm{B}_{4} \mathrm{C}}$ MMC and AA6063 alloy}

Joint configurations between metal matrix composites and monolithic metals are inevitable in many applications and can be very cost effective as we can use the costly MMCs only where necessary. The fusion welding between MMCs and monolithic metals, similar to the welding of MMCs, would be very difficult as the problems such as porosity and chemical reaction will arise [11]. In contrast, FSW may be a promising technique as it permits to weld metals without melting them.

In the present study, dissimilar joints between rolled plates of $\mathrm{AA} 1100-16$ vol. $\% \mathrm{~B}_{4} \mathrm{C}$ MMC and extruded plates of AA6063 aluminium alloy (T5 temper) were successfully produced using FSW process. All plates of composites were annealed $\left(400{ }^{\circ} \mathrm{C}\right.$ for $1 \mathrm{~h}$ ) before welding as it has been demonstrated that the FSW joints made in this condition have very good strength and much better ductility [122]. The welding parameters were selected to avoid macro-defects in the weld and excessive flash on the surface, as listed in Table 6.1. The offset means the distance of the FSW tool axis shifted to the 6063 aluminium side from the original interface of the welding plates.

The main content of this chapter is intended to be published in: Materials Science and engineering A, 2012. 
Table 6.1 Main welding parameters for different conditions

\begin{tabular}{cccccc}
\hline Code & $\begin{array}{c}\text { Advancing } \\
\text { side material }\end{array}$ & $\begin{array}{c}\text { Rotation } \\
\text { speed (rpm) }\end{array}$ & $\begin{array}{c}\text { Welding speed } \\
\left(\mathrm{mm} \mathrm{min}^{-1}\right)\end{array}$ & Offset $(\mathrm{mm})$ & Tilt angle $\left(^{\circ}\right)$ \\
\hline DF1 & 6063 alloy & 2000 & 100 & 0 & 3 \\
DF2 & 6063 alloy & 2000 & 200 & 0 & 3 \\
DF3 & 6063 alloy & 2000 & 100 & 0.8 & 3 \\
DF4 & Al-B4C MMCs & 2000 & 100 & 0 & 3 \\
\hline
\end{tabular}

All dissimilar joints between $\mathrm{AA} 1100-16$ vol.\% $\mathrm{B}_{4} \mathrm{C}$ and $\mathrm{AA} 6063$ alloy produced under investigated welding conditions were stronger than the base materials of $\mathrm{Al}-\mathrm{B}_{4} \mathrm{C}$ MMC and demonstrated high UTS at $\sim 126 \mathrm{MPa}$ and good elongation at $\sim 8 \%$. The variation of welding speed (from $100 \mathrm{~mm} \mathrm{~min}^{-1}$ to $200 \mathrm{~mm} \mathrm{~min}^{-1}$ ), the material side of welds or the use of $0.8 \mathrm{~mm}$ offset to the 6063 aluminum side did not have significant impact on the tensile properties of the joined assembly. Microstructure analysis of the $\mathrm{Mg}$ concentration and $\mathrm{B}_{4} \mathrm{C}$ particle distribution indicates that a good material mixing and seamless bonding was achieved around the interface between the $\mathrm{Al}-\mathrm{B}_{4} \mathrm{C}$ MMC and $\mathrm{AA} 6063$ alloy during FSW. The EBSD analysis shows that during dissimilar FSW, there was a gradual microstructure evolution on both material sides, resulting in a variety of grain structures in the different weld zones. In the weld zones of FSW joints, the materials underwent dynamic recovery and recrystallization to different extents depending on their thermal mechanical history. The grain refinement of both materials in the nugget zone was observed (MMC side: 15 vs. $8 \mu \mathrm{m} ; 6063 \mathrm{Al}$ side 76 vs. $20 \mu \mathrm{m}$ ). It is recommended that the 6063 aluminum alloy should be located on the advancing side and the use of an appropriate offset to the 6063 aluminum side is preferred in order to reduce the tool wear while maintaining good mechanical property. 


\subsection{Macroscopic structure}

Fig. 6.1 shows the macroscopic images of dissimilar FSW joints produced under conditions listed in Table 6.1. It was observed that sound welds could be obtained for all the welding conditions investigated. A macro interface between the $\mathrm{Al}-\mathrm{B}_{4} \mathrm{C} \mathrm{MMC}$ and the 6063 alloy can be readily identified. It is evident that the two materials were not completely blended and their identities were retained in the nugget zone for all four welding conditions. This can be attributed to the unthreaded feature of the FSW tool which was designed in our prior study [127]. It was reported [128] that the macro-interface can be also easily identified in dissimilar FSW of AA2024 alloy and AA2014-20\% $\mathrm{Al}_{2} \mathrm{O}_{3}$ MMC using a tool with square pin which is similar to the results in the present study. On the other hand, a banded structure in the nugget zone, which possessed alternated MMC and Al layers, was observed in dissimilar FSW of AA2024 alloy and AA2009-15\%SiC MMC using threads on the pin [129-130]. It seems that FSW tools without threads cannot fully mix the materials macroscopically as the materials experienced a weak vertical flow movement.

When the 6063 alloy was located on the advancing side (Fig. 6.1a), the weld nugget featured with a convex aluminum alloy surrounded by a wedge shaped layer of MMC on the top. When the welding speed increased to $200 \mathrm{~mm} \mathrm{~min}^{-1}$, it seems this wedge shaped layer of MMC became thicker and more MMC material transferred into the aluminum alloy side (Fig. 6.1b). The use of an $0.8 \mathrm{~mm}$ offset to the 6063 aluminum side (Fig. 6.1c) did not change the materials flow pattern though the position of interface was shifted somewhat to the MMC side compared to Fig. 6.1a. An appropriate offset to the 6063 aluminum side can 
significantly reduce the amount of the MMC in contact with the FSW tool. Thus, the use of an offset may reduce tool wear during FSW of MMCs. However, in our preliminary tests, the use of a $1.5 \mathrm{~mm}$ offset failed to produce sound welds with full penetration. Therefore, the maximum offset must be carefully examined as sound welds can only be obtained in a very narrow welding window especially with the use of an unthreaded FSW tool. On the other hand, when the 6063 plate was located on the retreating side (Fig. 6.1d), the materials flow pattern was significantly changed. The interfaces of two materials are close to the original interface and some aluminum penetrated deeper into the MMC side to form bands. However, the deep concave top surface illustrated in Fig. 6.1d was observed on the aluminum side where the surface finish of the weld was negatively affected. According to W.J. Arbegast [131], the Material under shoulder zone is dragged across the joint from the retreating side toward the advancing side. When the 6063 alloy was located on the retreating side, more material could be dragged away since the monolithic Al alloy has a much lower flow stress than the MMC.

\subsection{Microstructure}

Fig. 6.2 shows the typical micrographs of the base material and the weld nugget zone on the MMCs side under an optical microscope. Some breakage and rotation of $\mathrm{B}_{4} \mathrm{C}$ particles can be observed in the weld nugget of the dissimilar joints produced under all welding conditions investigated. However, the particle breakage was less severe compared with that occurred during FSW of same AA1100-16\% $\mathrm{B}_{4} \mathrm{C}$ MMC material [127]. The breakage of $\mathrm{B}_{4} \mathrm{C}$ particles is mainly due to the collisions between the welding tool and the 
particles or between particles themselves [127]. In the dissimilar FSW, the chance of collisions with the welding tool and between $\mathrm{B}_{4} \mathrm{C}$ particles themselves was significantly reduced during the material transfer.

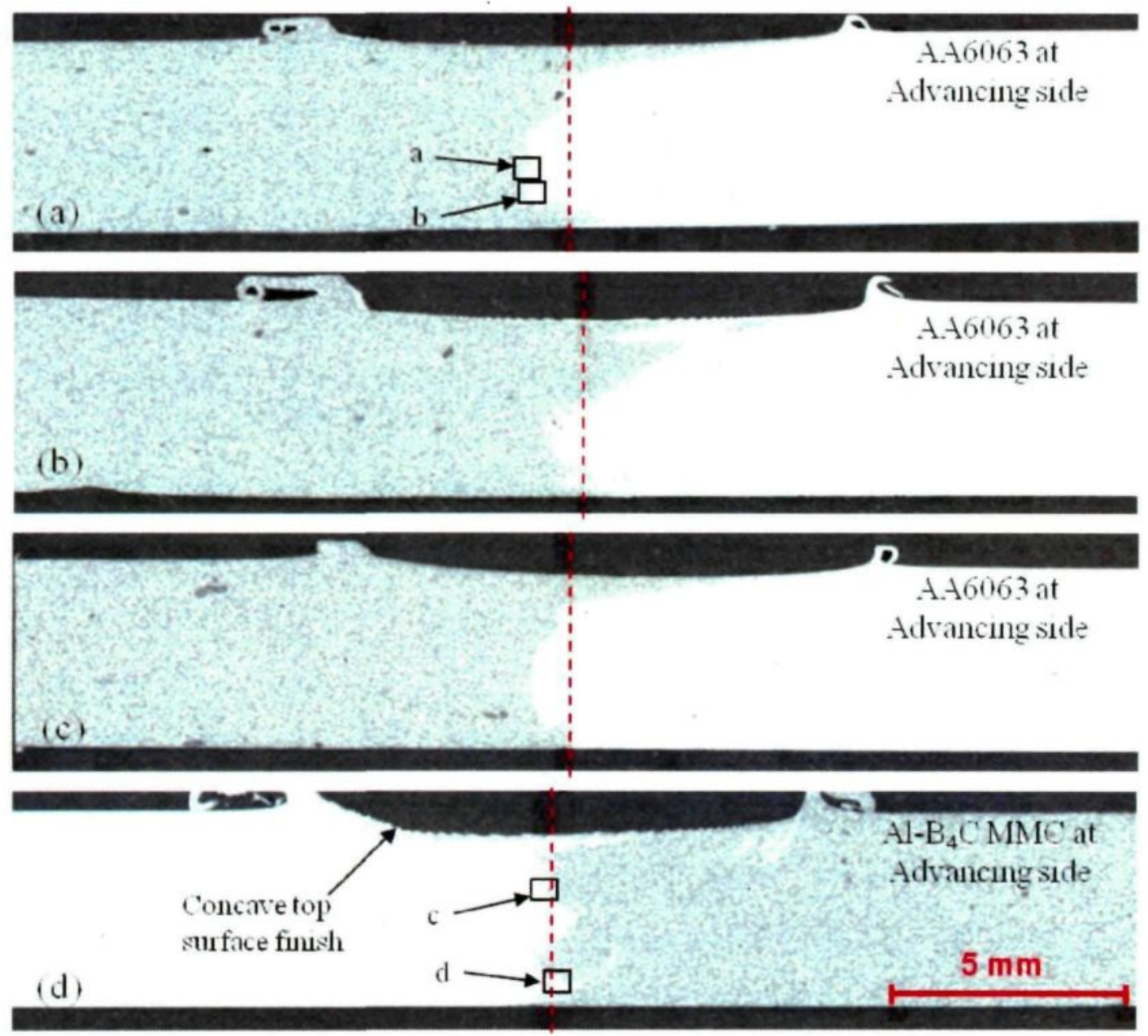

Fig. 6.1 Macroscopic images showing the cross-section of the dissimilar FSW joints produced under condition: (a) DF1, (b) DF2, (c) DF3, (d) DF4. Red dashed lines mark the original interfaces.

Fig. 6.3 shows the SEM images at the weld interfaces, corresponding to the two joint conditions of DF1 and DF4 in Fig. 6.1. To determine whether sound and seamless bonding 
between the two materials can be produced, the quantitative analysis of element $\mathrm{Mg}$, which was only contained in the AA6063 alloy (Table 3.1), was performed using SEM-EDS. Results of the Mg distribution at different positions of the interface are displayed in Fig. 6.3. The $\mathrm{Mg}$ content in the base 6063 alloy is approximately $0.5 \mathrm{wt} \%$. The presence of various $\mathrm{Mg}$ contents inside the MMC zone indicated that 6063 alloy was blended into the composite during FSW and that good material mixing was achieved microscopically at the $\mathrm{Al}-\mathrm{B}_{4} \mathrm{C}$ MMC and 6063 alloy interface. Based on the variation of $\mathrm{B}_{4} \mathrm{C}$ and $\mathrm{Mg}$ concentrations, a mixing zone of approximately $500 \mu \mathrm{m}$ wide can be recognized. In the mixed zone, the volume concentration of $\mathrm{B}_{4} \mathrm{C}$ particles evidently decreased and the $\mathrm{Mg}$ content gradually changed. It is obvious that the two dissimilar materials penetrated into each other. As a result, the interface had mixed profiles of $\mathrm{B}_{4} \mathrm{C}$ and $\mathrm{Mg}$ concentrations and a seamless bonding was formed between the $\mathrm{Al}-\mathrm{B}_{4} \mathrm{C}$ MMC and 6063 alloy during FSW.

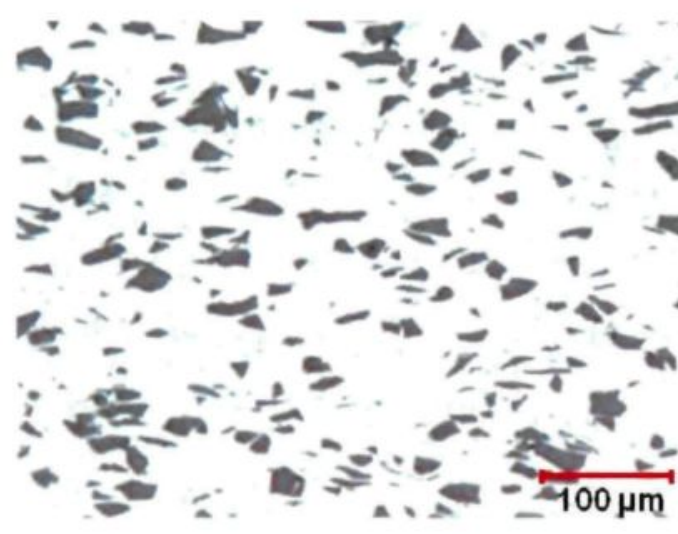

(a)

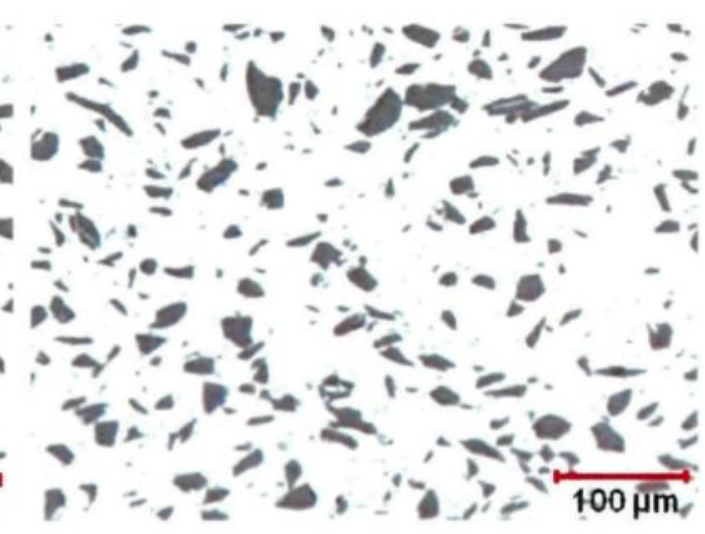

(b)

Fig. 6.2 Typical microstructure of the base material and the weld nugget zone on the MMCs side (DF4) 


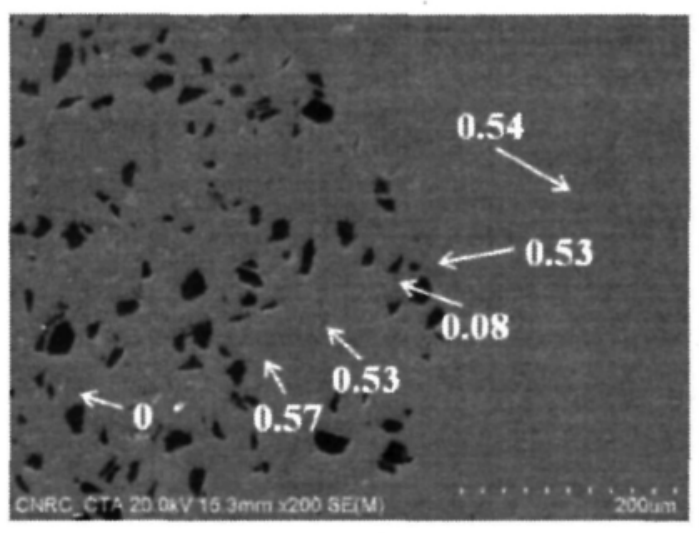

(a)

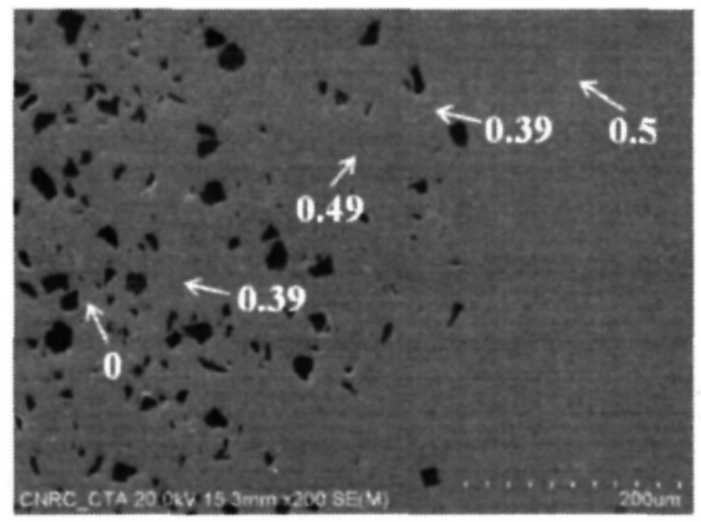

(b)

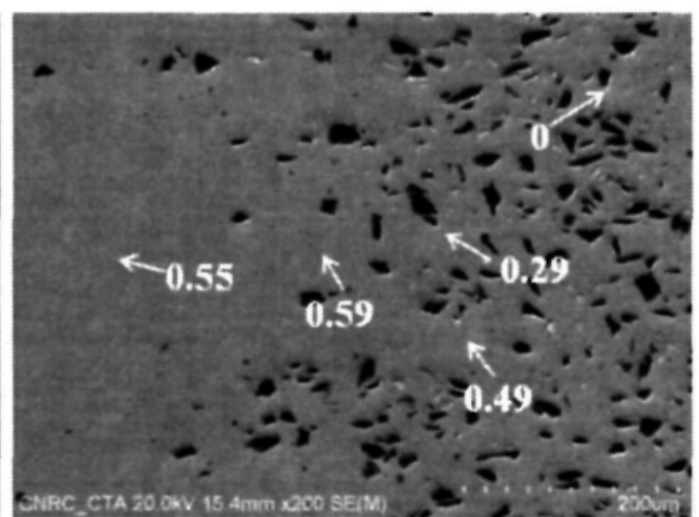

(c)

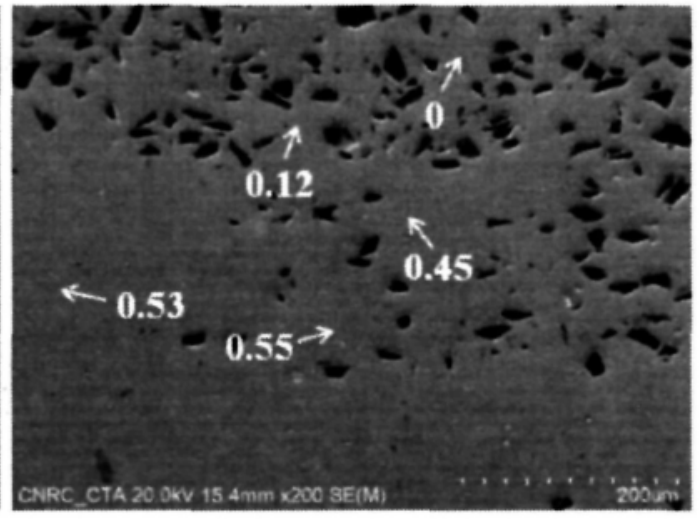

(d)

Fig. 6.3 SEM images showing the interfaces of the weld at positions marked in Fig. 6.1 (a, $b$ for condition DF1; $c, d$ for condition DF4).

The evolution of the grain and subgrain structures across the weld zone was analyzed with EBSD and the results, in the form of orientation maps with different misorientation angles are presented below. Fig. 6.4 shows the grain structure of the base materials before welding. Equiaxed grains with different sizes (average grain size in equivalent diameter of $15 \mu \mathrm{m}$ in $\mathrm{Al}-\mathrm{B}_{4} \mathrm{C}$ MMC and of $76 \mu \mathrm{m}$ in AA6063 alloy) were observed in the two base materials while more subgrains and dislocation networks could be observed in the matrix of $\mathrm{Al}-\mathrm{B}_{4} \mathrm{C}$ MMC. The typical grain structures in the weld nugget around the interface in the 
welds (DF1 and DF4) are provided in Fig. 6.5. After welding, grain refinement was observed in the nuggets produced under all welding conditions investigated. The average grain sizes in the nuggets were $8 \mu \mathrm{m}$ and $20 \mu \mathrm{m}$ on the sides of $\mathrm{Al}-\mathrm{B}_{4} \mathrm{C}$ and 6063 alloy respectively. It can be seen that many new recrystallized grains formed but a large amount of subgrains and dislocation networks still existed in the original deformed grains in both materials. This indicates the microstructure in the nugget was partially recrystallized on both sides of $\mathrm{Al}-\mathrm{B}_{4} \mathrm{C}$ and 6063 alloy. Several researchers [121, 132-134] attributed the grain refinement in the friction stir welding to continuous dynamic recrystallization, in which a continuous introduction of strain is coupled with rapid recovery and migration of subgrain/grain boundaries. During FSW, the material in the nuggets experienced severe deformation which continuously induced a very high density of dislocation. With continued deformation, the stored energy contained in these dislocations provides the driving force in the following recovery and recrystallization processes. It is worth noting that, in comparison with the 6063 alloy side, the $\mathrm{Al}-\mathrm{B}_{4} \mathrm{C}$ side in the nugget featured finer recrystallized grains. However, as no clear interface could be defined between the two materials, this demonstrated good mixing between $\mathrm{Al}-\mathrm{B}_{4} \mathrm{C}$ and the 6063 alloy.

The grain structure evolution along different weld zones was further analyzed in details using EBSD. Only the weld of DF1 was presented as the other conditions had a similar microstructure evolution behavior. At approximately $2 \mathrm{~mm}$ away from the nugget center (6063 alloy side, Fig. 6.6a), the grain structure featured a high level recrystallized microstructure. Many new recrystallized grains coexisted with the original deformed grains 
that contained a number of subgrains and dislocation networks. This indicates the materials in this zone experienced similar degree of deformation and have the same level of recrystallization as those in the nugget center (partial recrystallization). At approximately $3.6 \mathrm{~mm}$ away from the nugget center on the 6063 alloy side (Fig. $6.6 \mathrm{~b}$ ), the grain structure exhibited a low level of the recrystallization. A few recrystallized grains and many elongated grains with subgrain boundaries inside were observed. The elongated grains seem to follow the FSW tool shearing direction (vertical line of Fig. $6.6 \mathrm{~b}$ is parallel to the FSW tool axis). The materials in this zone experienced less severe deformation and hence lower driving force for recrystallization as compared with that in the nugget zone. At 4.4 $\mathrm{mm}$ away from the nugget center on the 6063 alloy side (Fig. 6.6c), a large amount of fine subgrains with low angles of 2 to $5^{\circ}$ misorientation were introduced inside the original grains. In this thermo-mechanically affected zone (TMAZ), the grains changed its shape from elongated to equiaxed one. As the materials in this zone only experienced a light deformation, only the dynamic recovery occurred. At $5.2 \mathrm{~mm}$ away from the nugget center on the 6063 alloy side (Fig. 6.6d), it seems that the grain structure returns to a coarse and equiaxed structure similar to that of the base 6063 alloy. In this heat affected zone, the mechanical deformation was negligible and the thermal energy induced by the friction could not change the grain structure.

On the other hand, the microstructure evolution on the $\mathrm{Al}-\mathrm{B}_{4} \mathrm{C} \mathrm{MMC}$ side demonstrated some different characteristics. The grain structure in the nugget center on the MMC side (Fig. 6.5) showed much finer recrystallized grains when compared with the 
6063 alloy side. This can be explained by two reasons: the particle stimulated nucleation effect induced by ceramic particles [135-136], and the original grain structure on the MMC side containing more high angle grain boundaries that can provide preferred nucleation sites for recrystallization [137]. At $3 \mathrm{~mm}$ away from the nugget center on the MMC side (Fig. 6.6e), the microstructure showed a partially recrystallized grain structure. In this TMAZ, the new recrystallized grains mixed with the original deformed grains that contained a number of subgrains with low angles of 2 to $5^{\circ}$. Unlike on the 6063 alloy side (Fig. 6.6b), elongated grains were rarely found. The grain structure difference on two material sides may be related to materials flow patterns experienced during FSW. At $4.8 \mathrm{~mm}$ away from the nugget center on the MMC side (Fig. 6.6f), there is no more recrystallization structure and only a number of subgrains with well-defined low angles were induced in the original grains.

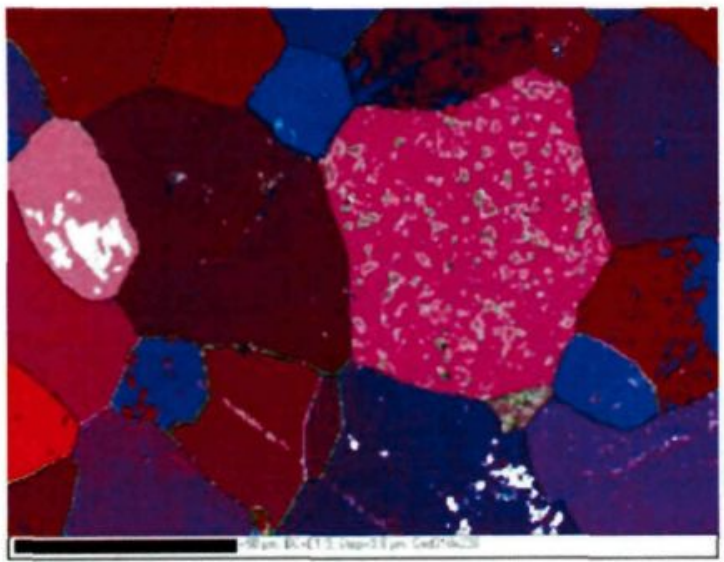

(a)

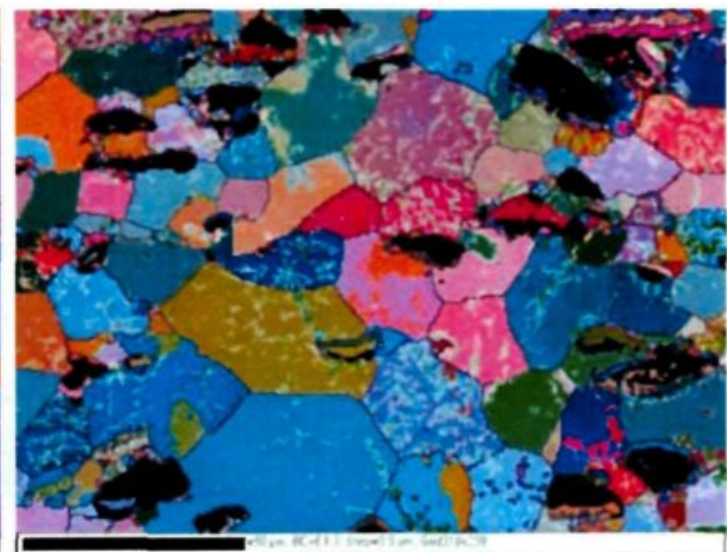

(b)

Fig. 6.4 Typical grain structure of the base materials before welding: (a) AA6063 aluminium alloy, (b) AA1100-16 vol.\% $\mathrm{B}_{4} \mathrm{C}$ MMC. Black color area in (a) represents $\mathrm{B}_{4} \mathrm{C}$ particles; black lines: $>10^{\circ}$, green lines: between $10^{\circ}$ and $5^{\circ}$, grey lines: between $5^{\circ}$ and $2^{\circ}$. 


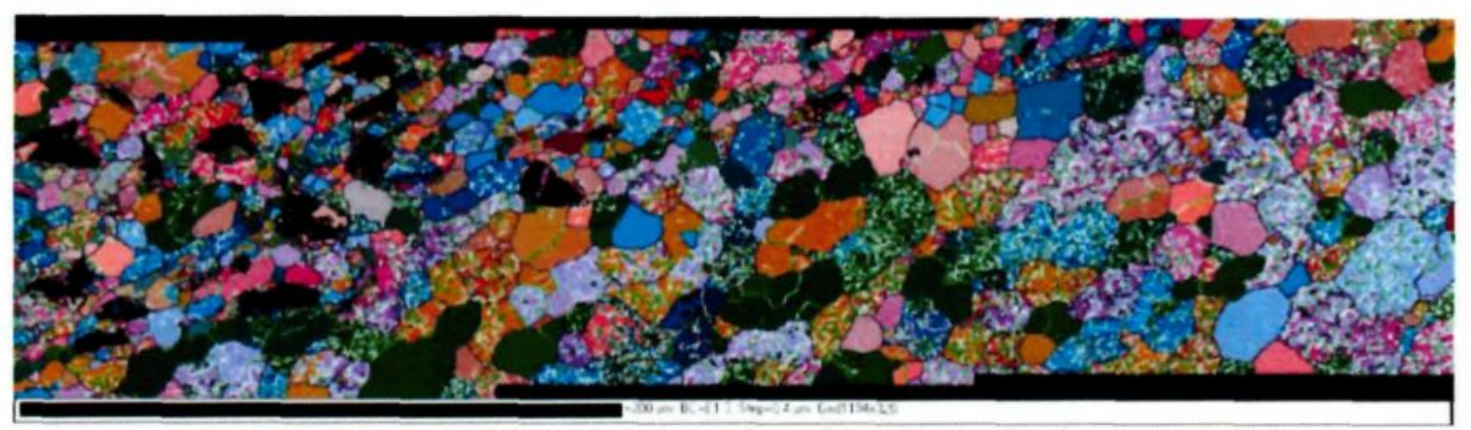

(a) DF1 (advancing side: 6063 alloy)

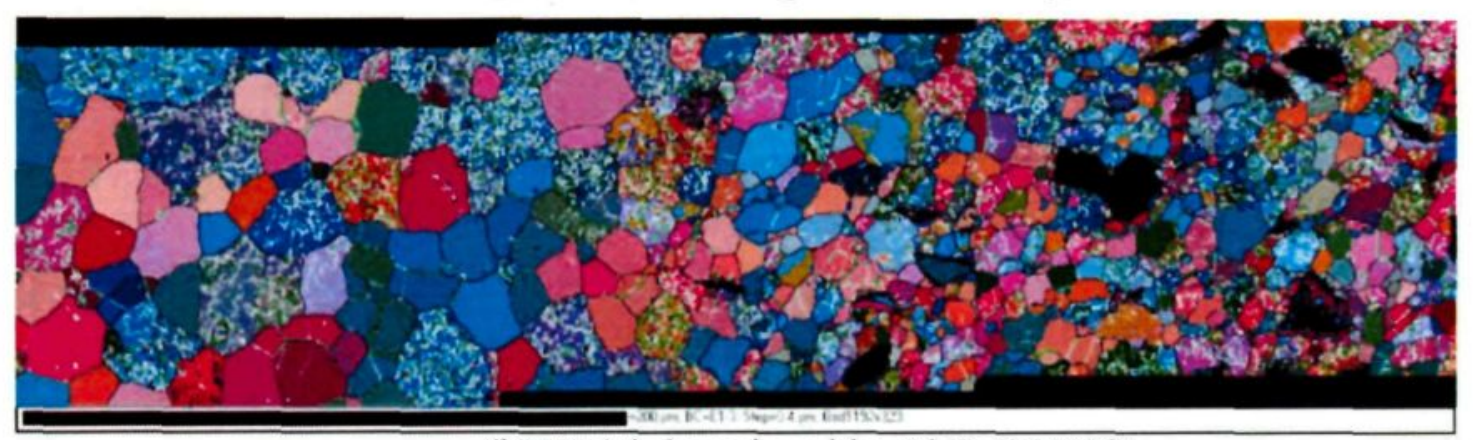

(b) DF4 (advancing side: $\mathrm{Al}-\mathrm{B}_{4} \mathrm{C} \mathrm{MMC}$ )

Fig. 6.5 Typical grain structures of the area around interface in the weld nugget of condition; (a) DF1 (advancing side: 6063 alloy), (b) DF4 (advancing side: $\mathrm{Al}_{-} \mathrm{B}_{4} \mathrm{C}$ MMC). Black color areas represent $\mathrm{B}_{4} \mathrm{C}$ particles; black lines: $>10^{\circ}$, green lines: between $10^{\circ}$ and $5^{\circ}$, grey lines: between $5^{\circ}$ and $2^{\circ}$.

The above EBSD results across the weld indicate that during dissimilar FSW, there is a gradual microstructure evolution on both material sides which results in a variety of grain structures in the different weld zones. In general, as the shear deformation and temperature sharply increase from the base materials towards the weld nugget, the initial non-deformed grains first undergo a subgrain development. At certain position close to the weld nugget, the subgrains with low angle boundaries with the original grains gradually transfer into individual fine and recrystallized grains with high angle boundaries. The transition from dynamic recovery to dynamic recrystallization towards the weld center leads to the grain refinement of both materials in the nugget zone. 


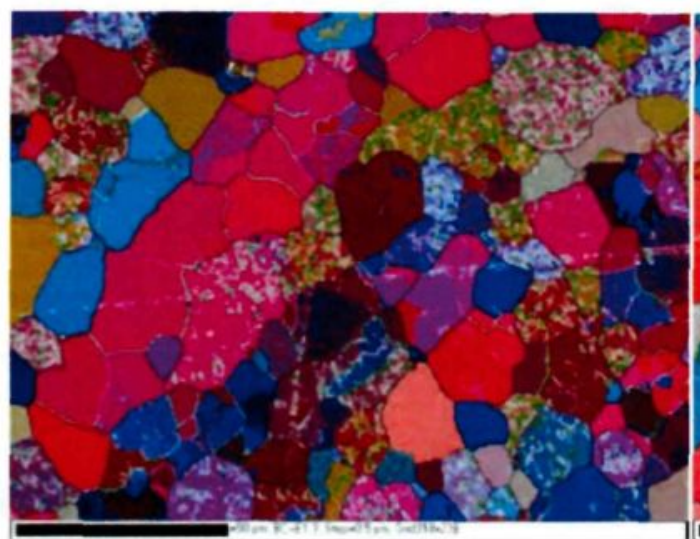

(a)

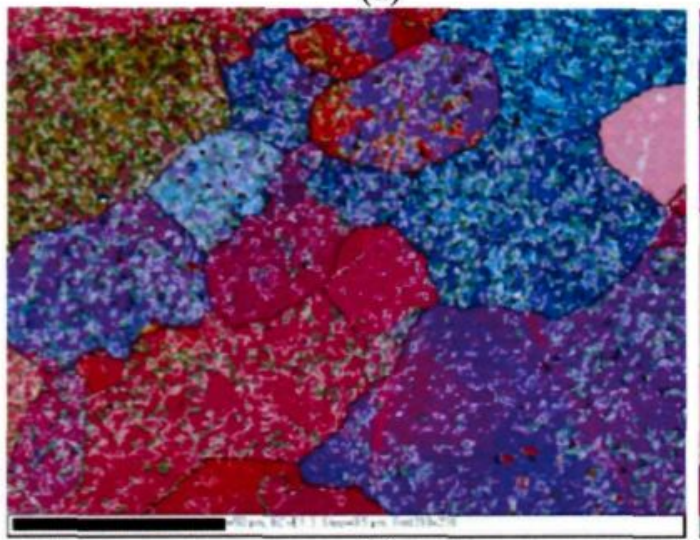

(c)

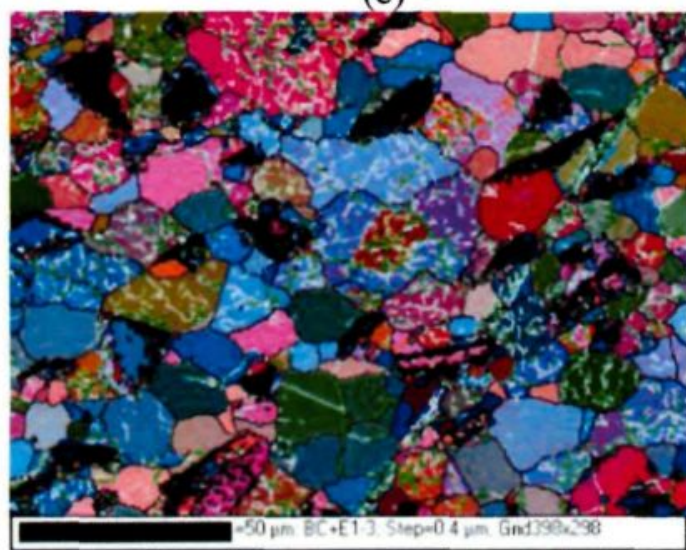

(e)

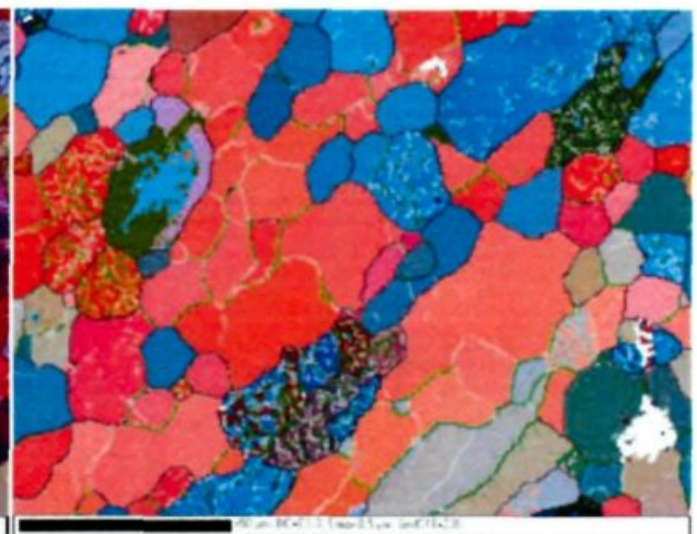

(b)

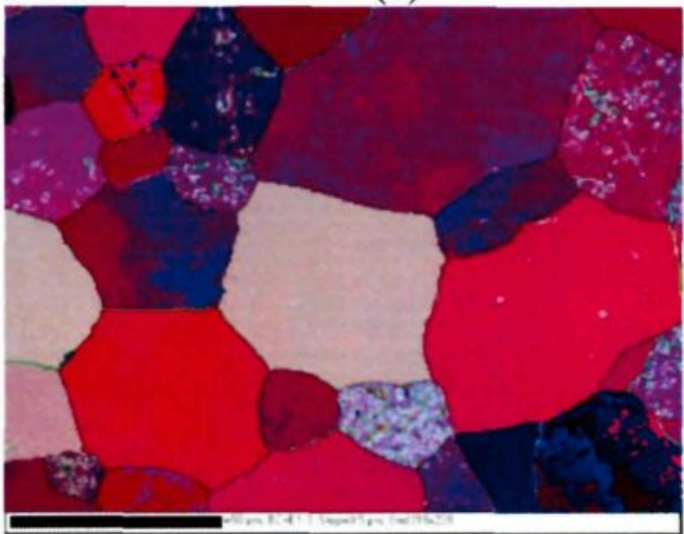

(d)

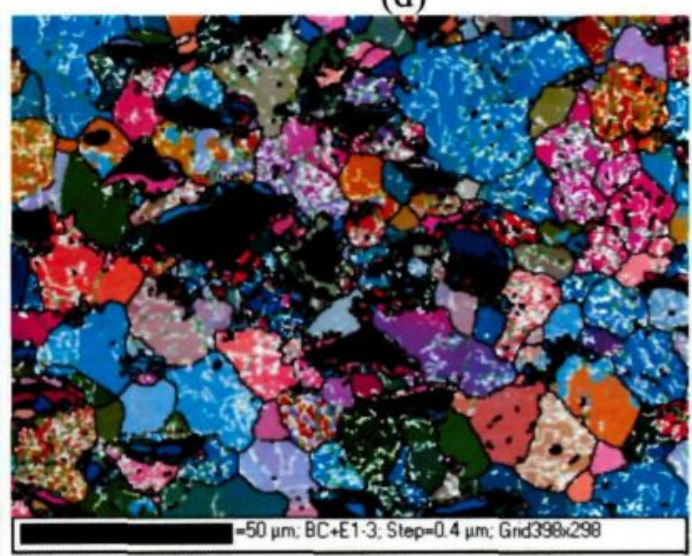

(f)

Fig. 6.6 Typical grain structure along different weld zones (a-d on the $6063 \mathrm{Al}$ side, e-f on the MMC side): (a) $2 \mathrm{~mm}$ from the nugget center, (b) $3.6 \mathrm{~mm}$ from the nugget center (TMAZ), (c) $4.4 \mathrm{~mm}$ from the nugget center (TMAZ), (d) $5.2 \mathrm{~mm}$ from the nugget center (HAZ), (e) $3 \mathrm{~mm}$ from the nugget center, (f) $4.8 \mathrm{~mm}$ from the nugget center. Black color areas represent $\mathrm{B}_{4} \mathrm{C}$ particles; black lines: $>10^{\circ}$, green lines: between $10^{\circ}$ and $5^{\circ}$, grey lines: between $5^{\circ}$ and $2^{\circ}$. 


\subsection{Mechanical Properties}

\subsubsection{Microhardness}

Vickers hardness of the dissimilar joints was measured at the top and bottom of each joint at intervals of about $0.5 \mathrm{~mm}$. The Vickers microhardness profiles across the joints were illustrated in Fig. 6.7 for DF1 and DF4 conditions. The microhardness profiles for the joints produced in the other two conditions are not reported as they are very similar to that of condition DF1. Fig. 6.7a shows that the base material of $\mathrm{Al}-\mathrm{B}_{4} \mathrm{C}$ has the lowest hardness values and indicates the failure would most likely occur in the MMC's side during tensile testing. The hardness in the nugget in the MMC side showed a modest increase compared to that of the base material. This is mainly due to the refinement of grain structure and the embedment of fine $\mathrm{B}_{4} \mathrm{C}$ particles. On the 6063 aluminum side, the hardness of the nugget displayed a significantly decrease compared to that of the base 6063 alloy. The hardness profile in 6063 aluminum alloy mainly depends on precipitate distribution and the effect of grain structure on the hardness is negligible $[18,75]$. It is interesting to note that the softened region on the 6063 side extends to approximately $15 \mathrm{~mm}$ away from the nugget center, which is much larger than that of the recrystallized / recovered region (around $5 \mathrm{~mm}$ from the nugget center) observed by EBSD technique. In this softened region, most precipitates were dissolved in the 6063 matrix due to a similar effect of the solution treatment induced by FSW thermal cycle. Moving away from the softened region, a partially softened region can be observed. In this region, the precipitates coarsened and partially dissolved. This is similar to an overaging process. Around the interface between 
two materials, some hardness values higher than that of 1100 matrix but lower than that of 6063 alloy can also be observed. This again demonstrated the good mixing of the two dissimilar materials. As described previously in section 6.2, the MMC material and 6063 aluminum alloy were blended into each other and the micro-interfaces have complex profiles of the composition. In Fig. 6.7, it is interesting to see that the microhardness profiles of the DF1 and DF4 joints are almost identical except that the DF4 has a reverse hardness profile because of the reverse material configuration of the joint.

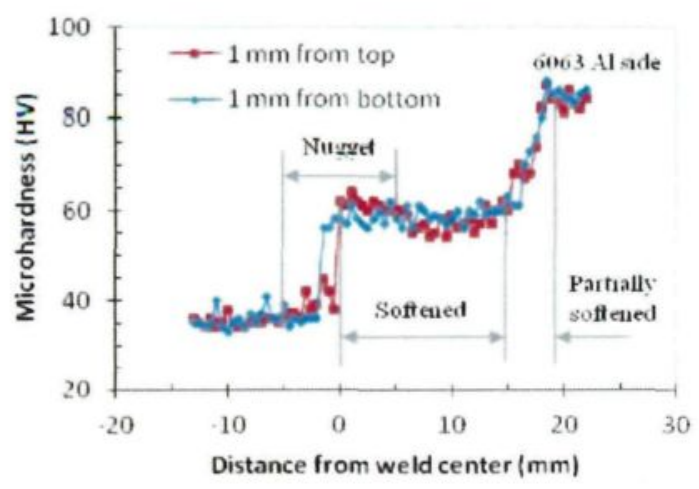

(a)

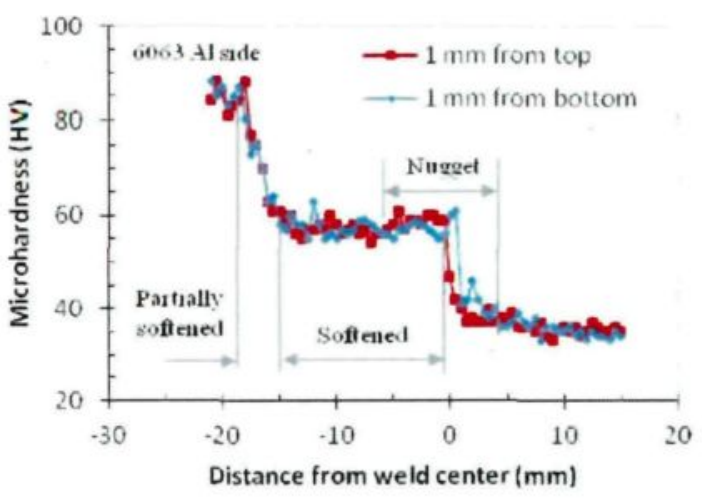

(b)

Fig. 6.7 Typical microhardness profiles across the dissimilar friction stir welds: (a) DF1, (b) DF4

\subsubsection{Tensile properties}

The transverse tensile testing of the base material of MMC and the dissimilar joints were performed. The results are listed in Table 6.2 and graphically illustrated in Fig. 6.8. All dissimilar joints showed similar values of ultimate tensile strength compared with the base materials of MMC. Most of the welded joints failed in the base material on the MMC 
side, far from the weld centers (Fig. 6.9). This indicated that the dissimilar welds were stronger than the base material of $\mathrm{Al}-\mathrm{B}_{4} \mathrm{C} \mathrm{MMC}$, which is attributed to the grain refinement of the weld nugget during FSW and the good mixing and seamless bonding between the two materials at the interface. A $100 \%$ joint efficiency (UTS) was attained for all dissimilar welds, when the joint efficiency was defined as the ratio of the UTS value of the joint versus that of the weaker material. In addition, the dissimilar joints produced under all welding conditions investigated showed much higher yield strength and slightly lower elongation compared to that of the base material of MMC. This is explained by the fact that the materials in the 6063 aluminum side were much stronger than in the MMC side (typical tensile values of AA6063-T5 are $185 \mathrm{MPa}$ in UTS, $145 \mathrm{MPa}$ in YS and $12 \%$ of elongation [123]. During tensile testing, the elongated deformation occurred mostly on the MMC side, as the total length of 6063 aluminum plate after testing remained almost the same as the original $90 \mathrm{~mm}$ (Fig. 6.9). Therefore, higher YS values were recorded at $0.2 \%$ strain and the slightly lower elongation of the dissimilar joints is measured because the material on the 6063 aluminum side was hardly deformed. At such condition and because the failure is far from the welds, the measured YS and elongation do not reflect the real tensile values of the welds. It is worthwhile to mention that variation of welding speed (from $100 \mathrm{~mm} \mathrm{~min}$ to $200 \mathrm{~mm} \mathrm{~min}^{-1}$ ), the material side of welds or the use of $0.8 \mathrm{~mm}$ offset to the 6063 aluminum side did not have significant impact on the tensile properties of the joined assembly. 
Table 6.2 Tensile tests results of dissimilar friction stir welded joints*

\begin{tabular}{llllll}
\hline Conditions & $\begin{array}{l}\text { UTS } \\
(\mathrm{MPa})\end{array}$ & $\begin{array}{l}\text { YS } \\
(\mathrm{MPa})\end{array}$ & $\begin{array}{l}\text { Elongation } \\
(\%)\end{array}$ & $\begin{array}{l}\text { Joint } \\
\text { efficiency } \\
\text { (UTS) }\end{array}$ & $\begin{array}{l}\text { Failure } \\
\text { location } \\
\text { (MMC side) }\end{array}$ \\
\hline Base MMC & $126 \pm 2$ & $61 \pm 1$ & $13 \pm 3$ & -- & -- \\
DF1 $\left(100 \mathrm{~mm} \mathrm{~min}^{-1}\right)$ & $127 \pm 1$ & $81 \pm 4$ & $9 \pm 1$ & $100 \%$ & Base \\
DF2 $\left(200 \mathrm{~mm} \mathrm{~min}^{-1}\right)$ & $128 \pm 1$ & $81 \pm 2$ & $10 \pm 1$ & $100 \%$ & Base/TMAZ \\
DF3 $(0.8$ offset) & $126 \pm 1$ & $79 \pm 1$ & $8 \pm 1$ & $100 \%$ & Base \\
DF4 (reverse side) & $127 \pm 1$ & $80 \pm 2$ & $8 \pm 1$ & $100 \%$ & Base/TMAZ \\
\hline
\end{tabular}

* Joint efficiency: ratio of the UTS of joints to that of the weaker material (Al- $\left.\mathrm{B}_{4} \mathrm{C} M M C\right)$ in the joint configuration.

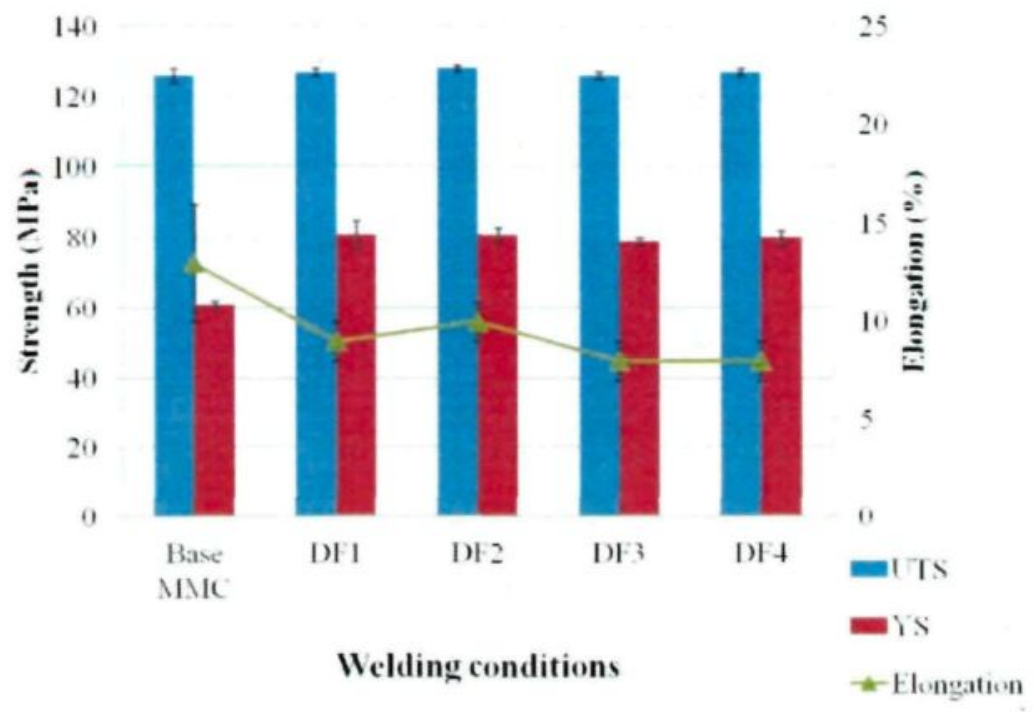

Fig. 6.8 Tensile test results of dissimilar friction stir welded joints.

It should be noted that a more concave top surface finish was always observed on the 6063 aluminum side when the 6063 aluminum was located in the retreating side (Fig. 6.1d). Although the concave feature on the top surface did not influence the tensile properties (DF4 in Table 6.2), it remarkably reduces the thickness of the weld section and affects the surface finish of the joints. In addition, the transverse fatigue life of the joints can be 
deteriorated [37, 138-139]. For this reason, it is desirable that the 6063 aluminum alloy be fixed on the advancing side. In addition, the use of an appropriate offset to the 6063 aluminum side is preferred in order to reduce the tool wear while maintaining good mechanical properties.

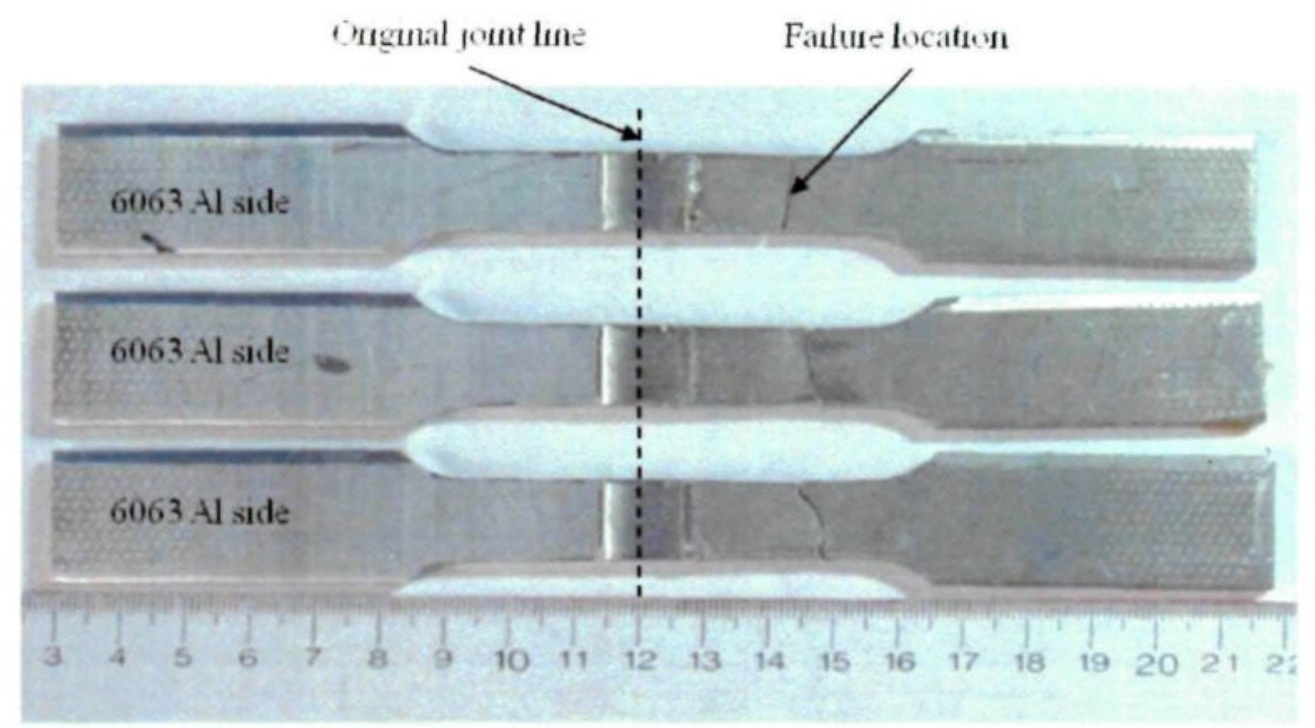

Fig. 6.9 Fractured tensile samples of the dissimilar joints showing the failure locations and the distribution of elongation (DF1)

\subsection{Summary \& Conclusions}

1. All dissimilar joints between AA1100-16 vol.\% $\mathrm{B}_{4} \mathrm{C}$ and AA6063 alloy produced under investigated welding conditions were stronger than the base materials of $\mathrm{Al}-\mathrm{B}_{4} \mathrm{C}$ MMC and demonstrated high UTS at $\sim 126 \mathrm{MPa}$ and good elongation at $\sim 8 \%$. The variation of welding speed, the material side of welds or the use of $0.8 \mathrm{~mm}$ offset to the 6063 aluminum side did not have significant impact on the tensile properties of the joined assembly. 
2. Analysis of the $\mathrm{Mg}$ concentration and $\mathrm{B}_{4} \mathrm{C}$ particle distribution indicates that a good material mixing and seamless bonding was achieved around the interface between the Al$\mathrm{B}_{4} \mathrm{C}$ MMC and AA6063 alloy during FSW. The materials in the weld zones of FSW joints underwent dynamic recovery and recrystallization to different extents, depending on their thermal mechanical history. The transition of dynamic recovery to dynamic recrystallization towards the weld center was observed, which leads to the grain refinement of both materials in the nugget zone.

3. The microhardness in the weld showed a slight increase on the MMC side and a significant decrease on the AA6063 side compared to their specific base materials.

4. It is recommended that the AA6063 alloy should be fixed on the advancing side The reverse joint configuration would cause a deep concave top surface on the aluminum side of the joints. The use of an appropriate offset to the AA6063 aluminum side is preferred. 


\section{Chapter VII}

\section{Conclusions and recommendations}




\section{Chapter VII Conclusions and recommendations}

\subsection{Conclusions}

Laser and friction stir welds have been produced in butt configuration at various process conditions for $\mathrm{Al}-\mathrm{B}_{4} \mathrm{C}$ MMC. Decomposition of $\mathrm{B}_{4} \mathrm{C}$ particles was observed and needle-like $\mathrm{AlB}_{2}$ and $\mathrm{Al}_{3} \mathrm{BC}$ phases were substantially formed during laser welding of $\mathrm{AA} 1100-\mathrm{B}_{4} \mathrm{C}$ MMCs (16\% and 30\%) without filler. In this case, a joint efficiency of $63 \%$ (UTS) was obtained after tensile test. The variation of laser power from 2 to $4 \mathrm{~kW}$ and welding speed from 1 to $2.5 \mathrm{~m} / \mathrm{min}$ did not affect the needle-like morphology. Based on thermodynamic calculation, Ti filler was used as a filler material aiming to improve the properties of laser joints. It was found that the addition of $\mathrm{Ti}$ with $150 \mu \mathrm{m}$ thick foil between the facing edges increased the joint efficiency to $75 \%$ due to the decrease of size and quantities of needle-like phases. However, the joints made with addition of $300 \mu \mathrm{m}$ thick foil only showed slight increase of joint strength because of the formation of a large amount of intermetallics. The addition of $\mathrm{Ti}$ with filler wire instead of $\mathrm{Ti}$ foil did not show significant mechanical property improvement even by varying the filler wire rate due to the Ti segregation and microstructure inhomogeneity in the weld zone. It should be noted that 
the ductility of all laser joints remains lower than $1 \%$ even with $\mathrm{Ti}$ addition since the strain was localized in the joint during tensile testing.

On the other hand, friction stir welding could produce sound joints without any formation of needle-like intermetallics because it is a solid state process. It was found that friction stir welding has a significant influence on the $\mathrm{B}_{4} \mathrm{C}$ particle size distribution and the matrix grain size. Tensile testing of welded joints showed up to $100 \%$ joint efficiency for both annealed $\mathrm{AA} 1100-16 \% \mathrm{~B}_{4} \mathrm{C}$ and $\mathrm{AA} 1100-30 \% \mathrm{~B}_{4} \mathrm{C}$ composite materials. However, if the ultimate tensile strength values of all the studied composites are similar at $\sim 130 \mathrm{MPa}$, the weld ductility is higher for the annealed materials. Besides, it was observed that for a given tool rotation speed varying the welding speed between 100 and $275 \mathrm{~mm} / \mathrm{min}$ does not influence the tensile properties and the particle size distribution in the nugget. Furthermore, the welding tool made of WC-Co showed much better durability than the steel tool $(0.8 \mathrm{vs}$. $19 \mathrm{~mm}^{3} / \mathrm{m}$ ) for which tool wear occurred mainly on the shoulder edges. The FSW joint surfaces using both tools exhibited lower corrosion resistance compared with the base material. However, the joints made by WC-15wt.\%Co tool showed a better corrosion resistance than those made by using steel tool.

The dissimilar joints between $\mathrm{AA} 1100-16 \% \mathrm{~B}_{4} \mathrm{C}$ MMCs and monolithic AA6063 aluminium alloy were also investigated. All dissimilar joints produced under investigated welding conditions were stronger than the base materials of $\mathrm{Al}-\mathrm{B}_{4} \mathrm{C}$ composites and demonstrated high UTS at $\sim 126 \mathrm{MPa}$ and good elongation at $\sim 8 \%$. Analysis of $\mathrm{Mg}$ concentration and $\mathrm{B}_{4} \mathrm{C}$ particle distribution indicates that a good material mixing and 
seamless bonding was achieved around the interface between the $\mathrm{Al}-\mathrm{B}_{4} \mathrm{C}$ composite and AA6063 alloy during FSW. The electron backscatter diffraction (EBSD) analysis shows that during dissimilar FSW, there was a gradual microstructural evolution on both material sides, resulting in a variety of grain structures in the different weld zones. In the weld zones of FSW joints, the materials underwent dynamic recovery and recrystallization to different extents depending on their thermal mechanical history. The grain refinement of both materials in the nugget zone was observed. It is recommended that the AA6063 aluminum alloy should be fixed on the advancing side and the use of an appropriate offset $(0.8 \mathrm{~mm})$ to the AA6063 aluminum side is preferred.

The present study revealed that laser welding may be a good alternative for joining $\mathrm{AA} 1100-\mathrm{B}_{4} \mathrm{C}$ MMCs as the maximum joint efficiency can reach up to $75 \%$ (UTS). It is expected that enhancement of mechanical properties could be achieved if an optimum $\mathrm{Ti}$ amount was added and the $\mathrm{Ti}$ was uniformly distributed in the weld. However, the elongation of all laser joints remains lower than $1 \%$ even with $\mathrm{Ti}$ addition. On the other hand, FSW was considered to be a superior choice for joining $\mathrm{Al}-\mathrm{B}_{4} \mathrm{C} \mathrm{MMCs}$ as it avoided chemical reactions and led to excellent mechanical properties. It is recommended that the FSW be used for materials in annealed conditions as the joint efficiency and ductility are higher than that of as rolled materials. Therefore, the industrial application of $\mathrm{Al}-\mathrm{B}_{4} \mathrm{C}$ MMCs will be expanded after this study as the joining of these materials is no longer a problem. 


\subsection{Recommendations}

The feasibility of laser welding and friction stir welding for joining AA1100-B $\mathrm{C}$ MMCs has been demonstrated in the present study. In particular, the microstructural evolution and mechanical property response of the materials during welding were investigated. Based on the present study, following recommendations can be made for future work in this field.

Laser welding of $\mathrm{Al}-\mathrm{B}_{4} \mathrm{C}$ MMC products with different reinforcement concentrations or different thicknesses can be conducted. These factors may change the temperature and the reaction equilibrium in the welding pool. Thus, welds with less brittle phase formation and good mechanical property could be produced.

Ti filler addition in other forms such as powder or electroplating can be tried to improve $\mathrm{Ti}$ distribution in laser welding pool and hence to optimize the mechanical properties of laser joints. Other filler metal containing Sc, Zr, or Ni elements could also be tested as they may also prevent the formation of brittle phases in fusion welding of $\mathrm{Al}-\mathrm{B}_{4} \mathrm{C}$ MMCs.

FSW tools with different wear resistant coatings can be examined to improve tool life and to reduce welding cost. 


\section{References}

[1] M. Rittner, "Metal matrix composites in the 21 st century: markets and opportunities", Report, Norwalk, CT: BCC, Inc., 2000.

[2] D.B. Miracle, "Metal matrix composites - From science to technological significance", Composite Science \& Technology, Vol. 65, No. 15-16, 2005, pp. 2526-2540.

[3] S. Rawal, “Metal matrix composites for space applications”, JOM, Vol. 53, No. 4, 2001, pp. 1417.

[4] J.S. Ahearn, C. Cooke and S.G. Fishman, "Fusion welding of $\mathrm{SiC}$ reinforced Al composites", Metal Construction, Vol. 14, No. 4, 1982, pp. 192-197.

[5] T.M. Stantz, D.K. Aldun, D.J. Morrison, T. Diebold, P. Martin and M. Bruskotter, "Weldability of boron carbide reinforced aluminium", Proceedings on International Trends in Welding Science and Technology, Eds. S.A. David and J.M. Vitek, Gatlinburg, Tennessee, USA, 1-5 June 1992, pp. 781-785.

[6] DURALCAN Composites, Arc Welding Guidelines, Duralcan USA, 1991, pp. 1-11.

[7] Z. Z. Xuan, X. Y. Gu, R. Zhong and D. Q. Sun, "Microstructures and mechanical properties of tungsten inert gas arc welded magnesium metal matrix composite (TiCp/AZ91D)", Materials Science and Technology, Vol. 26, No. 12, 2010, pp. 1513-1517.

[8] X. Cao, W. Wallace, C. Poon and J.-P. Immarigeon, "Research and progress in laser welding of wrought aluminium alloys. I. Laser welding processes", Materials and Manufacturing Processes, Vol. 18, No. 1, 2003, pp. 1-22.

[9] W.M. Steen, Laser Material Processing, $3^{\text {th }}$ edition, Springer, 2003, pp. 157-199. 
[10] W.W. Duley, Laser Welding, $1^{\text {st }}$ edition, John Wiley \& Sons. Inc., 1999.

[11] M.B.D. Ellis, "Joining of metal matrix composites - A review", The TWI Journal, Vol. 6, No. 1, 1997, pp. 67-128.

[12] I. Calliari, M. Dabalà and M. Penasa, "Pulsed Nd-YAG laser welding of MMCs", Advanced Engineering Materials, Vol. 2, No. 10, 2000, pp. 653-656.

[13] P. Bassani, E. Capello, D. Colombo, B. Previtali and M. Vedani, "Effect of process parameters on bead properties of A359/SiC MMCs welded by laser", Composites Part A: Applied Science and Manufacturing, Vol. 38, No. 4, 2007, pp. 1089-1098.

[14] F. Bonollo, A. Tiziani and M. Penasa, " $\mathrm{CO}_{2}$ laser welding of aluminium matrix composites", International Journal of Materials \& Product Technology, Vol. 17, No. 3-4, 2002, pp. 291-302.

[15] K.C. Meinert Jr., R.P. Martukanitz and R.B. Bhagat, "Laser processing of discontinuously reinforced aluminium composites", Proceedings of the American Society for Composites, Seventh technical conference: Composite Materials, Mechanics, Processing, H.T. Hahn (eds), State college, Pennsylvania, 1992, pp. 168-177.

[16] N.B. Dahotre, T.D. McCay and M.H. McCay, "Laser induced liquid phase reaction synthesis assisted joining of metal matrix composites", Materials and Manufacturing Processes, Vol. 9, No. 3, 1994, pp. 447-466.

[17] S. Vaucher and O. Beffort, "Bonding and interface formation in metal matrix composites (MMC)", MMC-Assess Thematic Network, MMC-Access Consortium, Vol. 9, Sep. 2001, pp. 1-41.

[18] X.-G. Chen, M. da Silva, P. Gougeon and L. St-Georges, "Microstructure and mechanical properties of friction stir welded $\mathrm{AA} 6063-\mathrm{B}_{4} \mathrm{C}$ metal matrix composites", Materials Science and Engineering A, Vol. 518, No. 1-2, 2009, pp. 1-11.

[19] L.M. Marzoli, A.V. Strombeck, J.F. Dos Santos, C. Gambaro and L.M. Volpone, "Friction stir welding of an $\mathrm{AA} 6061 / \mathrm{Al}_{2} \mathrm{O}_{3} / 20 \mathrm{p}$ reinforced alloy", Composites Science and Technology, Vol. 66, No. 2, 2006, pp. 363-371. 
[20] L. Ceschini, I. Boromei, G. Minak, A. Morri and F. Tarterini, "Effect of friction stir welding on microstructure, tensile and fatigue properties of the AA7005/10vol\% $\mathrm{Al}_{2} \mathrm{O}_{3}$ p composite", Composites Science and Technology, Vol. 67, No. 3-4, 2007, pp. 605-615.

[21] R.A. Prado, L.E. Murr, K.F. Soto and J.C. McClure, "Self-optimization in tool wear for friction-stir welding of $\mathrm{Al} 6061+20 \% \mathrm{Al}_{2} \mathrm{O}_{3}$ MMC", Materials Science and Engineering A, Vol. 349, No. 1-2, 2003, pp. 156-165.

[22] A. Machiels and R. Lambert, Handbook of Neutron Absorber Materials for Spent Nuclear Fuel Transportation and Storage Applications, Report, EPRI Proprietary Licensed Material, 2006, pp. 1.1-1.2 and 7.1-7.49.

[23] X.G. Chen, "Application of $\mathrm{Al}-\mathrm{B}_{4} \mathrm{C}$ metal matrix composites in the nuclear industry for neutron absorber materials", In: Grupta N, Hunt WH (eds) Proceedings of solidification processing of metal matrix composites, TMS 2006, San Antonio, USA, March 2006, pp. 343-350.

[24] T.W. Nelson, H. Zhang and T. Haynes, "Friction stir welding of aluminium MMC 6061- boron carbide", Proceedings of 2nd International Friction Stir Welding Symposium 26-28 June 2000, TWI, Gotherburg Sweden, Session 5, Paper 2. pp. 1-8.

[25] K.U. Kainer, "Basics of metal matrix composites", Metal Matrix Composites: Custom-made Materials for Automotive and Aerospace Engineering, $1^{\text {st }}$ edition, WILEY-VCH Verlag GmbH \& Co. KGaA, Weinheim, 2006, pp.1-52.

[26] J.V. Foltz, "Metal matrix composites", Properties and Selection: Nonferrous Alloys and Special-Purpose Materials, ASM Handbook, ASM International, Vol. 2, 1990, pp. 2520-2539.

[27] E. Alman, "Properties of metal-matrix composites", Composites, ASM Handbook, ASM International, Vol. 21, 2001, pp. 1908-1956.

[28] http://clev11.com/ composi1/?page_id=25, 2012.

[29] W. Robert and M. Mohan, "Fabrication of near-net shape graphite/magnesium composites for large mirrors", Advances in optical structure systems; Proceedings of the Meeting, Orlando, FL, 
Apr. 16-19, 1990 (A91-36651 15-74). Bellingham, WA, Society of Photo-Optical Instrumentation Engineers, pp. 554-561.

[30] R.A. Carden, "Metal matrix compositions and method of manufacture thereof", US Patent 5613189, March 1997.

[31] B.R. Jones, A.R. Prunier Jr. and A.J. Pyzik, "Brake or clutch components having a ceramicmetal composite friction material", US Patent 6458466, Oct. 2002.

[32] X.-G. Chen, "Interface reaction of boron carbide in aluminium matrix composites and its control", EPD Congress 2005, edited by Mark E. Schlesinger, TMS 2005, pp. 101-106.

[33] D.C. Halverson, A.J. Pyzik, I.A. Aksay and W.E. Snowden, "Processing of boron carbidealuminium composites", Journal of the American Ceramic Society, Vol. 72, No. 5, 1989, pp. 775 780 .

[34] J.C. Viala, G. Gonzalez and C. Esnouf, "Chemical reactivity of aluminium with boron carbide", Journal of Materials Science, Vol. 32, No. 17, 1997, pp. 4559-4573.

[35] G. Çam and M. Koçak, "Progress in joining of advanced materials", International Materials Reviews, Vol. 43, No. 1, 1998, pp. 1-39.

[36] H. Persson, "Guidelines for Joining of Metal Matrix Composites", MMC-Assess - Thematic Network, MMC-Access Consortium, Vol. 8, 2001, pp. 1-12.

[37] R.S. Mishra and Z.Y. Ma, "Friction stir welding and processing", Materials Science and Engineering R, Vol. 50, No. 1-2, 2005, pp.1-78.

[38] T.J. Lienert, C.T. Lane and J.E. Gould, "Selection and weldability of aluminium metal-matrix composites", Welding, Brazing and Soldering, ASM Handbook, ASM International, Vol. 6, 1993, pp. 1388-1400.

[39] A. Hirose, Y. Matsuhiro, M. Kotoh, S. Fukumoto and K.F. Kobayashi, "Laser-beam welding of SiC fibre-reinforced Ti-6Al-4V composite", Journal of Materials Science, Vol. 28, No. 2, 1993, pp. 349-355. 
[40] I. W. Hall, T. Kyono and A. Diwanji, "On the fibre/matrix interface in boron/aluminium metal matrix composites", Journal of Materials Science, Vol. 22, No. 5, 1987, pp. 1743-1748.

[41] Y. Coo, "Effect of in situ reaction on microstructure of TIG welding SiCp/A356 with $\mathrm{Ti}$ as filler metal", Materials Science and Technology, Vol. 23, No. 8, 2007, pp. 917-922.

[42] J. Grabian and J. Wysocki, "TIG-bonding of AlSi9/SiC composites", Welding International, Vol. 21, No. 4, 2007, pp. 368-371.

[43] R. Garcia, V.H. Lopez, E. Bedolla and A. Manzano, "A comparative study of the MIG welding of $\mathrm{Al} / \mathrm{TiC}$ composites using direct and indirect electric arc processes", Journal of Materials Science, Vol. 38, No. 12, 2003, pp. 2771-2779.

[44] T.J. Lienert, E.D. Brandon and J.C. Lippold, "Laser and electron beam welding of SiC reinforced aluminium A356 metal matrix composites", Scripta Metallurgica and Materialia, Vol. 28, No. 11, 1993, pp. 1341-1346.

[45] X.-P. Zhang, L. Ye, Y.-W. Mai, G.-F. Quan and W. Wei, "Investigation on diffusion bonding characteristics of $\mathrm{SiC}$ particulate reinforced aluminium metal matrix composites", Composites : Part A, Vol. 30, No. 12, 1999, pp. 1415-1421.

[46] A. Urena, J.M. Gomez de Salazar, M.D. Escalera and W.B. Hanson, "Diffusion bonding of alumina reinforced 6061 alloy metal matrix composite using Al-Li interlayer", Materials Science and Technology, Vol. 16, No. 1, 2000, pp. 103-109.

[47] M.J. Cola and C.E. Albright, "Inertia-friction welding of particulate-reinforced aluminium composites-initial studies", Proceedings on International Trends in Welding Science and Technology, Eds. S.A. David and J.M. Vitek, Gatlinburg, Tennessee; USA; 1-5 June 1992. pp. 1139-1146.

[48] A.A.M. da Silva, A. Meyer, J.F. dos Santos, C. E. F. Kwietniewski and T. R. Strohaecker, "Mechanical and metallurgical properties of friction-welded $\mathrm{TiC}$ particulate reinforced $\mathrm{Ti}-6 \mathrm{Al}-4 \mathrm{~V}$ ", Composites Science and Technology, Vol. 64, No. 10-11, 2004, pp. 1495-1501. 
[49] O.T. Midling and O. Grong, "Continuous drive friction welding of SiC particulate reinforced aluminium composites", Proceedings on International Trends in Welding Science and Technology, Eds. S.A. David and J.M. Vitek, Gatlinburg, TN; 1-5 June 1992, pp. 1147-1151.

[50] K. Nakata, S. Inoki, Y. Nagano and M. Ushio, "Friction stir welding of $\mathrm{Al}_{2} \mathrm{O}_{3}$ particulate 6061 Al alloy composite", Materials Science Forum, Vols. 426-432, 2003, pp. 2873-2878.

[51] D. Storjohann, O.M. Barabash and S.S. Babu, "Fusion and friction stir welding of aluminiummetal-matrix composites", Metallurgical and Materials Transactions A, Vol. 36A, No. 11, 2005, pp.3237-3247.

[52] C. Daweys, Laser welding: a practical guide, $1^{\text {st }}$ edition, Woodhead Publishing Ltd., Cambridge, UK, 1992.

[53] E. Kannatey-Asibu, Principles of laser materials processing, $1^{\text {st }}$ edition, John Wiley and Sons, Hoboken, New Jersey, 2009.

[54] J.C. Ion, Laser processing of engineering materials: principles, procedure and industrial application, $1^{\text {st }}$ edition, Butterworth-Heinemann, Burlington, MA, 2005

[55] G. Mathers, The welding of aluminium and its alloys, $1^{\text {st }}$ edition, Woodhead Publishing Ltd and CRC Press LLC, NW Boca Raton FL, 2002.

[56] M. Dabalà and M. Magrini, "Influence of $\mathrm{CO}_{2}$ laser beam welding on microstructure of aluminium metal matrix composites reinforced with $\mathrm{Al}_{2} \mathrm{O}_{3}$ particles", Science and Engineering of Composite Materials, Vol. 9, No. 3, 2000, pp. 123-130.

[57] M.J. Cola, T.J. Lienert, J.E. Gould and J.P. Hurley, "Laser welding of a SiC particulate reinforced aluminium metal matrix composite", Weldability of Materials: Proceedings of the materials weldability symposium, Eds. R.A. Patterson and K.W. Mahin, Detroit, MI, 8-12 Oct. 1990, pp. 297-303.

[58] N.B. Dahotre, M.H. McCay, T.D. McCay, S. Gopinathan and C.M. Sharp, "Laser joining of metal matrix composite", Proceedings of the machining of composite materials symposium, Eds. T.S. Srivatsan, C.T. Lane and D.M. Bowden, Chicago, Illinois, 1992, pp. 167-173. 
[59] Y.L. Chen, A. Shaban, L.G. Yu and H.M. Wang, "Laser beam welding of SiC particle reinforced aluminium metal matrix composite", Proceedings of SPIE, The International Society for Optical Engineering, Vol. 3862, 1999, pp. 443-447.

[60] J.T. Niu, D.K Zhang and G.J. Ji, "Effect of pulse parameters on microstructure of joint in laser beam welding for SiC/6063 composite", Transactions of Nonferrous Metals Society of China, Vol. 13, No. 2, 2003, pp. 289-293.

[61] H.M. Wang, Y.L. Chen and L.G. Yu, "In-situ weld-alloying/laser beam welding of SiC/6061 Al MMC", Materials Science and Engineering A, Vol. 293, No. 1-2, 2000, pp. 1-6.

[62] T.M. Yue, J.H. Xu and H.C. Man, "High power Nd-YAG laser welding of SiC particle reinforced aluminium alloy 2124", Materials Science and Technology, Vol. 14, No. 9-10, 1998, pp. 906-911.

[63] L.M. Liu, M.L. Zhu, D.S. Xu and L. Wu, "Interfacial reaction in aluminium matrix composite at laser welding", Transactions of Nonferrous Metals Society of China, Vol. 11, No. 5, 2001, pp. 671-674.

[64] K.W. Guo, "Influence of in situ reaction on the microstructure of SiCp/AlSi7Mg welded by Nd:YAG laser with Ti filler". Journal of Materials Engineering and Performance, 2010, Vol. 19, No. 1, pp. 52-58.

[65] C. Bosi and G.L. Garagnani, "Laser welding of aluminium alloys- $\mathrm{Al}_{2} \mathrm{O}_{3}$ composites: effects on joints microstructure", Materials Engineering, Vol. 13, No. 2, 2002, pp. 201-210.

[66] W. Guo, J.T. Niu, J.F Zhai, G.T. Zhou and M.Z. Wang, "The interfacial behaviors of aluminium matrix composite in different welding methods", Acta Metallurgica Sinica (English Letters), Vol. 17, No. 1, 2004, pp. 55-66.

[67] A.H. Wang, H.G. Xu, P. Yang, X.L. Zhang and C.S. Xie, "Nd:YAG laser butt welding of a 12 vol.\% SiC particulate reinforced magnesium alloy composite", Materials Letters, Vol. 61, No. 1920, 2007, pp. 4023-4026. 
[68] A.S. Isaikin, V.M. Chubarov, B.F. Trefilov, V.A. Silaev and Y.A. Gorelo, "Compatibility of carbon filament with a carbide coating and an aluminium matrix", Metal Science and Heat Treatment, Vol. 22, No. 11-12, 1980, pp. 815-817.

[69] J.T. Niu, D.K Zhang and G.J. Ji, "Mechanism of laser beam welding for SiC/6063 Al composite", Rare Metals, Vol. 21, No. 2, 2002, pp. 123-126.

[70] J.A. Lee, R.W. Carter and J. Ding, "Friction stir welding for aluminium metal matrix composites (MMCs)", MSFC Center Director's Discretionary Fund Final Report, Project No. 98-09, Marshall Space Flight Center, Alabama, Dec. 1999, pp. 1-21.

[71] W.M. Thomas, E.D. Nicholas, J.C. Needham, M.G. Murch, P. Templesmith, C.J. Dawes, “Friction-stir butt welding”, G.B. Patent Application No. 9125978.8, December 1991.

[72] R. Nandan, T. DebRoy and H.K.D.H. Bhadeshia, "Recent advances in friction stir welding process, weldment structure and properties", Progress in Materials Science, Vol. 53, No. 6, 2008, pp. 980-1023.

[73] J.C. Lippold and P.J. Ditzel, "Microstructure and properties of aluminium friction stir welds", Materials Science Forum, Vols. 426-432, 2003, pp. 4597-4602.

[74] J.-Q. Su, T.W. Nelson, R. Mishra and M. Mahoney, "Microstructural investigation of friction stir welded 7050-T651 aluminium", Acta Materialia, Vol. 51, No. 3, 2003, pp. 713-729.

[75] Y. S. Sato, H. Kokawa, M. Enomoto and S. Jogan, "Microstructural evolution of 6063 aluminium during friction-stir welding", Metallurgical and Materials Transactions A, Vol. 30, No. 9, 1999, pp. 2429-2437.

[76] Kh. A.A. Hassan, A.F. Norman, D.A. Price and P.B. Prangnell, "Stability of nugget zone grain structures in high strength $\mathrm{Al}$ alloy friction stir welds during solution treatment", Acta Materialia, Vol. 51, No. 7, 2003, pp. 1923-1936.

[77] T. Hirata, T. Oguri, H. Hagino, T. Tanaka, S.W. Chung, Y. Takigawa and K. Higashi, "Influence of friction stir welding parameters on grain size and formability in 5083 aluminium alloy", Materials Science and Engineering A, Vol. 456, No. 1-2, 2007, pp. 344-349. 
[78] Kh. A. A. Hassan, P. B. Prangnell, A. F. Norman, D. A. Price and S. W. Williams, "Effect of welding parameters on nugget zone microstructure and properties in high strength aluminium alloy friction stir welds", Science and Technology of Welding and Joining, Vol. 8, No. 4, 2003, pp. 257268.

[79] Y.S. Sato, H. Watanabe and H. Kokawa, "Grain growth phenomena in friction stir welded $1100 \mathrm{Al}$ during post-weld heat treatment", Science and Technology of Welding and Joining, Vol. 12, No. 4, 2007, pp. 318-323.

[80] S. Benavides, Y. Li, L.E. Murr, D. Brown and J.C. McClure, "Low-temperature friction-stir welding of 2024 aluminium", Scripta Materialia, Vol. 41, No. 8, 1999, pp. 809-815.

[81] F.J. Humphreys and M. Hatherly, "Recrystallization and related annealing phenomena", $2^{\text {nd }}$ edition, Elsevier Ltd., 2004.

[82] K.N. Krishnan, "The effect of post weld heat treatment on the properties of 6061 friction stir welded joints", Journal of Materials Science, Vol. 37, No. 3, 2002, pp. 473-480.

[83] M.M. Attallah and H.G. Salem, "Friction stir welding parameters: a tool for controlling abnormal grain growth during subsequent heat treatment", Materials Science and Engineering A, Vol. 391, No. 1-2, 2005, pp. 51-59.

[84] A.P. Reynolds, W. Tang, Z. Khandkar, J.A. Khan and K. Lindner, "Relationships between weld parameters, hardness distribution and temperature history in alloy 7050 friction stir welds", Science and Technology of Welding and Joining, Vol. 10, No. 2, 2005, pp. 190-199.

[85] L.E. Murr, R.D. Flores, O.V. Flores, J.C. McClure, G. Liu and D. Brown, "Friction-stir welding: microstructural characterization", Material Research Innovation, Vol. 1, No. 4, 1998, pp. 211-223.

[86] Y. S. Sato, S.H.C. Park and H. Kokawa, "Microstructural factors governing hardness in friction-stir welds of solid-solution-hardened $\mathrm{Al}$ alloys", Metallurgical and Materials Transactions A, Vol. 32A, No. 12, 2001, pp. 3033-3042. 
[87] H. Liu, M. Maeda, H. Fujii and K. Nogi, "Tensile properties and fracture locations of frictionstir welded joints of 1050-H24 aluminium alloy", Journal of Materials Science Letters, Vol. 22, No. 1, 2003, pp. 41-43.

[88] O.V. Flores, C. Kennedy, L.E. Murr, D. Brown, S. Pappu, B.M. Nowak and J.C. McClure, "Microstructural issue in a friction stir welded aluminium alloy", Scripta Materialia, Vol. 38, No. 5, 1998, pp. 703-708.

[89] N. Saito, I. Shigematsu, T. Komaya, T. Tamaki, G. Yamauchi and M. Nakamura, "Grain refinement of 1050 aluminium alloy by friction stir processing", Journal of Materials Science Letters, Vol. 20, No. 20, 2001, pp. 1913-1915.

[90] Y.J. Kwon, I. Shigematsu and N. Saito, "Mechanical properties of fine grained aluminium alloy produced by friction stir process", Scripta Materialia, Vol. 49, No. 8, 2003, pp. 785-789.

[91] H.J. Liu, Y.C. Chen and J.C. Feng, "Effect of heat treatment on tensile properties of friction stir welded joints of 2219-T6 aluminium alloy", Materials Science and Technology, Vol. 22, No. 2, 2006, pp. 237-241.

[92] L.E. Svensson, L. Karlsson, H. Larsson, B. Karlsson, M. Fazzini and J. Karlsson, "Microstructure and mechanical properties of friction stir welded aluminium alloys with special reference to AA5083 and AA6082", Science and Technology of Welding and Joining, Vol. 5, No. 5, 2000, pp. 285-296.

[93] S.R. Ren, Z.Y. Ma and L.Q. Chen, "Effect of welding parameters on tensile properties and fracture behavior of friction stir welded Al-Mg-Si alloy", Scripta Materialia, Vol. 56, No. 1, 2007, pp. 69-72.

[94] F.C. Liu and Z.Y. Ma, "Influence of tool dimension and welding parameters on microstructure and mechanical properties of friction-stir-welded 6061-T651 aluminium alloy", Metallurgical and Materials Transactions A, Vol. 39A, No. 10, 2008, pp. 2378-2388.

[95] P. Cavaliere, A. Squillace and F. Panella, "Effect of welding parameters on mechanical and microstructural properties of AA6082 joints produced by friction stir welding", Journal of Material Processing Technology, Vol. 200, No. 1-3, 2008, pp.364-372. 
[96] P.S. Pao, S.J. Gill, C.R. Feng and K.K. Sankaran, "Corrosion-fatigue crack growth in friction stir welded Al 7050", Scripta Materialia, Vol. 45, No. 5, 2001, pp. 605-612.

[97] G.J. Fernandez and L.E. Murr, "Characterization of tool wear and weld optimization in the friction-stir welding of cast aluminium $359+20 \% \mathrm{SiC}$ metal-matrix composite", Materials Characterization, Vol. 52, No. 1, 2004, pp. 65-75.

[98] M. Amirizad, A.H. Kokabi, M. Abbasi Gharacheh, R. Sarrafi, B. Shalchi and M. Azizieh, "Evaluation of microstructure and mechanical properties in friction stir welded $\mathrm{A} 356+15 \% \mathrm{SiCp}$ cast composite", Materials Letters, Vol. 60, No. 4, 2006, pp. 565-568.

[99] D.J. Shindo, A.R. Rivera and L.E. Murr, "Shape optimization for tool wear in the friction-stir welding of cast Al359-20\% SiC MMC", Journal of Materials Science, Vol. 37, No. 23, 2002, pp. 4999-5005.

[100] D. Contorno, M.G. Faga, L. Fratini, L. Settineri and G. Gautier di Confiengo, "Wear Analysis During Friction Stir Processing of A359+20\%SiC MMC", Key Engineering Materials, Vols. 410411,2009 , pp. 235-244.

[101] Z.Y. Ma, A.H. Feng, B.L. Xiao, J.Z. Fan and L.K. Shi, "Microstructural evolution and performance of friction stir welded aluminium matrix composites reinforced by $\mathrm{SiC}$ particles", Materials Science Forum, Vols. 539-543, 2007, pp. 3814-3819.

[102] A.H. Feng, B.L. Xiao and Z.Y. Ma, "Effect of microstructural evolution on mechanical properties of friction stir welded AA2009/SiCp composite", Composites Science and Technology, Vol. 68, No. 10, 2008, pp. 2141-2148.

[103] H. Uzun, "Friction stir welding of $\mathrm{SiC}$ particulate reinforced AA2124 aluminium alloy matrix composite", Materials and Design, Vol. 28, No. 5, 2007, pp. 1440-1446.

[104] S.C. Baxter and A.P. Reynolds, "Effect of friction stir welding on random composite structure: particle size distribution", Proceedings of the 8th International Conference on Structural Safety and Reliability, Eds. R.B. Corotis, G.I. Schueller and M. Shinozuka, Newport Beach, California, USA, 17-22, June, 2001, pp. 27. 
[105] P. Cavaliere, E. Cerri, L. Marzoli and J. Dos Santos, "Friction stir welding of ceramic particle reinforced aluminium based metal matrix composites", Applied Composite Materials, Vol. 11, No. 4, 2004, pp. 247-258.

[106] P. Cavaliere, G.L. Rossi, R. Di Sante and M. Moretti, "Thermoelasticity for the evaluation of fatigue behavior of $7005 / \mathrm{Al}_{2} \mathrm{O}_{3} / 10 \mathrm{p}$ metal matrix composite sheets joined by $\mathrm{FSW}^{\prime}$, International Journal of Fatigue, Vol. 30, No. 1, 2008, pp. 198-206.

[107] S.J. Vijay and N. Murugan, "Influence of tool pin profile on the metallurgical and mechanical properties of friction stir welded $\mathrm{Al}-10 \mathrm{wt} . \% \mathrm{TiB}_{2}$ metal matrix composite", Materials and Design, Vol. 31, No. 7, 2010, pp. 3585-3589.

[108] S. Gopalakrishnan and N. Murugan, "Prediction of tensile strength of friction stir welded aluminium matrix TiCp particulate reinforced composite", Materials and Design, Vol. 32, No. 1, 2011, pp. 462-467.

[109] H. Nami, H. Adgi, M. Sharifitabar and H. Shamabadi, "Microstructure and mechanical properties of friction stir welded $\mathrm{Al} / \mathrm{Mg}_{2} \mathrm{Si}$ metal matrix cast composite", Materials and Design, Vol. 32, No. 2, 2011, pp. 976-983.

[110] W.-B. Lee, C.-Y. Lee, M.-K. Kim, J.-Il Yoon, Y.-J. Kim, Y.-M. Yoen and S.-B. Jung, "Microstructures and wear property of friction stir welded $\mathrm{AZ91} \mathrm{Mg} / \mathrm{SiC}$ particle reinforced composite", Composites Science and Technology, Vol. 66, No. 11-12, 2006, pp. 1513-1520.

[111] L. Ceschini, I. Boromei, G. Minak, A. Morri and F. Tarterini, "Microstructure, tensile and fatigue properties of the AA6061/20 vol\% $\mathrm{Al}_{2} \mathrm{O}_{3} \mathrm{p}$ friction stir welded joints", Composites Part A: Applied Science and Manufacturing, Vol. 38, No. 4, 2007, pp. 1200-1210.

[112] R.A. Prado, L.E. Murr, D.J. Shindo and K.F. Soto, "Tool wear in friction stir welding of aluminium alloy $6061+20 \% \mathrm{Al}_{2} \mathrm{O}_{3}:$ a preliminary study", Scripta Materialia, Vol. 45, No. 1, 2001, pp. $75-80$.

[113] ASTM E8-04, "Standard test methods for tension testing of metallic materials", Annual Book of ASTM Standards 2005, American Society for Testing and Materials, West Conshohocken, Pennsylvania, 2005, Vol. 3.01, pp. 62-85. 
[114] Z. Zhang, K. Fortin, A. Charette and X.G. Chen, "Effect of titanium on microstructure and fluidity of $\mathrm{Al}-10 \% \mathrm{~B}_{4} \mathrm{C}$ composites", Journal of Materials Science, Vol. 46, No. 9, 2011, pp. 31763185.

[115] R. Spina, L. Tricarico, G. Basile and T. Sibillano, "Thermo-mechanical modeling of laser welding of AA5083 sheets", Journal of Materials Processing Technology, Vol. 191, No. 1-3, 2007, pp. 215-219.

[116] H. Zhao, D.R. White and T. DebRoy, "Current issues and problems in laser welding of automotive aluminium alloys", International Materials Reviews, Vol. 44, No. 6, 1999, pp. 238-266.

[117] N.B. Dahotre, M.H. McCay, T.D. McCay and S. Gopinathan, "Pulse laser processing of a SiC/Al-alloy metal matrix composite", Journal of Materials Research, Vol. 6, No. 3, 1991, pp. 514529.

[118] Y.J. Liang and Y.C. Chen, Handbook of inorganic thermodynamics, Northeastern University Press, 1993, Shenyang, China, pp. 449-485.

[119] R. Nandan, G.G. Roy, T.J. Lienert and T. DebRoy, "Three-dimensional heat and material flow during friction stir welding of mild steel", Acta Materialia, Vol. 55, No. 3, 2007, pp. 883-895.

[120] H.J. Liu, J.C. Feng, H. Fujii and K. Nogi, "Wear characteristics of a WC-Co tool in friction stir welding of $\mathrm{AC} 4 \mathrm{~A}+30 \mathrm{vol} \% \mathrm{SiCp}$ composite", International Journal of Machine Tools Manufacture, Vol. 45, No. 14, 2005, pp. 1635-1639.

[121] K.V. Jata and S.L. Semiatin, "Continuous dynamic recrystallization during friction stir welding of high strength aluminium alloys", Scripta Materialia, Vol. 43, No. 8, 2000, pp. 743-749.

[122] X.-G. Chen and R. Hark, "Development of $\mathrm{Al}-30 \% \mathrm{~B}_{4} \mathrm{C}$ metal matrix composites for neutron absorber material", Proceeding of Conference on 'Aluminium alloys: fabrication, characterization and applications', Eds. W. Yin and S. K. Das, TMS, 2008, New Orleans, LA, pp. 3-9.

[123] In 'ASM handbook', Vol. 2, "Properties and selection: nonferrous alloys and special-purpose materials", ASM International, 1991, Materials Park, OH, pp. 218. 
[124] V.V. Bhanuprasad, M.A. Staley, P. Ramakrishnan and Y.R. Mahajan, "Fractography of metal matrix composites", Key Engineering Materials, 1995, Vols. 104-107, pp. 495-506.

[125] Z.G. Wang, S. Li and L. Sun, "Fatigue and fracture behaviors of discontinuously reinforced aluminium matrix composites", Key Engineering Materials, 1995, Vols. 104-107, pp. 729-748.

[126] Y.M. Han, D. Gallant and X.G. Chen, "Corrosion behaviour of $\mathrm{Al}-\mathrm{B}_{4} \mathrm{C}$ metal matrix composites in $\mathrm{H}_{3} \mathrm{BO}_{3}, \mathrm{~K}_{2} \mathrm{SO}_{4}$ and $\mathrm{NaCl}$ solutions", Proceedings of Conference of Metallurgist: Light Metals, Eds. M. Fafard and G. Dufour, Oct. 2-5 2011, Montreal, Canada, pp. 415-425.

[127] J. Guo, P. Gougeon and X.G. Chen, "Characterization of welded joints produced by friction stir welding in AAl100- $\mathrm{B}_{4} \mathrm{C}$ metal matrix composites", Science and Technology of Welding and Joining, 2012, Vol. 17, No. 2, pp. 85-91.

[128] J.A. Wert, "Microstructures of friction stir weld joints between an aluminium-base metal matrix composite and a monolithic aluminium alloy", Scripta Materialia, 2003,Vol. 49, No. 6, pp. $607-612$.

[129] M. Sharifitabar and H. Nami, "Microstructures of dissimilar friction stir welded joints between 2024-T4 aluminium alloy and $\mathrm{Al} / \mathrm{Mg}_{2} \mathrm{Si}$ metal matrix cast composite", Composites: Part B-Engineering, Vol. 42, No. 7, 2001, pp. 2004-2012.

[130] B.L. Xiao, D. Wang, J. Bi, Z. Zhang and Z.Y. Ma, "Friction stir welding of SiCp/Al composite and $2024 \mathrm{Al}$ alloy", Materials Science Forum, 2010, Vols. 638-642, pp. 1500-1505.

[131] W.J. Arbegast, "Deformation (Mechanics) Congresses", Proceedings on Hot Deformation of Aluminum Alloys III, Eds. Z. Jin, A. Beaudoin, T.A. Bieler, and B. Radhakrishnan, TMS, Warrendale, PA, 2003, pp. 313-327.

[132] R.W. Fonda, J.F. Bingert and K.J. Colligan, "Development of grain structure during friction stir welding, Scripta Materialia”, 2004, Vol. 51, No. 3, pp. 243-248.

[133] R.W. Fonda, K.E. Knipling and K.J. Colligan, "Microstructure evolution ahead of the tool in aluminum friction stir welds", Scripta Materialia, 2007, Vol. 58, No. 5, pp. 343-348. 
[134] J.Q. Su, T.W. Nelson and C.J. Sterling, "Microstructure evolution during FSW/FSP of high strength aluminium alloys", Materials Science \& Engineering A, 2005, Vol. 405, No. 1-2, pp. 27786.

[135] R.A. Shahani and T.W. Clyne, "Recrystallization in fibrous and particulate metal matrix composites", Materials Science \& Engineering A, 1991, Vol. A135, No. 2, pp. 281-285.

[136] J.M. Root, D.P. Field and T.W. Nelson, "Crystallographic texture in the friction-stir-welded metal matrix composite A16061 with $10 \mathrm{Vol} \mathrm{Pct} \mathrm{Al}_{2} \mathrm{O}_{3}$ ", Metallurgical and Materials Transactions A, 2009, Vol. 40A, No. 9, pp. 2109-2114.

[137] P.L. Orsetti Rossi and C.M. Sellars, "Nucleation and growth of recrystallization in Al-1Mg during thermomechanical processing", Materials Science and Technology, 1999, Vol. 15, No. 2, pp. 185-192.

[138] S.A. McKelvey and A. Fatemi, "Surface finish effect on fatigue behavior of forged steel, International Journal of Fatigue", 2012, Vol. 36, No. 1, pp. 130-145.

[139] A. Eftekhari, J.E. Talia and P.K. Mazumdar, "Influence of surface condition on the fatigue of an aluminum-lithium alloy (2090-T3)", Materials Science \& Engineering A, 1995, Vol. A199, No. 2, pp. L3-L6. 


\section{Appendix}

Although the addition of small amount titanium has been shown to protect boron carbide from further reaction with aluminium matrix during all the casting processes, it is obviously not enough to prevent the formation of aluminium carbide during the laser welding of Al-B ${ }_{4} \mathrm{C}$ MMCs. Based on free energy data, it was shown that Ti element has a much greater affinity to boron and carbon under standard conditions. It can therefore be expected that the titanium addition would change the microstructure of the Al-B4C MMCs laser weld zone. The ideal amount of $\mathrm{Ti}$ addition should be adequate to capture all the boron and carbon elements while avoiding the formation of other unnecessary intermetallic phases. A chemical equilibrium analysis of amount of filler metal necessary to prevent the formation of aluminium carbide was provided below.

With the addition of Ti filler metal, the following chemical reactions I believed to occur in the system during laser welding.

$$
3 T i(l)+B_{4} C(s) \rightarrow T i C(s)+2 T i B_{2}(s) \cdots\left(\Delta G^{\circ}=-616.3 \mathrm{~kJ} / \mathrm{mol}\right)
$$

Theoretically, the molecular ratio between titanium and boron carbide needs to be around three according to the above equation. Assuming the weld pool has a cubic form, the volume of the weld pool is $\mathrm{V}_{\mathrm{W}}$, and the volume of titanium needed is $\mathrm{V}_{\mathrm{Ti}}$. Known the 
density of titanium and boron carbide are 4.51 and $2.52 \mathrm{~g} / \mathrm{cm}^{3}$, and the molecular mass of them are 47.9 and $55.26 \mathrm{~g} / \mathrm{mol}$. Then we have,

$$
\begin{gathered}
\frac{\rho_{T i} V_{T i}}{47.9}=3 \times \frac{\rho_{B_{4} C} V_{B_{4} C}}{55.26} \\
\Rightarrow \frac{\rho_{T i} V_{T i}}{47.9}=3 \times \frac{\rho_{B_{4} C}\left(V_{W}-V_{T i}\right) \times 0.16}{55.26} \\
\Rightarrow \frac{V_{T i}}{V_{W}}=0.189 \approx 19 \%
\end{gathered}
$$

